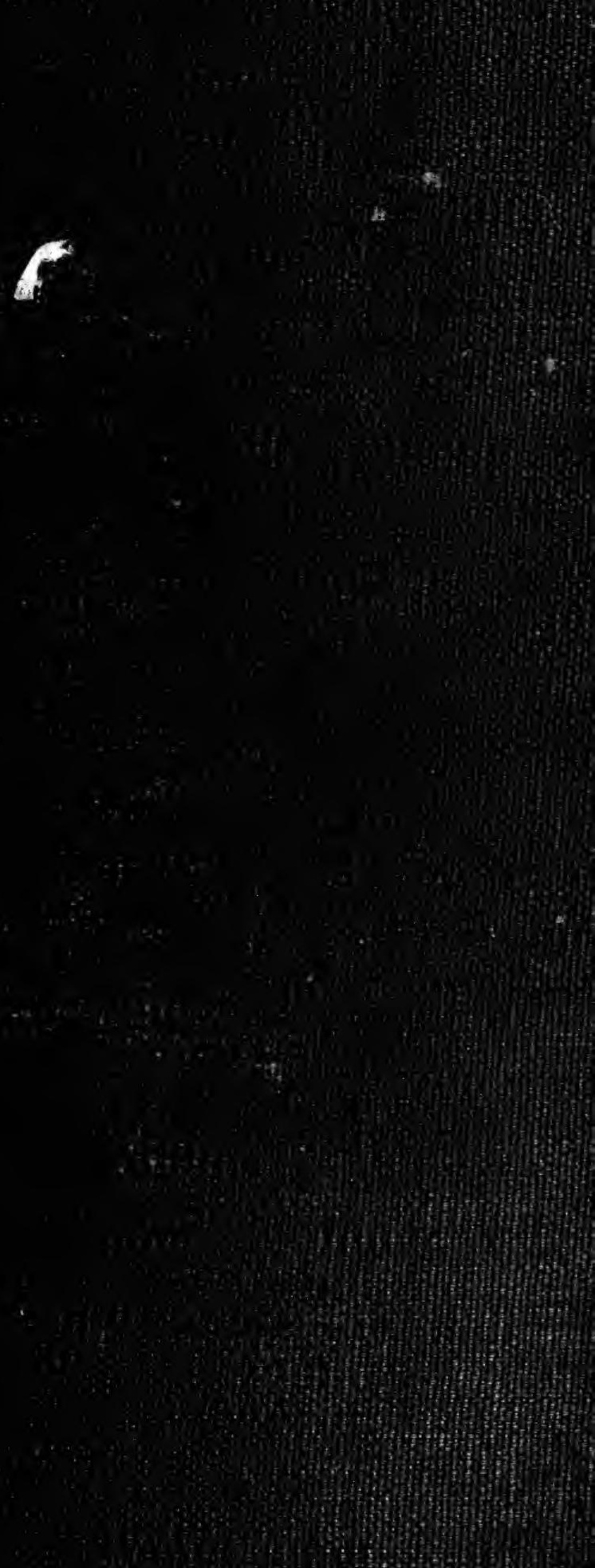




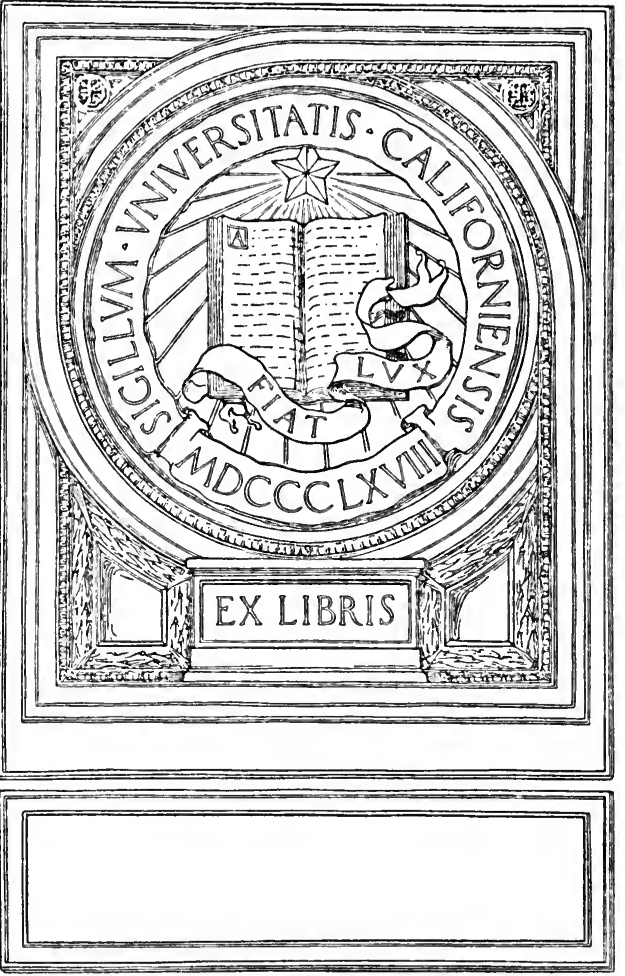




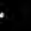




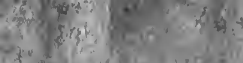

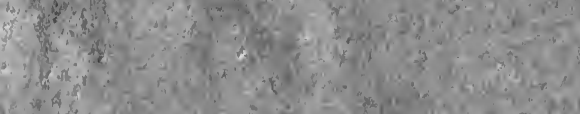

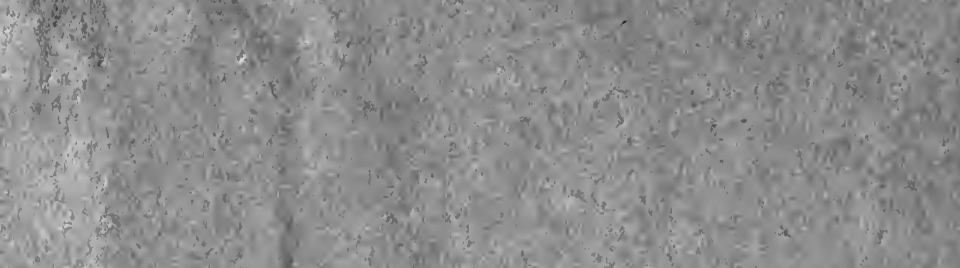

(1.

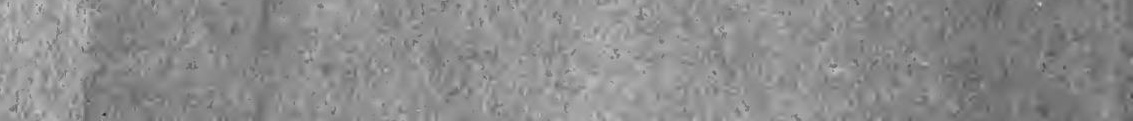

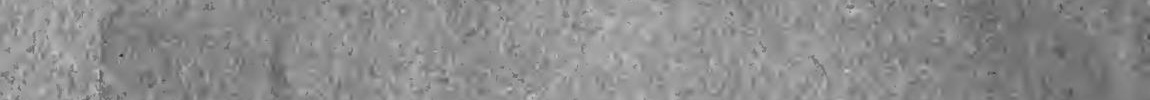
the

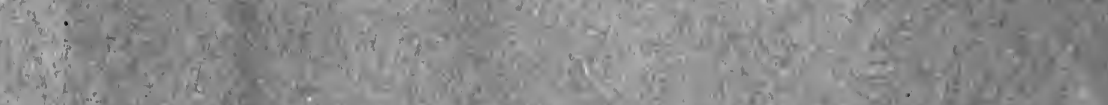

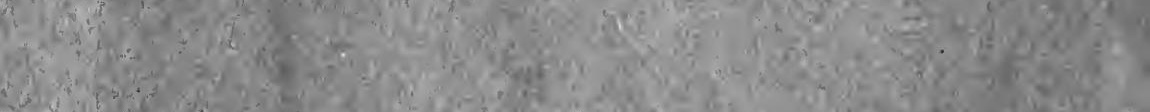

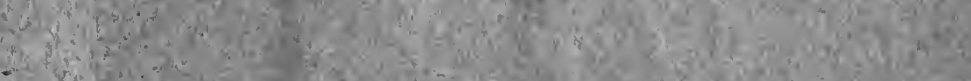
$x^{2}+1=0$

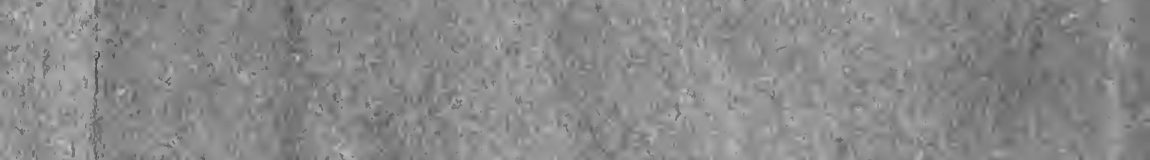

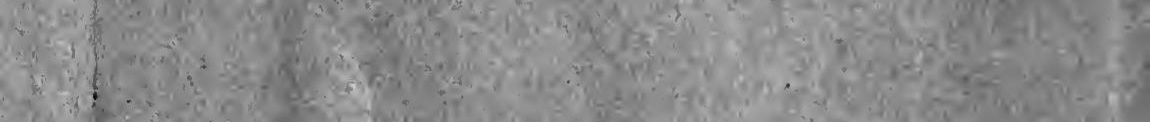

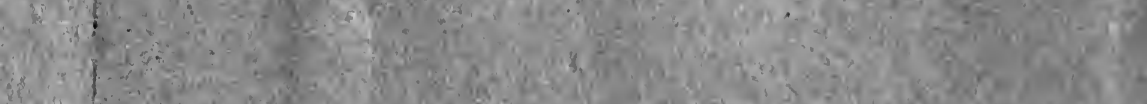
$\cos 20$

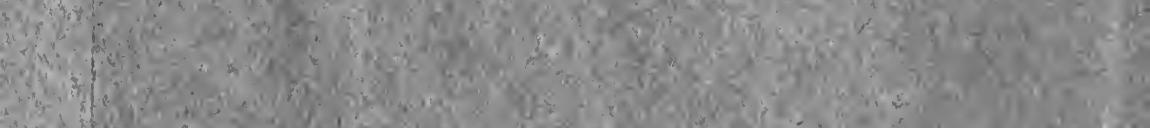

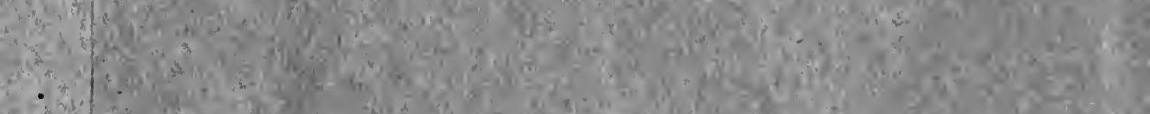
it

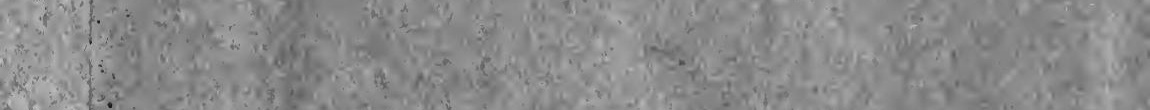

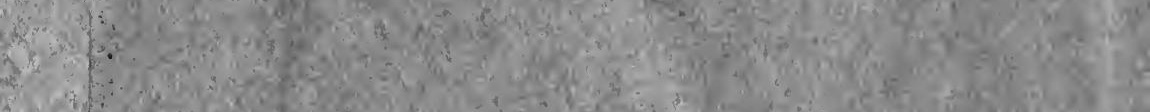
(1.

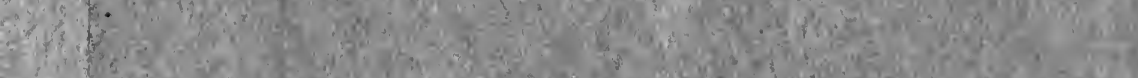

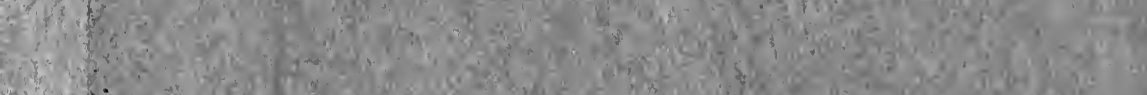
3it.

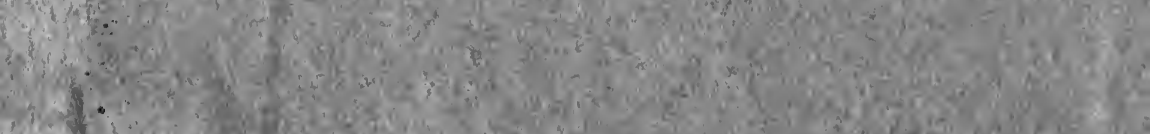



STUDIES IN ECONOMICS AND POLITICAL SCIENCE.

EDITED BY

The Director of the London School of Economics and Political Science. No. 60 in the Series of Monographs by writers connected with the London School of Economics and Political science.

\section{THE HISTORY OF SOCIAL DEVELOPMENT}




\section{Digitized by the Internet Archive in 2007 with funding from Microsoft Corporation}




\title{
THE 'HISTORY OF
}

\section{SOCIAL DEVELOPMENT,}

BY

\author{
DR. F. MÜLLER-LYER
}

Translated BY

ELIZABETH COOTE LAKE \& H. A. LAKE, B.Sc. (Econ.), F.R.A.I.

With an INTRODUCtion BY

Professors L. T. HOBHOUSE \& E. J. URWICK

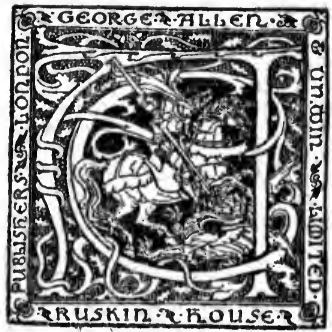

LONDON: GEORGE ALLEN \& UNWIN LTD. RUSKIN HOUSE, 40 MUSEUM STREET, W.C. I 
First published in 1920

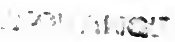

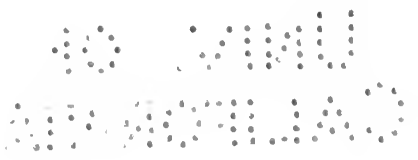

(All rights reserved) 


\section{INTRODUCTORY NOTE}

(THE value of Dr. Müller-Lyer's book is that it is a serious attempt at an Inductive Sociology./ The moment that the Sociological student passes out of the region of abstractions he finds himself wandering in an uncharted wilderness of fluid and disconnected facts. His natural impulse is to take refuge in specialism. He will study some particular region of contemporary life, or of the historic past, or of the Simpler Societies, and learn what is to be learnt about that nook or corner, since the whole field is too wide for his exploration. This method produces valuable special studies, but it does not give us a Sociology. It yields no theory of the nature and development of society as a whole, it gives no account of the general trend of civilization, and answers none of the questions about progress or retrogression. But these are the questions to which more urgently than heretofore the world needs an answer. The potentialities of good and evil in civilization have been multiplied many times by the increase of human power. What are we going to make of them ? What has human "Progress" amounted to so far as it has gone, and what can the watchman say of the night? Carlyle's question, "Whence, and oh heavens! whither? " is even more clamant for us than for him. Now we shall not know the future merely by recapitulating the past because the human mind is constantly introducing new factors. But neither shall we be able to guide our own future 


\section{$\because 6$. THE: HISTORY OF SOCIAL DEVELOPMENT}

intelligently unless 'we understand the present and how it came to be. "It is not a question of fatalistic prediction, but of focusing racial experience in a way that will throw clear and dry light on the permanent human problems.| This is the task of inductive Sociology, and the first step to a solution is to find methods of distinguishing, describing and correlating the successive phases through which human societies have in fact passed. These are Dr. Lyer's " Phases of Culture." The merit of his work is that with the minimum of hypothetical assumption he endeavours after a scientific classification of the mass of facts which the Anthropologist, the Archeologist and the Historian proffer to the enquirer, Just as in the sciences of life theories of descent are based on morphology, so in Dr. Lyer's handling are theories of social evolution. That he should be equally successful in the application of his method in all parts of his enquiry is impossible. That the method might be amended and supplemented by other methods is probable. But that it is a method to be taken into careful account is certain. Further, it is developed with a lucidity and evenness of temper which may surprise and enlighten those who imagine all German work to be crabbed, obscure and distorted by theoretical prepossessions. Mrs. Lake has done a service to students who cannot grapple with the original in offering them the present very readable version.

L. T. HOBHOUSE. 


\section{INTRODUCTORY NOTE}

IN common, I think, with most teachers of Sociology, I have often felt the need of some book which should co-ordinate the general facts of social development and so furnish the student with a scheme within which to group, in their due significance, the elements of both primitive and historical civilization. The late Dr. Müller-Lyer's Phasen der Kultur supplied thisneed-but only for students familiar with German. I therefore felt peculiarly glad when Mrs. Lake and her daughter undertook the task of translating the book into English. Those who are familiar with the original will find that the translation very faithfully reproduces both the simplicity of style and the clearness of expression which characterize Dr. Müller-Lyer's writing. The book is therefore excellently fitted to serve as a basebook for English students ; while the wide range of its survey and the inherent interest of the facts dealt with should make a strong appeal also to the general reader.

It is only right to add that the translators began their task in the hope that such a use of their leisure time might be of real assistance to others. Their unselfish perseverance should win the gratitude of both teachers and students of Sociology.

E. J. URWICK. 



\section{TRANSLATORS' PREFACE}

THE first rough draft of this translation was made for private reference in I9I3-I4, but in April IgI4, as it seemed unnecessary waste to bury months of labour in manuscript notebooks, application was made to the author at Munich for the official rights of translation. The permission was readily forthcoming ("Mit bestem Dank habe ich Ihre freundliche Aufrage erhalten und freue mich sehr dass Sie beabsichtigen eine englische Ubersetzung meines Buches Phasen der Kultur zu veröffentlichen "), but the negotiations were delayed by the exorbitant terms demanded by the German publisher, and were still unsettled at the outbreak of war. The translation remained in its rough state for two or three years, but, largely through the encouragement of Professor Urwick and Professor Hobhouse, we have now devoted some months to its completion.

Even in its present form the book is almost a literal translation from the German, the paragraphs, and almost without exception even the sentences, following the German original as nearly as possible. The object of this was twofold, being in the first place to retain the character of the book as nearly as possible, and in the second place to form a 


\section{0}

\section{THE HISTORY OF SOCIAL DEVELOPMENT}

convenient book of reference for English students reading the book in German.

The footnotes have similarly been translated, but since these often refer merely to authors, or in many cases give two or even three variants of the same title, we have thought it better to make a complete list of references, which is printed at the end of the book.

Finally, while yielding to none in our admiration for the industry, the enlightened views, and the clear-headed logic of the author, we wish to disassociate ourselves from certain of his expressed opinions.

ELIZABETH COOTE LAKE.

H. A. LAKE. 


\section{PREFACE}

\section{AIM AND PLAN}

IT is well known that in the course of immeasurable periods of time human society has risen from insignificant beginnings to more and more complex and higher forms of existence. At first there were separate small hordes which wandered about like animals in the woods; then these hordes united into tribes, the tribes later into nations, the nations into states, the states in their turn into great powers, and now nearly all the peoples of the earth are bound together through commerce into one great community of labour. And whilst step by step mankind passed over into more highly organized social groups, each generation was the teacher of the following one, and the acquisitions of culture were accumulated more abundantly. Man developed speech, the essential medium of culture, devised tools, controlled fire, then went on to the discovery of agriculture, the breeding of animals, and to the extraction and working of metals. He evolved religion, arts and sciences, produced all sorts of ingenious machinery, and learned more and more to master the forces of nature.

This stupendous process of the transformation of all human things which we call culture ran the greater part of its course, however, without man having had more than the very vaguest suspicion of what was happening. All great things were hidden from his narrow outlook by their very immensity; the slow progress of culture was just as 
much hidden from his perception as was the prodigious journey which he, in his own dwelling upon the earth, was making round the sun.

Then there arrived with the awakening of the abstract science of culture, or Sociology, that great moment in the drama of human history, in that crisis of incalculable significance, when the development of human culture crossed the threshold of human consciousness. Man perceived that he was in the midst of a huge progressive movement. Like a child who pronounces the little word "I" for the first time, human reason had arrived at consciousness of self.

From this critical moment the character of the progress of culture must necessarily change; instinctive striving must be transformed into conscious action.) Up to that time man had looked upon the culture movement as an unknown power which controlled the fate of mankind by means of invisible threads, but from that time onward his progressive intellect could hope to be more and more able to control the movement and at last to become lord and master of that culture to which he had hitherto, in his state of instinctive existence, been compelled to submit as if to blind fate.

However, the way to this goal is long. If the culture movement is to be controlled, it must first be understood. As a means to this end I have made use of a method of research which is not entirely new, but which has never yet been consistently carried out in the science of culture. This is the comparative method of the natural sciences which, when applied to the development of human culture, might well be called the " phaseological method." By this method the whole sphere of culture must be divided into its constituent parts, of which the most important are the propagation of the human race, social organization, language, science, belief, ethics and art. In each of these subdivisions the course which the separate culture phenomena 
have taken, from the earliest times up to our own day, will be arranged in a series of phases or stages. If, then, we compare these separate phases with one another, we shall discover that they have all followed certain lines which we shall call "the lines of direction of progress."

These lines enable us to perceive clearly that human development is a progressive movement, and one which does not proceed haphazard, but according to regular laws and in a fixed direction. They indicate to us the direction in which civilization has moved in the past. When there is opened up to us a tract of development which extends not merely over centuries, but over countless millenniums. the time has come when such an attempt can no longer be considered too presumptuous.

The lines of direction give us in addition a new outlook on the present. We realize that the conditions in which we live are not the climax, but merely part of an endless series of development. Thus, to take one example, we recognize that the much disputed feminist movement is only a necessary link in the developmental series illustrated by: $\mathbf{I}$. Sex differentiation of labour; 2. Division of labour among men; 3. Division of labour among women; and that even this series again is only one of the aspects of the universal law of differentiation which controls the whole organic and cultural development.

Finally, the lines of direction act as sign-posts to the future. By investigating the causes of present social phenomena we may discover the laws governing them and be able to surmise those of the future. Prophecy, in the sense of foretelling future events, is impossible, but it is of importance to perceive the goal towards which evolution is striving, and thereby to gain insight into the line of least resistance along which progress is moving.

This, then, is the method: We shall work from the sociological facts (which, speaking generally, include all people, 
all parts of the earth and all times) to the phases of culture, from the phases of culture to the lines of direction of progress, from the lines of progress to the laws of cultural development. Along this road we approach from afar, slowly, step by step, to the goal of Sociology; for as insight into the laws of Nature has led on to the control of Nature, so will a knowledge of the laws of human development enable men to perceive a definite purpose in its apparently tangled skein, and thereby to bring another and supremely important force under the influence of human volition.

The phaseological method can be used for the investigation of all important branches of culture. The whole subject divides itself up in the following manner.

The first part comprises the phases of economic development (the "phaseology" of economics). To this part might be assigned the title "Stages of Culture," since it is customary to measure the height of the cultural development by the standard of economic development and briefly to define the economic phases as stages of culture.

The second part deals with the phenomena of the propagation of the human race (courtship, marriage, the family, kinship, etc.).

The third part with the development of social organization, from the horde up to the great modern Power.

The fourth part-which was originally, many years ago, the starting point of this work-with the history of the human intellect, i.e. the development of speech, of knowledge, of philosophic and religious beliefs-

And the fifth part with the development of ethics, of justice, and of art.

A conclusion will comprise the whole of the lines of direction of progress and of the general laws which have been recognized up to the present in the development of culture. 
The whole work comprises in the first five parts the special principles, and in the conclusion the general principles of social development, and consequently covers the whole science of culture, or what is to Auguste Comte the same thing, the whole of social science or Sociology. At the same time it will acquaint the reader with the results of this new and glorious, although unfortunately still imperfect, science. Since Sociology, in spite of its brief existence, has already increased to such a gigantic extent that a complete statement would perhaps require as many volumes as this work contains leaves, only the most important fundamental principles of development will be considered throughout, and all details which are not absolutely necessary for the characterization of the phases and for the comprehension of the process of development will be conscientiously excluded.

Each part is composed of a series of detailed statements, which although members of a whole, are yet written as independent works, each one of which can be read and understood by itself, although naturally not with the same profit as if read in their entirety.

As there will be no special introduction to the separate parts, the first division begins with a preliminary chapter, which will introduce the reader to Sociology. 



\section{CONTENTS}

(The numbers refer to the pages)

\section{BOOK I \\ INTRODUCTION TO SOCIOLOGY}

CHAPTER I

\section{CONCERNING CULTURE AND THE SCIENCE OF CULTURE}

Conception of culture, 29.-Culture a progressive movement, 29.Primitive hordes and modern great states, 29.- Historic and prehistoric phases of culture, 30.-Deductions from the prehistoric phases, 31.-By means of palæontology, 3r.-By means of comparative ethnology, 31.By means of philology, 32.-By means of comparative mythology, the science of religion and other modern sciences, 32 .

Sociology, 32.-Its problems and aims, 32.-Forms of culture, 33.Phases of culture, 34.-Doctrine of phases or phaseology, 34.-General laws of the evolution of culture, 34.- Sociology in general and in particular, 34.Uses of Sociology, 34.-Comprehension of the advance of culture, 35.Comprehension of the present time, 35.- "Savoir pour prévoir " in Sociology, 35.-Its uses in practical politics, 36.- The greater understanding of mankind caused by soctal psychology, 36 .

Literature, 37. - The great number of works on Sociology, 37. - The growth of Sociology one of the chief accomplishments of the twentieth century, 37.

\section{CHAPTER II}

\section{CONCERNING THE ORIGIN OF CULTURE (Primordial Times)}

The relationship of the history of culture to the history of the earth (geology), 38.-Geological phases, 38.-Gradual rise of the geological formations through the metamorphosis of rocks, 4r.-Gradual metamorphosis of organisms into high forms, 4I.-The evolution of man from lower forms, 42.

Prehistoric phases, 42.-Delimitation of prehistory, 42.-Primordial times veiled in darkness, 42.-Comparison between animal and human, 43. -The uncultured ancestors of man, 43.- The genealogy of the hand, 44.Hand and tree, 44.-The origin of speech, 45.-Family groups and social groups among animals, 45.-Derivation from tree-climbing animals but from none of the species of apes now existing, 46.-Social origin of man, 47.-The creation of man, 48.-The tree and the ground, 48. - The significance of speech, 49.- Lazarus Geiger's dictum, " Speech has created reason," 50.Speech as a means of communication, 50.- Speech as a means of accumulating thought, 50.-The social intellect, 51 .- Its superiority over the intellect of the individual, 51.-Speech as a means of the conception of ideas, 52,-Taine's theory of thinking in signs (work thinking), 52.- 
Representations and ideas, 52.-Advantage of abstract thought over mere representations, 52. - The reciprocal effect of speech and intellect, 54.Hand and tool, 54.- The origin of the tool, 55.- Significance of the tool, 55.-Transposition of the struggle for existence from the material to the intellectual sphere, 55.-Decisive transition from the organic to the superorganic, 55.-Fire, 56.- The discovery of the kindling of fire, 56.-Primitive uses of fire, 57 .

Conclusion, 57.-The doctrine of the social nature of man, 58.-The power of man is based on the union of individuals into more highly organized associations, 58.-Relationship between the individual and society, 58 .

\section{CHAPTER III}

\section{THE CLASSIFICATION OF THE WHOLE SPHERE OF CULTURE}

The importance of a correct classification, 60.-Classification of the whole sphere of culture into the following nine subdivisions (sociological functions): 1. Social Economy (the provision of the means of existence : Food, weapons, tools, dwelling-place, clothing, etc.), 60.-2. Reproduction and the perpetuation of the species (marriage, love, the family, kinship), $6 \mathbf{r}$. -3. Social and political organization, 61.-4. Speech, 6r.-5. Science, 6r.6. Religious and philosophical beliefs, 6r.-7. Ethics, 61.-8. Justice, 6r.9. Art, 6r.

Observations on diagrammatic arrangement, 62.- Sequence and juxtaposition in Sociology, 62.--Sociological table, 63 .

\section{BOOK II}

\section{THE HISTORY OF THE EVOLUTION OF FOOD, IMPLEMENTS, CLOTHES AND DWELLINGS}

Classification of material phenomena, 67.-The division of the whole subject-matter into two parts: the goods produced (food, implements, clothing and dwelling) and the labour producing them, 67.

\section{CHAPTER I}

\section{FOOD}

Forms of food production, 68.-Hunting and fishing, 68.- The lower hunters, 69.- The higher hunters, 70.-Fishers, 71.-Cattle breeding, 7r.Agriculture, 72.- Its various forms : hoe culture (hoe culture with hunting, with fishing, with cattle breeding, etc.), 73.- Plough culture, 77.- Horticulture, 77.-Description of Chinese horticulture, 78:-Advantages of the Chinese as against European methods, 81.- "Commerce culture," 81.-Comparison with Chinese horticulture, $8 \mathrm{r}$. - Genealogy of the forms of food production, 84 . - Survey of the collective forms, 84 ,- The succession of phases, 84. - Sociological importance of the hunting stage, 85.-Its prehistoric distribution, 85. No counter-evidence supplied by vegetarian peoples, 85 .-The human set of teeth, 86.-The significance of children's games, 86.- Philological research, 87. - The place of cattle breeding in the phase series, 88. - The dissimilarity of development in the New and Old Worlds, 88.-The question as to the de- 
rivation of cattle breeders from hunters or from agriculturists, 89.-The pastoral life not a general culture stage, 91.-The phases of husbandry, 91.-An abstract representation of the genealogy of food production, 73, 92 .

The phases of food production and the culture stages, 92.-The three epochs of savagery, barbarism and civilization, 93.- Survey and classification of peoples according to their methods of food production, 95 .

\section{CHAPTER II}

\section{THE TOOL (The Development of Technical Arts)}

Survey of the Stone Age (Palæolithic and Neolithic), the Bronze Age, the Iron Age and the Machine Age. 97.-" Ages" and "Stages," 97.

Conclusions from Ethnology and History, 98.-Peoples still existing in the Palæolithic stage, 99.-Their tools and weapons, 99.-Fire, 99.-Peoples in the Neolithic stage, roo.-The "polishing" of stone, roo.-Weaving and pottery, ror.-The history of cooking, ror.-The Bronze Age, ro2.-The Bronze Age in America, ro2.-The Iron Age, 103.-The tise of iron by nature folk, 103. - The use of iron by the civilized peoples of antiquity, ro3.-The high level of accomplishment among the Babylonians, Egyptians, etc., 104. - The relative stagnation of the technical arts among the Greeks and Romans, 105.-Its causes, 106.-The Machine Age, 107.-The history of the machine, x07.-The growth of the natural sciences, 107.-Arab influence, 108.-The most important inventions and discoveries from the thirteenth century to modern times, ro9. - The invention of the great labour-saving machines at the end of the eighteenth century, rog.- The real beginning of the Machine Age and complete revolution of the whole of economic life, IIr.-The condition of the worker not alleviated by the machine, III.

Conclusions drawn from Archæology (prehistory), I11.- Summary of the prehistoric phases, 113.-Tertiary, I13.-Diluvial, 113.-The era of diluvial man, II4.-Parallelism with the culture stage of savagery, 115.Alluvial, 116.- The earlier Neolithic stage, 116.-The fully developed Neolithic period (Robenhausen), pile dwellings, Ir 7.-General parallelism with the culture stage of barbarism, Ir 8.-Copper and Bronze Age, I18.The so-called "Beautiful Bronze Age," 120.-The Hallstatt period, 121.The La Têne period (Celtic), I 2 r.

Uniformity of conclusions drawn from comparative Ethnology and from Archæology, 122.-Fragmentary character of available materials, 123. Archæology and "Primeval history," 123,-The three "Ages": Stone, Bronze and Iron, 124.- Their relationship to the three culture stages: Savagery, Barbarism and Civilization, 124.-Apparent exceptions to the rule, 125. - The early forms and genealogy of the tool, 126.-Cursory representation of the origin of our present technical possession in a few simple and primitive forms, 128 .

\section{CHAPTER III}

\section{CLOTHING}

Primitive nakedness, 132.- Nakedness still existing among peoples, r32.Nakedness among the civilized peoples of antiquity, 133.--Primitive clothing, 133.-Adornment older than clothing, 134.-Adornment among nature folk, 135.-Skin, grass and bark clothing, 135.-Fat as clothing, 135.

Clothing from manufactured materials, $136 .-$ Bast clothing (lintwat), 136. -Woven materials, 136. 
Fashion, 137.-Gradual development of modern costume, 137.-The successive steps, 137.-Hose, shirt and head covering, 138.-Origin of fitted clothing, 139.-Origin of fashion, 139.-Causes of fashion, 140.-Universality of present-day clothing, 140 .

Sociological significance of clothing, 140.-Mankind depicted by his clothing, I4I.-Each fresh period evolves a fresh costume, I4I.- Scrutiny of the most important fashions from this point of view, 141.--Individual clothing and the future of dress, 142 .

Summary, 142.-Three epochs: 1. Natural dress. 2. National dress. 3. The dress of fashion, $1_{42}, 1_{43}$.

\section{CHAPTER IV}

\section{DWELLING}

Primitive shelterlessness, 144.-Nature folk who camp out in the open, under trees, 144.-Or in caves, 144.

Wind-shelters, 144.--Primitive huts, I44.-Tents of the herdsmen, 145 . -Huts of agriculturists, 145.

Wooden houses, 146.-The dwellings of the Germans, 146.-Wooden houses in the Middle Ages, 146.- Stone houses, 146.-The beginning of architecture, 146.-Private houses and flats, 149.

Settlements: Villages and towns, 147.-The rise of towns, 148.

Summary, 149.

\section{BOOK III}

\section{THE HISTORY OF THE EVOLUTION OF LABOUR}

Introduction, 153.-Definition of the ideas : Organization of labour, 153 . -Co-operation of labour, 153.- Simple co-operation, I 53.-Complex division of labour, specialization or differentiation, 154.-Co-operation involving division of labour, I 54.-Differentiation is based upon co-operation, I54.

\section{CHAPTER I}

\section{THE STRUCTURE OF THE ORGANIZATION OF LABOUR}

Forms of organization, 155.-The following phases of these forms of organization arise through gradual absorption :

1. Early Kinship Phase, I55.

Organization of labour within the clan, 156.-Clan communism of labour, food and land, 156.-The family : no self-sufficing family households, 157 .

2. High Kinship Phase, 158.

The appearance of new forms of organization: inter-tribal barter, 159. -Forms of primitive barter, I59.- "Dumb barter," 159.-The " Guest gift," 160.-Its true significance, I6r.-Markets, I6r.-Direct exchange of goods, I62. - The clan and family on this stage, 162.

3. Early Industrial Phase (Farm and Village Economy), I63.

Social differentiation between masters and bondsmen, r63.-Economic differentiation in callings, 163 .- Organization of labour in Polynesia, I64.Authoritarian joint household, 164 . - Free handicrafts, 164 .-Clan and village communities, 165. - The family, I65.-Barter, 166.-Organization of labour in Africa, 167.-Clan and village communities, 167.-The family, 167. 
-Inter-tribal organization of labour, 167.-Tribal industries, 167.-Authoritarian joint households, 168.-Free industries, 168.

Summary, 169.- The derivation of specialized callings from slavery, free artisans, and tribal industries, 169.

4. High Industrial Phase (Town Economy), 170.

Economic conditions in Greece and in the Roman Empire, 170.-State and City, 170 .- The family household, 171 . - The authoritarian joint household, 171.-The "Oikos," 171.-International trade, 172.-Free artisans, 172. - The blindness of Homer and the lameness of Hephaestos, I 72.

5. Early Capitalistic Phase in Antiquity, I73.

Capitalistic enterprise, 173.- Trading and industrial enterprise, 174.Factories, 175. - The factories of the father of Demosthenes, 175.

Summary, 176 .

Introduction to the Sixth, or High Capitalistic Phase, 176.

The Germans before the "Völkerwanderung" (in the transition from the high kinship to the early industrial phase), 178.-The Germans in the early Middle Ages, I79.- Transition from the clan system to the manorial system, 179:- Town economy in the Middle Ages (industrial and early capitalistic organization), $\mathbf{r} 80$.

Agreement of the economic movement of development among the RomanoGermanic peoples with that hitherto described, 183.

6. High Capitalistic Phase, 184 .

From the end of the eighteenth century in England, from the middle of the nineteenth century in Germany, 184. - Victorious policy of capitalistic enterprise since the discovery of great labour-saving machines, 185.Superiority of the new system over the old, r86.- Influence on the Family, 186.- On handicrafts, $187 .-$ On international trade and traffic, I89.

7. Late Capitalistic Phase, 189.

Emergence of new forms of organization from the old: socialized trade, 190.-Two forms: State trading and co-operative trading, 190.-Early Socialistic phase, 192.

\section{CHAPTER II}

\section{REFLECTIONS ON THE STRUCTURE OF ORGANIZATION OF LABOUR}

The seven forms of organization, 194. - The rise of the economic phases from the absorption of these elementary forms, 195.-Table of the structure of labour organization, 196.-The epochs of the organization of labour, 198.

I Epoch. Clan Organization.

II Epoch. Industrial Organization.

III Epoch. Capitalistic Organization.

IV An epoch only now dawning (Socialized Organization ?).

The organoplastic groups, 199.-The two kinds of group unions: I. The social union, 199.-2. The family union, 199.- Social union has created the clan from kinship, inter-tribal organization of labour from the clan union, free handicrafts from the tribes and city states, capitalistic enterprise from the union of states, and socialized industry from the modern great states.Family union created the "Family " and authoritarian government, 20r.-The struggle between the family, and the social group can be traced throughout all economic history, 202. - It has ended with the triumph of social union, 203. 


\section{CHAPTER III \\ DEVELOPMENT OF DIVISION OF LABOUR (DIFFERENTIATION)}

Introduction : Differentiation a universal and fundamental law of development, 204.-At the same time the most exact standard of the culture of a people, 205.-The three epochs of the division of labour, 205.

I. Epoch of differentiation between the sexes, 205.

Division of labour between man and wife, 205.-Among hunting peoples, 205.-The subjection of women, 206.-Among pastoral people and hoe culturists, 208.-." Man discovered cattle rearing and woman agriculture," 209.

II. Epoch of differentiation among men, 209.

Beginning of the specialization of industries among semi-civilized peoples, 209.--Developed industrial differentiation among civilized peoples, 210.-Differentiation among capitalistically organized peoples, 210.Economic and social differentiation, 212.-The specialization of industries and the formation of classes or castes, 2r2.- Connection between class and calling, 212.-The class to which people belong is still the greatest influence in the choice of a calling, 213.-Differentiation among men and civilization, 214.-Civilization in its essence is sociologically identical with the differentiation of men into callings, 215.-Reasons for this view, 215.

III. Epoch of differentiation among women, 218.

First appearance of differentiation among women, 218.-Early history of the differentiation among women, 220.-The modern differentiation of women, 221.-Its history, 221.-Causes of the modern " woman's movement," 223. - Concerning the future of differentiation among women, 225.-Differentiation among women in the direct line of progress, 226.-Comparison of differentiation among women with that of men, 227.--Profession or marriage, 228.-Organization of the household, 228.-Associated joint household, 229. -Difficulties and hindrances, 230.- - Results of differentiation among women, 230.-The beginning of differentiation among women is the most important movement in the sociological planetary system at the present time, 231 .

Survey of the history of women's labour, 23 .

Survey of the history of the division of labour and its relation to the phases of organization of labour, 232.

\section{CHAPTER IV}

\section{DEVELOPMENT OF INTEGRATION. DISTRIBUTION OF GOODS}

What is integration? Integration as a necessary antithesis of differentiation, 235.-Division of labour and distribution of goods, 236.-The history of the medium of exchange of money, 236.-I Phase : Hordes without barter, 237.-II Phase: Intertribal barter without a medium of exchange (money), 237.-III Phase : Indirect exchange of goods by means of natural money. The different kinds of natural money : shells, skins, cattle, metal money, 238. -IV Phase: Exchange by means of minted metal currency, 240.-The discovery of money, 240.-V Phase : Exchange by means of "token" money, 240 .

The three epochs of Integration: Natural Economy, Money Economy and Credit Economy, 242.

Summary of the phases of Integration, 242.

Phaseology of the means of Transport, 243.

Phaseology of the means of Intercourse, 244. 


\section{CHAPTER V}

\section{A FURTHER SYSTEM OF STAGES}

The economic systems of Hildebrand, Engels, Schmoller, Bücher, Sombart and Roscher, 245.-These systems are not at variance but they supplement each other in forming a complete picture of economic development, 250.Recapitulation and summary of economic system of stages, 252.

\section{CHAPTER VI}

\section{THE ECONOMIC LAWS OF DEVELOPMENT}

"History teaches us nothing," 254.-The doctrine of phases indicates the direction in which sociological phenomena are proceeding, 254.-Formulation of these laws of direction: 1. Law of Size. 2. Law of Form. 3. Law of Organoplastic groups. 4. Law of Co-operation. 5. Law of Differentiation. 6. Law of Integration. 7. Law of Centralization, 8. Law of Concentration. 9. Law of Association, of Socialization, 255.

\section{BOOK IV}

\section{THE CAUSES OF THE PROGRESS OF CULTURE}

Introduction: Speculative and inductive method, 26r.-Historical materialism, 262.--Recapitulation of the phases of social economy, 262.The importance of the theory of causation to Sociology, 262.

\section{CHAPTER I}

\section{THE CAUSES OF ECONOMIC DEVELOPMENT}

1. The origin of the separate family and of division of labour between the sexes, 267.-The stealing of women and other property, 267.-Group contact through war, 268.

2. The origin of primitive trade, 268.-Robbery and barter, 269.-The barter of goods and women (exogamy), 269.-Migration and adoption, 270.The peaceful contact of groups, 270.-The exchange of local products, $27 \mathrm{I}$.

3. The origin of specialized industries, $27 \mathrm{I}$.

4. The origin of developed industrial organization, 272.-Density of population, 273.-The influence of environment, 273.-Civilization, 273.

5. The origin of capitalism, 274.- The influence of environment, 274.The Mediterranean Sea, 274.-The invention of metal coinage, 275.-The sovereignty of power and the sovereignty of money, 276.-The origin of pleonexy, 276.-The transition of money into capital, 276.-The stages of this transition, 276.-The problem of the acquisition of wealth by means of wealth, 277.--Retrospect, 277 .

6. The origin of mid-capitalistic organization, 278.-The decline of the ancient world, 278 . - The migration of culture to a more northerly climate, 278 . -The opening up of the East, 279. - The great geographical discoveries of the fifteenth and sixteenth centuries, 280.- The growth of the natural sciences, 280.-Labour-saving machinery, 28I.-The resulting decisive victory of capitalism, 281. - The abolition of bondage, 281 . - The phases of com- 


\section{THE HISTORY OF SOCIAL DEVELOPMENT}

pulsory labour, 281. - The long peace after the Napoleonic Wars, 283.-The extraordinary increase of population, 283. - Retrospect on the origin of midcapitalistic organization, 283 .

7. The origin of the late capitalistic phase, 283.-The enormous progress of the mutual dependence of labour in the mid capitalistic phase, 283.The transformation of the whole social economy, 283. - The incongruity between the social economy and the conditions on the other spheres of culture, 284.-Abuses caused by it, 284.-The advantages and disadvantages of individual production and of social production, 285. The incongruity between the division of labour and the distribution of property, 287.-The unjust distribution of property, 288.-The principal causes of this : inheritance and the retention of property within the family, 288.-The difficulty of the problem of just distribution of property, 289. - The communistic solution of the problem is a false one, 289.-A just principle, 289.The modern plutocratic class system, 290.-The weakness of this system, 291 . -A comparison between plutocracy and feudal aristocracy, 291. - The advance of democracy, 291.- Pleonexy, 292.-The history of pleonexy, 293.-Pleonexy and the joy of life, 294.-The uses of pleonexy. 295.-The superhuman energy of the capitalistic system, 295.-Anarchy of production, 296.Crises, 296.

The late capitalistic phase is characterized by movements which aim at the regulation of the social organism on the new economic basis, 297.Associations of workmen, 297.-Political associations, trade unions and cooperative societies, 297. - The iron law of wages, 297.-The significance of associations of workmen, 298.-Associations of entrepreneurs, 298.-Cartels, syndicates, trusts, corners and rings, 298.- The significance of associations of entrepreneurs, 299.-Insurance, 299.-The significance of insurance, 300.National organization, 300.- The raising of the moral tone of the State, zor. -Bureaucracy, Church and State : the final goal of state activity, 302.The modern woman's movement, 302.-Summary, 302.-The economic ideal of the present time, 303.-The dawning epoch, 303 .

\section{CHAPTER II}

\section{THE GENERAL CAUSES OF PROGRESS}

\section{(The Theory of Progress)}

The ultimate cause of progress : mankind, 304.-Social instincts, 304.Speech, 304.-Intellect, 304.-Exertions, 304.-The succession of generations, 304.- Necessity and compulsion, 305.-Leisure and plenty, 305.-The sporting instinct, 305.-Progress not immanent in mankind, 308.-Misoneism, 308.The power of traditional custom, 308.-Peoples who remain on the same culture stage for centuries, 308.-Livingstone's view, 308.-Progress brought about through change of environment, 308. - The effects of change of environment, 309. - Change of environment by means of continual migration, 310.Change of environment by means of amalgamation and reciprocal influence, 3 ro. -The theory of Gumplowicz, 3ro.-Its soundness, 3 ro.-The phaseology of group contact: in antiquity, in the early and mid clan phases and the early and mid industrial phases, 3I1.-Group contact among civilized peoples (China, Ancient Egypt) and among peoples having capitalistic organization, 312.- Achievements of culture due to other nations, 313.--Formulation of the theory: Progress comes about through the contact of groups and the association of nations, 313.- Various kinds of group contact (war, oppression, slavery, incorporation, commercial treaties, a knowledge of extinct races), 314. -Extension of progress by means of the struggle for existence, $3 \times 5$. 


\section{BOOK V \\ A SUMMARY OF THE CULTURE STAGES}

\section{CHAPTER I \\ THE STAGES OF CULTURE}

The reality of a progressive development of culture, 319.-The death of nations a means of advance of culture, 320.- Homogeneity of the course of development, 321.- Heterogeneity of environment, 321.-Influence of race, 321.-Characteristics common to the whole course of development, 321.Higher and lower forms, 322.-Possibility of and authority for a general system of culture stages, 322.- Standard for the height of culture, 323.Fundamental importance of social economy, 323.-Synopsis of economic development, 324.-Graduated scale of the most important economic subfunctions: Food production, Technique and Labour Organization (Differentiation), 326. -The systems of Schönberg, List and Bos, 327.-Characterization of the stages of culture, 327.-Stages of culture in the future, $33 \mathrm{r}$.

\section{CHAPTER II}

\section{ON THE DURATION OF THE CULTURE PERIODS}

Early views on the size and duration of the "World," 332.-Present day views on the size of the universe, 332.- On the age of the earth, 333.-Vast spaces of time assigned by astronomers and geologists, 333.-Age of the human race and of culture, 334.-Period and duration of the Ice Age, 334.Age of the Neolithic period, 335.-The Bronze Age, 336.-The comparative duration of the different culture epochs, 336.-Kant's proposition, 336. The epochs of Universal History, 336.-The duration of the primeval ages, 337. -Savagery, barbarism, 337.-Universal History represents, in respect of time, only a small fraction of the whole course of culture, 337.-General summary of the phases of geology and of culture, 338.-The future of the earth and of culture, 339.-Semi-culture and its completion, 339.

\section{BOOK VI \\ CULTURE AND HAPPINESS}

Introduction, 343.-Of what does culture consist? 343.- Has culture made men happier ? 343. - The idea of happiness, 343. False views of it, 344.-Happiness dependent on the harmonious expression of individuality, 344. - The lot of the individual not essentially improved by culture, 345.Causes of this apparent riddle, 346.-Progress aims at the perfecting of society, even at the cost of the individual, 346.-Culture has hitherto been an unconscious process of nature, 348.-Without plan or purpose, 348.-Is culture a blessing or a curse? 349.-Rousseau's view, 349.-Upon the first epoch, the perfecting of society, there follows a second, the perfecting of the individual, 350.- The reason for this view : the stunting and deterioration of the individual in animal communities, notably the ants, 350.- The striving after happiness of mankind, 351.--Individualism and socialism, 351.- "Social-individualism," 352.-The old and the new religion, 352.- The awakening of the masses, 352.- Transformation of the war community in to the labour community, 353.- The theory of progress and adaptation, 353.- Over population, 354.The humanizing of propagation, 354.-The discovery of the culture movement : transition of the social intellect from unconsciousness to consciousness of self, 354.-The science of nature and the science of culture, 355.

Summary, 355 . 


\section{LIST OF THE SUMMARIES INSERTED IN TEXT}

PAGE

Summary of Geological Phases . . . . . . . . 39, 40

Summary of Sociological Functions . . . . . . 63

Genealogical Tree of the Forms of Food Production $\quad 92$

Summary of the Most Important Peoples on the Various

Stages of Culture . . . . . . . . . 95-96

Summary of the Prehistoric Phases . • • . . . . 113

Genealogy of The Tool • . . . . . . . . . I3O-I3I

Summary of the Forms of Labour Organization • • • 194

Summary of the Structure of Labour Organization . • 196

Summary of the Phases of Division of Labour (DifferenTIATION) • • • • • • • • • • • • • 233-234

Summary of thb Phases of Integration • • • . 242-243

Summary of the Economic System of Stages • • • 252

Synopsis of Universal Economic Development . • 324-325 


\section{BOOK I}

\section{INTRODUCTION TO SOCIOLOGY}





\section{CHAPTER I}

\section{CONCERNING CULTURE AND THE SCIENCE OF CULTURE}

\section{The Conception of Culture.}

CULTURE is generally understood to be the sum of all man's progress and achievements and their resulting manners and customs.

Man, living in correspondence with his fellow-men, can utilize his knowledge for the good of the community. Intellectual possessions, accumulated during the millenniums through heredity and environment, can become the property of all owing to the advance of language and permanent records. Each new generation can proceed from the point where the last stopped and progressive metamorphosis continues.

Take, for instance, the two widely separated examples of a tribe of savages wandering aimlessly through the woods, living on wild fruits and vegetables and the flesh of hunted beasts, and camping at night under the stars or in natural caves, and on the other hand the life of men of our day in a big European state, with towns and villages, cultivated arable and pasture land; the railways, factories, schools, churches, theatres, libraries, art collections, exchanges, parliaments, prisons ånd lunatic asylums. See the huge army and navy obedient to the command of one ruler, and the merchant service trading with all parts of the world. Mark the vast population producing and exchanging goods, in thousand-fold divisions of labour.

These are two stages in the course of civilization gradually travelled by men, each life being but as a tale that is told-a Aream when one awaketh. In the earlier stages the 
progress was unnoted by those most concerned, but in the latest he who runs may read it.

\section{Historic and Prehistoric Phases of Culture.}

As we mentioned above, the earliest peoples would only have noticed in a very slight degree the upward movement of civilization. Many believed things had always been as they were with them. The more advanced possessed traditions; the most civilized held records of a golden beatific period whence men had fallen through disobedience. Some of those on the higher levels of Greek and Roman thought, especially Empedocles and the Epicureans, had reached much the same ideas of attraction or repulsion as some philosophers of to-day.

On the overthrow of these civilizations, barbarians took a leading part on the world's stage and reverted to the former myths, which remained with us for centuries. It is interesting to make a study of the ages from this reversion to barbarism onwards through the Middle Ages to our own times. We observe thus the phases through which the earlier civilizations must have passed, these later men traversing them much more rapidly on account of the contact with the superior intelligence of the conquered people.

Till quite recent times the duration of the world was believed to be about six thousand years, that is, that it originated but a short time before historic times. This calculation is now recognized as untenable, for the civilization of the most ancient people who appear in the light of history is so high and so far removed from the conditions of primitive times, that it is as absurd to consider the Egyptian dynasties as the beginning of civilization as if an investigator in future eras considered the piano the beginning of music and the steam-engine the earliest form of transport.

Writing in some form must have been known before any records could have been left, and this implies quite a late acquisition of civilization, needing many phases whose history lies hidden in the darkness of a long forgotten past which it is not easy to illuminate. 


\section{Deductions from the Prehistoric Phases.}

I. By Means of Palmontology.

Failing a written record of the prehistoric phases, other means of research must be employed.

In the strata of the earth's surface may be found traces left there by primeval man-weapons, tools, drinking and cooking vessels, and with them many other objects both useful and decorative, as well as graves and monuments, all of which enable the prehistorian to gain a fairly clear idea of the civilization in those times.

In the year 1836, in the Valley of the Somme, Boucher de Perthes discovered remains of men who must have belonged to the Diluvial period, while in I853 the lake dwellings were made known. These traces were first noticed in Europe, but were soon found to be in every quarter of the globe, and collected to such an extent that museums were filled with them. As they accumulated a new science was formed, known at first as prehistory, or the " Science of the Spade," but as its dimensions increased this modest title became too narrow for it, and it acquired the more fitting designation of Human Palæontology.

\section{By Means of Comparative Ethnology.}

An entirely different road is that followed by another new science, Comparative Ethnology, the study of racial characteristics.

In his day Schiller hinted at what we might call Dynamic Ethnology. He says: "The discoveries made by European travellers in far-off seas and distant coasts show us a picture as instructive as it is entertaining of peoples of various stages of civilization in our world standing round us, just as we may see the children of various ages in a family standing round an elder brother, and by their condition reminding him what he was formerly, and through what stages he has come to man's estate. An overruling Providence seems to have reserved these immature races for our learning until we were wise enough to profit by the lessons set before us and to be able to reconstruct from these examples the ost history of the beginnings of mankind. The picture of the childhood of our race is sufficiently depressing and 
humiliating, but we must remember that farther back our forbears were much less rational than the lowest of these. . .."

This idea that Ethnology shows us contiguously in the present what history might show us successively in the past, has proved very useful in modern research, now that facilities of transit and publishing of travels make known the life of the whole earth to whomsoever cares to know it.

\section{By Means of other Sciences.}

By Palæontology and Comparative Ethnology we have two quite different ways of arriving at our goal.

To this Philology may now be added, for although language like everything else is continually changing for better or for worse, the root of the words is fixed in them from their origin, and we can frequently trace, by comparison, meanings which these roots had, thereby throwing light in a surprising manner on the lives of people long since passed away.

What applies to language applies also to the mythologies, fairy tales, and religious sagas which are possessed by nearly every race and date from primitive times. Absurd and senseless as many of these seem, they are of the highest sociological importance, and have led to material results in the study of comparative mythology and the science of religion.

Then, too, the "survivals," as Tyler calls them, must not be ignored. These are practices which have outlivec their primordial meaning and are retained as empty form: through the two most conservative influences, Custom anc Religion. For example, among many peoples " marriagt by capture" survives as a ceremony, although it is now quite a peaceful rite.

\section{SOCIOLOGY : ITS PROBLEMS AND AIMS.}

By means of the foregoing and kindred sciences, whicl complete and check each other, it has been possible $t$ gain knowledge of prehistoric times. The deciphering 0 hieroglyphics and cuneiform characters has done much and certain modern sciences have done more still. Statistics 
economics and political science, the history of civilization and of literature and art, ethnological jurisprudence anthropology, race psychology, etc., all tend from various standpoints to throw light on our knowledge of man as a social being.

Yet with all our knowledge of these sciences we should have had, as it were, only a body without a soul had it not been for the giant strides of geology and biology. These have discovered that all present existence and formations of any kind are but transformations of former existences. Through evolution and morphology it is possible to locate man in his proper place in the great plan of Nature, and to understand his history as part of the great scheme of natural events, and thus to acquire a deeper understanding of all human things.

This soul of science owes its birth to men like Lamarck, Goethe, Geoffrey de St. Hilaire, Erasmus, Charles Darwin, spencer, Haeckel and others. It was distinguished by the ame of Sociology by Auguste Comte, and has for its aim the collection of every fact known about man as a social jeing and the evolution of human society.

\section{Problems of Sociology.}

It is necessary to have full proof of evolution before eeking for the laws governing it.

As the botanist collects all kinds of plants for his nlightenment, so must the sociologist collect, describe nd systematically arrange the most perfect array of facts ossible of the forms of civilization under which men have ved during all ages and in all parts of the earth.

The material for building up this new science must be ollected from the long list of sciences previously indicated, alæontology, ethnology, comparative philology, etc. In his way is originated sociological morphology, which has 0 sift and arrange the collected material.

A second problem then confronts us, as it must be ascerained how these forms have developed one from another. o far as history reaches back and the succession of forms unrolled before our eyes, this is a comparatively simple iatter, but where there are no records to enlighten us, as the ease with the important prehistoric phases, then the 
lines of evolution must be constructed by the comparative method.

One of the axioms which guides us in so doing is that, in general, evolution has steadily progressed, and is still progressing, from simple to complex, from spontaneous to mechanical, from homogeneous to heterogeneous. In this manner we establish the course, or rather courses, of evolution, for there is not merely one scheme in the different strata, but a number of lines which, taken together, show the development of civilization.

In order to make the complicated picture of all these developments as clear as possible we must divide the long lines of evolution found in every sphere of civilization into larger or smaller sections, such as phases, periods and epochs. It must be understood, however, that there are no sharply defined epochs of civilization, all is continuous Nature takes no leaps but connects all together by gentle transitions. However, for purposes of study, the artificial sections are of great value, as one can lay stress on the specially important points.

This classification, as well as the demonstration and the description of the course of evolution, is the task of phase ology, the sociological doctrine of phases.

In it the forms which morphology has supplied to us ar arranged as phases, according to their historical evolutiona entirety. Phaseology will provide us with a clear outloo? over the development of the various spheres of culture, genealogical tree of sociological phenomena which it ha only been possible to show since the introduction of th phaseological method in the form of a clearly arrange general plan.

Then having by means of comparison and inductio extracted the general laws of evolution out of the materia collected and arranged, sociology strives to obtain a bett, insight into their social drift.

We will now consider what is the use of all this detaile investigation and laborious work.

\section{Uses of Sociology.}

In the first place, there is certainly a general intellectu need among all who arrive at a certain stage of education 
know how the conditions in which we live originated, and how they have succeeded in raising themselves by force or quality of motion above the narrow limits of the ego in which our ephemeral life is confined, and to cast a brief glance into the unending world of everlasting beginnings and passings. Without science, the existence of man seems only too like that of the beasts, his vital spirit being encompassed in the twilight of a life of mere toil, while he feeds himself, propagates his species and dies.

But in evolution lies the key to existence. If we wish to understand what is around us we must know how it came to be; if the complicated social conditions in which we pass our lives are not to remain an inextricable chaos to us we must know the history of their development.

The antithesis in which the German language places the words

$$
\begin{aligned}
\text { verwicklung } & =\text { complication } \\
\text { entwicklung } & =\text { development } \\
\text { and } & \\
\text { verstehen } & =\text { to understand } \\
\text { entstehen } & =\text { to grow out of }
\end{aligned}
$$

has a deep meaning. For the understanding of a complicated object there is no better way than the knowledge of its origin, of its development. The construction of the most complicated timepiece becomes plain to me if I see it put together in front of me. Sociology teaches us to understand civilization while it traces its growth before our eyes, and one of the principal aims of the present work will be to offer a guide for the comprehension of our own times.

One of the highest aims of all science is to glance into the future, to know what is imperceptible in the present. "Savoir pour prévoir," as Comte has happily said, and Coleridge expressed it, "In to-day already walks to-morrow."

Civilization is a progressive movement going in a definite, lirection, according to fixed laws. These laws once understood, we may calculate towards what goal we are tending ind what we may expect in the future, even as the astrononer foretells the movements of the heavenly bodies. The nore we know of evolution, the more certainly shall we be 
able to foretell the next phases which are to be traversedhence the great importance of palæontology.

Sociology is still so much in its infancy and its subject is so complicated that it is premature as yet even to attempt to indicate the future, but, as the poet Campbell writes, " Coming events cast their shadows before," and we firmly believe that it will be possible to do so later.

Practical as well as ideal results should follow this study. It prepares the path for progress, and by bringing the ever-changing phases before our eyes it shows clearly that every event is only a transition to higher things. This fact is distasteful to human vanity, but it combats in the most effectual way the pernicious error that evolution has reached its zenith, and that new ideas must be opposed. It is obvious that deep insight into social movements and the wider outlook that this affords must be useful to the politician. It may easily happen that a statesman, a stranger to sociology, may be carried along by the stream of time, instead of steering himself. In spite of good abilities he may after all his efforts land at a point quite different to the place for which he was aiming. Through our lack of knowledge evolution appears much more tragic than it really is. Only he who understands it can control it; while hẹ who lacks understanding is controlled by it. Just as man dominated Nature and guided it to his own advantage as soon as natural science had placed the means in his hands, so will he control civilization for his own profit when the science of civilization has provided him with the requisite insight.

The utility of sociology extends to other sciences, especially psychology.

Man is essentially social, a political animal as Aristotle says, and only as such can he be psychologically understood.

The ideas which set our minds in motion, whether concerning the common things of daily life or the latest problems of religion or philosophy, were not generated by ourselves, by the individual, but arose in other brains long since dust, and have been passed down to us as communal property. All that we think, feel, wish and do is through this transmission; it has become part of our flesh and blood, through heredity and education, and has, much more influence 
with us than the little that any man as an individual achieves for himself by his own intellectual worth. Having grasped this simple fact psychology entered on a new era. Individual psychology is simply studying the tubes through which the stream of intellectual phenomena flows. Social psychology strives to show us the manner in which the ideas have originated which constitute the capacity of our mind and accompany us from the cradle to the grave, modifying and defining all things for us.

\section{Literature.}

Sociology fills a great gap in our intellectual life. Of all the sciences, this affects man the most, and will have a more beneficial and decisive influence on his life if he will receive the truths, startling and revolutionary as they are, unprejudiced by class or party interests. It is small wonder that the number of students in this research work is always increasing. Since this century began, progress has succeeded progress and discovery been added to discovery, and one may well believe that as the nineteenth century was the century of the natural sciences, the twentieth should be the century of the science of civilization. One might fill a volume cataloguing the works of sociological literature. I refer the reader who intends to make a thorough study of this to Eisler's Sociology, where he will find a list of the more important works. ${ }^{I}$

x Personally I owe a debt of gratitude to the following men, who have helped me by their works, as well as to others already mentioned: Condorcet, Comte, Herder, Spencer, Mill, Taine, Lyell, Darwin, Rousseau, Montesquieu, Bastian, Waitz, Peschel, Ratzel, Fritz Müller, Schurtz, Lubbock, Tylor, Lippert, Morgan, Grosse, Letourneau, Espinas, de Greef, McLennan, Laveleye, Cunow, Kohler, Post, Westermarck, Starcke, Zenker, Gumplowicz, Vierkandt, L. M. Hartmann, Simmel, Stammler, Maine, Achelis, v. Dargun, Wachsmuth, Hellwald, Henne am Rhyn, Klemm, Kolb, Honegger, Buchsenschütz, Buckle, Hahn, Hehn, Sombart, Marx, Engels, Schaffle, F. A. Lange, Bücher, Roscher, Schmoller, A. Wagner, Carey, Duhring, George, Schrader, Noiré, Steinthal, M. Lazarus, Laz. Geiger, Ed. Meyer, Friedländer, Lamprecht, Dahn, Prutz, Breysig, Hörnes, Ranke, de Mortillet and many others. 


\section{CHAPTER II}

\section{CONCERNING THE ORIGIN OF CULTURE}

ThE history of Mankind is only a chapter, and a late and comparatively short chapter, in the history of the earth. When Mother Earth brought forth man, she had already attained to a great age, and had a history extending over millions of years behind her. When, therefore, we ask about the primordial condition of man and about the genesis of culture, we must go for assistance to the history of the earth, to geology and palæontology. A brief glance over the epochs of the history of the earth, over the geological phases, shows in the simplest possible manner the relationship of man to the earth, and what position he occupies in the wide realms of Nature.

\section{A. Geological Phases.}

The crust of the earth is composed chiefly of two kinds of rocks : volcanic rocks, which have issued from the interior of the earth in a molten condition and then solidified, and stratified rocks, which have been deposited by water forming layers or strata, and are very numerous. As a rule the older rocks are those that lie deepest. These stratified rocks may be looked upon as a huge chronicle, as the fossils preserved in them relate the history of the earth and its inhabitants. The arrangements of the strata and the fossils found in them are shown in the following tables.

If we read this table from below upwards in the natural order of the strata, we find at the bottom gneiss, mica and primitive argellite deposited to a thickness of thirty kilometers from the foundation of the earth's crust. The formation of this layer must have occupied enormous periods, but up to the present time no signs of fossils have been 


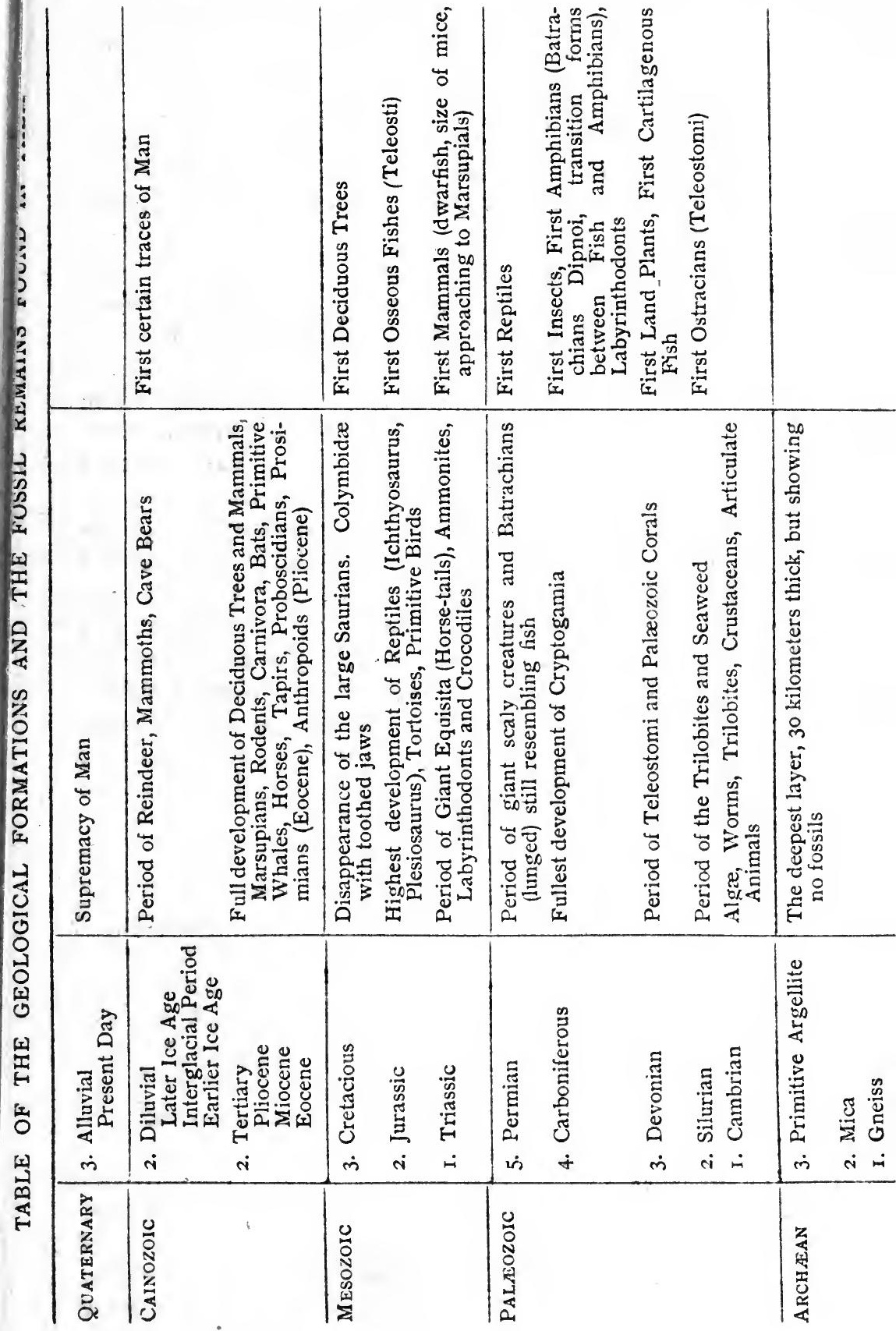


found in it. Yet it could not be called Azoic, for we must assume from later research that the first plants and animals originated in these archaic periods, although they have left no traces behind; for in the lowest stratified rocks we find numerous species of plants and animals, the Trilobites for example, which have attained a comparatively high state of development.

In the next stratum, the Cambrian, are found the first traces of animal and vegetable life, developing always through the higher layers into more complex and higher forms. In each new formation appear new plants and animals (named in the right-hand column) which are continually developing and becoming characteristic of their period (in the lefthand column). These groups for the most part become extinct and are succeeded by higher forms.

We find, for example, the first ostracea in the Silurian System; in the Permian the first reptiles; and in the Triassic the first traces of mammals. In the Tertiary, the development of the Mammals reaches fuller perfection, and progresses as far as lemurs and anthropoid apes; in the Diluvial appears man, who later on, in the Alluvial, which is our present system, dominates the earth, and is as characteristic of this period as the saurians were in the Jurassic.

If we condense to the utmost the facts spoken of above we arrive at the following table:

I. Eozoic period of the Earth

Apparently only Water-dwellers;

Algre and Acranial animals

2. Palreozoic

Ferns and Fish

3. Mesozoic

Coniferous trees and Reptiles

4. Cainozoic (Tertiary)

Deciduous trees and Mammals

(Quaternary)

Man

Cuvier, the anatomist, a fierce opponent of Evolutionism, had the idea that each stratum may have begun after some violent gyrations of the earth, whereby all existing plants 
and animals were annihilated, and after which new species were created in some equally mysterious manner.

This was known as the Catastrophe Theory, but it had to give way to a more rational one. Lyle especially teaches that the strata succeeded one another for the most part calmly and quietly, during many millenniums, through the play of forces which we see in action before our eyes to-day. Through the gradual cooling of the earth, by movements for the most part imperceptible, the crust is displaced, some pláces rising, others sinking below sea-level; by some more sudden movements the layers are folded and mountains are formed. The earth crust impresses us as fixed and motionless, but it is thin in proportion to the size of the planet, being no thicker relatively than the varnish on a globe, and it is flexible.

At the present time in some places the solid land is rising quite slowly out of the sea, as for instance the coasts of Sweden and Spitzbergen, while other regions, notably Greenland, are gradually sinking. During long periods of time whole continents may emerge from the waters and rise to very great heights; in the Himalayas sea-snails and mussels have been found at a height of 20,000 feet, and in the Andes of Peru at I4,000. These same continents may be again submerged, so that the same place may become, many times in succession, land and sea-bottom. New formations are always being originated through the action of water. It rises as vapour from the ocean into the air, and being discharged as rain over the solid earth, it decomposes and corrodes even the hardest rocks by constant action; in the form of ice it bursts them apart, and as brook and stream it carries them down as plunder to the sea, thus forming new deposits which slowly and gradually, without need of catastrophe, grow up in imperceptible transition vut of other formations.

Having realized this view, we can now see the analogy with the vegetable and animal world and put aside the fantastic theory of haphazard origin. As all geological strata resulted through gradual transitions from the oldest rocks, so all the higher animals and plants, instead of being created at random were developed in uninterrupted sequence out of the lower ones already existing, in the course of 
enormous periods of time; and these metamorphoses came about through forces which we can observe with certainty in our own day by means of variation, selection in the struggle for existence, adaptation to new environment and heredity. This theory of the descent of living beings has been confirmed by such an enormous mass of facts in the domain of geology, comparative anatomy, physiology, pathology and biological theory of evolution (for instance, the transformations the human embryo undergoes in the womb), that it would need a very great deal of scepticism, or else an excess of doubt or ignorance, to attempt to refute it.

\section{B. Prehistoric Phases.}

Assuming that this theory is correct, neither pride nor prejudice must frighten us from the conclusion that Man also must have developed from lower forms. Which, then, are these lower forms?

In the Tertiary system, the development of the series of mammals to which man belongs had reached the stage of prosimians or earliest apes. Quite certain traces of man have not yet been found here.

In the Diluvial system, however, we meet with a type of man who is far past the primogenous condition, having a degree of culture corresponding nearly with the rank of the "lower hunters," as ethnology describes them. It was believed when first these Lower Hunters were met with in the races of Bushmen, Australian tribes and Terra del Fuegans that the representatives of the earliest type of man were found; but with greater knowledge that idea of them has been abandoned and we consider them much nearer to ourselves. Without exception, they possess various tools and weapons, a language which is, comparatively speaking, highly developed, a knowledge of kindling and using fire, certain religious conceptions, and no small wealth of traditions and other inherited knowledge, as well as a civilization which stands high above the primordial condition and could only have been acquired through long periods of time.

It is here that there yawns an enormous gap in the line of evolution, about which neither geology nor ethnology 
can give any information. Here is hidden the much sought secret of primitive man, for during this fotal period of humanity those important and momentous advances in development were made which raised man so immeasurably high above all his other fellow-creatures. None of the later brilliant discoveries and inventions equal in the remotest degree the mastery of fire, the perfecting of speech, and the production of the first tools.

Concerning the first and most important of all the epochs of civilization, our knowledge at present has not reached beyond the grade of hypothesis. Conclusions, however, which are strictly founded on scientific actual facts must throw more light into the darkness than mythical stories coming to us from a lower stage of culture and still governing a wide circle. Since we can state nothing of this with certainty, I would omit the following considerations if another view were not connected with them.

Modern sociology has come to conclusions concerning the nature of man, the value of the individual and his relation to society which are in opposition to the generally accepted opinion and to the views of important philosophic thinkers who have not studied these theories. These conclusions signify an extraordinary progress, one of the most powerful " changing of values" of modern science. We can best introduce the reader to these new theories and, at the same time, to sociology by a discussion of the problem of the origin of culture, because here while we compare it with the animal we can lay bare humanity at its deepest root.

\section{The Uncultured Ancestors of Man.}

As we have said, speech, tools and weapons, and sundry transmitted acquirements such as religious ideas and familiarity with the kindling and use of fire, were the attainments of the lowest stages of culture known to us in man, these acquirements putting him out of all comparison with the most highly developed of the animals.

If we now proceed with our efforts to find out what manner of men our forefathers must have been to arrive at these earliest fundamental acquirements, we shall not hesitate to assert that in the first place they must have had hands, 


\section{THE HISTORY OF SOCIAL DEVELOPMENT}

since without these they could have invented no tools; and in the second place they were gregarious animals, since only those living in communities could bring speech to the higher stages of development.

Let us now consider these two points.

\section{The Genealogy of the Hand.}

The enormous usefulness of the hand could only be apparent after tools, no matter how primitive, were invented.

What did man do with his hand before the invention of tools? Wherein lay its function, its use ?

It is well known that all mammals belonged originally to the quadrupeds, thus the early ancestors of man were four-footed. This we must conclude from the history of his evolution and also from various characteristics which he still bears to-day; for example, the rudimentary intercostal vein valves which could only have had a function so long as the body was carried horizontally, not upright. The upper extremities of man were thus, like the lower ones, originally organs of motion. How then did hands originate from them?

As the simplest solution of the riddle it is suggested that the forefeet were changed into hands through adaptation to life on trees. In conformity with this suggestion is the striking affinity of man with the tree-climbing ape, which is distinguished from other animals by the possession of the hand, and stands nearest to man of all kinds of mammals. Certainly the differences between the highest species of apes and the lowest races of man, even the purely anatomical and physiological ones, are still very considerable. If we arrange a series with all the transitions from the lowest of the apes up to man, we find a gap in the continuity of the line of development. This gap does not come, as we should have expected, between the anthropoid ape and man, but between the very low and the lowest apes, between the apes of the Old and New World and the lemurs. According to Huxley, the difference between man and the chimpanzee is almost unimportant in comparison with the difference between a chimpanzee and a lemur.

Further, the adaptation to tree life explains in the most 
natural way not only the genealogy of the hand, but the later upright walk of man. Through this adaptation the body was directed from the horizontal to the upright position and was prepared for the later differentiation of the upper extremities into prehensile organs and the lower exclusively into organs of locomotion. On these and many other grounds which it is not necessary to discuss here, ${ }^{x}$ we have come to the conclusion that the hand became prehensile before the invention of tools in order to serve as an organ for climbing, that it was a corollary of the tree life, and that the primitive ancestors of man were tree climbers.

\section{The Origin of Speech.}

We may assert with equal probability that our forefathers were gregarious beings, as otherwise they could not have elaborated speech.

It is certain that there could be no object in evolving a language except as a medium of communication. Its origin thus presupposes a community, a social life. There are two types of gregariousness among mammals. First, animals that live in separate families, each group consisting merely of the parents and their young. The young leave the parents as soon as maturity is reached and set up for themselves monogamous groups, the members of which for the most part only remain together for one year. ${ }^{2}$ This type having solely reproduction for its aim we will call "family groups." The second type are those animals living in larger groups where the young do not leave the parents when adult life is reached. Reproduction is not their sole aim, but they live together for mutual offensive and defensive help. These we will describe as "social groups" as distinguished from the "family groups." To

1 For discussion of the subject in greater detail see:

Darwin: Natural Selection; Origin of Species; Descent of Man, etc.

Huxley, T. H.: Zoological Evidences of Man's Place in Nature. 1863.

Häckel : Anthropogenie.

Wiedersheim: Der Bau des menschlichen Körpers als Zeuge seiner Vergangenheit.

Bölsche: Die Abstammung des Menschen.

2 Brehm, i. 33. 
this second class belong such insects as ants and bees, and such mammals as horses, wolves, dogs and many varieties of simians, such as baboons and the long-tailed monkeys. Lions, tigers, cats, bears and foxes are examples of animals living in family groups.

It is quite obvious that highly developed speech could only be elaborated among the animals in social groups, for the fundamental conditions of community and continuity are lacking to those in the family groups. Among the latter the sounds would be restricted to alluring love cries and warning noises to the young, as strange groups would probably not understand each other, and the time would be too short to teach the young any long vocabulary. Only in the social groups would there be an opportunity of forming such a vocabulary which could be steadily increased as it passed on uninterruptedly from one generation to another.

This theory of the social origin I of man is disputed, as the anthropoid apes-such as gorillas and chimpanzeesdo not live in social groups, but it must not be imagined that man is a direct descendant of the anthropomorphoids, or of any now existing species of apes. In the enormous periods of time that have intervened since the Tertiary epoch the different kinds of apes, like all other mammals, have gone through many evolutions. How momentous these evolutions were may be conjectured from the fact that in the tertiary period almost all the genera of the land mammals of to-day were in existence, although all the species have become extinct or have evolved into others. ${ }^{2}$ Out of I2I genera of fossil mammals with 360 species, no fewer than fifty-nine genera have disappeared or degenerated in metamorphosis. Even if direct descent from the same ancestor could be proved in the case of the now living anthropoid apes and man as at present existing, it might demonstrate in the one case progression, and in the other atavism, or reversion to type. The apes, who lacked the social instinct, could never rise to speech or culture as did their better organized kindred. In fact, many things favour the view that they are an early degenerate form of man's ancestors-for instance, the greater likeness to the s Notably by Professor Westermarck.

2 Mortillet: Le Préhistorique, p. 128. 
genus homo in infancy. According to fundamental biogenetic laws, this would signify that man had not descended from these anthropoid apes, but that they had branched off from him. ${ }^{x}$

This, too, would uphold Darwin's theory that the apelike ancestors of man were gregarious, as are the majority of quadrimana to-day. ${ }^{2}$ If we consider the strong confederation known to exist among many species of apes, the solidarity which unites them for mutual help in danger, the obedience which all, even the adult males, yield to their leader, we cannot fail to see that it is the same trait as that which has led to human supremacy.

Brehm and Perty furnish us with other resemblances between primitive men and baboons. The latter live in enormous herds, numbering many thousands, who at night time sleep huddled together for warmth after having posted sentinels. If attacked the whole band sets up a furious roaring, screaming and howling, the most powerful of the males throw themselves with terrible rage upon the enemy, the strongest protect the weak and the young, and fight valiantly to save them from the enemy; they bring the wounded into safety, and set a rearguard as they retreat. Baboons prey not merely upon fowls, but upon antelopes and the stately bushbuck. They hunt carefully under the stones for insects, snails and worms, several of them uniting frequently to turn over the larger rocks.

These are striking characteristics which we shall notice again later on among the hunting races. Even the much ridiculed human vanity is not lacking, a powerful trait which may put the individual quite at the mercy of the community. Baboons, for example, are so extraordinarily vain that cases have been known where mocking laughter or even a single sharp word or glance have driven them frantic.

The social origin of man is further confirmed by the fact that up to now not a single example has been found of human beings living in independent separate families.

I [In connection with this suggestion it is interesting to note Charles Kingsley's views to the same effect in Water Babies, published in 1863. - (Trans.)]

2 Darwin: Descent of Man, i. $x 66$. 


\section{THE HISTORY OF SOCIAL DEVELOPMENT}

No matter how unfavourable the climate or unprofitable the ground, making the struggle for existence unduly hard, still the families remain in groups if possible, or being forced to scatter, keep in correspondence with one another. ${ }^{\mathrm{r}}$

Taking every detail into consideration, we must conclude that, firstly, the primitive ancestors of man were tree climbers, who apparently had a common origin with the quadrimana of to-day, but stand in no direct descent of relationship with any of the now living species of apes; and secondly, that man is born with social instincts and has descended from a gregarious race.

\section{The Creation of Man.}

The question then arises why the other gregarious treeclimbers have not similarly progressed to the mastery of speech and tools. Why has man alone risen to abstract thought, to religious and moral ideas, and the knowledge of good and evil, to such a mental superiority over all beasts that it mocks at comparison?

All this marvellous progress took place during some epoch-making change of environment, when for some reason unknown to us our pithecanthropic ancestors were induced or compelled to change the tree for the ground. Many kinds of apes at the present time, when they descend from the trees to hunt for prey, habitually walk on their hind legs, leaving their hands free. One particular species, having adopted a permanent upright position in order to have better opportunities in the chase, would reach paths of evolution which would carry them far beyond their four-footed kindred.

To dexterous climbing creatures the tree offers a place of refuge where they find safety and freedom from danger, needing but small means of defence against stronger enemies, as they can escape by flight, while at the same time the food grows there ready to hand without fighting and struggling for it. It is easily seen, then, that these tree-dwellers lack all incentive towards higher development.

A very different life awaited primitive man on the

I See the classification in Professor Westermarck's History of Human Marriage. 
ground. The peaceful vegetarian evicted from his tree must become a hunter and a fighter. In this arena war, hunting, insecurity and constant danger called forth all his powers; the third dimension was no longer always open to him as in tree life; cunning, skill, courage and endurance were needed in his encounters with huge wild beasts, man's first teachers, whom he must in some way subdue unless he were to go under in the struggle for existence. In comparison with the monotony of tree life, there was opportunity for an endless diversity of environments, and to these man adapted himself in the course of many ages and thus continued his development.

As we have already seen, our forerunners in coming into this new environment brought with them two powerful aids in the struggle for existence, firstly the unity of the horde, and secondly the hand, that tool of tools. We will now consider the significance of these momenta on the origination of culture.

\section{Hordes AND LANGUAGe.}

We have already spoken of the solidarity which exists among many species of apes. Such an alliance of many for offence and defence is really an organization of a very high kind. One brain controls dozens, nay, hundreds of eyes, ears and limbs, which, scattered over some arranged space, can unite from all sides to a chosen goal. This obviously can only be if the separate members work together on a concerted plan, understanding one another. For this a means of communication was necessary, and speech arose.

Elementary speech is a not infrequent possession among the higher animals. According to Dupont, fowls and doves have twelve different sounds, dogs fifteen, horned cattle twenty-two, while the vocabulary of the unlearned man does not consist of more than 300 words. The language of apes, who chatter unceasingly, quarrel, and play pranks on one another, is composed, according to Garner, ${ }^{\mathbf{x}}$ of twenty sounds, supplemented by countless gestures and lively mimicry.

- Garner: Gorilla und Schimpanse, p. 64. 
We thus get some insight into the idea of how these primitive cries began to act as a means of communication and sufficed to organize the hordes, so providing the germ of a nervous system. The association of these groups into widely scattered co-operating communities resulted in such efficiency that every isolated creature had to give way before it, no matter how formidable the natural means of self-defence it possessed.

Such a useful expedient in the struggle for existence must through natural selection be continually improving, since in the everlasting warfare between the different hordes of men the more highly organized survive as victors. While speech was being perfected, it became the parent of human intellect. The much disputed but far-seeing utterance of Lazarus Geiger, " Speech has created reason; before speech was developed man was irrational," I sounds at first sight paradoxical, but it is perfectly true. Indeed, only when we have learnt to understand this wonderful phrase with the depths of our psychological knowledge do we get the right insight into its epoch-making importance. For at its beginning speech was only a means of communication, but as it gradually developed it acquired two wider functions, namely, the social accumulation of thought and the potentiality of expressing thought in words. Let us consider first

\section{The Accumulation of Thought through Speech.}

Since language enables us to communicate our thoughts to each other, every single individual may become a participator in the highest thoughts ever evolved by the most gifted brains of humanity during the course of countless generations. This wisdom, accumulated by tradition and educational institutions, may make each individual a perfect Crœsus of thought, and allow a scholar of our own time to share in the researches of the divine Plato. This is a marvellous thought, that every man, even the least educated, has within him wonderful potentialities which he has inherited, not produced, going far beyond anything he could

r Geiger, Lazarus: Ursprung und Entwicklung der menschlichen Sprache und Vernunft, 1868, ii. 81. 
have evolved for himself. From this standpoint he looks with contempt on the lower animals shut out from such an inheritance.

The powers working in the brain of any individual are not merely the result of his brief life's intelligence, but of the intellect of humanity transmitted through countless individuals now passed from this world. As the process of accumulation continues that social intellect is evolved which enables human reason to gather together the work of millions of human brains. Even the contribution of the world's greatest genius is comparatively small, seeing that he is standing on the pyramid built by the accumulated work of all his ancestors, and that it is only by one stone that he increases it.

We see here that the enormous superiority of man's intellect above that of the animals is due to a great extent to the cumulative effects of speech, since the intellect of an individual man and that of the higher animals are extraordinarily akin.

Animals have the capacity of connecting ideas, drawing conclusions, considering carefully, profiting by former experiences, and of divining the thoughts of men. They possess memory, reason, fancy, powers of judgment, and often, markedly in the case of elephants, monkeys, dogs or foxes, give proofs of wonderful intelligence. In fact, among dogs one frequently finds examples of such affectionate sagacity that we believe they only need speech to be human.

On the other hand, take the case of a human child brought up without any kind of education, without speech and without understanding. In what way would he surpass a chimpanzee or orang-outang in intelligence? He would be simply an animal. In fact, cases have been known of children separated and ensavaged in infancy who, when discovered in adult life, were so little differentiated from the animals that they were considered at first to be speechless idiots, the Homo ferus of Linnæus.

\section{The Potentiality of Thought through Speech.}

The superiority of the human over the animal intellect is in great part social, not individual, and can be explained as being the accumulated result of speech. 


\section{THE HISTORY OF SOCIAL DEVELOPMENT}

Yet there still remains a fundamental distinction between human and animal understanding - the animal does not conceive abstract ideas and effect results from them. Only with abstract thought do those higher thought-processes begin which are characteristic of the human intellect, and which have made of it an instrument of the highest power. This wonderful capacity of man, abstract thought, is a gift of speech only. This is the true solution of a puzzle ${ }^{1}$ that even the great Kant in the Critique of Pure Reason declares insoluble.

As is well known, speech depends on the fact that everything, or rather the imagination of it, is connected in the human mind with a word. This word then "signifies" the thing, it is literally the " sign" of it ; for example, the word "apple" causes a mental picture of the fruit with all its attributes to rise before our eyes.

The speech-endowed man, in opposition to the speechless animal, can think, not only in memory pictures and representations, but also in these signs; and this word thinking, according to Taine, occupies a larger space in his brain than we are inclined to realize. If, for example, I read the sentence, "Useful knowledge is increased by observation and research, and in this manner the worth and power of man are enhanced," I understand the phrase perfectly, without any pictorial representation being presented to my consciousness by it. I have thought without representing; I have thought in signs.

Mental operations with mere signs have an immeasurable advantage over those with representations, as can be quite briefly shown.

(a) The Sign is more Comprehensive than Representation.

For example, a representation of a triangle must be either equilateral, isosceles or scalene, while the word triangle embraces any conceivable form of it. What I speak of as "I" is a complicated system of thousands of ideas, thoughts, desires, efforts and actions. Had mar never grasped this chaos by this little sign "I" and placec it in juxtaposition with the equally great chaos of the outside

1 Geiger, Noiré. 
world, he would never have been able to rise to the consciousless of his own powers.

(b) The Sign is more Flexible.

For example, if I say colour or size, I can separate qualities from things which in representation are inseparably jound up with it, and I can work on with the idea freed from the weight of objectivity.

(c) The Sign is more Accurate.

For example as representations $33^{\mathrm{I} 2}$ and $3 \mathrm{I} 3$ apples lie so near together that they may be confused, but as signs they can be kept distinct in our own minds.

The mind which can thus carry on its thought processes with words, i.e. with abstract signs, pursues a subject a very great deal further than another which has only clumsy representations and memory pictures at its command. One might compare it to copper currency and bank notes. With the former all high financial operations would be out of the question. Imagine counting out a million pounds in copper coins and transporting it in sacks instead of passing over 6r,000,000 note. So with the paper money of words man is able to carry on thought processes which for the animal, only provided with the small change of representation, are impossible.

Thus did man rise on " the wings of words" out of mere animal representation into the realm of that which is no longer material, but purely intellectual; and this mighty progress he owes to speech.

On looking back over what has already been said, it seems that the gulf between human and animal intellect is not as impassable as it appeared at first sight ; the chasm has been bridged by the wonderful structure of speech. The effects of this means of self-expression were cumulative and threefold:

(a) The communication of ideas from one to another was the origin of all social organization;

(b) The accumulation of individual thought formed the basis of a powerful social intellect;

(c) Through the potentialities of Speech human brain power was led from mere clumsy representation to flexible abstract thought. 


\section{THE HISTORY OF SOCIAL DEVELOPMENT}

The conspicuous importance of Speech was first recognized by Cuvier. Wilhelm von Humboldt, the founder of the science of language, said, "Man is only man through the medium of speech," but when he continues, "but in order to invent speech he must already be man," we cannot agree with him. Speech was not invented; it developed slowly, growing almost word by word. From the first cries of animals to their offspring, it went on till it became instrumental in organizing the horde, and so was a powerful weapon in the struggle for existence, while during countless ages it has been perfected through natural selection.

But let it not be imagined that the intellect was wholly created by speech. Rather was it that speech and thought advanced alternately; each progress of speech leads on to a progress in thought, and in the same way each progress in thought effects a progress in speech, just as in walking one leg always helps the other a step further on. ${ }^{\mathrm{I}}$

\section{HAND AND ToOL.}

Primitive man brought with him into his new environment gregarious habits and prehensile hands. The hand, while being itself no tool, is yet the parent of all the most formidable and effective weapons and tools of to-day.

We have already remarked among animals elementary organization and a certain co-operative intelligence; in the same way we find primitive tools among them. Apes walk with the help of sticks, and fling stones, boughs and prickly fruit on the heads of their enemies. ${ }^{2}$ With stones, too, they break nuts and open oysters. 3 The chimpanzee builds himself a little hut out of tree trunks which is very similar to that of many savage men. Thus there exists among apes something like a "wood and stone age." It was, however, quite other incentives that urged man forward to the use of tools in the course of evolution. Once having become a dweller on the ground, man walked on the soles of his feet like the bears, who easily raise themselves upright ;

I A corresponding account of the intellectual development of man will be found in the History of Human Understanding (see Preface, p. ro).

2 Wallace: The Malay Archipelago.

3 Perty: Seelenleben der Tieve, p. 703. 
the upper extremities were so differentiated as to be no longer of use for locomotion and were free to be adapted for new functions in addition to seizing and clinging. Having knocked nuts to pieces with a stone, it was only a small step forward to break other stones into any desired shape with it, and in this manner originated that famous primitive tool, the coup de poing of the French archæologist. This roughly hewn stone did duty as knife, saw, scraper, hammer, axe and chisel, but naturally was not the best possible tool for any of these purposes. For this reason men improved it, as time went on, by adding a handle for fighters, teeth for a saw, and so on, until it was gradually differentiated into different tools for each work. In the same way the wrenched-off branch of the tree developed into sticks for throwing, digging or fighting, then into spears and clubs, and later into swords, bows and arrows, and oars and rudders.

The tool or weapon once established, the struggle for existence depended principally on its development, especially with regard to weapons of warfare. The hordes who first brandished the spear or the battleaxe could therewith beat off all others from the field, in spite of superior bodily strength. Thus the struggle for existence changed its sphere from the material to the intellectual; the survivors in the fight were those with the fittest intelligence, those who had elaborated the best weapons of offence and defence. Through the continual recurrence of these results by the development of the tool the minds of men were led to see the superiority of the quick inventive brain over rude force.

In fact, the era of the invention and perfection of the tool marks the most decisive change between the natural and the civilized man. As Noiré puts it: "A knife held in the hand works exactly like a natural organ as long as one needs it, and has the great advantage that when done with it can be put away or replaced with another implement." I In fact, the hand that clasps a knife is practically another organ to the same hand that holds a paint brush, an auger, a drinking vessel, pen, hammer or pistol. In the hand man has thus a number of organs corresponding to the number of different tools he possesses. If all these tools

$$
\text { I Noiré: Das Werkzeug, p. Io6. }
$$


were part of the physical anatomy, we should have a monstrosity like the Japanese goddess Kwannon, who holds a different object in each of her hundred hands.

Progressive evolution must necessarily leave the organic sphere at a certain point and gradually work along the lines of the processes of civilization. This inevitable transition has been brought about by the above-mentioned causes, and principally by the discovery of the tool, and indirectly by the tool of all tools-the hand.

\section{FIRE.}

The knowledge of the kindling of fire may be considered as the last great achievement of the primitive age. The evolution of speech and of tools apparently proceeded simultaneously, but the knowledge of the kindling and control of fire must have been acquired considerably later, as it needed great care and complicated labour for its achievement.

Its discovery is probably explained in the following way :

All primitive peoples in manufacturing their wood or stone implements bore holes in them by rotating a pointed wooden stick for hours on end.

In this whirling movement, at which primitive man possesses a dexterity and skill which amazes Europeans, it not infrequently happens that the wood-dust in the hole catches fire from the heat generated by the friction. If these sparks are allowed to fall on dried moss and carefully tended, the whole can be kindled into flame.

Considerable support is given to this theory by the fact that among nearly all primitive people the art of kindling fire is almost identical, that is by rubbing, boring or twirling two pieces of wood; many tribes make use of a bow-shaped instrument to turn the drill. In many places also the first fire may have been supplied by volcanic agency. The glowing lava is utilized to this day by the inhabitants of Oceania for cooking. It is possible, too, that some races discovered fire by the beating together of ferruginous stones. " Firebeating" is occasionally practised yet by the Terra-delFuegians and the Eskimos, who are still in a low stage of culture. 
It is almost more difficult to give a reason why man should undertake all the trouble of kindling and keeping up a fire in those early ages than to guess how he discovered it. Since the original home of man certainly was not in the frigid zone, warmth could not have been the chief desideratum. Still less could it be its service for cooking, for uncivilized man possesses a very conservative appetite, and shrinks from anything to which he has not been accustomed from his youth up. The destructive power of fire was only realized later, when men hollowed out the trunks of trees with it, and used prairie fires to drive away wild animals. Probably the first attraction was its light, the magic witchery of the flickering, fork-tongued flames, all yellow, red and blue, which consumed everything offered to them, while they whirled upward like things of life. The children of to-day, as in the childhood of our race, have bonfires simply for the pleasure of looking at them. Especially in the gloom of night the illuminating power must have been very acceptable, and all the more so when it was seen that lions, tigers and other wild beasts shrank away from it in unconquerable fear.

The charm that fire first exercised over man was largely due to the joy in light and terror of darkness that is still evident in our children, and that even our higher civilization cannot totally destroy. This is illustrated by the fine verses in Goethe's Faust, and the opinion is confirmed by the philosopher Geiger, who says: "It is not the beneficent results of fire, nor its warmth, which, according to available records, was appreciated most in early ages, but its lustre, its red glow; and so far as linguistic designations can be explained with certainty, it is neither its warmth nor its powers of burning, wasting, or of giving pain that provided a name for it, but the glow of red colour. The idea of colour is the oldest that attracted men to fire."

\section{CONCLUSION.}

With the discovery of fire our ancestors emerged from their primitive condition. During the untold millenniums which formed the Tertiary Period, man was raised from the animal condition to that of a rational being. We have shown that the most important media which produced this 


\section{THE HISTORY OF SOCIAL DEVELOPMENT}

result were, firstly, the hand, which evolved from an organ of motion to one of prehension and became free when men gave up tree life for the ground; and secondly, the social instinct, which led men by way of speech and reasoning powers to unite into highly organized associations. This is the grand secret of his dominion over the whole earth.

For it is not to his individual power and supremacy that man owes his superiority over the animal kingdom, but to his union with other men into a powerful organization whose widespread system of mutual support is effective throughout the whole earth.

This relationship between society and the individual is especially noticeable in comparing widely different stages of culture. There is an enormous contrast between a modern great state and a tribe of Veddas or of Australian aborigines, but the difference between an individual Vedda or an Australian on the one hand and a European on the other is relatively insignificant.

Indeed, the greater the power of society the more dependent, one-sided and helpless does the individual become. A savage makes for himself every tool and weapon he needs, but the man of a civilized country can scarcely yet obtain any complete object for himself except through the medium of money, that bill of exchange on the work of another. Left alone, he is the most pitiable object in creation. It is only under the pressure of society that he can keep himself on the high plane of civilization.

A tale is told by Peschel that "In the year I540 De Soto and some companions landed in the south of the United States with certain stores, but for some reason they never received any more supplies from Europe. Their horses died, their guns became useless when powder failed, their swords rusted and broke, their clothes and boots wore out, and many years after, when seen, they were marching and fighting, clothed and armed like the Red Indian tribes." In the same way that these civilized men fell rapidly back into barbarism, one may be sure that if a man in the latter state were isolated he would not rise to civilized life, but if he survived at all, would revert to a condition having neither speech nor reason. 
The doctrine of social gregariousness is the root of sociology and the key to the understanding of all the phenomena of civilization. This must be remembered through every page of this volume.

We now emerge from the darkness which enshrouds the life of primitive man, in order to take up the study of the prehistoric and historic phases, but before devoting ourselves to this we will briefly review the whole sphere of social development. 


\section{THE CLASSIFICATION OF THE WHOLE SPHERE OF CULTURE}

THIs subject is a wide one, and we cannot master it except by remembering the lesson taught in the fable and dividing it first into its component parts. Each of these must be subjected to scientific investigation, and the material so obtained classified and arranged. We must not attempt to establish any fictitious system of arbitrary regularity but the arrangement must be adapted to the nature of the material.

This can be achieved if we select from the intricate mass of sociological phenomena those which seem to fall into natural groups, and then so arrange these groups that each successive one is based on that which preceded it.

The fundamental stipulation for the existence of human society is the provision of means for such existence, in the first place food, then dwelling-place, clothing, weapons, tools and implements.

Thus the first group of phenomena which we have to consider will embrace all that concerns those material means which are necessary for the maintenance and defence of individual life, and this group we may, in the widest sense, include under the name of social economy.

This group having shown the possibility of maintaining individual life, the next in importance will include those life-processes tending directly or indirectly to the continuity of the human race, that is the customs relating to the continuance of life from generation to generation, reproduction, sexual relationship, marriage, the family, etc.

Having studied these groups which concern the general essentials of physical life, we shall proceed to the third group, 
which consists of those phenomena which deal with social relationships, that is to say, with the mutual relationship of the individuals forming a society, with the relationship of such a society to the world at large, and finally with the inter-relationship, whether peaceful or hostile, of separate societies. This group also includes the structure of the social body and its social and political life, and may be summed up briefly as social organization and everything in direct association with it.

Social economy, reproduction and social organization form a triangle which includes all life processes necessary for the existence of a social organism, that is, everything that is necessary for a community of living beings. These three prepare the ground for all progressive higher intellectual life. We will now classify these intellectual or psychical phenomena as follows:

All intellectual life has its root and origin in speech. "In the beginning was the word." We have dealt with this mighty phrase in a former chapter.

Intellectual life itself falls into three recognized divisions, the logical, the ethical and æsthetic; or in other words, into science, morals and art.

I. The logical sphere can be further resolved into two parts: science in its narrowest sense, and belief, both of which spring from one and the same source, since both are based on physical or intellectual experience.

The more certain deductions from experience, those having a very high degree of probability, are termed knowledge, and the sum of such knowledge is called positive science. The higher but less certain deductions from experience, which are frequently erroneous and as a rule provisional, we describe as belief, of which the most important forms, religion and philosophy, will be considered here. It is self-evident that knowledge and belief are not sharply divided from each other, but must frequently overlap, since all degrees of probability lie at the root of our convictions.

2. Ethics in the widest sense includes the great sphere of manners and customs, as well as its narrower meaning of justice.

3. Finally we have art, which, being the offspring of 
leisure and plenty, stands furthest from the purely utilitarian phenomena of life, and is the highest summit of the superstructure of civilization, which has its foundation in material things.

The whole sphere of culture can thus be divided into groups or sociological functions which can be classified as follows :

\section{Sociological Functions.}

I. Social economy (or the material) function)

2. Reproduction (or the geneonomic function)

3. Social Organization (or the political function)

4. Speech

5. Science

6. Religious and philosophic belief

7. Ethics

8. Justice

9. Art

A. Foundation.

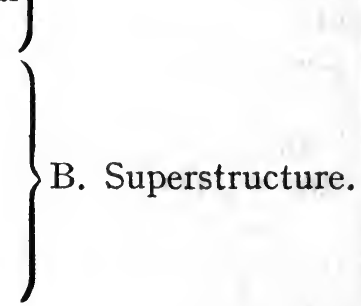

In undertaking a phaseological arrangement of this great sphere, we have two methods open to us, which can best be explained by the following diagram.

In this diagram the perpendicular columns indicate the successive phases of the separate sociological functions, while in the horizontal ones all contemporary sociological functions are placed together in juxtaposition and indicate the whole culture of a definite section of development. The whole phaseology can thus be divided in either one of these directions, that is either by taking the collective phenomena phase by phase ( $a$ to $b$, then $c$ to $d$, and $e$ to $f$, etc.) by horizontal sections, or else by following each separate sociological function through all its phases ( $a$ to $g, h$ to $i, k$ to $l$, etc.) by a method of perpendicular division.

The first method would be useful for a historical representation of any particular stage of culture. We get from it a complete picture of the whole condition of certain peoples at a definite stage of development. But for phaseology the "horizontal method" is an impossibility, 


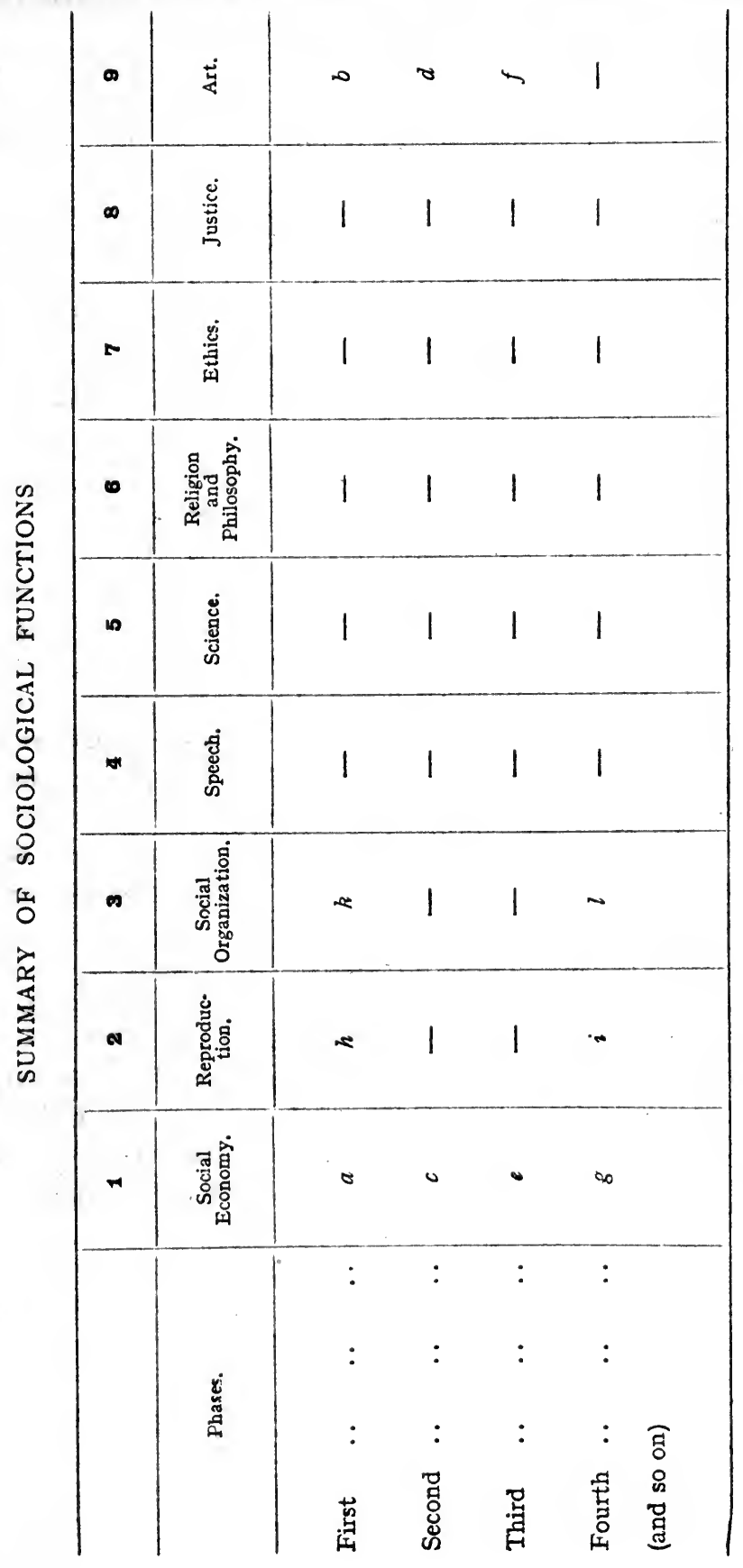




\section{THE HISTORY OF SOCIAL DEVELOPMENT}

firstly, because the phases which the separate functions have passed through are divided up by it, and secondly, because these phases do not coincide with one another in length of time.

The "perpendicular method" has, it is true, the disadvantages that the reader must constantly reascend the ladder and continually traverse the regions between the lowest and the highest stages; it has the further inconvenience of the severance of the juxtaposition of phenomena. This latter disadvantage, however, can be met by the use of synoptic tables, while all others are far outweighed by the fact that the "perpendicular method " alone is in a position to arrange the phases in a clear and concise form.

I have therefore adopted this method throughout, not only for the chief divisions of the whole sphere of culture, but also for the subdivision of the sociological functions, and I believe that only through the consistent carrying out of this course of action can phaseology become possible. Only when we have traced out the separate phenomena of civilization throughout the whole of their phases can we attain to a survey of its whole development ; the sociological tables which are placed at the end of each main section provide that the advantages which the horizontal method offers shall not be lost.

By neither method can repetitions be entirely avoided, as they lie in the nature of the matter. Sociology is, so to speak, of two dimensions, it has to deal both with succession and juxtaposition; human language, on the contrary, is of one dimension, and deals with succession only. We are therefore compelled to hang all our narrative on a single thread and to present it through that medium alone. 


\section{BOOK II}

\section{THE HISTORY OF THE EVOLUTION OF FOOD,}

IMPLEMENTS, CLOTHES AND DWELLINGS

(SOCIOLOGICAL SURVEY) 



\section{CLASSIFICATION OF MATERIAL PHENOMENA}

THE first and most important condition for the existence of human society is the acquisition of the means for such existence; above all food, then shelter, clothes, weapons, tools-in short, of all the details necessary for the maintenance and protection of life.

All activities which fend to the production of these things we include together-in the Sociological sense-under the title of Social Economy.

From this definition it follows that the evolution of material phenomena is capable of scientific treatment from two different aspects-the study of the material objects themselves, and the study of their production. In the first case we have to consider the goods produced; in the second, the skill and labour which have led to their production. We thus divide the history of economic evolution to which the next treatises are devoted into two parts:

I. The evolution of goods-Artifacts.

II. The evolution of labour.

Goods are again divided into several branches, of which only the most important can be considered here. These are the means of subsistence, implements in the widest sense of the word, clothing and shelter.

I See "Introduction to Sociology," p. 60 


\section{THE HISTORY OF THE EVOLUTION OF FOOD}

\section{Forms of Food.}

IT is usual to divide the early races of the earth into the following stages of culture-Hunters and Fishers, Pastoral People and Husbandmen. By this arrangement we tacitly assume that the degree of culture of any people might be measured by the standard of their food production, and we have good grounds for this assumption.

For, since the production of the means of existence is the most important condition of animal life and the basis of all development, it is precisely through the epoch-making amplifications of the sources of food supply that culture has been able to pass on through successively higher stages.

In the following pages we shall keep for the most part to this time-honoured division. We shall begin with the hunting races, and continue through the herdsmen and the husbandmen up to modern peoples; and thus we shall study all the forms by which man has procured his daily bread from the most remote times to the present day in the various regions of the earth. A description of these various forms may be somewhat dry reading, but it will furnish the reader with a brief survey of researches made and with much useful material. After this we will investigate the laws or principles according to which the phases evolved one from another.

\section{Hunting and Fishing Races.}

On the lowest stage of culture known to us, stand those races which practise neither cattle breeding nọr husbandry. They are little more intelligent than animals, and their only food is that which is supplied by Nature, often scantily 


\section{HISTORY OF THE EVOLUTION OF FOOD}

enough. Their sources of food are hunting and fishing and the collection of wild plants.

At the time of their discovery by Europeans, a great number of races which are now in process of rapid extinction were found in this primitive stage of culture. They were distributed over all parts of the earth with the exception of Europe, and may be divided into the following three groups :

\section{First Group : Lower Hunters.}

The lowest of these groups are those races which inhabit the infertile and unfavourable regions at the extremities of continents or remote islands, or who dwell in inaccessible mountain fastnesses and in dense primeval forests, with no established dwelling place, no distinction between rich and poor, and practically no leaders, but who roam the woods nomadically in little hordes in which all men are equal. These peoples are known as the Lower Hunters.

The best known representatives of this sociologically interesting group are the Australians and Tasmanians, the aboriginal dark-skinned population which, on the discovery of Australia, exclusively peopled the whole of that continent. Among these the Tasmanians and the Western races stand lowest, the Southern somewhat better, whilst in comparison the Northern had the most favoured position. Slightly higher came the pigmies in the forests of Central Africa; the Mountain Veddas in Ceylon; the Mincopies in the Andaman Islands; the Äita in the interior of the Philippines; the Terra del Fuegans or Pescheraks at the southern extremity of the American Continent ; and the Eskimos in the Arctic regions.

The chief food of these races is the meat which is obtained by hunting, and the marrow of bones is held in great esteem. Yet there is no hunter race which lives exclusively on animal food, for everything eatable, in the very broadest sense of the word, which Nature provides is accepted as food. Even the Eskimos, many races of whom live entirely by hunting, are not quite without vegetable additions, since they take the half-digested Iceland moss out of the stomach of the slaughtered reindeer and devour it. The only drink of the hunter is water. Salt is unknown to him. 
This miserable existence is maintained by means of everything that can serve for food. As hunting is often unsuccessful, the Bushman often consumes, in addition to game, such things as ants' eggs, worms, frogs, larvæ, wild honey, branches, roots, serpents, lice, and so on. The Veddas I consume berries, roots, bark of trees, decayed wood, the inner bast of trees, leaves, fruits, green vegetables and fish, which they have cleverly shot with arrows; their favourite food, however, is the honey of wild bees. The food of the Australians ${ }^{2}$ consists of different kinds of roots, fungi, shell fish, caterpillars, bats, frogs, serpents, honey, worms, cockroaches, birds, birds' eggs, fish, tortoises, dogs, kangeroos, and sometimes seals and stranded whales. The latter give an opportunity for rollicking feasts lasting for many days, even when the whales infect the whole neighbourhood through being in an advanced stage of decomposition. The so-called "Phthiriophagia"=lice-eating, actually exists to a large extent among these races. The lice, for which they hunt on each other, are consumed as delicacies, and if a great number are collected, they are devoured amid shouts of joy.

The man of this stage is decidedly omnivorous; he consumes everything, however loathsome, and even such food is often unobtainable. In the life history of the Lower Hunters need and hunger play a great part. The hungergirdle, which is tied round the body in hard times to appease the longing for food, is very general among them, and the capacity of devouring incredible quantities of food, and, on the other hand, in times of famine, of fasting for weeks together, is developed in an astonishing degree.

\section{SEcond Group: Higher Hunters.}

A higher economic condition is found in the second group, to which belong the Indian hunting peoples, the Californians, the Apaches, the Comanches, most of the races of the Dakota (Sioux), the Chippeways, the Shoshones, the Athapascan races of the Beaver, Hare and Dog-ribbed Indians, and others. They owe their improved condition to the enormous wealth of buffalo, or, more correctly, bison,

S Sarasin.

${ }^{2}$ Lubbock: Prehistoric Times, ii. p. 142. 
in the prairies, and of stags and reindeer with which the thick forests are filled. In North America another important means of subsistence is furnished by wild plants, such as plums, pumpkins and water rice, or wild barley.

\section{ThIRD GRoup : Fishers.}

Finally, the third group is formed by the fisher folk of North-West America and North-East Asia, on the coast lines of both sides of the Behring Straits, the now extinct Itelmen in Kamchatka, a few tribes of the Chukchis and Coreans, the Aleutians, the Gilyaks, the Koluschen or Thlinket, the Haidah on Queen Charlotte's Island, the Vancouver tribes, the Chinuks, etc. These people take an exceptionally high position among the races which practise neither cattle breeding nor husbandry, for they have at their disposal enormous riches in the sea and rivers, which yield them fish, especially salmon, in great abundance, and such a wealth and variety of food that they are far better off for means of existence than the husbandmen of inland countries. Most of these people are sedentary, possess big houses, produce all kinds of ingenious implements and utensils, and do not hold their arms and possessions in common; they keep slaves for the most part, and they are trading peoples, with a knowledge of division of labour. Their stage of civilization, which is based as much on the wealth of animal food as on articles of commerce, such as otter skins, surpasses in many respects that of cattle breeders and husbandmen.

\section{Cattle Breeding Races.}

The chief regions for pasturage are those of the steppes and deserts of Asia and Africa.

Among those peoples who live principally by cattle rearing, the best known in Asia are the numerous Mongolian and Turki Tartar nomads, who keep their huge herds of horses, oxen, sheep and camels on the wide steppes of Central Asia. These are the Kalmucks, Turcomans, Uzbegs, Baschkirs, Yakuts and the Kirghizes or Kassocks, who alone are estimated at between two and three millions; there are in addition the Thibetans in Higher Asia, and the Todas 


\section{THE HISTORY OF SOCIAL DEVELOPMENT}

of Southern India, and finally the reindeer nomads, the Samoyedes, Ostyaks, Voguls, Tungus, etc. In Africa the best known examples are the Bedouins, Dinka, Bari, Masai, Wahuma, Galla, Somali, Ova-Herero, Hottentots, etc. Europe has only one pastoral people, the Lapps; and in America, at the time of its discovery, there were on the whole no cattle breeders save the Peruvians, who had tamed the llama. The original progenitors of the Aryans, the Scythians, Parthians, etc., were pastoral people.

These people are meat eaters, but not wholly carnivorous. A herdsman would not lightly decide to kill a head of cattle, for there lies his wealth, towards the increase of which his whole activity is directed. For the most part animals are only slaughtered when sick or badly wounded, or when festivals are held, or sacrifices required for religious rites. Moreover, herdsmen are very fond of milk; an Ova-Herero, for example, consumes daily from five to nine quarts of sour milk, and in addition to this $\mathbf{I}$ the Dinka, Masai, Bari, etc., drink the blood which they manage to procure from the living beasts by periodical blood-letting. Among no pastoral people are the herds the exclusive source of food. The men have mostly remained true to their primitive occupation, hunting, and the women do the cooking, and also collect all edible things that the vegetable kingdom provides in the way of roots, bulbs, berries, fruits, etc. Then, too, most of the pastoral peoples carry on a certain amount of agriculture, and at times they procure vegetable food from neighbouring agriculturists by exchange, or by the authority they exercise over them.

\section{Agricultural Races.}

The mass of mankind consists of husbandmen. The Chinese, with their four to five hundred millions, alone make up nearly a third of the world's population, and the dense masses of the civilized races collectively make up sixsevenths of the inhabitants of the earth. But the different agricultural peoples stand at very different levels of culture, and their systems of working are very varied. According to Hahn's admirable classification in Domesticated Animals, we can differentiate the following forms of agriculture :

Casati. 
I. Hoe Culture.

2. Plough Culture, or Agriculture, in its narrowest sense.

3. Horticulture.

To which, in order to be complete, we must add a fourth,

4. Commerce Culture.

Thus we have four grades, or rather four principal forms of "agriculture," which we will now describe seriatim.

\section{Hoe Culture.}

Hoe culture is a very simple form of agriculture: the ground is only superficially worked with the hoe, without plough or draught beast; it is little manured, but the area is constantly changed.

The greater number of nature folk carry on hoe culture, and fall naturally into the following groups, arranged according to the height of their culture.

\section{(a) Hoe Culture with Hunting.}

To this group belong most of the American Indian races. A widely spread juvenile literature has given the erroneous impression that the Redskins should be considered chiefly as hunting folk. True, we have become acquainted with a number of such hunting Indians, but the greater part of North and South American races had risen at the time of their discovery by Europeans to a higher stage of civilization, and combined husbandry with hunting. For example, in North America there are all those multitudes to the east of the Mississippi and south of the River St. Lawrence, the best known being the Iroquois, Delawares, Mohicans, and the Crees; while further to the west of the Mississippi are the Arikara, Mandans, Osage, a part of the Sioux, the Omaha, the Ponca, and others. In South America there are the Guiana tribes, the Caribs, the Uaupes, the Araucans, the Brazilians (Tupi, Mundruku, Guarani, Bakaïri) and others.

\section{(b) Hoe Culture with Fishing.}

The second group, in which hunting is supplemented by fishing, and occasionally by cattle rearing, consists chiefly of the inhabitants of the islands of the Indian and Pacific 


\section{THE HISTORY OF SOCIAL DEVELOPMENT}

Oceans. These stretch from Madagascar to Easter Island, and are divided into two main groups. The first group is known as Indonesia, and consists of the islands of the Malay Archipelago, the Molacca Islands, the Philippines, and the Sunda Islands, which include Sumatra, Java, Borneo and Celebes. The second group is Oceania, which is subdivided under three heads : firstly, Melanesia, consisting of New Guinea, the Solomon Isles, the New Hebrides, Fiji and New Caledonia; secondly, Polynesia, consisting of Hawaii, New Zealand, Tonga Islands, Samoa, Rotamah, Marquesas Islands, Society Islands, and Easter Island ; and thirdly, Micronesia, consisting of the Marianne or Ladroni Islands, the Caroline, Marshall and the Gilbert Islands. The Indonesians and Polynesians are Malayan, the Melanesians are Papuan, while the Micronesians are a hybrid from both races.

\section{(c) Hoe Culture Solely.}

In this third group the natural sources of food, hunting and fishing, fall far behind agriculture. The group is principally represented by many Indonesian peoples and by the African husbandmen, that is by all Africans who do not belong to the hunters and herdsmen; for instance, the people of Zambesi, the Ma Kalaka, the Ba Yeye, the Njam-Njam, the Ba Lunda, etc.

The fourth group consists principally of Africans, who combined

\section{(d) Hoe Culture with Cattle Breeding.}

and to this belong the Kaffirs, Zulus, the OvaMpo, Ba Kuba, Waganda, etc.

Almost all the hoe culturists among nature folk are vegetarians. The staple food consists of farinaceous plants. The ripe corn is roasted and ground and boiled up with water into a sort of porridge. ${ }^{\mathrm{z}}$ To this meal porridge is attached a distinct historical importance, as from the lowest stage of agriculture up to quite advanced civilization it is the "pièce de resistance," the food of the populace, the material basis upon which the solidification of peoples, with all its results, is founded. We find it as the so-called

x See p. IoI in the next chapter for the origin of the art of cooking. 
pulmentum, ${ }^{\mathbf{x}}$ as the national diet among the Ancient Romans until the date of the first Punic War, at which time bread first came into vogue; and it was this porridge which helped the old Roman heroes to gain their victories, for a pouch full of meal which each soldier carried for himself took the place of the special commissariat columns, and gave the legions their great mobility and strength. Even to-day the Italians remain faithful to the old national food; the "pulmentum" has maintained its position as "polenta," now composed of maize meal. In Germany, too, among the peasant population in many parts, especially in Bavaria and Tyrol, this time-honoured national food still supplies " the daily bread."

The Indians prepared this porridge from maize, often mixing with it the flesh of game; this was known as sagamite among the Iroquois. In addition to maize they cultivated beans, pumpkins, mandioc, tobacco, bananas, sweet potatoes and peas.

The Oceanians, who live in a climate which is quite ideal for agriculture and horticulture, get their taro-pulp from the root of a kind of arum. They have besides an excellent food supply, consisting mainly of the bread fruit, of which three trees are enough, unsupplemented, to support a man for life ; the banana, which, according to Ritter, will nourish twentyfive times as many people as wheat grown on a similar area can do; the yam, with its heavy roots, often weighing from thirty to forty pounds; sweet potatoes, cocoanuts, sugarcanes and ferns with edible roots. ${ }^{2}$ There are in addition many kinds of seafish and molluscs, and a few warm-blooded animals, such as fowls, doves, ducks, rats and albatrosses. Swine and dogs are occasionally domesticated.

Among the Africans the chief food is a thick porridge prepared from millet (Kaffir corn or carrot millet) ; they also cultivate maize, beans, sweet potatoes, manioc and cassava, as well as rice and tobacco and many kinds of vegetables.

Those African tribes which combine cattle breeding with

I And similarly among the ancient Greeks.

See Büchsenschütz: Die Hauptstätten des Gewerbefleisses im Alter-

tum, p. ror.

Noiré : Das Werkzeng, p. 339.

Lafitau: Moeurs des Sauvages améric. ii. 83.

2 Forster: A Voyage Round the World, i. 294. 
hoe culture keep sheep, goats, swine, dogs, hens, turkeys, ducks, doves and geese, but their staple food is millet porridge mixed with milk.

If we now compare these four groups of nature folk who practise hoe culture in relation to the height of their material culture, we find that the American Indians take the lowest place. Hoe culture, combined with hunting, is the lowest stage of agriculture. The man is fully occupied, body and mind, in hunting, that primitive means of procuring food; while the artificial production of food by cultivating the fields is the woman's task. The man's main energy is devoted to the production of food from natural sources only, and hence he is left behind in a primitive condition, while the woman has advanced beyond him.

The Oceanians, among whom hunting is supplemented by fishing, stand higher; fishing does not take complete possession of a man as hunting does. It does not prevent him from taking part in the cultivation of the land; in which work even the chiefs do not disdain to help. The Oceanians domesticate dogs, swine and birds, so that among them artificial food predominates over the natural.

Yet more is this the case among the Africans. Here the natural sources of food give place almost entirely to the artificial. As hunters and fishers the African hoe culturists are not to be compared with the American Indian; on the other hand, they belong to the best agriculturists among the nature folk. We even meet with a number of tribes among them who combine-agriculture with cattle breeding, and are provided with both animal and vegetable sources of food.

If, then, we take the artificial production of food as a standard of civilization of those people standing on the stage of hoe culture-considered as a whole, and ignoring the many individual exceptions-we may classify them in the following order:

I. American Indians.

2. Oceanians.

3. Africans.

The justice of this arrangement will become more and more 
apparent when we come to examine other standards of culture.

\section{Plough Culture.}

We will now briefly consider plough culture, which is agriculture in its narrower sense, in that form which every one can see for himself. The soil is prepared for seed by a plough and some draught beast, much in the same way as has been done by Aryan and Semitic races from very early times in Europe.

The most important forms through which plough culture has passed are :

(a) Burning, or brand tillage, the crude pasture husbandry, which is used in the first endeavours to wrest land from primeval forest or steppe. Manuring is only effected by the ashes of burnt plants, or by cattle pasturing in the field. Where there are not considerable layers of humus at hand, the area must be constantly changed.. Essentially more progressive is

(b) The field system, where the arable land is divided into fields, mostly three-the three-field system-of which the one lies fallow, the second is planted with summer and the third with winter grain; the fallowness saves manuring and labour. This system was in use at the time of Charlemagne, and remained in vogue up to the last century throughout almost the whole of Germany. Similar is

(c) Meadow husbandry, by which a few years of pasture alternate with a few years of grain culture. Higher stands

(d) Rotation of crops. This distinguishes between plants which enrich the soil, such as clover, tobacco and pulse, and plants which impoverish it, such as grain, oil plants, flax and hemp, and these are changed in regular rotation. The fallow year is abolished; the increase in the output of forage makes stall-feeding possible, and the land generally is more intensively cultivated, thus leading to greater demands for labour, capital and improved agriculture.

\section{Horticulture (Spade Culture).}

Far superior to all other forms of cultivation of the soil is Horticulture. In ancient Peru and Mexico, and even now in Japan, and especially in China, its classical home, 


\section{THE HISTORY OF SOCIAL DEVELOPMENT}

horticulture nourishes an astonishingly dense population, and there constitutes the basis of an ancient civilization.

In order to do justice to this highly attractive form of husbandry, which is far too little understood, we will here recount as briefly as possible the experiences gained through long years of observation and strenuous study by G. E. Simon. They are found in his interesting book, La Cité Chinoise.

Let us take as a standard example the village of UangMo-Khi. It lies in a broad hilly valley, and consists of seven or eight hundred houses, which are not built in rows, but are scattered widely apart, among gardens and fields. It is only round the market place that the houses of the merchants and craftsmen form a thicker nucleus. Distributed on the heights stand pagodas, which serve as places of assembly, as theatres for strolling players, or refuges for strangers. Some of these, which are Buddhist temples, contain libraries for public use. The village numbers not less than 10,000 inhabitants, who live on 3,000 acres. Externally there is little resemblance to our own homesteads, and the life there is as far removed from the tedium and vulgarity of our small and detached villages as from the noise and bustle of our cities. It unites in the happiest possible way the advantages of country life with those of the town.

Each house is exclusively inhabited by a "joint family," which consists not merely of two generations, the parents and children, but of three to four generations. Grandparents, parents, children and grandchildren live peaceably with the married daughters-in-law under one roof, the elders enjoying, until their lives' end, a respect and love from the young people which contrasts favourably with our old age pension system. There is no attempt to divide the estate; each member of the family is perfectly free and independent and works for his own profit, while the taxes are very small. Such a joint family, consisting of about a dozen persons, finds a plentiful subsistence on the fruits of a piece of garden land which does not exceed five acres and surrounds the house. This intensiveness of production is attained by a system of management which can be characterized in three words, water, manure and labour.

Water is conveyed everywhere by artificial means; it is 
even carried over mountains from which it trickles down in countless little channels and keeps the gardens fertile in spite of lack of rain. These Chinese are past masters in artificial irrigation, and are thereby much more independent of the caprices of the weather than are our peasants, for all their contrivances against drought.

For manure, human ordure is chiefly employed. That great source of fertility and wealth, which is not merely wasted by our great cities in millions of tons, but worse than wasted by the pollution of rivers and the sea, is utilized by the Chinese to the very last atom. Between man and the soil there is a continual exchange of organic matter, which guarantees an everlasting existence for the race, and the Chinaman carries out Nature's law in this respect almost as conscientiously as he performs the duties enjoined by his religion.

Finally, the intensity of the labour which the Chinese perform in their gardens surpasses all European ideas. At cock-crow the members of the family arise and work till evening with the greatest industry, for they love their work, and its performance is to them a pleasure, even a passion. Gardening in a fertile country is charming and delightful in the extreme. It brings all the human activities into harmonious development, for while the body performs the requisite exertion, the mind is concentrated on providing for the needs of the different kinds of plants; and as the long days are spent in the open air, this occupation is more beneficial to the health than most of our industrial pursuits. The Chinese horticulturists push their zeal so far that they cultivate not only useful vegetables, but a number of plants, and especially flowers, to please their eyes and their fancy. Plants like rice and wheat are indeed " pricked out," that is, each separate little blade is transplanted by industrious hands and well manured, by which method its productiveness is increased exceedingly; one head of wheat may produce as many as sixty ears. In order that all members of the family may find increasing occupation, as many varieties as possible are planted.

The results are extraordinary. What a Chinese family of gardeners can produce in the way of rice, tea, sugar, oranges, wheat, maize, oil, buckwheat, tobacco, cotton, silk, yams, 
cabbages, beans and similar vegetables and fruits out of their five acres of garden land would seem utterly incredible to our husbandmen. ${ }^{r}$

This splendid result is produced with the simplest implements imaginable. While with us two and a half acres would need a working capital of $£ 25$ to $£ 30,{ }^{2}$ the Chinaman needs nothing more than a dibble, a watering-can, a hoe, a little wooden plough, and above all a spade, his chief instrument, from which horticulture has received the name of "spade culture."

Animal food, which obviously would take a lower place in their domestic economy than vegetable food, is provided by the rearing of poultry and swine, both of which are useful by-products of horticulture. The flesh of other animals is not desired, for the garden displaces pasture-land everywhere, horticulture being overwhelmingly more productive than cattle rearing.

The family supplies almost all of its own needs; it provides oil and sugar; it spins its own hemp, cotton and silk, and prepares from them its own clothes and household needs. Individual production covers nearly the whole of their requirements, so that very little need be bought or sold.

In this way the many millions of families forming the great masses of the enormous population of China live and provide for themselves. Garden culture not only gives a numerous population the possibility of being fed, it provides it also with an agreeable, peaceful and happy existence, such as is unknown to the great masses of Western peoples, with the monotony of their occupations, the excitement of the hunt for gold, and the misery and bitterness brought by such a life. The Chinese understood thousands of years ago the Voltairean "Plantez vos jardins," and converted the phrase into action. Hesiod saw in this method the happy solution of the problem of life. The whole huge empire is held together by the contentment of these enormous multitudes, whereas few European States are not dependent on force for their protection.

In fact, the advantages of the Chinese as against European

I See Simon's definite statistics on the subject, p. 364 .

- This estimate is written about Germany.--(TRans.) 
methods are so obvious that experts have pronounced Chinese horticulture as the highest economic stage, and indeed have considered the question whether it were not possible to introduce it into Europe. Hahn says "That two and a half acres of poor garden land produces more than an equal area of good pasture land is known to every peasant, but we have never troubled to draw any deductions from this;" and Simon reckons that after the introduction of intensive horticulture France could easily feed two to four times her present population. But apparently just the reverse happens, and European capitalization will disturb the Chinese idyl-indeed, it has already made its way into Japan, and is stretching out its feelers to China. However, we will go no further into this question, but follow the entirely different development which has superseded plough culture in European spheres of civilization.

\section{Commerce Culture.}

If we wish for a just standard of perfection for one form of industry, we must not merely consider the amount of food which has been wrested from the ground, but we must also consider the sum of labour which has been put into it. The fewer forces needed to provide for the whole population, and the less men used up in mere food production, the more are left to turn to other callings, to bring forth all those good things and actions which are characteristic of the higher culture.

For this reason commerce culture gradually arose, and has grown up parallel to the development of capitalism among modern peoples in the European spheres of culture, with whom it has been brought to much higher perfection than horticulture. A comparison of both systems will prove this, and at the same time will make clear the characteristic qualities of commerce culture.

I. Chinese horticulture is carried on entirely for the purpose of providing for the individual joint families engaged in it ; commerce culture, on the contrary, is a capitalistic undertaking, which aims at satisfying an external demand, and exhibits its products as wares in the market. It is for this reason that in default of a better title we have chosen 
that of "Commerce Culture." I In Europe, in earlier times, plough culture was governed by individual needs. But later, the different forms of plough culture (the three-field system, grass husbandry, etc.) were adapted more and more to capitalistic development, and gradually changed into a commercial enterprise. This is especially the case with the newest form of plough culture, the so-called " free farming," which is influenced rather by the state of the market than by an arranged succession of crops.

2. A second characteristic sign of commerce culture is the employment of agricultural machines, which take the place of human muscles, preparing the land, reaping the products and manufacturing the raw materials. As we have seen, the simplest tool suffices for horticulture, but, greatly as the industry of the Chinese is to be admired, he cuts a poor figure with his spade and dibble beside the machine possessing European. For the more human labour is saved by the greater perfection of the machine, the greater is the profit in proportion to the effort expended; and the more the centre of gravity is transferred from labour to capital, the more will its organization be esteemed from the standpoint of civilization. The highly organized capitalistic system of "commerce culture" in Europe is obviously more effective than Chinese methods.

3. We are indebted to the eruption of science into practical life for the invention of machinery. Science has had a remarkable influence on the production of the means of existence in many other respects. The use of artificial manures is a distinctive feature of " commerce culture," which also, by means of selection, effects constant improvements in the useful plants and in the breeding of domestic animals. These, with the acclimatization of fresh plants and animals from all parts of the world, and especially the rationalization of the

I A strong case may not illogically be made out for the following alternative grouping of the subject:

Agriculture in its widest sense.

A. Individual production.

x. Hoe culture.

2. Plough culture.

3. Horticulture (spade culture).

B. Commerce culture. 
whole of agriculture, are fruits of European science with which the skill and empiricism of the Chinese gardener are quite unable to compete on equal terms.

4. We have thus shown that the Chinese have brought the soil and the Europeans have brought human labour to the highest degree of productiveness. This accounts for the unprecedented number of the population in China, whose activities are almost entirely absorbed by the soil; whilst in Europe, where the food-producing part of the population is continually diminishing in proportion to the whole, the extension of learning is regarded as being of more importance than any other calling.

The growth of towns, and their eventual preponderance over the rural districts until agricultural countries are transformed into manufacturing ones, is a further noteworthy symptom of lands where "commerce culture" exists. But this transition would not have been possible, in spite of all the perfecting of agriculture, if the population had been restricted to its home produce. It only came about through progressive countries, whose temperate climate was more favourable to industrial activity, importing raw material and foodstuffs from other countries which were less developed, or else, owing to their more fertile climate, had a greater food-production than they needed. It is through international division of labour, based mainly on the reckless and wasteful exploitation of virgin soil in new countries, that commerce culture has prepared the way for modern industrial conditions. For "commerce culture" is in its very essence founded on trade, and modern commerce culture on worldwide trade, which at last has united nearly all the peoples of the earth into one great organization of labour.

5. Whilst every atom of the body of a Chinaman is literally built up from the soil on which he stands by means of the vegetable food taken directly from his garden and consumed on the spot, the table of the European is supplied from all countries of the world. Our vast system of communication by sea and land not only brings about a more harmonious distribution of the individual advantages of each land, but at the same time it helps to regulate the variations of production caused by unforeseen vicissitudes of weather.

Whole regions have often been decimated by famine 


\section{THE HISTORY OF SOCIAL DEVELOPMENT}

while food has been plentiful in surrounding districts in countries, notably in India and China, where means of transit were lacking. This spectre has long been banished from nations engaged as a whole in commerce, and this is another great advantage due to commerce culture.

If, then, we compare the advantages and disadvantages of horticulture and commerce culture, it would be difficult to place one above the other; a higher level could only be reached when both methods were combined.

The highest conceivable form of food production would not be reached even by this means; it can only be attained when chemistry finds a means of producing foodstuffs synthetically from their component parts, as found in the earth, air and water surrounding us.

\section{Genealogy of the Forms of Food Production. ${ }^{x}$}

We have now examined eleven different forms or types of food production, viz. :

I. Hunting and Fishing $\left\{\begin{array}{l}\text { I. Lower hunters. } \\ \text { 2. Higher hunters. } \\ \text { 3. Fishers. }\end{array}\right.$

II. Cattle Breeding .. 4. Cattle breeding races.

5. Hoe culture with hunting (American Indians).

6. Hoe culture with fishing (Oceanians).

7. Hoe culture as the chief III. Husbandry .. .. $\quad$ source of food (Africans).

8. Hoe culture with cattle breeding.

9. Plough culture.

Io. Horticulture.

II. Commerce culture.

I See De Mortillet: Origine de la chasse, etc.

Gerland: Anthropolog. Beiträge, i. 1875.

Hahn: Die Haustiere und ihre Beziehungen zur Wirtschaft des Menschen.

Nowacki: Uber die Entwicklung der Landwirtschaft in der Urzeit Landwirtschaftl. Jahr b. ix. 853 .

Bos: Jagd, Viehzucht und Ackerbau als Kulturstufen Internat. Archiv. f. Ethnographie, X. 187 . 
We must next inquire into the manner in which these forms arose, or rather how they evolved, as phases, one from another. At one time the answer to this question appeared to be very simple, as it was believed that the hunting stage gave way to cattle breeding, and that this in its turn was succeeded by agriculture, while all people who had attained to the agricultural stage were assumed to have reached it by way of hunting and cattle breeding. Now, however, it has been proved that it is by no means true that all agriculturists were formerly pastoral people, but that, speaking generally, there is no one fixed course of development, but several, which vary according to the environment, while all leading to higher stages. We will now endeavour to trace out these different ways, and will first consider the hunting and fishing stages.

\section{Sociological Importance of the Hunting Stage.}

It is hardly necessary to say that Hunting and Fishing, which only profit by natural sources of food, stand lower as regards culture than cattle breeding and husbandry, which provide food by more artificial means. More difficult to answer is the question whether the pastoral people and husbandmen likewise passed through the hunting stage earlier, whether the hunter races were our ancestors, or whether they are only to be considered as lateral branches of the great stream ; whether they claim a universal history, or only an individual and local importance. When Darwin was on his journey round the world and saw for the first time the naked savage Terra del Fuegans, the thought came at once to him, "Such were our forefathers!" Is this true?

On the following grounds we must recognize a universal sequence in the hunting stage :

I. We shall see later on that there are found over the whole earth prehistoric weapons and implements, with bones which, being half burnt, cracked and gnawed by human teeth, bear witness that man everywhere was a hunter and meat eater in the earliest times.

2. Nowhere in the world does man entirely reject animal food. Those people who, like the Indians, Peruvians, Mexicans, Chinese and Japanese, care least for meat, have 
become vegetarians through agriculture or horticulture. The Indians, who abstain rigidly from animal food on religious grounds, are obviously descended from pastoral people, like the whole of their Indo-European relations. Man is only a herdsman when he was formerly a hunter. It would hardly have entered the mind of simple vegetarians to breed animals for food unless they had hunted them for food formerly, and by the same line of reasoning it is quite clear that the necessity for vegetable food was always recognized, for it is even less likely that hunters would trouble to cultivate plants if they despised them as food. Among all pastoral peoples whom we know of, hunting plays an important part in providing food. As to the Peruvians and Mexicans, it is clearly indicated by the lines of development, which in America lead on without interruption from the simple hunters through the phases of hoe culture with hunting to the highly civilized agriculturists, that the ancestors of these vegetarians were originally hunters. Further, the Chinese and Japanese regard animal food as a special delicacy, although they choose to live on vegetable food because garden produce is at their disposal in such sufficiency.

3. Another witness is provided by man himself-his set of teeth. Just as in his nature he combines the courage of the beast of prey with the perseverance of the vegetarian creatures, so does his set of teeth, like that of the higher apes, combine the characteristic qualities of carnivorous and vegetarian mammals. Indeed, the " bill of fare" of the lower hunter bears an astonishing resemblance to that of the higher apes. That the eye-teeth are less strongly developed in man than in apes is easily explained by the fact that implements have greatly reduced their work. His teeth proclaim man to be omnivorous.

4. In children's games we have a strong testimony to our descent from hunter folk. Rightly considered, all animal games are atavistic signs.I In all animal races the play of the young is simply the instinctive use of those physical and mental powers which are necessary for self-preservation in the life of the adult. Kittens exercise themselves in pouncing and climbing, and especially in catching all small moving objects. Puppies when they play together try till they are

- Groos: Die Spiele der Tiere. 
exhausted to lure their prey to run so that they may get it into their power by a bite in the neck. Colts cut all sorts of capers, through which they become fleet of foot, and capable of resisting assaults.

In the games of the young, then, we observe the training of qualities which are of the greatest importance for the preservation of the species, recognizing those instincts which Nature has transmitted through heredity in every race of animals.

The games of children, especially boys, indicate in a striking manner hunting and war. Fighting, scuffling and the chase of everything that crawls, swims or flies--for instance butterflies, fish, beetles and mice-are the favourite occupations of boys. Nor can we doubt when we consider many men who have reached maturity that they were born with the same hereditary hunting instinct as the wild beasts. Civilization has long made it unnecessary and the environment in many places makes it ridiculous, but the hunter instinct which for thousands of years was necessary to his life is still born with the human animal.

Having invented implements and weapons he was metamorphosed from a wild beast into a hunter and warrior, but the history of the world, even down to the slaughter houses of our great cities, is written in blood, and bears witness that the wild beast nature has never been entirely eradicated.

Philological researches confirm this opinion. Lazarus Geiger says: "The science of language puts it beyond all doubt that ever since man was man he has fed on the flesh of beasts. The conception suggested by the words flesh, or even animal, is almost invariably that of food." "The roast," in German "Braten," signified in the earlier time of our language animals that served for food. From the same root is derived the German "Wildbret," meaning game, and "Brod" = bread, and the root signifies " eating." At Logau, in Central Africa, food is "Tha," flesh is "Thu," and cattle "Tha." Among some other African races there is only one word for animal and meat; fish is called water meat, and so on.

From the facts now quoted and many others we can only conclude that the hunter stage is a stage of culture universally passed through in the transition from animal life to 


\section{THE HISTORY OF SOCIAL DEVELOPMENT}

that of men. Certainly all those races who have now risen highest in civilization must have passed through it.

Fishing races of the type of those who inhabit the coasts of the Behring Straits I represent obviously only one branch of the great stream of culture which has its origin in local causes, and we need not consider them further.

\section{The Place of Cattle Rearing in the Phase Series.}

The position which the Pastoral life occupies in the phase series is extremely difficult to determine, as firstly, it is certainly incorrect to take the pastoral age as a necessary preliminary to husbandry, and secondly, whether a hunting folk passes to cattle rearing or husbandry depends entirely on the fauna and flora at its disposal.

In America there was big game in abundance-buffalo, deer, reindeer, etc., but none that were easily tamable; on the other hand there was a field product of extreme utility and easy cultivation - this was maize. Naturally the Indians became husbandmen without going through the shepherd phase. At the time of the discovery of America there was not a single pastoral race of people in it: the civilized Peruvians alone reared the llama, which they used principally as a beast of burden. On the other hand, as already mentioned, every grade of transition was found, from the simple hunters up to the horticultural Mexicans and Peruvians, which evidently shows that in the New World civilization had advanced to horticulture without cattle rearing having played the slightest part in this development.

Development in the Old World proceeded on quite other lines. Here there were numerous varieties of edible plants, especially cereals, which were difficult to cultivate, and on the other hand there were a great number of tamable animals : the horse, ox, sheep, goat, etc. Therefore the inhabitants of the Old World were predominantly cattle rearers, and only took up husbandry at a much later period. This is the general rule, and applies to those races who have risen the highest and are the ruling powers-I refer to the peoples of the Aryan race.

It was thus along very different lines that evolution pro- 
ceeded in the Old and New Worlds. In the New World, the pastoral stage was completely passed over.

This shows that cattle rearing is not a necessary preliminary to husbandry. Of late, some scientists have retraced their steps, asserting that husbandry is not derived from the pastoral stage, but that the contrary is the case. ${ }^{\mathrm{I}}$ The reasons which have been given for this opinion may be briefly summarized as follows :

I. The difficulties of animal taming are too great for nomadic people; they can only be overcome by a sedentary race such as husbandmen.

2. Animals closely confined under domestication as a rule are not prolific. This disadvantage of too narrow confinement can only be overcome by a sedentary people.

3. The herdsman imperatively needed a vegetable addition to his diet. This necessary supplement to their food can only be acquired by pastoral people if they are themselves agriculturists or overlords of agriculturists, or else by barter.

4. The first realized advantages derived from the domestication of animals were meat, hides, bones, etc.-for the use of milk followed considerably later-and these were more easily obtained from the chase. Thus hunting races have no material advantage to induce them to keep cattle. This theory, which has much support and is shared by many famous modern sociologists, is nevertheless open to attack if universally applied.

Even if the difficulties of animal rearing were greater for nomadic than for sedentary races, we must not forget that it is a known fact that the hunters of the lowest stages almost everywhere have tamed the dog. The Veddas, the Australians and the Eskimos possess dogs, often quite a pack of them. The dog was a domestic animal before ever there was a "domus," and the hunting races have not only tamed the dog, but they have trained it to hunt, draw sledges, etc. Some hunter races in Australia, who are also quite efficient cattle breeders, keep dogs for the purpose of slaughtering them and consuming their flesh. If we suggest that the first animal to be trained was the dog, it simplifies matters, because this domestic animal could help to watch over the 
others and keep them together. There is really no reason why the taming of the reindeer, the sheep, the goat and other gregarious animals should have been more difficult than that of the very wild kinds of wolf dogs which the Eskimos have so cleverly tamed and trained.

The fact that the hunter has made the dog into a domestic animal proves that the argument that animals in captivity are not prolific is not a very strong one. Husbandmen have overcome this difficulty ; they enclose immense spaces, often fencing in whole peninsulas, where they keep the animals confined. Hahn alleges that "even those who are simply hunters use this method, and enclose spaces which in their circumference are scarcely equalled by our most extensive and ostentatious royal hunts." It is this very plan, adopted by the hunting races, of driving wild beasts into a huge enclosure, and so preserving them for future use, that must have been one of the earliest forms of cattle rearing.

The objection that pastoral folk could not well exist without the cultivation of the ground is contradicted by the fact that pastoral folk - the Hottentots, for example-do exist of whom we have the certain knowledge that they neither carry on agriculture themselves, nor have any connection with agricultural people. Again, if hunter races could exist without cultivating the land, it is fairly certain that herdsmen, who are better equipped in all ways, could do so.

Finally, even the last argument that cattle rearing did not produce originally more than what was gained in the chase is weak. Certainly meat, skins, bones, etc., could be obtained by hunting-but not always! For hunting is uncertain, and its lack of success is emphasized by the sharp pangs of an empty stomach. By rearing animals, however, a supply is assured which lessens the probability of want, and this advantage nature-man cannot fail to observe, for his chief interests are centred in satisfying his appetite.

I myself think it is by no means improbable that herdsmen sprang directly from hunters, and that we have overestimated the difficulties of the transition. For example, there is nothing to prove that the Reindeer nomads, the Thibetans and other inhabitants of Higher Asia, or the Hottentots have ever passed through the stage of agriculture before they came to that of cattle rearing; it is much more 
ikely that they moved directly out of the hunter stage to the jastoral.

On the other hand, history shows us people who have passed from agriculture to cattle rearing; in this way the nhabitants of Iceland have in historic times given up the cultivation of the ground and live now by cattle rearing and fishing. Neither is it improbable that the Asiatic and African steppe and desert nomads, who are surrounded by agricultural peoples and who almost all carry on some kind of husbandry, sprang formerly from husbandmen, and only became herdsmen when they emigrated into the steppe.

Other peoples, however, such as the Jews, Aryans and Basques, are known to have been at first principally cattle rearers, and only turned to husbandry and a sedentary life in later times. But it is not impossible that even these races still earlier were husbandmen, and have behind them a somewhat complicated history.

To summarize, nomadism and the pastoral life do not form a general culture stage, but merely a local phenomenon, although a very important and widespread one. Several ways led up to it: some peoples rose directly to it from the hunter stage, others had previously attained the stage of husbandry, and became nomads through being transplanted into a new environment, for example, the steppe; and of these peoples many returned again to husbandry when another change of environment gave them the opportunity. Which of these developments prevailed in individual cases must be very difficult to decide.

\section{The Phases of Husbandry.}

If we now pass to the different kinds of husbandry we find a bifurcation of development, the extremes of which we have designated "Horticulture" and "Commerce culture."

Horticulture is merely a perfected hoe culture, and has evolved from it. America, as we have already mentioned, is the classical instance of all the transitions-from the pure hunters who only make use of wild plants, through the hoe culture of the hunter agriculturists, right up to the civilized Mexicans and Peruvians, who practise horticulture.

Hoe culture in all probability preceded plough culture. 


\section{THE HISTORY OF SOCIAL DEVELOPMENT}

According to Oswald Heer, hoe culture with millet must have been fairly universal all over Europe even in the early times of the lake dwellings. Barley culture with plough and oxen followed as a second phase ; wheat, rye and hay came later. ${ }^{\mathrm{I}}$

Finally, "commerce culture" has in modern times resulted from plough culture. The capitalistic spirit and organization only arise, as we shall see later, among people who carry on cattle breeding.

If we summarize the whole, we come to the following abstract of the phases of food production :

GENEALOGY OF THE FORMS OF FOOD PRODUCTION

Commerce Culture

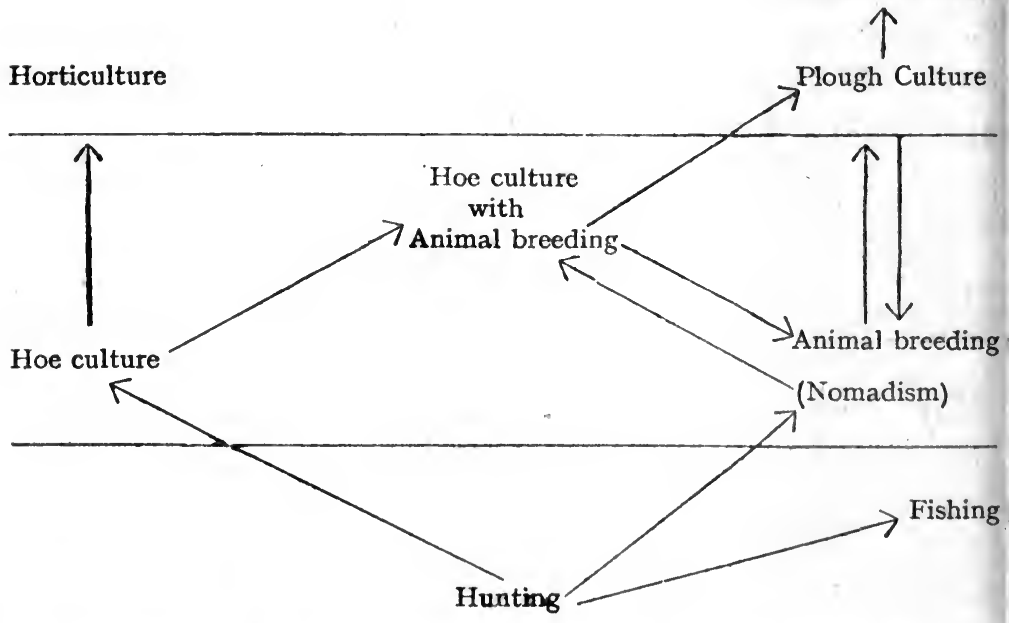

\section{The Phases of Food Production and the Culture Stages.}

As is made evident by the foregoing, the division of peoples into hunters, herdsmen and agriculturists, valuable as it is, is no longer of use as a system of stages. The development is not so simple as was at first thought; it is not to be compared to a ladder whose rungs can be climbed consecutively, but rather to the growth of a tree with its ramifications.

But since a system of stages is of very great practical use in Sociology, we have followed Sir E. Tylor's example 
and divided the peoples into three stages in another way, .e. Savagery, Barbarism and Civilization.

Sociology allows a wide amplification to this system. In t Savagery includes the hunters and fishers; Barbarism, the aerdsmen and hoe culturists; while Civilization, used in a much narrower sense than its popular one, includes the peoples who practise plough, garden and commerce culture.

The relation of this system to our genealogical tree is thus a very simple one. We need only draw two horizontal ines through the latter to understand the three divisions of the system. We can then characterize it in the following manner:

On the lowest stage, Savagery, man lives almost as animals live, on such food as Nature offers. He takes, giving no forethought for future growth and production.

The second stage, Barbarism, begins as soon as man has learned to introduce artificial sources of food into his life. Here the ways divide; the elaboration of animal food production led to cattle rearing, that of vegetables to husbandry and to hoe culture.

The characteristic distinction of the variety of food in both lower stages give their own definitions.

As Civilization progresses we cannot define it with the same sharpness and decision, for the transition is not a gradual and easy one. New sources of food appear which have not developed either from cattle rearing or husbandry.

Since the distinction is not qualitative it must be quantitative. $A$ priori, one might think that this quantitative gradation must arrive in some way through a union of agriculture and cattle rearing. But it is not so. For example, we find among many African and other nature folks a union of hoe culture and cattle rearing; but the civilization of the ancient Mexicans and Peruvians, the Chinese and Japanese was actually attained by husbandry. It sufficed for the origin of civilization that one useful plant which offered food in great abundance should be obtainable. For example, maize gave the essential material basis for the early American civilization, rice for the Japanese, Chinese and Indian, and cereals for the Egyptian and other Eastern races. The difference between civilized and uncivilized peoples has not depended on the multiplicity of food sources, but on the 


\section{THE HISTORY OF SOCIAL DEVELOPMENT}

greater intensity of ground cultivation which was brought about by plough, garden and commerce culture.

However, we have as yet only laid bare the immediate causes, not the essence of civilization. For it is not only this intensive land culture that constitutes civilization, but, as we shall see later, a resultant phenomenon of it, the division of labour and the differentiation of men into professions or trades. As already said, this phase of culture first appears when the production of food has attained such great abundance that men's energies are free for other work. Among the Red Indians who carry on hunting and hoe culture we find no differentiation in their callings; among the Oceanians and the African hoe culturists the first trace of it appears; while among civilized people the division of labour has made so much difference that now "Quality" is more considered than "Quantity." The resultant phenomena, notably the foundations of the modern state, are of such far-reaching importance that we cannot simply designate civilization as a third culture stage, but must place it in apposition. Civilized peoples are culture peoples, the rest are nature peoples.

We can only go into these questions later in the following treatise on the history of the evolution of labour; here, where we are only dealing with food phases, these hints must suffice.

In conclusion, we may now summarize the three great epochs into which the history of food falls, and which themselves indicate the stages of culture, in the following way:

I. Savagery.-Man gathers his food directly from nature: he feeds himself by means of hunting, fishing and the collection of wild plants.

II. Barbarism. - He begins to tame and rear animals and to cultivate plants. In addition to the natural sources of food, artificial sources appear in the shape of cattle rearing and agriculture.

III. Civilization.-Here artificial food production becomes more intense, and by it forces are set free to devote themselves to other activities besides the production of food. Division of labour, the basis of all higher culture, arises in the form of different callings and professions.

If we gather into this system of stages the most important 
races which we have hitherto mentioned, we arrive at the following summary:

\section{A. Nature Peoples.}

I. Savagery.

(a) The nature condition of man, primitive stage of culture, primeval ages. The representatives are extinct and unknown.

(b) Lower hunters. Representatives are Australians, Tasmanians, Central African dwarfs, Bushmen, Mountain Veddas, Mincopies, Terra del Fuegans and Eskimos.

(c) Higher hunters. The Indian peoples in the West and North of North America, Californians, Apaches, Comanches, the Athapascan tribes, etc.

(d) Fishers. The Itelmen, Aleutians, Gilyaks, Kolyaks, Haida, Tsimshian and Vancouver tribes.

\section{BARBARISM.}

(a) Pastoral people. In Asia: Kalmucks, Kirghizes, Baschkirs, Uzbegs, Yakuts, Tibetans, Todas, Reindeer Nomads, Ostyaks, Voguls, Tungus, Samoyedes. In Europe : Lapps. In Africa : Bedouins, Dinkas, Baris, Masai, Wahuma, Galla, Somalis, Ova-Hereros, Hottentots, etc.

(b) Agriculturists. I. Hoe culturists with hunting: Most of the Indians in North America, Iroquois, Hurons, Delawares, Mohicans, Crees, Ojibwa, Sioux, etc. In South America : Caribs, Uaupes, Araucans, Brazilians, etc. 2. Hoe culturists with fishing: Oceanians (Polynesians, Micronesians, Melanesians). 3. Hoe culturists solely: The African Zambesi tribes, Ma Kalaka, Ba Yeye, Njam-Njam, Kalunda, Indonesians, etc. 4. Hoe culturists with cattle rearing: Kaffirs, OvaMpos, Ba Kuba, Waganda, Dahomians, Ashantees and the ancient lake dwellers.

\section{B. Culture Folk.}

III. Civilization.

(a) Horticulturists: The old American culture peoples, who fall into three culture cycles, namely, the Toltec-Mexicans, 


\section{THE HISTORY OF SOCIAL DEVELOPMENT}

the Mayas of Yukatan, and the Inca-Peruvian culture cycles, and the Chinese and Japanese.

(b) Plough culture: (aa) Assyrio-Babylonians, Egyptians, Phoenicians, Carthaginians, Jews, Arabs, etc., Persians, Indians. (bb) The classical people of Antiquity: Greeks and Romans. (cc) The Romano-Germanic peoples of Mediæval Europe.

(c) Commerce culturists: The peoples of the modern European culture cycle. 


\section{THE DEVELOPMENT OF THE TOOL ${ }^{x}$}

IN the history of the development of the tool-taken in its broadest sense-we recognize four great phases or epochs.

I. The Stone Age, which is divided into the older or Palæolithic and the more recent or Neolithic periods.

2. The Copper and Bronze Age.

3. The Iron Age.

4. The Machine Age.

As is evident from the expression "Age," we are treating not merely of the evolution of the tool, but of the general culture of the ages concerned. The tool is, next to food, the most important standard by which we can estimate the degree of culture. That the phases of artifacts are called "ages," and those of food production "stages," is owing to purely external circumstances, Ethnology designating the one, and Archæology the other.

With respect to the prehistoric phases through which the tool has passed, we are in no wise restricted to Archæology alone. Among peoples still living there are numerous and valuable representatives of the stone, bronze and iron age, which put at our disposal material more abundant in many ways than Archæology can do; and place us in a position to ascertain the phases of all technical development from Ethnology alone without being dependent on Archæological research.

All the races of whom we have spoken have survived until comparatively recent times, and have come into contact with Europeans.

- For bibliography see Sombart, Brauns, Arch. xiv. p. 26. 
While the three divisions of the Old World-Asia, Europe and Africa-had long entered into the Iron Age, the more recently discovered continents and islands-America, Australia and Oceania-remained in entire ignorance not merely of iron, but of all use of metals. The only exceptions were the ancient civilizations of Peru and Mexico, which at the time of the discovery of America were in the Bronze Age, but had still no knowledge of iron.

If we draw a line round the three connected continents of the Old World we may say that the Iron Age was restricted until quite recent centuries to that very limited space, while the Stone Age still reigned in the whole of the rest of the world, and only the ancient civilizations of America had arrived at the Bronze Age.

Ethnology thus provides us with a rich treasure of material for the study of the development of the tool, and we will now place these ethnological facts with those derived from history-as distinct from pre-history-and arrange them by the same methods as those previously employed, leaving the question of pre-history until the following chapter.

\section{Conclusions from Ethnology and History.}

I. The Stone Age.

(a) Older or Palcolithic Phase.

The characteristic of the Stone Age is that all material from which tools, weapons, domestic implements, etc., are prepared, is taken directly from nature, in the same way as were the means of nutriment in the lowest stage of culture. The materials employed are :

I. Stone.

2. Wood, viz. tree trunks, bast, bark, branches, etc.

3. Skin, bones, sinews, claws, teeth, intestines, horns, muscles of creatures taken in the chase, fish bones, shells, etc.

The realm of the older Stone Age includes, as we know, nearly all the races of the lower and higher hunters. Among their technical accomplishments the fabrication of weapons plays naturally the chief rôle; tools and household imple- 
ments are extremely limited, as everything has to be carried about by these wandering peoples.

The principal weapons are the club, the beating stick, the spear, the bow and arrow, the throwing club and the throwing disc, which latter was used to increase the slinging power of the arm. The points of the spears and arrows of this stage are mostly made from hard stone, shell or pointed bones; the arrows are frequently poisoned, and often so cleverly made that the shaft breaks off, leaving the point in the wound by means of barbs. Among Australian races we find the boomerang, and among the Eskimo the throwing stick, both used as distance weapons. The blow-pipe with poisoned darts was a later invention. Slings and traps are used for catching wild animals, and fish are caught by hooks, nets and spears. Large trees, hollowed out by means of fire, or punts of bark or hide serve for travelling by water. The tools, all of stone, are knives, chisels, axes and scrapers for dressing skins. Needles are prepared from fish bones or thorns ; and thread from the sinews and intestines of animals and twisted bast. Baskets are plaited from reeds, rushes and twigs; while bottles are pouches or flasks, consisting simply of the uncut skins of small animals.

If we ignore those objects which serve merely as ornaments, the above inventory comprises practically the whole of the material possessions of man at the "Hunting Stage." No tribe, in fact, possesses the whole list. The Australians are the only people possessing the boomerang, and they have not bows and arrows. The Tasmanian had a straight stick pointed at one end for his only weapon, and, according to Sir John Lubbock, even among neighbotríng tribes great diversities are found. $x$

At this stage of culture, and this is characteristic of the older Stone Age, weaving and pottery are not found, and are completely unknown.

On the other hand, the knowledge of the kindling and use of fire has already been attained by all hunting people. No race has ever been discovered in historic times having no knowledge of fire, which is subjugated and guarded by mankind in the earliest culture stage known to us and used for the most manifold purposes. Fire enables men to make food

I Lubbock: Prehistoric Times, ii. 145. 
more palatable, to smoke and preserve meat, to burn round the foot of trees, so causing them to fall, when they can be transformed into canoes, to harden the points of spears, to protect stakes from decay, to drive the wild creatures of the prairies towards the hunters by means of burning the grass, and further, to give warmth in cold weather, and light and protection at night, when wild beasts prowling about in search of prey are easily kept away by the sight of the flames. But the sum total of this knowledge of fire is not found in any one tribe of hunters, the usages of any single group being much more limited. The Australians make use of fire for roasting food, burning grass, and especially to lighten their darkness, this last not for protection against fierce beasts, which scarcely exist there, but from a superstitious fear of ghosts.

Many tribes of Eskimos use fire neither for cooking, as they eat their meat raw, nor for warming their houses, which, being built of ice, would melt and collapse, but only in oil lamps to brighten the long nights, and for turning ice into drinking water.

(b) The More Recent Stone Age or Neolithic Phase.

To the Stone Age belong not only the hunters, but the great groups of American and Oceanic hoe culturists. If we compare these agricultural peoples with the hunters just portrayed, we find such important advances that we must differentiate and regard their civilization as a new phase, a Neolithic or more recent Stone Age. The dissimilarities extend over culture in general quite as much as over technical skill in particular.

While purely hunting peoples make their tools by simply rough-hewing stone into shape, the peoples in the Neolithic stage obtain a nicer exactitude by grinding ("polishing ") and boring the rough weapons and tools; for example, the American Indians possess the art both of grinding and boring, although the Oceanians, with the exception of the Maoris, only know that of grinding.

Nomadic hordes naturally have few household requisites, but the lower agriculturists, as they trend to a sedentary life, gradually acquire home comforts, and with it symbolic pro- 
gress. For instance, among the agricultural Red Indians, who are still half nomadic, besides the hammocks of their own invention are found beds, consisting sometimes of low matcovered benches, and sometimes of boxes covered with skins, into which they creep through a square hole. ${ }^{x}$ Earthern pots, wooden plates and dishes, leather bottles, skin-rugs, etc., are also found.

The household furniture of the Oceanian is still ampler and more decorative. The various vessels and implements are frequently beautifully carved and artistically ornamented, and this is the case too with furniture and weapons. The clubs in particular are often turned by the labour of years into real works of art.

Two notable inventions which appear at this stage of culture and are symbolic of the later Stone Age must now be considered; they are Weaving and Pottery. The hunters of the Palæolithic times made nets, but knew nothing of spinning or weaving. Among many Indian tribes of North America excellent hammocks are produced, but still there is no weaving. South and Central American Indians, having arrived at stretching the threads by means of the spindle, have advanced to hand weaving with chains and small balls; and the hand loom is found among the Oceanians and Malays.

Still more important was the invention of pottery. The pot betokens sedentariness-and the art of cooking; the latter, indeed, is only possible by means of this contrivance, since without pots it would be difficult to keep water in position for cooking.

In the history of cooking three phases may be distinguished :

I. On the lowest stage the art of making water hot or boiling it is quite unknown. On this stage are the lower hunters; it is related of the Australians that they scalded themselves with boiling water when first they saw it by touching it unconscious of the danger. Among these people meat is either eaten raw or roasted on embers, the ashes of which are used to supply the want of salt, or else it is laid in holes in the earth which have been previously heated, and left for many hours in the gentle heat. This method, I Waitz, iii. 9I. 
universally praised by travellers, furnishes a very savoury meal, and is practically the same in its results as that used by more civilized peoples.

2. On a second stage, to which belong the Indian hunters and many Polynesians, but not the Melanesians, water is heated to the boiling point in wooden vessels or in watertight plaited baskets by throwing heated stones into it. This is called stone boiling.

3. Finally, there appears among the Agricultural Indians, Melanesians, etc., as a third stage-the pot. It originated, as the transition forms show clearly, by the Indians surrounding vessels or baskets with clay to make them fire-proof. Noticing that when the clay was burnt the wooden or plaited basket was unnecessary, it soon followed that they prepared the clay without their support, shaping it with their hands, for the potter's wheel for turning was a much later invention. In order to strengthen the vessels, crushed stones and mussel shells were often mixed with the clay. The vessels are often of considerable size, as in New Guinea, and are mostly in the shape of beakers or amphoras. The Fijians even understand glazing. The plastic material gives the opportunity for simple decorations, which, in the early work, consisted of symmetrical finger prints, butlater of various artistic ornamentations, a very frequent idea being the imitation of the plaited work of the waterproof baskets and vessels.

\section{The Bronze Age.}

Neither Palæolithic nor Neolithic man arrived at the knowledge of the immensely valuable qualities of metals for all useful arts. If the development of any race is not influenced by a more advanced people, it naturally happens that the softer and more easily fusible metals are first brought into use, such as copper, and its alloy with tin ore, that is bronze. Iron, which is much more difficult to work, is only turned to account after further progress.

We find this order followed in pre-Columbian America, where comparatively uniform races which were thrown entirely on their own resources have exhibited all the transition phases from the Hunting, through Lower Agricultural and right up to Civilization. 
Whilst the Indian hunters and hoe culturists lingered in the Stone Age, a few Northern peoples, notably about Lake Erie and in Alabama, worked the copper, which is found there in sterling condition, not by smelting it, but characteristically by hammering it, as they had been used to do with stone. A rich copper and bronze culture is also found among the peoples of Central and South America in Mexico and Peru. These nations were acquainted not only with copper and tin, and their alloyage into bronze, but also with lead, silver and gold-but not with iron. Stone always maintained its position, for it is not wholly replaced by the softer metals, but is only superseded by iron. Therefore the prominence of stone implements is characteristic of the Bronze Age, and the American bronze culturists are no exception to this rule. Stones were broken with wooden clubs, and a heavy wooden hammer skilfully used was sufficient for the production of knives, sword blades, stone chisels, etc., out of obsidian: Preference was given to basalt, obsidian, porphyry and jaspar. The grinding and polishing of stones and the boring of the hardest minerals was practised by them by means of flint powder. Metals were obtained from properly worked mines. Copper was mixed with tin, silver or gold in order to make it more malleable, and the different amalgams were worked into axes, bores, chisels, knives, etc., as well as for ornaments and all kind of art productions, with such a refinement of skill that, as the Spanish plunderers saw with astonishment, the Europe of that date had nothing of equal value to compare with them.

\section{The Iron Age.}

We find iron prevalent over the whole of the old world in historic times; not only among the peoples of the earliest civilization such as the Sumerians, Assyro-Babylonians, Egyptians, Greeks, etc., but even among most of the nature peoples of the old continents.

The Iron Age in European prehistoric times is left for discussion in the next chapter, but it may seem strange that "nature folks" in Asia and Africa standing on the culture stage of Barbarism should possess iron, whilst the more highly developed Peruvians and Mexicans had only risen to 


\section{THE HISTORY OF SOCIAL DEVELOPMENT}

the Bronze Age. Another irregularity of the phase series is to be noticed among these nature folks, in that one is accustomed to find a copper and bronze age inserted after the stone, but these peoples jumped directly from stone to iron.

This departure, however, from the usual order is only an apparent one. For these nature folks did not rise to the Iron Age through their own inventions and discoveries, but in all probability iron was introduced to them by more civilized peoples who had previously gone through a bronze age.

On closer consideration, such a transference can hardly be doubted. It is obvious that a metal of the valuable qualities of iron should be carried into regions as far as intercourse reached as soon as it became known. In Africa, as well as in Asia, the less advanced races were in more or less direct contact with civilized peoples, and could get in touch with them on all sides by means of intercourse going on from tribe to tribe along ways which were nowhere interrupted by impassable natural barriers. That there is a means of transference among African nature folks must be presumed, because only proportionately few negro races understand how to smelt iron, although the metal is universally known among them $;^{\mathrm{I}}$ and again, the bellows and the method of smithing are essentially the same all over Africa. The same truth is shown by the rapid rate at which hemp from the East, and maize, tobacco and other useful plants from America have spread all over Asia and Africa.

Thus it is by means of a possession acquired from more cultured nations on a higher level that the herdsmen and hoe culturists of Asia and Africa have been enabled to pass at a bound to the Iron Age, omitting the Bronze Age altogether; we will therefore delay no longer over this nature folk who have a knowledge of iron, but take up again the threads of development among the more cultured nations mentioned above.

The oldest of the civilized nations, the Babylonians and Assyrians, whom we regard as the ancestors of our own civilization, possessed a highly developed knowledge of metals when first they appeared to us on the page of history. By

\& Waitz, ii. 97 . 
means of organized mining they obtained copper, the first known metal of antiquity, lead, gold and silver, in addition to iron, which was known to the Western Asiatics from the most remote historic times as well as to the Egyptians from the foundation of the "New Kingdom." They knew of many alloys such as bronze and brass, of casting and hammering metals, as well as the art of gilding; and their metal work, such as richly adorned and inlaid swords, helmets, shields and vessels, reached a high degree of perfection. They understood how to work the hardest stones, and carve them artistically, to manufacture burnt bricks, cement, plaster of Paris and durable pigments, to glaze pottery, to prepare glass with the blowpipe and make fancy glass, which was variously coloured. They were acquainted with the arts of enamelling and varnishing, and with the chemical effects of numerous salts such as soda and saltpetre; they possessed tissues of the finest weaving known, surgical apparata, pharmaceutical drugs and cosmetics. Further, they knew almost all simple machines and a great number of complicated ones, wedges, levers, cylinders, rollers, screws, potter's wheels, turning lathes, pulleys, blowpipes, hand-mills, hand-weaving looms, windlasses, winders, winches, different kinds of vehicles, well-wheels, leathern bellows, wedge, lever and screw presses, wagons, rowing and sailing ships and military machines, etc. Their mechanical implements indeed reached such a degree of perfection that Peschel could say with reason: "If we compare the technical inventory of the ancient Egyptians with our own, it is evident that before the invention of the steam-engine we scarcely excelled them in anything."

This high condition of technical culture was the great and imperishable work of the Eastern peoples of antiquity, who belonged mostly to the Semitic and Hamitic races.

It is an astonishing fact in the course of technical evolution that the Greeks and Romans, the earliest of the gifted Aryan culture folk, were not able to add anything of essential importance to this mass of accomplishments which had been handed down to them. On the contrary, all skill in these practical arts seems to have been lost by them. It is noteworthy that the Romans were obliged to be shown by the half barbarous Celts such processes as the turning of pottery, 
the manufacture of silks and the use of wooden vessels. Not even in armour did this warrior folk make any essential progress ; from Augustus to Diocletian no changes were made in the equipment of the legions. ${ }^{x}$

This startling phenomenon may largely be explained by the fact that after technical skill had run such a splendid course among the Hamo-Semitic races, and its development had spread so widely into many spheres, a period must necessarily come in which other problems of civilization would take their turn. The Greeks distinguished themselves by their encouragement of Science, Philosophy and Art, while the life work of the Romans was the establishment of political organization into a well co-ordinated world-kingdom. One of the chief causes of this stagnation of practical work was certainly the continuance of slavery and the attitude of mind which this caused among the slave owners. At that time all labour was despised as fit only for slaves, and all active contact with material things was looked at askance. Only in philosophical speculation did the great thinkers find a problem worthy of them, and all manual work was contemptuously proscribed and regarded as a disgrace. This folly was hostile to all progress of positive science, and especially to that of technical skill.2

In yet another respect slavery was a drag upon technical development : as long as man had human machines he needed no others. With reference to this it is significant that water mills were in use in Asia Minor at the time of Mithridates, yet throughout the days of the Roman Empire the cruel and weary work of grinding in hand-mills was performed by slaves.

The classical stagnation of mechanical development continued until the Middle Ages. Then events occurred which entirely transformed the old technical science, at first by gradual stages, but later by increasing velocity until the development of the latest epoch.

I Seeck: Gesch. d. Untergangs d. antiken Welt, i. $25^{8}$.

2 Roscher says with much truth: "Not only the slaves but also their masters were lazy, for in slave-owning countries all labour is despised. What a society in which one-half of the population remains idle from malice, while the other half remains idle from pride !" $-($ Nat. Ök. 15I). 


\section{The machine Age.}

The Machine Age does not actually begin with the appearance of machinery, but at that date when the machines began to acquire such a predominant position that owing to them all former technology had to be changed. This occurred about the end of the eighteenth century.

The developments through which machinery had previously passed may be divided into the following sections :

Ist Section.-The period of great paucity of machinery, extending from the lowest stages of culture up to the beginning of civilization. The machines of this period, according to our modern ideas, are very primitive, consisting as they do of fire drills, hand looms and bows and arrows, but we cannot withhold the name of machine from them according to the definitions which our modern technologies give of the machine..$^{1}$

2nd Section.-The period from the rise of civilization until about the time of the Crusades. The inventions of this epoch, as already mentioned, were wholly attributable to the ancient peoples of the East; the classical nations added nothing of importance, nor did the Romano-Germanic people of the Middle Ages. The only exception is the windmill, which is mentioned as far back as II05, but that also had been in use long before in Asia Minor.

$3^{\text {rd }}$ Section.-From the Crusades to the eighteenth century. After the prolonged quiescence of what is known as the Dark Ages, new life first stirred at the time of the Crusades when the Western lands came into contact with the Arabs. Arabic civilization had directed the treasures of knowledge which they had obtained from the Alexandrians, Byzantines and Persians into quite fresh courses. The Greek and Roman philosophers fostered knowledge exclusively for its own sake, for the enrichment and ennobling of the mind, and rejected with contempt every application of science to actual utility. This magnificent but unpractical enthusiasm was absolutely foreign to the Semitic mind. They

I Machines, according to Reuleaux, are objects by the intervention of which a motive power is made to act upon any body and overcome the force by which the latter resists the effort to change its state of rest or motion. 
recognized knowledge as a power which should serve not only to ennoble the mind, but to help alleviate all human suffering and enhance all human joys. In the place of useless subtleties they advocated useful intercourse with nature, and thereby created a basis on which natural science was built. Thus for the second time did the practical mind of the Semitic race guide the world into the path of progress. The Crusaders who marched forth to conquer or convert the heathen gained from their enemies a treasure beyond price which, in the hands of their descendants, was to unfold magical qualities and bring forth surprising results.

Until this wisdom was transmitted from the East, science had borne no useful fruit, but with it came a new conception which was to turn all the forces of nature to man's use, encouraging him to learn how to control them. ${ }^{\mathrm{I}}$

In the thirteenth century the new light shone forth in the persons of Roger Bacon, I2I4-I294, and Albertus Magnus, II93-I280. From that time the ban was removed which had been crushing intellectual life during the early Middle Ages in Europe. Numberless scholars travelled along the new paths, and success followed after success.

For with knowledge came the power of understanding, the advance of research led to progress in all spheres of science; and there began a time of the most brilliant discoveries and inventions, now no longer attributable merely to chance, but to properly organized scientific labours.

The following is a brief summary of some of the most useful and important of these numerous discoveries and inventions. ${ }^{2}$

As far back as the thirteenth century, magnifying glasses

1 Prutz: History of the Crusades.

2 Most of the inventions were not given to the world suddenly in the form in which we know them, but had a "latent period." This frequently proved very disconcerting to a late inventor who thought he had come upon some new thing. For example, the first spinning machines were invented before A.D. I 500 (Book of Inventions, Vol. III), but it was not until the end of the eighteenth century that the revolutionary changes in spinning took place in England. The steamengine was already invented in 1700 , but it was only about seventy years ago that it was brought into practical use in England. The steamship had been anticipated by Papin in 1707 in the Fulda. It is well known to have been the same with the telephone, the bicycle, etc. 
and spectacles were invented by Roger Bacon. The invention of gunpowder in the fourteenth century may be considered to be the third great advance on the way to man's dominion over the earth; the two earlier being the subjugation of fire and the working of metals. Further inventions in the fourteenth century were wire drawing, linen paper, wood engraving, compasses, cannon and guns. In the fifteenth century the art of printing appeared. For this invention certainly no deep knowledge of natural science was necessary, yet it owed its origin to the newly awakened spirit of nature research, which endeavours to look into all material things and to leave its stamp thereon. The discovery of America was equally a result of progress in another natural science, i.e. astronomy. Further inventions in the fifteenth century were copper engraving, porcelain, glass bottles, sluices, etc.; in the sixteenth century-stocking knitting, lace bobbins, saw mills, watches, microscopes; in the seventeenth century-telescopes, barometers, air-pumps, pendulum clocks, Denis Papin's safety-valve; and in the eighteenth century the first steamboat, I707, typefounding machines, I7I4, and the lightning conductor, I749.

In the second balf of the eighteenth century came the discoveries of the great industrial machines which revolutionized science and manufacture, and led on to the capitalistic system which places the whole civilized world on a different basis, and so introduces another epoch.

The following inventions were of especial importancefirst, the spinning machine, I764-I775, by Arkwright; second, the steam-engine, I765-I784, Watt; third, the mechanical weaving loom, I785, Cartwright ; and fourth, the Langform paper machine, 1799, by Robert. The most momentous of these is the steam-engine, whose epoch-making significance lies in the fact that in the first place it can set all other machines to work without the co-operation of human muscles, and in the next place, at a given point it is able to develop a power which has never before been possible to any number whatever of men or animals. Further, in the eighteenth century were invented the puddling process, 1780 ; sowing and threshing machines, the combing machine, I789, and glass chimneys for lamps, I783, Argand. The year I780 was that of the discovery of galvanism; the year 1774 that of 


\section{THE HISTORY OF SOCIAL DEVELOPMENT}

oxygen, simultaneously by Priestly and Scheele; and this, through Lavoisier, led to the founding of modern chemistry. Of the discoveries and inventions of the nineteenth century we will name the production of gas from coal in 1803 ; in 1805 the Jacquard machine, phosphorus matches and morphia; in I8II, mowing machines; in I8I4, the sewing machine by the master tailor Madersberger; in $18 \mathrm{I} 7$, velocipedes; in I $82 \mathrm{I}$, steering wheels, and the analysis of fat by Chevreul; in I824, turbines; in I828, photography, and the synthetical formation of urea by Wöhler; in 1829, the locomotive by Stephenson; in 1830 , the first railway train; in 1833 , the telegraph; in 1837, electro-metallurgy; in I840, artificial manure by Liebig; in 1846 , gun-cotton and nitro-glycerine, and ether anæsthetics by Jackson, of Boston ; in 1847 , chloroform narcotics by Simpson, of Edinburgh; in 1858, gaspower machines; in I86I, the telephone; in I867, the dynamo machine, knitting machine, and dynamite by Nobel ; in 1869 , the synthetic production of alizarin ; in 1876 , that of indigo from the component parts of tar, etc.

This inventive activity continues. It goes unremittingly on its way, and every year brings new inventions and discoveries, each of which proves how false was that old proverb of Rabbi Ben Akkiba, "There is nothing new under the sun"; for even the least observant must admit that "everything is in flood," everything moves onward. Every page of this book will show that a progressive movement is taking place in every sphere of civilization, and not in that of technical development alone, although certainly the pace varies. ${ }^{\mathrm{I}} \mathrm{He}$ who has followed the course of Evolution up to the present time must feel almost dizzy when he looks forth on the illimitable possibilities of the future. The newest discoveries, such as the Röntgen rays, diphtheria serum, radio-active substances, dirigible airships, etc., are each in some way so surprising that we fail to imagine what the next century or millennium will bring forth. With regard to one problem only-the threatened exhaustion of the coalfields-inventive genius must find for us some entirely new paths.

Our present knowledge allows us to transfer all purely mechanical labour from man to the machine. Beyond the

I For amplifications of this subject see Book VI, Culture and Happiness 
magnificent capabilities of mechanism as to spinning, textiles, iron, machinery and chemicals, we have at our disposal machines which sow, mow, thresh, etc., and even those which would exempt men and women from the sordid work of dish washing, laundry work, boot cleaning and even dusting. He who knows only the technical side of our civilization might easily think that we had reached that condition that Aristotle apparently considered impossible when he said: "If shuttles would work by themselves, and the plectra and the zithers could play by themselves, we should need no more slaves" (Pol. I. 2. 5.). He might reasonably believe that in a community which ruled over millions of iron slaves all might lead a life of learned leisure even as the highest of the Athenians were able to do.

But proletarianism and pauperism have taken the place of slavery; machinery has not succeeded in making the life of the masses run smoothly. In this fact, astonishing and hard to be understood, lies one of the greatest problems of our age, with which we shall have to deal more minutely in its proper place. We shall find, as one of the chief causes of the difficulties in question, that the development of social organization could not keep pace with the enormously rapid flight of technical art and of our general economic life, for by reason of various social hindrances the process of adaptation of the latter is so slow that it acts like a brake on the former. Only when social organization shall have undergone a revolution similar to the technical and the economic ones, only when this adaptation of the whole of our civilization to modern economic conditions has been accomplished, can our sublime technical possessions enter fully into life; and only then will the machine age proper begin, of which, until now, we have known only a preliminary phase.

\section{Conclusions drawn from Archæology or the Palæontology of Mankind.}

In the foregoing pages we have tried to learn the prehistoric phases of economic evolution from Ethnology. But there is another way, already mentioned in the Introduction, of arriving at that knowledge, that is by Archæology, the prehistory or Palæontology of mankind, "the Science of the 


\section{THE HISTORY OF SOCIAL DEVELOPMENT}

Spade." The results of this science are of very great importance, for by a comparative method only can we judge which are the older and which the more recent of the forms of evolution; and here Geology comes to the help of the archæologist, since the strata of the earth's crust are so superimposed that as a rule the recent lie over the more ancient, thus the geological formation in which a prehistoric discovery is found shows its age. Archæology thus brings the succession of evolution directly before our eyes, and this we could only infer comparatively from Ethnology. It tests our opinions formed from Ethnology and confirms them. This test does not comprise only the evolution of technical art. Archæology includes the whole civilization of those peoples who lived on this earth in long past ages as shown in food, tools, dwellings and clothing as well as in the intellectual life, knowledge, art, religion, etc. But what has been discovered of this lost world consists so largely of implements, weapons and tools that Archæology is wont to classify its periods by the standard of technical art reached, and to measure them by the development of the tool.

Archæology confines itself here to Geology. As the "Palæontology of Mankind," it is only the continuation of the Palæontology of the rest of creation, which we have already tabulated in an earlier treatise. ${ }^{x}$ Each summary has shown us that man appeared as the latest and last member of animal evolution, that his first traces, so far as we know at present, are found in the Diluvial formation, that he thereafter had dominion over all things, and that human history has played its part in both of the two last formations, namely, the Diluvial and Alluvial.

The following table, which is a continuation of the Geological one before mentioned, gives a summary of the prehistoric phases and their classification in the Geological strata. The table is to be read upwards in the same manner as the strata followed on one another.

Since the results of Archæology and Ethnology agree on the whole, as may be seen from this table, we will briefly recapitulate our statement. ${ }^{2}$

Introduction to Sociology, p. 39.

2 The following may be useful to fill in these bare outlines: Die Urgeschichte der Menschheit, Hörnes, Vienna, 1892; Le préhistorique, 
SUMMARY OF THE PREHISTORIC PHASES

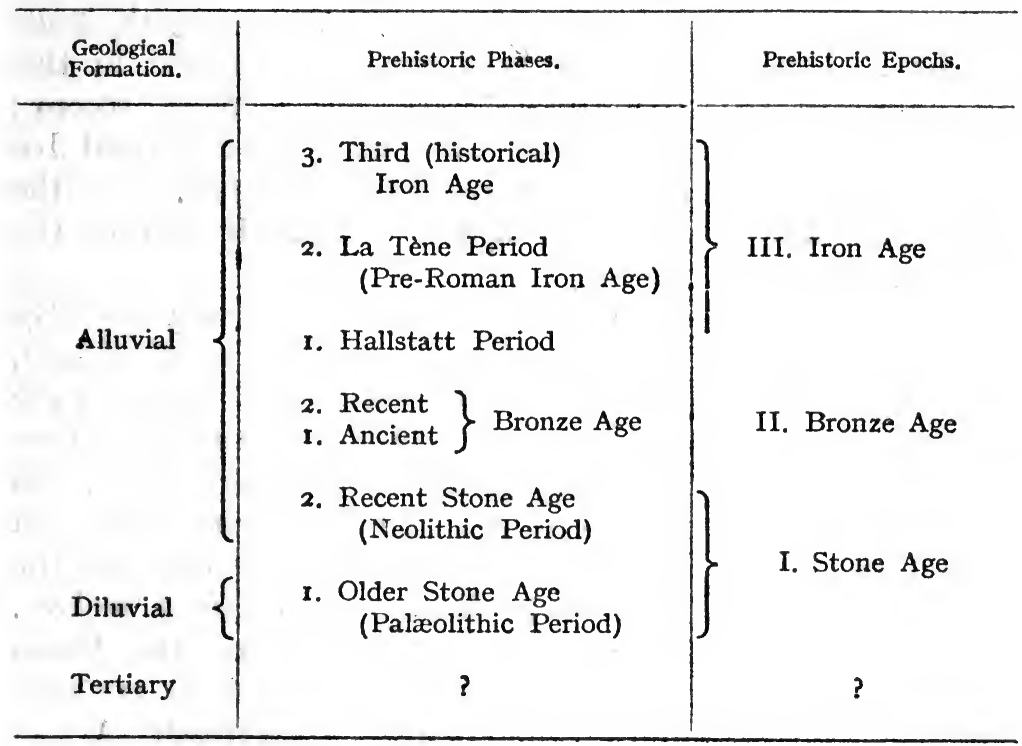

I. Tertiary Formation.

In the strata of the Tertiary formation no certain traces of man have as yet been found. A few scholars, it is true, believed they had discovered some remains, but since these discoveries are isolated and of doubtful authenticity we will not consider them here. In any case, it is certain that the development of mammals must have risen to that of the true apes in the most recent strata of the Tertiary.

\section{Diluvial Formation.}

In the Tertiary the climate of Europe was somewhat similar to that of North Africa in the present day, except that it was much damper.

Upon this warm period there followed, from causes not yet explained, a lowering of temperature : it began with the Diluvial period, the true Deluge, which was much earlier than the Noachian one, an ice age in which Europe was

G. de Mortillet; Der Mensch., Ranke. There is a bibliography in Hörnes. 


\section{THE HISTORY OF SOCIAL DEVELOPMENT}

almost entirely ice-bound from Scandinavia to the Hartz Mountains, and South Germany was covered with huge glaciers. Three periods at least are distinguished in this Ice Age-an older, an interglacial, and a more recent; probably according to Penck there have been several Ice Ages with several interglacial periods, characterized as the periods of the cave bears, of the mammoth and of the reindeer.

In the interglacial periods the climate was comparatively mild, the fauna consisting of such animals as elephants, mammoths, hippopotami, rhinoceroses, cave lions, cave hyenas, wolves, bears, beavers, wild hogs, aurochs, stags and deer, an extinct variety of horse, and huge bears. In the glacial period the temperature sank, and the fauna and flora had an Arctic character. Reindeer, the red and the Arctic fox, chamois, marmot, the Cygnus musicus, wolves, cave lions and three extinct species of bears (the Ursus spelaeus, priscus and tarandi), and mosses such as are now found in Lapland and Greenland were widespread.

From the warmer interglacial phases as well as from the later Ice Age numerous discoveries have been made ince the middle of last century in Germany, in Taubach, in Gera, the Linden Valley caves, Thiede in Brunswick, Blaubeuern, Thayngen, Schussenried, etc., and more still in much explored France, as well as in England, Spain, Portugal, Belgium, Austria, Italy, etc. These discoveries not only show beyond all doubt the existence of Diluvial men, but they also give us a fairly clear picture of the life of the ancient Stone Age or Palæolithic period, as we call the era of Diluvial man.

Palæolithic man was a hunter and a fisher. He hunted reindeer, stags and roes, wild horses and great-headed ponies. He killed the mammoth in traps and successfully hunted cave bears, as is evident from the weapons he manufactured out of the jaws of those terrible beasts. He lived a precarious life, making his home in caves and other natural hiding-places, probably also in primitive huts, of which no traces could have remained. For clothing he wore skins, which were sewn together with awls and wooden needles; he manufactured weapons and tools out of wood, bone and horn, but most frequently from stone. His knives, arrow 
and lance points, daggers, chisels, scrapers for dressing skins, axes and hatchets were also of stone, mostly pebble or flint. The polishing of stone was unknown, this being first found among the Neolithic people, on which account the older and more recent Stone Ages are also differentiated as the unpolished and the polished. The chief food was the flesh and marrow of animals; to obtain the latter all bones were broken. As many human bones have been found broken, no doubt cannibalism was practised. We infer that the painting of the skin was customary, as lumps of ochre earth have been found among treasures and ornaments composed of horn, stone, shell, and the teeth of wild beasts. On mammoth bones marks have been found, which, if they are genuine, give evidence of artistic talent and keen observation.

These hunters were absolutely unacquainted with husbandry and cattle breeding. They can have known nothing of pottery, for not a single potsherd has been found among the thousands of objects unearthed up to the present, and undoubtedly dating from Diluvial times. However, they carried on inter-tribal trading, for in isolated places jade hatchets have been unearthed, which unquestionably must have been imported from a great distance.

It must not be forgotten that the Palæolithic culture extended over millenniums, and the stages of its evolution are very distinct. On that account Broca and Mortillet divided the older Stone Age in France into four successive phases, which they called after the chief places of discovery: I. Chellian (Elephas antiquus) ; 2. Mousterian (cave bears); 3. Solutrian (mammoths); 4. Magdalenian (reindeer). In the Chellian period all weapons, tools, etc., were quite primitive, being roughly and clumsily worked. Later the work became more detailed, and in the Solutrian and Magdalenian periods it attained to a highly advanced condition.

But even in the latest periods of the earlier Stone Age men remained in the savage or hunter stage, which corresponds in every particular with what we have found among the Red Indians and Australian aborigines. In fact, many palæontologists have surmised that the Eskimos of to-day are not far removed in succession from Palæolithic man. It is quite possiblo that they followed the reindeer, their 


\section{THE HISTORY OF SOCIAL DEVELOPMENT}

chief food supply, as it retired further north at the end of the glacial period, and so finally arrived in the Arctic circle.

\section{Alluvial Formation.}

\section{The More Recent Stone Age.}

While the transition from the Diluvial into the Alluvial, which is the present geological formation, was gradually being accomplished, the Ice Age ended, the climate grew warmer, and Europe became a land of moderate temperature. The mammoth and the cave bear became extinct, the reindeer and other Arctic animals retreated towards the North, while the chamois, the marmot and the ibex migrated to the high mountain country.

As to civilization, the later Stone Age is divided into two encirely different stages:

(I) The Earlier Neolithic Stage (néolithique ancien), whose remains have been found in the shape of enormous heaps of refuse=Kjokken-möddinger or kitchen-middens, most frequently on the coasts of Denmark, but also in France, Sardinia, Portugal, South Brazil and elsewhere. These Kjokken-möddinger, often hundreds of metres long, I50 metres broad, and about three metres high, consist principally of millions of shells, especially the shells of oysters, mussels, and periwinkles. In the heaps have been found the bones of stag, roe, wild boar, wolf, fox, dog, bear, lynx, marten, hedgehog, beaver, seal and cat; fishbones, such as herring, eel and cod; tools and weapons of flint, bone and staghorn; and finally ashes, charcoal, potsherds, and up to the present time one single spindle whorl. The kitchenmiddens contain nothing that would lead us to believe that there was then either husbandry or cattle rearing, and certainly the builders of these heaps did not know how to polish their stone implements.

The culture of the earlier Neolithic peoples was thus that of the hunter and fisher folk, and it was. almost by the knowledge of pottery alone that it rose above the Palæolithic stage. It apparently stood on a level with many hunter and fishing peoples, such as the Fuegans and others, who at the time of their discovery by Europeans raised 
similar midden-heaps of shells, etc. Yet the latter races possess no pottery, nor neighbours acquainted with it.

Incomparably higher stood the culture of the

(2) Fully Developed Neolithic Period, which the French call Robenhausen.

These Neolithics were husbandmen and cattle rearers. They cultivated wheat and made a kind of bread out of it, and kept numerous domestic animals-cattle, goats, sheep, dogs and often horses. Moreover, they practised hunting, especially of stags. In addition to meat they ate apples, raspberries, hazel-nuts, and other wild fruits. They were a sedentary people, who lived in pile dwellings on the lakes, ${ }^{\mathrm{r}}$ or in huts or " pit dwellings," that is, cavities in the ground which they roofed over, preferring these to cave dwellings. They made pottery out of clay, shaping it with their hands, for the most part rounded underneath like an egg. They raised monuments with huge stones, the so-called Megalithic remains, dolmen, in the form of tables, menhir, rows of stones, cromlechs, circles of stones, and grave chambers. They had division of labour and carried on trade. Numerous workshops have been found, fifty-three in Poitou alone, in which stone implements were made in great quantities, and these partly out of stones which had been imported from a distance. The stone implements of these Neolithics give evidence of a notable progress. It is a distinctive sign of the late Stone Age that the implements were more carefully worked, being not merely chipped into shape, but polished, thus giving rise to the alternative title of the Polished Stone Age. The implements were in addition brought to a point of greater utility by having holes drilled in them.

Other remains of the more highly developed Neolithic Age are found in the pile dwellings in Switzerland, South Germany and Austria, in addition to those pile dwellings which can be proved to belong to the later Metal Ages. Typical examples of the Neolithic pile dwellings are afforded

- There are still such pile dwellings in different parts of the world, for instance in Borneo, on the North Coast of New Guinea, in the Central African lakes, in South America, in Lake Maracaibo and elsewhere. See Peschel's Ethnology, 6th edition, p. 42, and Waitz, Anthropologie, vi. $5^{87}$ et seq. To sum up briefly, there are still some ten million men living in our own day in such water strongholds. 
by Robenhausen in the Pfäffikon lake, near Zurich, Wangen, near Constance, Clairvaux, near St. Claude in the Zurich Jura ; furthermore, numerous discoveries have been made in other countries, especially France, where, at Becken on the Seine alone, I,080 stations have been discovered. Traces of them have also been found in Germany, Italy, Greece, Palestine, Armenia, Egypt, Assyria, India, and in China. In short, authentic signs of the Neolithic period are to be found everywhere where civilization has developed in later times.

Until well into the Middle Ages, stone weapons were retained in isolated parts of Europe. Thus the Slavonic Prussians wielded stone war axes against the knightly orders ; and towards the end of the thirteenth century the Scots, under William Wallace, fought with similar weapons against the English.

If we now compare the results of Archæology" with those of Ethnology, we find that our prehistoric Neolithics stand on the culture stage of Barbarism. But whilst Ethnology knows several species of Barbarism, viz. (a) herdsmen, (b) different groups of hoe culturists, and (c) hoe culture with cattle breeding, Palæontology at present can only enlighten us about the last. Here a gap yawns in Archæology, a much discussed "hiatus." After the records of the Diluvial period there is a striking stillness concerning European vestiges, for the hunters of the Ice Age seem to have disappeared; the alluvial deposits which succeed on the earlier ones contain absolutely no human traces. Then there appears quite suddenly the higher Neolithic culture with husbandry, cattle rearing, polished stone weapons, and many improvements and advances. Thus several stages are wanting; we can only assume that at that time there emigrated from Asia into Europe an Aryan race, who had passed through the previous phases, but whose records are not as yet forthcoming.

\section{Copper and Bronze Age.}

As has already been said, among most peoples who have progressed from stone to metal, the knowledge of softer metals is older than that of iron. After the Stone Age, 
unless the development is influenced from without, a Copper and Bronze Age follows, which generally coincides with the transition from Barbarism to Civilization.

Thus, as we have said, the Peruvians and Mexicans rose from the stone to the bronze grade, iron being quite unknown to them. Through the Spanish Conquests, the former American civilization was utterly destroyed, and the native bronze culture disappeared before the iron culture of the conqueror. In China a Bronze Age succeeded to the Stone Age, as the remains found in the "Loess" testify; and this again, according to Chinese tradition, gave place to the Iron Age as early as the third century B.C. Iron is not found in the sarcophagi and sepulchral monuments of Egypt until the New Empire, which dates from B.C. I50o. Bronze, which succeeded to copper, was the universal metal of the old Empire. It is obvious that the Egyptians had passed through the Stone Age before the copper from the fact that circumcision was performed with a stone knife. Religious ceremonials, always inimical to any new thing, retained stone implements from the dawn of time until the Middle Ages. India, Chaldea, Syria, etc., are also shown by prehistoric research to have passed through the Bronze Age.

The excavations which Schliemann has carried on in the famous heap of ruins at Hissarlick, the site of ancient Troy, are particularly interesting. At this place, where men lived for thousands of years, no fewer than nine layers of earth, etc., were formed one above another, concealing and saving for us an abundance of prehistoric objects. There were found :

I. In the lowest layer, dating probably from B.C. 3000 to 2500 , stone implements, such as drilled hatchets, flint knives and saws, and copper objects, but nothing of bronze or iron.

2. In the second and up to the sixth layer, dating B.c. 2500 to I000, weapons of stone and bronze, and some silver and gold, but still no iron.

3. In the seventh up to the ninth layer, B.c. Iooo to A.D. 500, were iron tools and weapons.

The knowledge of bronze probably came into Europe 
from the East. After the glittering metal became known by intertribal commerce, the Europeans who were still in the Barbaric stage soon learnt to produce and work bronze for themselves. As chemical analysis shows, the alloy was not brought about by the melting together of metallic copper and tin, but much more simply by the melting of tin ore with gravelly copper ore; metallic tin was apparently not known till later than bronze. We may mention, in passing, that the Romans prepared brass out of copper and zinc in a similar manner, without knowing generally the use of metallic zinc. $x$ The requisite tin ore was obtained for the most part from the mines of England and France.

At first; and while it was still a rarity, the precious new metal was used chiefly for ornament, such as bracelets for arms and legs, and for pendants, as well as for vases, bowls, and decorative armour. But soon it served for weapons and tools; and daggers, swords, lance and arrow-heads, chisels, sickles, saws, shears and hatchets were made from it. The hatchets were not in the form of our present tools; they were still, like the stone ones, fastened to a curved handle, and had wing-like additions on one or both sides, being either flanged or socketted, and so hammered as to keep the handle held firmly. Bronze, however, could never wholly supplant hard stone, and in the discoveries of the Bronze Age we find that stone implements still hold an important place.

The evolution of the bronze industry was quite different in the individual countries of Europe. The countries which lay nearest the starting point of metal culture and within easy reach of it, for instance Greece, Italy, Southern Austria and Southern France, had a short and early Bronze Age, which was brought to an abrupt end by the incoming Iron Age. Switzerland, on the contrary, had a long Bronze Age (known as the "Beautiful Bronze Age "), which attained to great perfection, iron being unknown. To this period belonged the pile dwellings of the "Grande Station," near the Lake of Geneva. We may add to this longer Bronze Age the whole of Middle and Northeri Europe, especially Denmark, Sweden and Great Britain. It is estimated that the Bronze Age in the first-named countries, Greece, Italy, \& Wibel: Kultur der Bronze-zeit, pp. 36-44. 
etc., lasted till about B.C. I000 ; in Switzerland and Hungary till B.C. 600 ; and in Northern Europe till B.C. 400.

\section{The Iron Age.}

The Iron Age, like the Bronze, probably had its rise in the East. It is supposed that it was first discovered and worked in that richly ferruginous district which extends between the Black Sea, the Caucasus and the Caspian Sea on the North, and the plains of Mesopotamia in the South. In very ancient times various peoples had settled there who became familiar with iron, among them the Chalybes, in Pontus, famed for their smithery, after whom the Greeks called steel "Chalybs." From its place of discovery in Western Asia, iron supplanted bronze as civilization moved onwards; it reached Egypt about B.C. I500 and Greece about B.C. Iooo. Later it found its way to the still barbarous peoples of the rest of Europe by way of Italy, South Austria, and up the Rhone to Gaul, finally penetrating as far as Scandinavia about the fourth century B.C.

The prehistoric Iron Age is divided into two sub-periods, the older of which is designated

\section{The Hallstatt Period,}

after the famous excavations at Salzberg, near Hallstatt in Salzkammergut. It spread over nearly all Europe, among the Greeks, Italians, Celts and Germanic races. It lasted the shortest time among the Greeks and Italians, because there it merged into the authenticated " historic Iron Age." Elsewhere in Europe the prehistoric Iron Age lasted until each country fell under the rule of Rome, and in these countries the Hallstatt period was succeeded by a second prehistoric Iron Age, the "La Tène" period. The Hallstatt period is characterized by a tendency towards show, and being overloaded with ornament; and also that bronze was employed with iron in various ways. This may be noted among the Homeric Greeks. The next period was called the

\section{La Tène Period,}

from a place particularly rich in discoveries near the village of Marin, north of Lake Neuchatel in Switzerland. 
The productions of this period are distinguished for simplicity and usefulness, and give scope for a far wider sphere in the working of iron than was the case in the Hallstatt age.

The La Tène culture was the work of the Celts, who in the last centuries B.C. had become masters of a wide domain, viz. Britain and Gaul, almost the whole of Central Europe and Northern Italy; the Upper Rhine and South Austria, and part of the Balkan Peninsula and had advanced as far as Galatia in Asia Minor. The power of the Celts finally received a check on the one side by the Germanic tribes, and on the other by the Romans, who had extended their empire over Gaul and the Alpine countries. This ended the "La Tène" Period, and at the same time the last prehistoric phase in Europe. Next followed the so-called Third or "Historic Iron Age," to which we have referred in a previous chapter.

\section{Summary.}

We have intentionally in the foregoing pages kept Palæontology separate from the other auxiliary sciences of Sociology, although we were thereby led into a certain amount of repetition which at first may seem superfluous; but our aim was to show the means by which the result's of our research have been gained. Comparing the results arrived at by the different tracks of the history of the development of the tool, Palæontology clearly confirms the view presented by Ethnology, that there have been three prehistoric periods-the stone, the bronze and the iron.

It is not merely that the uniformity of conclusions tallies on the whole, when we study the long extinct races shown us by Palæontology and the still living races which Ethnology brings before our eyes; but the resemblance in all essential points extends to the smallest details, and proves conclusively the correctness of Schiller's idea: that peoples who dwell around us on the various stages of culture are like children standing round an adult, and bring to his remembrance, through their condition, what he himself formerly was. ${ }^{x}$

Yet in one respect the two sciences differ: Ethnology is much richer in materials than Palæontology. Whilst we

s Schiller: Einführung in der Gesellschaftslehrer. 
could produce a parallel in Ethnology for every Palæontological phase, we have seen great gaps in Palæontology which are still waiting to be filled. Nevertheless these deficiencies are quite easily accounted for. Only a small part of the crust of the earth has up till now been accessible to archæological research, and whole regions of the earth which are quite the most important are not yet opened up. Further, the crust of the earth contains only an immeasurably small part of the life that has been enacted upon its surface, whilst all the rest has vanished, leaving no trace in the unresting metamorphosis of nature.

In one point Ethnology as well as Palæontology has left us groping in the dark. Up to the present time neither of these sciences has succeeded in throwing light on the "primeval stage of culture" in those earliest times of man's differentiation from the brutes. The lower hunters represent quite the lowest stage of culture which Ethnology and Palæontology are able to bring to our notice. Here we can expect nothing more from Ethnology; no scientist imagines that on the much explored surface of the globe any less developed race may be found surviving which could show us that condition which has so long passed away. As we now see nature folk die away before the peoples of civilization, so were all the lowest tribes exterminated by the stone weapons of those hunters who have themselves long since vanished from the earth. Here we can only hope for elucidation through Palæontology, for the crust of the earth is for the most part unknown to us, although its surface is so well explored. As long as these hopes are unrealized, the name of "primeval history," so often applied to the Palæontology of Man, is a misnomer, for we are at a standstill in our search for knowledge of all time previous to the discovery of fire, as we have endeavoured to show in an earlier treatise. ${ }^{\mathrm{I}}$

Further, Palæontology as well as Ethnology points out that the three stages-the Stone, Bronze and Iron Ageswere not always and everywhere passed through in this order. It is quite obvious that many peoples having iron at their disposal, and no copper, would be acquainted with iron before bronze; and others, again, lacking tin ore would have been familiar with pure copper instead of bronze, and

$$
\text { s See p. } 56 .
$$




\section{THE HISTORY OF SOCIAL DEVELOPMENT}

so on. In short, it is self-evident that various environments must have led to exceptions to the rule. It must be always borne in mind, however, that the three-stage system, " Stone, Bronze and Iron," put forward by the Danish scientist, Thomson, is justified and supported by facts, which is all that can reasonably be expected from a system. It was incidentally mentioned by Lucretius, and hinted at much earlier by Hesiod and in Chinese traditions. ${ }^{x}$ It must be noted, too, that philology suggests that the Indo-Germanic primitive people were of the Stone Age, and copper alone was known to them. They were equally ignorant of gold, silver and iron.2

The importance of palæontology to sociology is obviously not limited to the history of the evolution of the tool. The "Science of the Spade" shows much more, indeed, it proves almost universally that in all spheres of civilization a progressive development has taken place; it informs us that this evolution, as was stated in an earlier chapter on comparative ethnology, has passed through the three culture stages of Savagery, Barbarism and Civilization.

Concerning the relation of these culture stages to the technological stages of the Stone, Bronze and Iron Ages, a few words here may not be out of place. As we have studied two different classifications, and since we have measured the height of civilization first by the standard of food production, and secondly by the standard of technical evolution, the reader must certainly have wondered in what relation these two classifications stood to one another. The answer is briefly that, as a rule,

Savagery corresponds to the Palæolithic,
Barbarism " "
Civilization

IAccording to Lucretius, "the oldest weapons were the hands, nails and teeth, then stones and wrenched-off branches; later, iron and iron ore were worked, the use of iron ore being older than that of iron" (De natura rerum, v. 1282-85). Chinese annals relate that Fu-hi had made wooden weapons, his successors made such weapons from stone and later manufactured them from metals.

2 Schrader: Sprachvergleichung und Uvgeschichte, pp. 345, 514. 
This is the rule with numerous exceptions, some of which have already been mentioned.

If we consider these exceptions closely, it is quite apparent that they arise from outside influences on the race, such as sudden contact with a higher civilization and a transfer of ideas from it to themselves. For instance, those North American fisher folk, still on the stage of barbarism at the time of Captain Cook's first visit to them, were familiar with iron, owing their knowledge to their contact and proximity with Asia. Even more are we struck by the case of the Mountain Veddas who, although themselves lower hunters, practise simple barter with the Cingalese for iron arrowheads, axes, etc., so as to save themselves the work of manufacturing stone implements.

It is true that other nature folks have been familiar with metals when we cannot attribute the knowledge to a similar derivation. For instance, as we have alreadysaid, there were several North American hunting tribes who worked up the native copper with which nature had richly supplied them. This clearly is more the result of copper in their environment than a so-called Copper Age, for in the first place these people did not know how to smelt copper, but only how to hammer it ; and in the second place, the precious metal was used principally for ornament, and although widely disseminated, was still considered a luxury, and had not influenced their condition of culture, which remained that of the Stone Age.

The same may be said of those primitive races of Europe, Asia and Africa who learnt from other tribes how to work iron. It was only to outward appearance that they were in the Iron Age, for in reality they were at the level of the later Stone Age, and far below that of the ancient American civilizations, who were certainly only in the Bronze Age, but had attained to it, and ultimately to Civilization, by their own enterprise.

Speaking, then, only of those peoples among whom the knowledge of metal working developed as a gradually ripening fruit on their own tree of knowledge, we may truly say that Savagery corresponds to the older Stone Age, Barbarism to the more recent, and Civilization to the age of metals. What culture stage will be connected with the Machine Age 
no man can yet say, for this new form of culture is as yet in its infancy, and we see it growing slowly out of the earlier civilization without knowing what form it will finally take.

Lastly, if we review the evolution of technical science we may come to this conclusion about the origin of

\section{The Early Forms and Genealogy of the Tool.}

The first tools were objects taken directly from nature. All three materials from realms of nature-stone, vegetable and animal-were at hand.

I. A stone could be used in an unworked condition as a missile or to deal a hard blow. After using stone to break other objects, shells, nuts, etc., it was quite natural to break other stones with it, and so obtain a useful cutting edge. In this way originated the primitive instrument known as the coup de poing, which did duty as knife, saw, chisel, hammer, scraper, wedge and axe. It was soon noticed that a broad stone with a specially jagged edge was suitable for sawing, but not for cutting, scraping, etc., and that a very sharp pointed stone was the best for boring. When man learnt to appreciate and turn to account these varieties, the striking stone was formed through differentiation into all the above-mentioned tools in their simplest forms. The missiles, however, long remained just as nature formed them. We read that Homer's heroes were wont in battle to " sling the jagged stone of the region."

II. The implements provided by the vegetable kingdom were more varied from the beginning; people used boughs of trees, branches, shrubs, creepers, tree trunks, thorns, etc.

The bough of a tree served as a stick, either for beating, throwing or digging; later it was differentiated into club, spear, lever, oar, plough (even the Egyptian plough was simply a forked branch of a tree), and the blowpipe and bows and arrows. The invention of the bow is variously explained. Some maintain that it was derived from the drill which was used to kindle fire by means of a wooden stick revolving as swiftly as possible. Others consider that the musical sounds that can be evolved from a string stretched on a stick first excited attention, and that later 
the possibilities of the elastic spring were noticed. Travellers assert that negroes will pull at a single stretched string for hours at a time, never wearying of the sound. In Homer ${ }^{\mathrm{I}}$ it is said :

Like as one skilled in song and on the harp

Extends with ease the cord round a new peg

Twining the twisted sheep's gut well both ways;

So did with ease Ulysses stretch the bow :

He then assay'd the string with his right hand

Which sounded clear like to the swallow's notes.

It is possible that such an elementary joyousness of sound, which our cultured ears consider crude, may have led to the discovery of the bow. In any case drill borers, shooting bows, and all stringed musical instruments are near relations, little though the relationship may show at first sight.

Through the amalgamation of wood and stone in primitive tools-for instance, a stone implement inserted in a wooden handle-there arose that whole group of compound implements, the stone axe, stone club, stone hammer, etc. ; and from the stick the stone-headed spear and arrow.

The earliest wickerwork was made from the twigs of trees and shrubs and is similar to that made by apes. The orang-outang, for example, shows great skill in making itself a nest in the trees in a very short time simply by drawing twigs and small branches together and interweaving them. Through gradual differentiation this first basket work resulted in nets, slings and traps, woven vessels and baskets, and later, spinning and weaving. The woven basket enclosed in clay to make it fireproof led on to pottery.

The tree trunk has two qualities which make it the parent both of the ship and the carriage-it swims and it rolls.

The primitive ship is still found among the Hottentots, who travel on tree trunks in the water, steering them laboriously by hands and feet. Later on the trunk, hollowed out by burning, became a "dug-out," which was propelled by oars and a rudder. When men desired bigger ships,

s Odyssey, xxi 405 (EDGinton's trans.). 
ribs were joined together to make a larger vessel of the same shape as the dug-out, and covered with bark or skins.

The other manner in which the tree was burden-bearer was as a roller. It turns easily, and was used to propel over the ground heavy loads, which no doubt in the first place were other tree trunks. This roller fastened to the load was the first wagon. Wheel and axle were originally made out of one piece, and when the axle was made as a separate piece it was at first fastened to the wheels, which turned together with the axle. The Romans had such wagons, and on account of the tremendous noise they made they were called by the poets stridentia plaustra. ${ }^{x}$ Wheels with spokes and ships with ribs were later inventions, the spoked wheel being of later date than the wagon.

The discovery of the wheel has proved to be more pregnant with results than any other human invention, as it is the parent of that whole family of machines, by which, as Reuleaux says, "everything rolls on," and which at the end of the eighteenth century was to set in motion "the greatest revolution ever seen in the life of the human race."

III. The materials derived from the animal kingdom, important as they naturally are to hunting peoples, contributed more to the enrichment and perfection of the materials derived from the mineral and vegetable kingdom than to the invention of original forms; those implements which are completed by teeth, bones, horns, claws, etc., could have been finished just as well with wood or stone. Still, among other debts, man owed his first clothing to the skins of beasts, as well as leather bottles, pockets, sacks, etc., which must have been of great service in transporting his meagre possessions.

The prototypes to which the magnificent wealth of our present technical science is to be traced were extremely simple and scanty. At first only such objects were borrowed from nature as could be of use to man without any elaboration. From these more diversified tools resulted, while men ventured on improvements which became more and more elaborate for special purposes. Consider, for example, the course of development from the stick to the gun, from the tree trunk to the locomotive; from the bow to the piano,

s Schrader: Ling. hist. Forschungen über Handelsgesch., i. I9. 
etc. The most of these achievements were certainly not invented through special thought or conscious intention, still less through so-called "organ projection," as a popular theory suggests, ${ }^{\mathbf{I}}$ but they originated accidentally and then were improved and perfected from generation to generation as science has made research possible.

In the following table, which is to be read upwards, we will endeavour to illustrate the genealogical tree of some of the most important tools.

x According to the "organ projection" theory, man copied the organs of his own body for implements-the hammer from fist; pincers from teeth; stick as elongation of arm, etc. Putting on one side the fact that such ingenious currents of thought must lie very far from the consciousness and subconsciousness of primitive man, this theory would explain very few tools, and only lead to vexatious and improbable interpretations. 


\section{Preserved unchanged over a long period}

Sword, stone-headed axe, hammer, hatchet, spear, and arrow

\section{Differentiated implements of the various handicrafts}

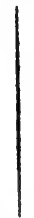

Organ

Combination of wood and stone
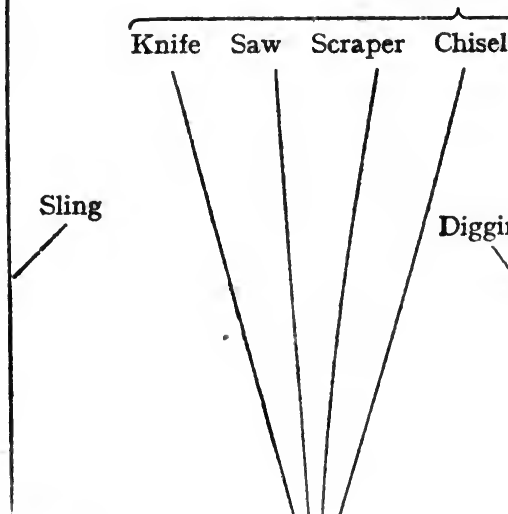

Throwing

Stone
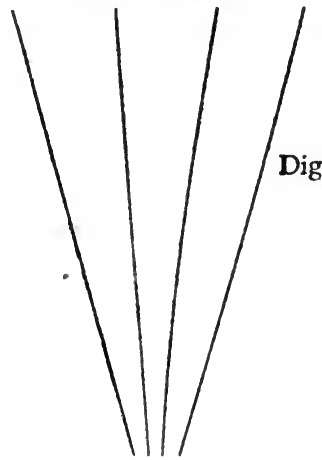


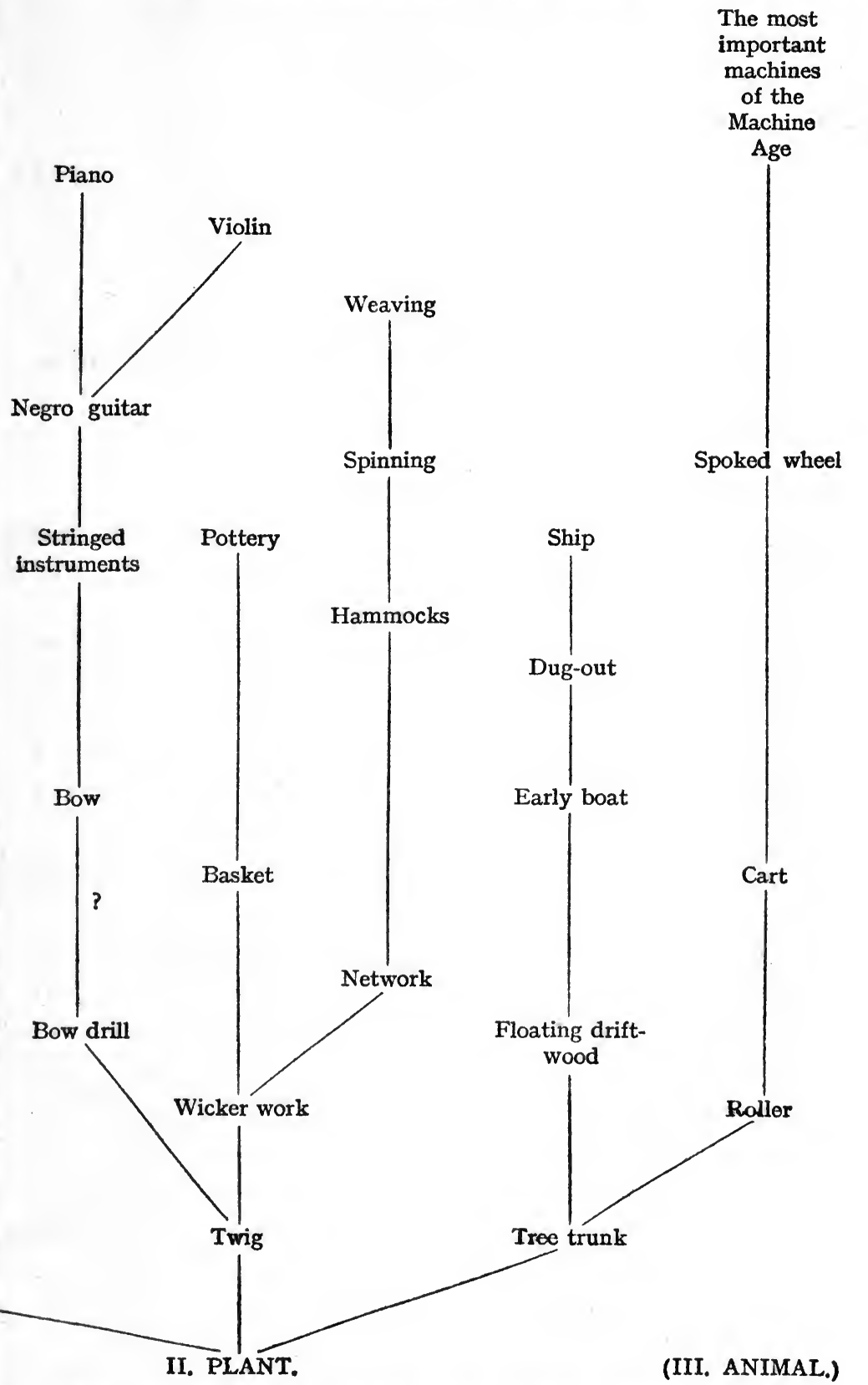

GENEALOGICAL TREE OF THE IMPI.EMENT. 


\section{HISTORY OF THE EVOLUTION OF CLOTHING}

\section{Epoch of Nakedness and Primitive Clothing.}

\section{NAKEDNESS.}

THIs natural and original condition of man still exists among many nature folk, especially in the torrid zone, where, moreover, nude man reaches a high stage of culture. Among the numerous tribes in this condition ${ }^{x}$ may be mentioned the Australians, among whom most of the tribes were quite unclothed in Cook's time and even later, and so are the Bushmen, the Andaman Islanders, and many Dyak races in the interior of Borneo, the inhabitants of the Marquesas Islands, New Hebrides, Easter Island, and many other Oceanians. At Geelvink Bay, in New Guinea, J. B. Meyer met with tribes without the slightest pretence of clothing (Globus, I874, p. I65).

The Eskimos put off all garments whilst in their underground dwellings. Nudity is widespread in tropical Africa. For the most part the Latukas, the Djurs, the Dinkas, the Bawe on the Zambesi, the inhabitants of Darfur and many other regions are naked. The Queen of the Balonda when she gave audience to Livingstone was absolutely naked, and the women of the Kissama negroes appeared at festivities in the same fashion. Among the American Indians many tribes wore no clothing, nor did the Brazilians, the old Caribs, Patachos-Botokuden, and the inhabitants of the Lesser Antilles. The Spaniards found the natives of

I Bibliographies in Lippert: Kulturgeschickte, I. 66 ff. WaitzGerland: Anthropol. der Naturvölker, I. 357. Peschel: Volkerkunde, I 74 ff. Lubbock: Origin of Civilization, 46. Westermarck: History of Human Marriage, 187, etc. 
the Bahama Islands and many tribes in Venezuela and Guiana without clothes. "Some Indians on the Orinoco were indeed ashamed of clothes, and refused on that account to wear them; however, it seemed to them particularly unbecoming to appear before strangers unpainted" (Waitz, i. 358, and also Fritsch "Clothing and Morality").

But there are also civilized peoples who have risen far above the nature stage, possessing considerable culture, a highly organized state of decorum, and great strictness of ceremonial etiquette, who continue in a state of nakedness. For example, the sculptures on the ancient temples of India represent nude men and women; and according to Ferguson, up to the Mahomedan conquest in India nudity did not in any way offend against the feelings of propriety there. ${ }^{\mathrm{I}}$

It was the same in the pictures and carvings of ancient Egypt. Indeed, the king appears there before the assembled people wearing a magnificent adornment on the head, and beyond that nothing but a loin cloth; the women of the highest rank were veiled in a garment of transparent material, serving as ornament and not as concealment of the person. The women servants and dancers were quite naked, except for a decorated perineal band. It was more especially in Egypt in remote antiquity that the gods shone forth in primitive nakedness: Ammon- $\mathrm{Ra}$ is a notable example of this. In Japan it is still the custom to receive visits in the afternoon from both sexes whilst in the bath.

\section{Primitive Clothing.}

In order rightly to understand primitive clothing, we must anticipate and take into consideration bodily ornaments. There are three motives which decide men to renounce their original nakedness and put on clothing-the need of protection, the desire for ornament, and in a much later stage the feeling of shame.

The feeling of " bodily shame " from nakedness is entirely unknown to primitive man; it only appeared later, as will be shown elsewhere, and was not the cause but rather a result of the habit of wearing clothes.

I Lubbock: Prehistoric Times, ii. 262. 


\section{THE HISTORY OF SOCIAL DEVELOPMENT}

Of the two other motives, we do not now consider that the need of clothes was the earlier one, but rather vanity and the desire for self-adornment. Hence it follows that in the lower culture stages ornament is of far more importance than clothing. The overweening vanity of the nature man places an exceptional value on bodily ornament, and he undergoes the greatest discomfort and pain to attain it. From every source within reach he loads his naked body with barbaric ornament and decoration. We find the painting and tattooing of the body very widespread, the latter operation needing often months and years of painful endurance. Again we see fabulous head-dresses, on which perfectly naked people set a great value-for example, the Nilotic negroes, who often make up their hair with a mixture of fat, ochre and cowdung into a stiff mass, which is arranged in most curious forms, resembling the trees in the gardens at Versailles. The hairdressing is an arrangement of much trouble, and has to be kept in order for months; so that it may not suffer, the wearers undergo the most astonishing discomfort, laying their heads at night on a low wooden stool, the so-called head-rest, and sleeping on their backs without moving.

The vanity of the nature man shrinks from no kind of bodily mutilation if it can be considered beautiful. The teeth are knocked out or filed like sharks' teeth, or blackened ; the head is pressed flat, the ears and lips are bored and are made enormously larger by means of increasingly thick wooden pegs being inserted; the septum of the nose, too, is bored and adorned by a transverse nose-pin or a nose-ring. Until quite recent times these barbaric mutilations have been retained among women, as is shown by the foot-binding of the Chinese women, and above all by the tight-lacing of European women, which presses the pelvis and the bust in an unnatural and crude way out of the lines of nature; this, of all bodily disfigurement, is the most injurious to health.

For personal adornment we find nature man decorated with everything nature offers that is bright-coloured or glittering. Ingenious head-dresses are made out of feathers ; stones, shells and teeth are strung together for necklaces. Perineal bands and girdles are brightly decorated, and rings 
for lips, ears, arms, nose, ankles and feet are often worn in great numbers. ${ }^{x}$

The Hottentot women wear strips of sheepskin round their legs, often as many as a hundred pieces, so that they can scarcely walk; the Herero women wear numerous iron rings on their legs and arms, as well as a leathern head-dress, which weighs as much as $20 \mathrm{lbs}$.

That the nature peoples in hot countries considered clothes simply as an ornament is evident from the fact that many of them, for example, the ancient Caribs, possessed clothes and yet generally went naked, and only adorned themselves therewith at festivals. The experience of travellers who have presented garments to savages confirms this ; the natives of Botany Bay hung the red quilts which had been given them on their heads. ${ }^{2}$ Cook tells the same tale; after presenting a shirt he next saw it arranged as a turban.

There are, however, in the lowest stage some races whose clothing is not for ornament, but for protection against the inclemency of the weather; for example, the Eskimos and all dwellers in the Arctic circle. But in the hot countries, which is where the human race originated, the desire for adornment is evidently older that that of protection as the object of clothing.

Having reached the stage when clothing is no longer subordinate to ornament, we find the first materials for it were taken directly from nature-first, skins simply thrown over the shoulders or girt round the hips; then plaited grass, leaves, bark and bast. On the same level of civilization as this primitive clothing was "smearing" with fat.

Fat clothing, which is so repugnant to us, seems to be

- The history of the ring shows us in which direction development is moving. Among nature folks we find the ring on all possible parts of the body: there are nose-rings, lip-rings, rings for neck, arms, legs, fingers and toes. In our epoch we have only retained rings for ears, arms and fingers. In recent decades the ear-ring has completely disappeared from masculine attire and almost disappeared from that of refined women, and seems almost as barbarous to us as the nose-ring did formerly. The bracelet or arm-ring is now worn only by women, the finger ring keeps in fashion most tenaciously. but is becoming more and more rare among men.

* Philipp. 
of very great antiquity. Ehrenberg says, "Cosmetics are older than clothing." Fat forms a very easily produced covering, protecting the body from cold and damp as well as from vermin; it makes the skin supple, and in no way hinders its activity. Colouring the body, so much admired by nature folk, becomes easy by means of it, since ochreearth, soot or other pigments may be mixed with the fat. Owing to this advantage, rubbing with fat or oil is in vogue all over the world where there are nature folk existing. In South Africa resinous oil is used. With the high-born Hellenes, the bath and anointing with olive oil were among the rites of hospitality. It is true that usually one cannot say much in praise of the cleanliness of those who are smeared with fat. The Galla rub their bodies with mutton fat, and they smell abominably. According to Livingstone, the Makololo women use water sparingly, rubbing themselves instead with butter melted. This certainly keeps away parasites, but it causes their clothes to smell most unpleasantly rancid. The Hottentots mix soot or ochre with their unguents. The Bushmen, who use a similar mixture, have a proverb, "Dirt warms." Their skin is often entirely encrusted.

\section{Epoch of Clothing from Manufactured Materials.}

A second epoch in the history of clothing begins with the invention of manufactured materials. Leather takes the first place; the North Americans make clothing from this which covers almost the entire body. Then follow the materials which are produced from the bast and bark of certain trees, by steeping and proper subsequent beating. In this manner is made the Tapa of the Oceanians, which is hammered out from the bark of the paper mulberry, and the Mbugu of the Negroes. The lintwât, whence later came the word linen, the most ancient type of clothing of the European Aryans, was prepared from the inner bark of lime-trees.

The second epoch is chiefly characterized by fabrics which were skilfully woven out of the fibres of plantscotton, flax, etc.-by means of the loom. Woven materials are found among most of the more advanced nature folk; 


\section{HISTORY OF THE EVOLUTION OF CLOTHING 137}

the Oceanians prepare their tissues from strips of bark, thus they weave without spinning. This is also seen among African tribes. The epoch-making influence of the loom first makes its appearance in history among those people who had reached the stage of the older civilizations. Among these peoples clothing of woven material was universally known. The long close-fitting coats of the Assyrians, the waistcloths of the Indians and Egyptians, the braccæ or breeches of the Medes and Persians, and finally the draped garments of the Greeks and Romans are too well known to need further description.

The characteristic qualities of these costumes of antiquity will be best evident if we compare them with the clothing of the third and last epoch.

\section{Epoch of Fashion.}

The third epoch cannot be sharply distinguished from the preceding one either in kind or in period. It was a slow transition which changed ancient into modern clothing.

If one compares British or Roman habiliments of the date of the first Empire with our own, it is apparent that the process that united these extremes must have been very gradual.

We find that modern dress is distinguished from the ancient principally by the four following particulars :

I. By its complexity.

2. By being much narrower; this is effected by tailors and dressmakers making clothes to fit the person. 3. By the continual change of "Fashion" to which it is subject, and which was quite unknown to the ancients.

4. By its universality; it embraces all civilized nations.

I. Let us now inquire how the complexity of modern dress was evolved. The costume of antiquity consisted of one garment (Chiton, Tunica), which was at once coat and shirt ; for outdoor wear was added a mantle (Himation, Toga), which was wrapped round, not drawn tightly; and for the feet a pair of sandals. And that was all. Trousers, stock- 


\section{THE HISTORY OF SOCIAL DEVELOPMENT}

ings, shirts, hat, etc., were for our robust ancestors either unknown or quite superfluous things.

New articles of clothing were from time to time added to these.

Trousers, which were at first separate garments for each leg, were not as once thought introduced by Germans to the Romans, but vice versa. The Romans had found leg coverings among the Gauls, Dacians, Pannonians, Sarmatians, etc. ${ }^{x}$ The Germans, therefore, received this article of dress, which was so well suited to their northern climate, partly from the Romans, in whose armies they served, and partly from the Gauls, who exercised an important influence in transmitting Roman civilization. As we mentioned above, the hose or trousers were originally two separate leggings, covering the whole lower limbs, over which the straps of the shoes were fastened: Charlemagne wore such hose. The shirt followed, but for a long time was only owned by the wealthy. In the thirteenth century the possessor of two shirts was considered unusually rich in underclothing, and throughout the Middle Ages ordinary folks were strangers to such luxury. During the first centuries of our era, head coverings were only worn on rare occasions, in the form of fillets, wreaths or diadems. It was only in the twelfth and thirteenth centuries that the hat came into general use.

Later, the number of articles of clothing was increased by extra undergarments, and by dividing the hose into trousers and stockings, and so on, finally reaching its present complexity and weighing many pounds. Tacitus, who praised the simplicity of the early Saxons with much eloquence when comparing it with the effeminacy of the Romans, would be horrified if he could see the present complexity.2

- See Falke, Kostümgesch., I10, I29.

2 What the ancients would have thought of our clothing can be judged from the following extract from the Cyropadia of Xenophon, viii. 8. I7, in which he says that one of the causes of the downfall of the Persian Empire was that their effeminate luxury was carried so far that in winter the Persian was not content to cover only head, body and feet, but that he even covered his arms and hands with leather gloves. 


\section{Modern Fitted Clothing.-At first the woven material} was worn very simply, either hanging as the skins had been, or loosely fastened round. The poncho of the American and the tunic and toga of antiquity, all of which developed from the shawl, were types beyond which ancient civilization did not go. Fitted clothes are quite a late invention which gradually came into vogue.

I. From the eleventh century dates the tendency to make the draped clothing somewhat scantier, so as to define the figure. This movement began with the ladies of high rank, who wore their clothing fitted to bosom and hips.

II. In the twelfth and thirteenth centuries the dress was cut away under the arms, and laced so that among women the bodice was tight-fitting. Wolfram von Eschenbach mentions figures like a wasp. ${ }^{\text {I }}$

III. The final step in arranging a close-fitting costume was taken in the fourteenth century. Clothes were made to open down the front and to be fastened by buttons, no longer being simply slipped over the head or hung round the shoulders. Now for the first time properly fitted garments came into vogue, and the modest contrivance which made this possible was the button.

3. Fashion.-Most characteristic of the last epoch is the continual change of fashion, which was a condition of affairs equally unknown to nature people and the Greeks and Romans. Formerly among all nations the costume was determined by climate, the products of the country and the customs of the people, and remained unchanged for centuries.

This period in which each country had its characteristic dress may be styled the era of national costumes. It exists still in the East among the Chinese, etc., and continued in Europe to the fall of the Roman Empire. From that time fashion's changes have ruled us, at first very gradually, changing only from century to century. From the fourteenth century onwards its changes have been much more rapid, until at the present time it varies not merely from year to year, but in some circles even from month to month. This compulsory uniformity of fashion, which I Falke; 159. 
serves neither for beauty nor usefulness, nor considers differences in individuals or climate, compels its followers to appear in similar guise in nearly every country of the world.

The chief cause of this phenomenon lies in the plutocratic character of society. The higher classes object to being copied by the lower. Two courses are open to them. By the first of these, they can wear materials, trinkets and jewels so costly as to be beyond the reach of those less wealthy, but this can only be taken on festive occasions, as too great a display of finery in ordinary life would be regarded as in bad taste. Therefore people have recourse to a more refined way, and change the fashions so quickly that the less wealthy, who must wear out their garments before buying new ones, are not able to keep up in the race and fall behind.

4. The disappearance of national costume is a fourth characteristic of our period. Even in the twelfth and thirteenth centuries there was uniformity of clothing among each nation of almost the whole of Christendom; to-day, Japanese and English, Norwegians and Italians have the same fashions forced upon them.

This uniformity of dress is the expression of the fact that all these nations have reached the same stage of civilization, and their culture has become uniform through the transmission and exchange of ideas and merchandise.

\section{Conclusion.}

A deep significance can be found even in matters of dress. Clothes may " make" some persons, but they cannot "make" mankind-on the contrary, it is mankind who evolves the clothes. As man reveals himself at his greatest and at his meanest in his gods, so does he reveal himself in his clothes. If we glance over the phases of dress from the standpoint of this thought, we shall find this truth confirmed throughout.

In the first epoch, the epoch of natural clothing, which might also be called tropical clothing, man is very near to nature conditions. His almost complete nudity is subordinated by savage ornamentation; and his incomparable 


\section{HISTORY OF THE EVOLUTION OF CLOTHING 141}

vanity, which is one of the most important of human passions, is as yet unrelieved by any refinement of taste.

In the second epoch, which we may briefly call that of national dress, civilization spread from the tropics to the temperate zone, and reached a considerable height in the East. A happy mixture of nature and culture was expressed in the noble simplicity of ancient dress, which was closely akin to natural clothing, but had discarded the barbaric glitter of ornaments.

In the third epoch, which brings us to fashionable dress, the North makes its influence more and more felt. Byzantine dress, which has been preserved up to the present day in the mass vestments of the Roman Catholic Church, is distinguished by its undraped stiffness: all exposure of the body is proscribed, to guard against the lusts of the flesh, thus the figure is concealed as much as possible. The richly stored intellect for which the Byzantines are proverbial was shrouded in the richly embroidered tortoise-like garment. In the age of the Minnesingers in the thirteenth and fourteenth centuries, when men discovered the spell of love, or, as one might say, when they rightly discovered woman and reverenced in her the highest ideal, the appearance of the knight was distinctly feminine-smooth face, long coat, long hair. The fourteenth and fifteenth centuries were times of the sharpest transition; refinements began to spread from the castles into the towns.

Confusion and corruption are bound to be associated with sudden changes, and at this time to the private quarrels with their deeds of violence was added the terror of the Plague. All this is reflected in the eccentric costumes known as the Beak, the Bell, and others.

With the Reformation a dress expressing dignity and gravity appeared, and a little later the rough adventurous soldiers of the Thirty Years' War added their own characteristics. In the seventeenth and eighteenth centuries, when French dress prevailed, a useless and effete aristocracy led the fashion, and the clothing was as shallow and vain as the wearers. When the storm wind of the Revolution swept away all this vainglorious rubbish, it was replaced by the costume of the present day, top hat, coat and trousers, which symbolically enough originated in America. The 
ungraceful and characterless dress of our own day, with its continual variation of fashion, in its turn reflects the commercial spirit of a plutocratic age which measures the worth of a man by his possessions, and expresses this standard by its costume so prominently I that the sense of beauty, usefulness, comfort and individuality is almost lost.

Hence every fresh human outlook brings forth a new type of clothing. This significant fact makes its study a much more important branch of the science of civilization than it would otherwise be. Our forerunners, the Cimbri for example, balanced their powerful naked bodies on their huge shields and went tobogganing over the snowdrifts and gliding over the slopes of the Alps into Italy, with shouts of joy. If we think of these unclad forerunners, and then of ourselves in our respectable complicated clothing, we see the difference in their thoughts and aspirations was as different to ours as was the costume, or lack of it. The extraordinary changefulness of man and his adaptability give well-founded expectation that our successors will rejoice in a nobler and more rational dress than that of the twentieth century. A rational dress ought, before everything else, to be individual. For this, however, a fresh era of society must arise, a society of free individuals who dare to wear a dress peculiar to themselves, apart from class and mass restrictions. Until then all criticism and dress reform is but labour lost.

To summarize: In the evolution of dress the three following phases are recognizable:

I. Natural or tropical. Characterized by nakedness, painting of the body, tattooing, ornamentation, mutilation ; further, by the employment of natural materials, skins, bast, leaves, grass and fat. This phase comprises the lowest nature folk.

II. National or sub-tropical dress. "L Characterized by the use of artifically produced, that is woven, stuffs, and further by the simplicity and durability of the clothing. This division includes the higher order of nature folk, and especially the highly civilized nations of antiquity. Out of this gradually evolves 


\section{HISTORY OF THE EVOLUTION OF CLOTHING 143}

III. The dress of fashion, or Northern dress. Characterized by its complexity, by its fitting to the figure, which is peculiar to this phase, by its constant change of fashion and by its universality. This includes the whole sphere of modern civilization. 


\section{THE EVOLUTION OF THE DWELling PLACE}

\section{Primitive Houselessness.}

WE still find many peoples in the primitive condition as regards their dwelling place: as there are people without clothes, so are there people without a home. For example, the Mountain Veddas have no dwellings--they usually spend their nights under a tree, or in the trees, ${ }^{\mathrm{x}}$ and inhabit the caves in the rainy season. The inhabitants of New South Wales live in the numerous caves to be found in their country, and a fire is kept burning before every inhabited cave. The Tasmanians used to sleep in hollow trees. The Bushmen, too, do not construct any dwelling place; they camp out in the open, only here and there erecting a wind shelter of branches, more as a protection for the fire than for themselves. Still more rarely, they drive piles into the earth and cover them with moss and twigs.

\section{Huts.}

The first constructed homes were pit dwellings and huts, the latter apparently evolved from the wind shelter. The hut of the Fuegan, for instance, is only a rather more elaborate wind shelter, which has taken the form of a hollowed mound with its opening towards the fire.

In the fertile regions of Australia, the natives have huts so small and low that only two or three persons " rolled together like hedgehogs," or huddled together for mutual warmth in sleep, can repose in them. Other Australians live in pit dwellings or weave huts, like beehives, out of 
branches, which are then covered with grass and earth. A few Australian races build large huts, which will contain as many as thirty persons; those, for example, on the banks of the Darling River.

The dwelling of the herdsman is a tent, consisting of a wooden framework covered with skins, hides or felt. Tents are so erected that they can easily be taken down at any time, carried elsewhere and re-erected. In the tents of the Mongols and Kirghiz there is often room for twenty or more people.

The huts of the lower Agriculturists are somewhat more durable. But even here we find the old nomadic ideas very prevalent; hence, among most Red Indians as well as among negroes, the huts last at longest for two or three years, and then fall into decay. True sedentariness had no place till the period of towns.

The huts of American Indians are mostly of a very simple description; the well-known wigwam was composed of poles erected in a circle and bent together at the top. The Algonquians and some other tribes covered them with the bark of trees, whilst the Sioux used buffalo hides.

The negro hut is mostly hive shaped, with pointed roof ; its wall is formed by two parallel rows of palisades, the space between being filled with earth. The huts of many tribes, the Mandingoes and others, have stone walls. The roof is thatched with straw, reeds, bamboo and leaves. The dwelling has neither window nor opening forr the smoke, which has to escape through the low door.

\section{The House.}

With increasing civilization the hut is supplanted by the house. Wooden houses, however, have been found even in the lower culture stage. The inhabitants of North America, for example, built great log houses from huge tree trunks, in which a great number of families dwelt together. The houses of the Iroquois, built of timber and covered with bark, were as much as 500 feet long. The early appearance of big houses is to be taken as an expression of the spirit of solidarity and communism which frequently inspires nature folk. 


\section{THE HISTORY OF SOCIAL DEVELOPMENT}

Moreover, the smaller dwellings of the Oceanians, which were built of timber and provided with carefully cut boarded partitions and mat curtains, and frequently containing several apartments, almost deserve the title of houses.

The house of wood was typical of the early Aryan culture. According to Weinhold, the Germans only built of wood, hence the connection of the words "bauen" = to build, and "baum" = tree. The houses were made roughly of tree trunks, which were not fitted together nor in any way elaborated. In winter they preferred pit dwellings, which were covered over with dung, the so-called "tunc." The women usually lived in these subterranean dwellings, which must have been more protective than comfortable, and it was there that the work of weaving was done. Wooden houses held their place, even in the towns, when mediaeval architecture was highly developed. Von Eicken, writing of the Middle Ages, says: "At the time when the castles of princes and nobles were dark, narrow, crooked and poorly furnished, and the houses of the burghers in even the largest and wealthiest towns were principally of wood and timber, covered with straw or shingles, the great Norman and Gothic cathedrals were erected among them. . . The houses of a mediaeval town lay at the feet of the mighty Cathedral like fragile and diminutive toys." 1 According to statistics, even in I8I6 nearly ten per cent. of all the buildings in Prussia had massive circular walls, and two-thirds of all the buildings were still thatched with straw or reeds. The wooden houses were the cause of the frequent conflagrations which raged in the Middle Ages, and this, with the constantly recurring feuds, epidemics, and dearth of food and water, kept the people in hopeless misery. In Silesia, for example, Henne am Rhyn tells us that between the years 1440 and I526 every second year on an average some town was wholly or in great measure destroyed by fire; almost every town suffered from fire many times in every century. ${ }^{2}$

Stone Dwellings.- Real architecture only begins with the use of stone. Its precursors are found in Europe in the cromlechs, dolmen, menhirs and other primitive stonework of the Neolithic Age. The building materials used in

s Von Eicken: Mittelalter, 536.

2 History of the Civilization of the German People, i. 316. 
countries where stone was not easy to be had were bricks. At first these were simply sun-dried clay, but later the bricks were burnt ; the mighty cities of the Assyrians and Babylonians were built of these. In mountainous regions Cyclopean walls were built from unhewn and roughly fitted quarry stones, to be succeeded later by hewn stones. Quite early in the history of stone dwellings there appear other architectural buildings, such as temples, monuments to the dead, aqueducts, amphitheatres, fortifications, towers, embankments to keep out floods, etc.

The erection of stone into perpendicular walls, and especially the roofing in stone, was at first a work of great difficulty, hence the tendency to pyramidal buildings. In order to get over the difficulty of roofing, the early builders laid the stones on one another so that each projected slightly inwards beyond the one below-this is the so-called false vaulting, practised, for example, by the ancient Mexicansor they formed a covering with huge flat stones as in Egypt, where suitable materials were at hand, or they retained the older roofing of timber work. For the solution of the problem vaulting had to be invented. This was certainly known to the Assyrians and Egyptians, as well as to the Incas, and even the Eskimos. It was, however, little used till it was disseminated by the Romans, who had probably learned it from the Etruscans, and then a new era of architecture began.

The further record of houses, their different varieties, and the development of their styles of building belong to the history of architecture, and will not be discussed here. We need only notice one very important sociological change which has taken place of recent years, this is the transition from the small private houses to the many storied flats. The importance of this fact can be dealt with later; here we must speak of dwellings in communities, the most important of which are villages and towns.

Villages and Torons.-In the lower culture stages we have found houses as well as huts, but the town is only evolved when men have arrived at the threshold of civilization.

The settlements of the nature folks serve as small strongholds. They are surrounded with palisades, earthworks and ditches as a protection against foes; or they are built 
on hill crests, or on piles in water, and even in trees. In Hawaii, strongholds have been built on mountain peaks, which are protected by walls of lava I8 to 20 feet thick, and are used as refuges by the people in times of danger.

The nearer we get to the higher stages of civilization the more do separate villages increase. Indeed, in many negro kingdoms we find towns. Thus King Mtesa in Uganda had two capitals, in which he resided alternately. Kukaua, the capital of Bornu, in Central Africa, had walls I4 feet thick, seven towers, and 60,000 inhabitants. Other towns in Bornu contained from I0,000 to 30,000 inhabitants. The population of Benin, which is surrounded by a deep moat 20 feet wide, runs to 80,000 ; that of Timbuctoo to 40,000 , of whom 10,000 are foreigners. However, this computation rests only on an estimate of the numbers, not a census. All negro towns are trading centres.

Among certain stages of civilization of the ancient Mexicans and Peruvians, in China and Japan, and among various peoples of antiquity we find a different condition; large towns were not mere trading centres, but took a leading place in the dissemination of knowledge.

A town is distinguished from a village by the number of individuals, and it is evident that so large a concourse of people can only live together when division of labour has reached a certain stage. Agriculturists and cattle rearers cannot concentrate themselves at one point in large numbers, since they would have to live too far from the scene of their labours. The town is the dwelling place more especially of merchants and artizans, as it is the home of specialized labour, and it becomes a commercial centre. The character of the town, whether as fortress or residence, market or pleasure resort, is naturally determined by locality and surroundings. It may be the headquarters of the army, which constitutes it a stronghold, so that in case of hostile attacks it becomes a protection to the whole country. It may be the resort of priests and scholars, who invest the locality of the great temples and of the national sanctuaries with the character of a religious centre. It may be the place of assembly of the rulers and higher authorities, through whom the town becomes a political centre. The town is the result of division of labour, and the two develop 
on parallel lines. The more extended the division of labour, the larger and more numerous the towns will become.

Since the town is the expression and result of division of labour, it is the cause of further ramifications of it, so that the contrast between town and country is always becoming more sharply defined. This contrast rests on the distinction between the functions peculiar to each. In point of fact all advances, all inventions and progress, whether it be in technics, science, art, literature, even husbandry itself, not to mention fashion in dress, emanate from the town.

The rural districts always remain conservative, avoiding sudden radical changes. Even in this twentieth century many of the inhabitants of out-of-the-way places are scarcely above the conditions characteristic of primitive husbandmen. ${ }^{\mathrm{r}}$

But by its very immovability the rural district ensures that development shall not be too hasty and violent, but move at a reasonable pace, that being conducive and essential to real progress. For civilization is a fragile thing. If it is driven too rapidly along its course it is thrown back in the race, or even collapses altogether.

The foregoing brief sketch indicates the phases in the history of the dwelling.

I. Primitive houselessness. Camping in the open or under trees, in caves and pit dwellings, in the shelter of wind screens, and in the simple leafy enclosures derived from them.

II. Huts.

Huts, tents, and large block houses; villages.

III. Houses. The town.

(a) Wooden houses. (b) Stone houses.

I. Houses for single families.

2. Flats.

I The stability of the country as contrasted with the ever-changing town is well illustrated in the famous work on Colonization by Meitzen. He says: "In every village we are walking in some degree among the ruins of a former age; indeed, among ruins which for antiquity leave the romantic ruins of mediæval towns and city walls far behind. At every step, everywhere, in farm and field, we may meet with traces of the oldest foundations, and the map of the estate is a kind of special document which enables us to read, as in hieroglyphics, the ideas and purposes of the founders." The interpretation of these hieroglyphics is the great service Meitzen has rendered us. 

BOOK III

\section{ON THE HISTORY OF THE EVOLUTION OF LABOUR}





\section{INTRODUCTION}

"THERE are many mighty things, but there is nothing more mighty than man." Modern science expresses itself somewhat more modestly. It is not merely to his individual strength that man owes his power and superiority over the brute creation and over Nature, but in a far higher degree to an organized collaboration with his equals. The harmonious confederation of the many, the linking together of elementary forms into an organism of higher order, has led finally to a world-wide system of co-operating forces.

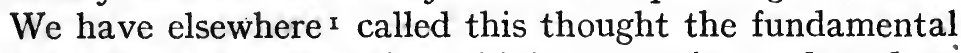
truth of sociology, and this will be strongly confirmed as we consider the evolution of labour. Human labour gains its power so much through the co-operation of individuals that we may say that the history of labour is the history of co-operation, and that this is increasing intensively and extensively.

By means of co-operation work is accomplished which would be utterly impossible to the individual. There are two kinds of collaboration which depend upon the nature of the task, which may be either too strenuous or else too complicated for the individual.

I. If the labour is too strenuous, many unite in performing the same or similar activities; for example, when many roll a tree trunk which is too heavy for the individual they work together in simple co-operation.

2. If the task be too complicated then another principle of union comes into play-complex division of labour or specialization. This leads to differentiation, in which the different individuals devote themselves more or less exclusively to their various callings, and thereby gain a greater 


\section{THE HISTORY OF SOCIAL DEVELOPMENT}

dexterity; this is exemplified by shipbuilding, shoemaking, violin playing, etc.

It may appear at first sight as if in complex division of labour or differentiation there were no special principle of combined effort; the shoemaker and the boatbuilder work separately and without concerning themselves in any way with the work of the other. And yet the differentiated workman only apparently works as an isolated man. For while the shoemaker sits at his bench, others plant his wheat for him, grind his corn, bake his bread, prepare his tools, tend the animals from whose skin yet others prepare his leather, and so on. In fact, all of these collaborate with him indirectly, with the result that the work is done in a more effectual and competent manner than he could possibly accomplish alone.

Hence co-operation and differentiation are absolutely essential principles, and up to the present man has not been able to devise any ideas that will take their place or improve on them. For when individuals unite in order to assist each other by their specialized activities, as when, for example, the carpenter, the bricklayer and the tiler unite in the building of a house, they do it by means of a union of co-operation and differentiation. 


\section{THE STRUCTURE OF THE ORGANIZATION OF LABOUR}

A GROUP of men who work together either in single or complex co-operation, or both combined, may be defined as possessing organization of labour in contra-distinction to the labour of Isolated Man. The groups may assume the most varied forms of organization according to their size, that is as they include few or many individuals and according to the nature of their union. We will now consider these separately.

The evolution of organized labour is now proceeding in such a way that new forms of it are continually appearing and new phases are arising to which the old forms must adapt themselves. We will follow step by step this interesting development of organized labour from its lowest stage, the hordes, in which man is wholly dependent upon the caprices of Nature, up to international commerce, on which stage he has learnt to rule the world. In order to do this more clearly we will intentionally ignore for a time the causes which led to this development and concentrate our attention exclusively upon the description of the forms themselves. Later, when we have defined its progress morphologically, we will devote a special chapter to its underlying causes. ${ }^{I}$

\section{THE FIRST OR EARLY KINSHIP PHASE.}

\section{Organization of Labour in the Selfasufficing Horde or Clan.}

On the lowest stage of culture known to us man lives in small hordes or clans, the members of which are bound together by common extraction and ties of blood. These 
groups look upon every one who stands within their circle as a comrade, and on every one outside as a stranger or enemy. They consider vengeance for an offence to one of their number to be a common duty; they live in continual strife with neighbouring hordes; in short, they carry on the struggle for existence in united solidarity.

But the solidarity of the horde is not confined to external relations such as war, which is the nursery of public spirit ; it extends also to peaceful activities, hence it leads to economic union and organization of labour. Between them the members of the horde accomplish work which would be too severe or too unprofitable for the individual. In hunting they send out beaters to track out the game and to concentrate it in a small space; they unite in attacking the larger beasts of prey; they fish together; they co-operate in order to fell trees and to dig great pitfalls for wild beasts; they kindle fire by friction; they help each other in the preparation of long fish nets and in the building of boats, huts, etc.

Together with the communism of labour found especially among peoples having clan organization, there is a mutual possession of goods-a kind of communism of food. Universal hospitality prevails among these savages; any man can sit down at his neighbour's table, and in times of famine everything they have is divided equally among them all. With most of the surviving hunter and fisher folks the prey belongs to the community, and among many, such as Australians and Eskimos, the quarry is divided according to rigid laws. Generosity is considered as second only to bravery, whilst a neglect to share abundance with comrades is regarded almost as theft.

The hospitality of nature peoples has often astonished civilized travellers. It is practised even by those who are themselves in need; for example, when the emaciated inhabitants of Easter Island ungrudgingly invited Cook's companions to share their poverty-stricken meal. ${ }^{x}$ Among the Fuegians, according to Darwin, even a piece of cloth that is given to one is torn to pieces and divided, that no man may be richer than his neighbour. ${ }^{2}$ Among the Indians

I Forster: A Voyage Round the World, ii. 218.

2 Darwin: Zoology of the Voyage of the Beagle. 
hospitality was carried to an exaggerated extent, the idle remaining as guests with the industrious, and so sloth was often encouraged at the expense of industry. In Africa the universal custom obtains of sharing the meal with all who come to it. ${ }^{2}$ This custom is still conscientiously observed by the peasant population of Italy and many parts of Germany.

When we add that the ground and soil of the country inhabited by the horde or clan is also considered common property, we see, among primitive races; a far reaching communism. It would, however, be an error to think that primitive man was lacking in a sense of personal possession. Weapons, tools, household implements, ornaments, etc., which are the product of individual labour-and at this stage of culture great scope is allowed to individual production-count so much as personal property that it is not even bequeathed, but accompanies the dead possessor into his grave. In all cases the horde or clan, even at the lowest culture stage represents a comparatively powerful organization which stands and works together both in war and peace. 3

But even in the clan which is the lowest stage of culture known to us there is found a second form of organization of labour; that is the Family, the strong tie which binds together a man, his wife and their children. The family is not only a social, but also and above all an economic creation which rests on the division of labour between man and wife, on differentiation of work according to sex. The husband is a warrior and hunter, and makes the arms and tools necessary to these occupations; the wife builds the hut, keeps up the fire, prepares the food, looks after the smaller children, and has to take upon herself almost all the more difficult and arduous work. Thus, as will be fully explained later in a chapter on the "Phases of Differentiation," labour is divided between the sexes into specialized

I Loskiel : Mission der evangelischen Brüden, p. 85 .

2 Livingstone: Missionary Travels and Researches in South Africa, ii. 234 .

3 Refer to Bücher : Development of National Economy, 4th edition, p. $73 \mathrm{ff}$. Schurtz: Outlines of the History of the Evolution of Wealth, p. ro. Waitz-Gerland: Anthropology of Nature Peoples ii 89, 70, 165, etc. 
male and female labour, and since all division of labour is only possible if the specialized agents work harmoniously, man and woman must mutually supplement each other. Primitive marriage is simply the expression of this economic union.

The family is a part of the clan, and the clan or horde itself produces everything that it needs. We might therefore speak of a self-sufficing clan, although not yet of self-sufficing families; for this, as we shall see, was a later phenomenon.

As has been said before, we find on the lowest culture stage two forms of organization of labour-(I) the union of the whole horde or clan with its communism of labour, food and soil; (2) the union of the family, with the division of labour between the sexes.

Which of these two organizations is the older cannot be stated with any certainty. As we shall see later, it is probable that in the earliest times the horde organization alone existed, and that the family, presenting an early form of differentiation, arose later. But in any case, the peoples who represented such a primeval organization have vanished and are unknown.

\section{THE SECOND OR HIGH KINSHIP PHASE.}

\section{Clan Organization with "Foreign" Trade.}

As we have just seen, the two oldest forms of organization of labour were the clan and the family, which are at the same time the oldest forms of social units known to sociology. The clan produces within itself everything which is in general demand among the members.

The next step on the long road from self-sufficing clans to interdependent nations, from individual production to world-wide administration, is brought about when neighbouring tribes come into contact with one another and exchange the products of their land. In addition to the first two forms of organization, the family and the clan, there now comes a third and extended organization of labour, i.e. division of labour and commerce between neighbouring tribes, which for brevity's sake we will designate " Foreign" trade. That in fact this extended division of labour (extended 
differentiation) is more ancient than the differentiation of callings within the tribe (restricted differentiation) is made quite evident by comparative Ethnology. Nearly all races as yet unacquainted with division of labour, such as most of the hunter or pastoral peoples, agriculturists of the lowest stage, Indians, Papuans, etc., already possess this intertribal intercourse which is only lacking among the all but extinct representatives of our first phase, viz. a few hordes in Australia, the interior of Borneo and the Terra del Fuegians. Captain Cook says of the Australian races which he visited in 1770: "We were unable to carry on trade with them. They accepted the things we gave them, but never seemed to understand our signs that we wished for something in return." And Dampier tells of them: "They had no notion of trade; all the signs we made to them were no good, they remained stock-still, grinning like monkeys and staring at one another." According to Bock, certain races in the interior of Borneo behaved in the same way; " they were accustomed to obtain any object they desired by force, even by murder if necessary."

\section{Forms of Primitive Barter.}

We will now inquire into the interchange of objects between nature peoples who have reached the second phase. One of the oldest forms is

I. The So-called Dumb Barter. - This was known to Herodotus, who relates of the Carthagenians visiting the West African coasts that " when they arrive among these people and have unloaded their merchandise, they set it in order on the shore, go on board their ships, and make a great smoke; that the inhabitants, seeing the smoke, come down to the sea, and then deposit gold in exchange for the merchandise, and withdraw to some distance from the merchandise; that the Carthagenians then, going ashore, examined the gold, and if the quantity seemed sufficient for the merchandise they take it up and sail away; but if it is not sufficient, they go on board their ships again and wait; the natives then approach and deposit more gold,

x Bock: Among the Cannibals of Borneo, p. I86. 
until they have satisfied them. Neither party ever wrongs the other, for they do not touch the gold before it is made adequate to the value of the merchandise, nor do the natives touch the merchandise before the other party has taken the gold." I

As a matter of fact, this kind of barter is still practised after all these centuries in West Africa on the Niger, and is found in various parts of the world. ${ }^{2}$ The whole trading is carried on at a distance and without a word being exchanged ; this is typical of the primitive mistrust and hostility which existed between alien hordes. Trading is well known to have been of great value in the progress of civilization, as it brings the peoples together on a peaceful footing. A second form of primitive trade exhibits a more conciliatory outlook.

2. Barter by Means of the So-called Guest Gift.-A clear picture of this method of procedure is given by $\mathrm{K}$. von den Steinen in his famous work, Among the Nature Folks of Central Brazil.3 There existed there, he says, an old form of barter which indeed was a necessity, since certain materials, for example stones suitable for axes, were only found in definite regions. Thus certain specialized objects of barter were exchanged between the separate tribes-the Bakairi had as a speciality necklaces of square pieces of white shell, as well as cotton yarn and hammocks; the Nahuqua had pumpkins, as well as chains of red shells and tukum beads; the Mehinaku and related tribes had fine cotton yarn and pottery; the Trumai and Suya had stone hatchets and tobacco.4 These products were passed on from tribe to tribe, and were exchanged in the following way as guest gifts: "The traveller brought certain goods with him, and if he were hospitably entertained he presented some to his hosts, making known what he would like in exchange. $\mathrm{He}$ received a small quantity of the desired equivalent on his

x Herodotus, iv. I96 (CARy's Trans.).

2 See the bibliography in Kulischer: Jahrbuch f. Nat. Ök. iii. I8, p. 321. Schurtz: Das afrikan. Gewerbe, p. I22. Schrader: Linguist.histor. Forschungen über Handelsgesch. i. I I.

3 P. 333.

4 Sir E. im Thurn speaks of similar conditions in his book Among the Indians of Guiana, p. $27 \mathrm{I}$. 
arrival and the balance when he left. In Maigeri we experienced a typical example of their methods when we took leave of our hosts. We were made to sit down and then received a basketful of meal. For this reason the Bakairi translate the Portuguese 'comprar' = to buy by 'yakadile' $=$ to sit down. Commerce is thus apparently an interchange of guest gifts. It is not in reality an indication of the generous disposition of the nature man, but has been developed in the early stages of civilization. The American Indian does not show large hospitality and feel highly honoured and grateful to a visitor for coming to consume his 'cakes and ale,' or rather his 'bejus' and strong drink. He wants his quid pro quo, and if the guest stays with the idea of living cheaply, his host soon becomes impatient and frankly requests him to leave the encampment .. t the never ending discussions as to whether such and such a tribe were ' $k$ ura'= good, that is liberal, showed plainly that true hospitality was their least defect. Our practical and business-like fashion of exchanging directly object for object was altogether a new idea to all these races at first. They learnt quickly, however, with many comical incidents as they learnt. One man picked up a handful of pebbles and fiercely demanded a big knife for it; another wanted some beads because we had bound up a wounded hand for him."

On analysis the guest gift is clearly not a gift as a rule, but a primitive and rough form of barter. It appeared as a gift later on when they had advanced to a higher form of trade, and the gift was preserved as a ceremony of hospitality, when the true sense of it had been lost. Homer tells us, for instance, "But now Zeus son of Kronos took from Glaukos his wits in that he made exchange with Diomedes, Tydeus' son, of golden armour for bronze, the price of five score oxen for the price of nine" (Andrew Lang's translation, Iliad, VI. 1. 232).

3. A more progressive form of barter is provided by the establishment of markets. Among many nature folks a custom exists of leaving a more or less wide zone on the border of their territory unoccupied for the avoidance of disputes. In these neutral spaces, which are often in the midst of the primeval forests, markets or fairs are held at 
fixed periods, and the products of the neighbouring tribes are exchanged. Thus North American Indians had a big market on the Mississippi. "At this spot all met together for trading purposes and a truce from all hostile action among the tribes was enforced."' I Such markets have been found almost everywhere among the higher stages of nature folk in America, Polynesia, Africa and ancient Europe, and led in a later stage of culture to the establishment of market towns.

Among all these forms of primitive barter business is effected simply by a direct exchange of the various goods. On this stage there is no money, no medium of exchange: moreover, every one is at once buyer and seller. According to Schrader" the German words " kaufen = to buy, ver kaufen, to sell; tauschen = to exchange, and täuschen, to deceive," were originally very intimately connected, since commerce and fraud were often connected and buyers were also sellers. There was no special class of traders, in fact, no specialization at all, every one baing his own tradesman as well as his own armourer, butcher, tailor and hairdresser.

\section{$\begin{array}{ccc}* & * & * \\ \text { ThE CLAN AND FAMILY ON } & \text { ThIS Stage. }\end{array}$}

It is obvious that the "foreign" trade described above plays a comparatively small part in the primitive economic life of these tribes. It takes place spasmodically and need hardly be considered as an essential part of production. Alike among the higher hunters, the pastoral people and the lower agriculturists, the clan and the family are the most important form of the organization of labour. The clan attained to its greatest importance on the lowest stage of agriculture, as among the Indians and Malays. In all places agriculture was originally carried on in common. The ground was tilled by united labour, and the products shared according to the needs of the separate members. Cultivation of the land requires combined forces, and as the clan settled down from nomadic life it became more

x Klemm: Allgem. Kulturgeschichte, ii. 133.

2 Schrader: Handelgesch., i. 89. 
closely united, as in addition to the bond of relationship it had that of joint agricultural labour. The organization of the clan is in certain cases so strong that, as we shall see later, it leads to an actual weakening of family ties, yet the latter remains the most important form of organization of labour after that of the clan.

We have thus found that in our second or high clan phase the organization of labour was composed of the following forms or elements :

I. Clanship, which reaches its zenith at the lowest stage of agriculture.

2. The division of labour between members of the family.

3. "Foreign" trade, i.e. division of labour and barter between neighbouring tribes.

\section{THIRD OR EARLY INDUSTRIAL PHASE.}

\section{The Administration of Farms and Villages among Semi-Civilized Peoples.}

Amiong the peoples we have hitherto studied all men were equal, socially as well as economically; as yet there were no masters and no bondsmen, no rich and no poor, and at the same time no special vocations and no division of labour beyond that of the sexes.

If we now proceed from these hunters and pastoral people and hunters with hoe culture to the Oceanian and African agriculturists, the scene changes. Social inequality appears, and with it economic differentiation, i.e. men take up specialized callings.

For instance, as soon as agriculture has led to a sedentary life it becomes quite clear that it would be more advantageous to enslave prisoners taken in war and make them work for their captors than to kill them and possibly eat them. This leads to social differences, followed shortly by economic differences; for the masters take up the easy and pleasant occupations, leaving the rough and thankless tasks to their bondsmen. We will now examine the new phase of organization of labour brought about by this process of differ- 


\section{THE HISTORY OF SOCIAL DEVELOPMENT}

entiation, first as it appears in Polynesia, and then in its African form.

\section{A. Organization of Labour in Polynesia.:}

\section{Authoritarian Joint Households.}

Throughout Polynesia, society is divided into three classes $-\mathrm{r}$. the nobles, who are the governing classes; 2 . free men; 3. slaves, who are prisoners of war. The nobles possess large estates which are worked by slaves. Among this third or early industrial class there is division of labour which is carried to such an extent that all the needs of the joint household are supplied by its own activities; even the free men are enrolled as menbers and are dependent on the proprietor. On the estate of a Polynesian noble there are field labourers, fishers, boat builders, carpenters, thatchers, net makers, wood cutters, domestic servants, cooks ; as well as women who weave and sew, and musicians and dancers.

In these large establishments, in addition to the former division of labour between the sexes there now appears. differentiation among the men, each of whom works at one specialized calling to satisfy the demand on that particular estate. The whole self-sufficing organization providing for its own wants is an economic continuation of the smaller family household. It has been developed from it by the enrolling of unfree differentiated labour, and soon brings in a new form of the organization of labour which is of great importance in its history. It is found in a more advanced stage in the Latifundia, the large pastoral estates of the Romans, and in the manorial system of the Middle Ages.

\section{FREE HANDICRAFTS.}

Beyond the differentiation among the un-free members of the large establishments in Polynesia, there are free artisans who have probably risen from slavery to freedom. Their work is of the same nature as that of the slaves, but

x Sartorius von Waltershausen : Ztschr. f. Sozial. und Wirtschaftsgesch., 1896, iv. B. p. I. 
they may hire themselves to anyone who is willing to pay their wages.

We find, then, two new forms of organization in Polynesia :

I. Authoritarian joint households, the large establishments of the nobles, with the differentiated un-free labour.

2. The free handicrafts.

These two elements, added to those already described, compose the third phase of organization of labour. But in the meantime the earlier condition of clan, family and "foreign" trading has not remained stationary.

\section{Clan and Village Communities.}

Among most of the peoples on this stage, clanship has already declined; the community is no longer arranged on the principle of consanguinity, but it is ruled by a superior lord.x Many clans have banded themselves into a village community; many village communities have unitedd into a tribe under a chief or king; and the village communities or tribal unions, the precursors of the future state, have taken from the clan its most important functions. Nevertheless the old communistic clan spirit often survived in the villages. We shall speak later of the "Andreia" of the Cretans and the "Syssitia" of the Spartans-both being forms of community of food in ancient Greece which were almost universally practised. ${ }^{2}$ It was only with the introduction of money that these ancient customs gradually disappeared.

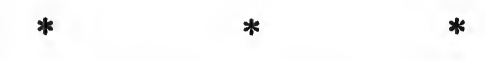

\section{The Family.}

In the previous phase, i.e. on the lower stage of agriculture, the clan reached its high-water mark, indeed frequently encroaching on the rights of the family. After

s See the third volume in this series-The Development of Social Organization (Introduction).

2 Büchsenschütz: Besitz und Evwerb., p. 29. 


\section{THE HISTORY OF SOCIAL DEVELOPMENT}

the zenith of the clan came the zenith of the family. The newly arisen state being at first insufficiently strong to act as an economic power, the declining clan transmits all its economic functions to the family. This has therefore not only to preserve its former position and enlarge the claims of the higher culture, but also to undertake the administration of this economic inheritance. Thus the family was the most important form of organization of this and the following phases, and this supremacy lasted over a long period. The powerful manors of this phase are no other than the extended families, and like them they are almost self-sufficing. The means of existence were agriculture, cattle rearing and fishing; the members built their own simple dwellings, and made their own household and cooking utensils, bows, arrows, spears, combs, mats, baskets, etc. Only a few industries of a highly specialized nature, such as tattooing, shaving, rigging of ships and medical aid, were carried out by those outside the household staff, and for this either free artisans or differentiated slaves were hired by the nobles.

Rarer and more luxurious needs were supplied by foreign trade. This was facilitated by overseas traffic, which, as the regularly held markets show, was not negligible, but yet remained comparatively unimportant since trade was still carried on by means of barter. Therefore this stage too is self-sufficing; production for export is the exception, and the most important form of organization is the family.

If we now glance over the organization of labour in this early industrial phase, which may be called the administration of farms and villages, we find the following facts:

r. The clan has fallen into decay. Its successors are on one side the village community and the tribal union, and on the other side the family.

2. The family is the most noteworthy form of this stage.

3. Foreign trade is as yet of comparatively small importance. 
4. In the authoritarian joint households and

5. The free artisans we find the beginnings of specialized labour among men.

\section{B. The Organization of Labour in Africa.}

The same elements as in Polynesia are to be found in Africa, but they are in quite different proportions.

\section{Clan and Village Communities.}

Among African agriculturists society is differentiated into the three classes of nobles, freemen and slaves. Clan existence is on the verge of decay. The clans are combined into village communities, and the communities into a tribal union which is presided over by the chief or king, and a council composed of the elders of the clan. To this new political body the clan has abrogated its political functions, while its economic functions for the most part have been taken over by

\section{The Family.}

In Africa, as in Polynesia, this is the most important form of organization. Tillage, corn grinding, baking, weaving, sewing, painting, brewing, pottery making are understood and carried on by each household, so that most of the needs of the family are supplied by itself. Speaking generally, the lion's share of the work falls to the women. ${ }^{\mathrm{I}}$

\section{3. "Foreign Trade" or External Organization OF LABOUR.}

In Africa this has had a peculiar and characteristic development and has led to inter-tribal trade, due to whole villages or tribes devoting themselves more or less exclusively to specialized work and local industries. Among the Marotse, for example, one tribe makes boats and oars, another lances, while a third is occupied with fishing. The separate tribes have become Guilds, and bear the names of their respective handicrafts ; for example, the smiths, the fishers, etc., which by degrees have become tribal names. There are whole

- Schurtz: Das Afrikanische Gewerbb, pp. 29, 66. Bücher: Entstehung der Volkswirtsch, 4 aufl. S. 68 ff. 


\section{THE HISTORY OF SOCIAL DEVELOPMENT}

tribes engaged in the same trade, such as the Jolofs, who are smiths, like the Balongo in Usindya, whose villages lie in a ferruginous district; there are salt villages and labour colonies, where the inhabitants are employed almost exclusively in making pottery, and armour, boat building, tannery, in the preparation of palm wine or of leather ; in the production of trimmed garments and in hunting or fishing. One finds, too, but quite as exceptions, the pariahs who, like our gipsies, make a precarious living by wandering among the sedentary population as wizards, fortune tellers, singers, menders of pots, quack doctors, etc. The intercourse between different tribes is facilitated by numerous markets.

\section{Authoritarian Joint Households.}

This, with its differentiated slave labour, is a less important element of African labour organization. On the estates of the negro princes the most skilful artisans, such as smiths, gold and silver workers, brewers, cooks and musicians, are maintained : indeed, in the palace of the King of Dahomey there is the wholesale manufacture of pots, pipes, clothes and mats, the production of which he has monopolized.

But these are exceptions. In general, in Nigritian Africa, according to the exhaustive researches of Schurtz, slavery has very little to do with the development of trade. It is always the free men who carry on trade as a professionslaves are chiefly employed in agriculture and in the manufacture of raw material, so that the middle classes are free to carry on trade, whilst the wealthy folk avoid all kinds of work.

\section{Free Industries.}

This plays in Africa a far more important part than in Polynesia. The typical African negro ${ }^{1}$ does not hold manual labour in contempt; he is glad to increase his income by his industry. Amongst the trades carried on by the free artisans the most widely spread is that of the smith, often an alien, who is both despised and feared. Besides this there are carpenters, joiners, wood cutters, ivory cutters, boat builders, tanners, leather workers, shoemakers, butchers,

s Schurtz, i. p. I4I. 
barbers--these latter introduced with Mohammedanismsingers, dancers, basket makers, etc. It is more unusual to find tailors and builders, as the members of each family carry on these occupations for themselves. These handicrafts are frequently passed on from father to son, and these hereditary occupations contain the unmistakable germs of the caste system.

This brief synopsis, taken chiefly from the excellent work of Schurtz on African handicrafts, has thus given us the following analysis of African organization of labour :

I. The clan has given place to the tribal union and the village community; the latter is still the more important, as many industries can be carried on in it in common.

2. The family is the most powerful organization, and has to supply most of the needs of its members.

3. "Foreign trade" or external organization of labour is of appreciable importance and is especially characteristic of the development of inter-tribal trade in Africa.

4. Authoritarian joint households are not very important.

5. The free artisans are to be considered as a valuable element of this organization.

We have now seen two types of the early industrial phase-the Polynesian, which may be described more as an administration of farms, and the African, which is rather the administration of villages. Hence we have seen that the specialized labour and economic differentiation has sprung from a three-fold root:
I. From slavery.
2. From free artisans.
3. From inter-tribal trade.

In Polynesia unfree labour prevails, but in Africa the free artisans are the more important. Which of these two types will predominate in the future? We shall soon show that antiquity grew and widened more on the Polynesian 
lines, and the Middle Ages more on the lines of freedom. Yet with regard to labour organization the Polynesian on the whole is much more to be considered our cultural ancestor than is the African.

\section{FOURTH OR HIGH INDUSTRIAL PHASE.}

\section{Industrial Organization as developed among Civilized Peoples. Town Economy.}

We will now consider the development of the organization of labour among the Greeks and Romans. From an economic standpoint the development of these peoples may be divided into two phases:

I. The earlier, as a fourth phase, which is a direct continuation of the Polynesian organization, and differs from it only in that the potentialities of the one are brought to full development in the other.

2. The later or fifth phase, which introduces the new element of Capitalistic enterprise.

In the earlier history of Greece and Rome, the forms of organization of labour, as we have already stated, remain the same as in the third phase. No new elements have been added, but the child has meanwhile grown to manhood, and the germs visible in the former stage have now reached maturity, as we shall see when we review the separate forms of organization of the new (fourth) stage.

\section{State and City.}

At the beginning of the historical period we find Greek and Roman society divided as among the half-civilized peoples into three classes, nobles, citizens and slaves, to which is added as a further class the aliens, the metoikos, who are half citizens. The clan principle has left important traces, but has fallen into disuse. Clan organization has given way to an authoritarian rule, not limited to the village communities and tribal unions, but now extended to the union of many tribes into a great social factor, the State. In the same way as the place of the tribe has been taken

- We will speak later about the designation "Town Economy." 
by the state, so the place of the village community is usurped by the city community. The city, which as we have already seen $^{x}$ owes its existence to the fact that it is the centre of specialized handicrafts, is so characteristic of this phase that we might equally call it the "city" phase. The state and the city community are the political heirs of the clan. The economic heir is

\section{The Family.}

Civilization had made great progress, yet the family home life was still the most important element in the organization of labour, for, as in the third phase, most objects in daily use were provided by home labour. In order to satisfy those demands the women worked now almost exclusively at home, and moreover the household of the ordinary citizen was strengthened and increased by the introduction of slaves. Concerning the number of slaves employed in the households, statistics differ so widely that we can form no accurate idea on this point.

\section{Authoritarian Joint Households.}

The nobles introduced slaves in very large numbers as field workers, herdsmen, fishers, bakers, butchers and so on, so that they were in a position to supply by their own labour almost all the needs of "The Oikos," as the selfsufficing household is called. This Oikos system attained its fullest development later on, in the large pastoral estates of the Roman nobility. Here the Latifundia belonging to the different patricians widened out into principalities, the palaces with their grounds grew into cities, and separate "oikoi" grew into states within the State. The Family (from famulus-a servant) included thousands of slaves, so that they were divided into groups and superintended by hosts of overseers. Amongst them all kinds of callings were carried on-field labourers, shepherds, weavers, tillers, tailors, smiths, domestic servants, stewards, book-keepers, even slave artists, surgeons, doctors, teachers, librarians and rhetoricians, philosophers, etc. But this excessive development did not take place till a late period.

s Book II. chapter iv, History of the Development of the Dwelling. 


\section{INTER-TRibal Barter}

\section{(Foreign Trade)}

has developed in this stage through the introduction of money into international commerce. ${ }^{I}$ The importance of its influence on the organization of labour was greatly increased by the traffic on the land-girt Mediterranean. This led to the accumulation of wealth by individuals, and was one of the most important factors in the later and world-wide development of industry.

\section{Free Artisans.}

In addition to the un-free differentiated labour there were also free artisans, who were called by the Greeks " demiourgos," because, unlike the slaves who work for private individuals, they were free to work for any members of the public (Demos-the people).

Even in Homeric times each village had its artisan's and especially its workers in metal. 2 Since in antiquity wage earning was despised and regarded as unworthy of free men, these only acquired handicrafts under the pressure of poverty, and the free artisans were mainly recruited from

I. The lower Proletariat, who were without landed property, and so were forced to provide for themselves by the labour of their own hands.

2. From the weaklings and physically defective, who were incapable of agricultural labour. This explains why the blind Homer became a poet, and the lame but strong Hephaestus a smith.

3. From Metoken, that is aliens, who, without possessing the rights of citizenship, were yet free and independent, and controlled a great part of the industrial activities of the cities. It was due chiefly to the metoken, in addition to the slaves, that in spite of the general contempt for the artisan, the handicrafts in Athens attained to a position of such importance. At a census taken in the II 7 th Olympiad, out of 2I,000 citizens no fewer than I0,000 were metoken.3

× The history of money is given in a later chapter.

2 Ed. Meyer: Die wirtschaflliche Entwicklung des Altertums, p. 70.

3 Büchsenschütz: Di\& Hauptställen des Gewerbefleisses im Altertum, p. I2. 


\section{FIFTH OR EARLY CAPITALISTIC PHASE.}

\section{Beginnings of Capitalistic Enterprise in Antiquity.}

Similarly in Rome, in addition to the preponderating slave labour, there existed a freedom of the artisan which was particularly marked during the Empire. Here too the hand worker had few or no city rights, but was a provincial or alien, or most frequently a freed man. The continually increasing number of freed slaves naturally sought to earn their living, as a rule, by the handicrafts they had learnt in slavery. The police force was recruited from the freed men, and the greater number of subordinate officials came from their ranks.

In the older economic phases which we have just briefly analysed is found, as we have said before, the same elementary forms of organization of labour as among the more advanced semi-civilized nature folk, but the organization which had been in its beginning weak came to fuller development in the fourth phase, which coincides with the foundation of civilization. The tribal union has widened and raised itself into a state, and the village communities have developed into towns, which now take a leading position; the family is at its zenith, authoritarian joint households have in places acquired huge dimensions, foreign trade, from being mere barter, has reached the stage of international commerce, and the specialization of labour among slaves, metoken and freed men has reached a high stage of development.

Development, however, did not stop at this point; it went further, and added to the organization of labour the new element of

\section{Capitalistic Enterprise.}

Although the full citizen would not invest his own labour he was quite willing to invest his money, and so brought capitalistic enterprise into existence.

\section{a. Commercial Enterprise.}

The impulse to this new development was given by contact with foreign peoples. As Herodotus says, the people of

I Friedländer: Sittengeschichte Rom, 3 aufl, 1. 249, 29I-2. 


\section{THE HISTORY OF SOCIAL DEVELOPMENT}

antiquity settled round the Mediterranean like frogs round a pond. The geographical position was exceptionally favourable for trade and intercourse, and the demand for foreign products must have been caused by the facility with which the various nationalities could communicate with each other by sea. At first trade was insignificant and greatly despised. The Homeric Greeks used all sorts of contemptuous epithets about the Phœnician merchants, and Odysseus was greatly disgusted when Phaeacian Euryalus took him for a merchant. The Græco-Phœnician commerce as described in Homer resembled that between modern European merchants and half barbarous negroes. Laden with numerous trifles I the Phœnician ship landed on the Grecian shore, where it lay until the exchange of goods was accomplished, sometimes even for a year. ${ }^{2}$ After the favour of the chief or king had been bought by rich presents, the goods were exposed for sale on the shore, usually under tents. The Phœnicians bartered chains strung with amber, fine clothes and fabrics, jewels, glittering trinkets, metal work of every kind, purple dyes and simple industrial articles, all of which were chiefly intended for feminine vanity. The Greeks could only pay for these goods with raw produce, with wheat, wine, wood, skins, ore, slaves, etc.

But as trade passed more and more from the Phœnicians to the Greeks, the rich, and especially the nobility, soon learned to appreciate the easy art of gaining money by. lending money in commercial transactions. At the time of the golden age of Athens, all the most prosperous citizens were engaged in overseas commerce; the richer ones lending out their capital to others at high interest, the less important people transacting it.

Thales and Hippocrates must have been engaged in commerce, and Plato supplied himself with travelling expenses by the sale of oil.3 In the Roman Empire there arose a capitalistic class, a financial aristocracy, and it was chiefly the patricians who carried on banking and commercial affairs, often of a very corrupt description, in which they mostly employed slaves and freed men.4

I Schrader, i. 69.

2 Odyssey, xv. 455 .

3 Hermann: Privat altertiimer, 3 aufl. 419.

4 Friedländer, i. 254. 


\section{b. Industrial Enterprise.}

From commerce, capitalistic enterprise soon extended to industry. For example, the slaves were not only made to work for domestic needs, but to manufacture goods for the market. Each of the better class artisans in Athens had a couple of enslaved workers. ${ }^{\text {I }}$ Indeed, not infrequently a capitalist gave his slave a business or a booth in the market where he sold or worked for his master's profit. The richer slave owners built factories, in which numerous slaves produced articles wholesale for the market. Thus the father of Demosthenes had, as we know from his son's statements, ${ }^{2}$ two factories-a cutlery with thirty-three workmen and a chair factory with twenty-by means of which he made so much money that he was able to leave behind him a fortune of about forty talents. (One talent equals $£ 235$ Is. od.) Clion possessed a tannery, Hyperbolos a lamp factory, the father of the orator Isocrates, a flute factory, and Cleophon, a lyre factory. The capitalists had simply to provide the necessary room, slaves and materials, all the rest was left to a foreman. The ease' with which money could be earned by such enterprises attracted the rich people to place their capital in them, with the result that in Greece nearly all industries, such as milling, tanning, pottery, baking, weaving, etc., were carried on in such factories. 3 Thus metal and leather work, shields, mantles, furniture, medicines, ointments, oil, etc., were factory made. In the shoe factories the separate parts of the work for the same shoe were made by various persons, and the division of labour was so highly developed that in the clothing industry, for example, there were factories which specially undertook the making of mantles or overcoats. Some towns actually became manufacturing towns; thus Corinth must have employed 460,000 slaves, and the Island of Egina 470,000.4 In the Roman Empire enormous fortunes were accumulated in this way. Indeed, the agricultural, commercial and industrial capitalists can only be compared with our modern millionaires.5 The produce of the paper

x Ed. Meyer, p. 722.

3 Büchsenschütz, p. 336.

5 Bücher, p. 118.
2 Demosthenes: Aphobus, i. 9-1r.

4 Ebenda, p. 137. 
factory of Firmus, for example, was so great that he boasted it could provide the whole military forces with papyrus and glue. ${ }^{\mathrm{I}}$

Thus in later antiquity a new element of the organization of labour appeared-capitalistic enterprise. Hence at a time of the greatest economic development of antiquity the main forms were the following:

I. The Family, which was the oldest and most important of all elements in this phase.

2. Foreign trade, which united all the nations of the ancient world during the peaceful centuries of the Roman Empire.

3. Authoritarian joint household, which degenerated in character to a great extent.

4. The work of the free artisans, which was carried on by the landless classes, aliens, metoken and freed men, as well as by the poorer citizens, who worked largely with the slaves as helpers.

5. Capitalistic Enterprise, mostly taking the form of overseas commerce and industrial wholesale manufactures. ${ }^{2}$

\section{INTRODUCTION TO THE SIXTH PHASE.}

After the decay of the great powers of antiquity, there was a long period in which civilization made no further

× Friedläbder, ii. 135 .

2 Unfortunately our information concerning the quantitative proportions of the economic development in antiquity is scanty, and the views of historians and national economists on this point are widely at variance. One may compare for instance Edward Meyer's Economic Development of Antiquity, Almanac of National Economy, third series, 9 vol. Büchsenschütz: Industries and Property in Greek Antiquity; The Principal Sites of Industrialism in Greek Antiquity. Blümner: The Commercial Activities of the Peoples of Classical Times. Honegger: The History of Culture, vol. ii. Bücher: Origin of Political Economy, p. II 7 ff. Beloch: Almanac of National Economy, I8 vol. p. 626 ff. L. M. Hartmann: Journal of Social and Economic History, vol. iv. p. I53 ff. Kulischer: Almanac of National Economy, third series, 18 vol. p. $384 \mathrm{ff}$. Friedländer: History of Roman Customs, 3rd edition, 1. 245 f.; The Third Position, ii. 55-70; Commercial Transactions; and others. 
progress, but rather retrogressed. New barbaric peoples, especially those of Germanic origin, came upon the world's stage and set themselves the slow and difficult task of climbing to the heights which had been reached by the Greeks and Romans before their fall. It was fifteen hundred years before there came any further development of culture, any progress to higher forms unknown to antiquity. It was not until the eighteenth century that this further economic development occurred.

If then it were a question of taking up the thread of evolution where we left it, we might simply pass over the whole period from the fall of the Roman Empire till the eighteenth century as a deviation from the direct course; yet this deviation must not be ignored for the following reasons.

The development hitherto described has been built up by new elements on the foundation of the old, and the arrangements have always been in the same order:
I. Clan association.
2. The Family.
3. Foreign trade and barter.
4. Authoritarian joint household.
5. Free handicrafts.
6. Capitalistic enterprise.

(a) Wholesale business transactions.

(b) Wholesale industrial manufactures.

We are able to follow with certainty the course of Germanic culture from its primitive beginnings, as described by Cæsar and Tacitus, through all its phases up till the present day, a period of two thousand years. History places before our eyes a clearly defined stretch of development which offers us an extraordinarily valuable opportunity of testing our theories.

For this reason we insert here a summary of the development of the sixth phase, showing that while the two courses may differ in detail, their main outlines are the same. 


\section{The Germans before the "Völkerwanderung." :}

I. Association of Clans.-As among the Greeks and Romans in semi-historic times, a clan system of government was general among the Germanic tribes before the "Völkerwanderung." Primitive communism of kindred was strongly rooted among them. There was no private ownership of land; every year all was divided afresh by lot, and a general change of dwelling went with a change of land. The aim of this, as explained by a chief of the Sueri to Cæsar, was economic equality among the clan.

2. The Family, with division of labour between the sexes, came into its own and supplied its own modest needs. War and hunting, cattle rearing and house building, were the only occupations worthy of a free man. Agriculture, according to Tacitus," was left to "the women, the old men and the weaklings."

3. Foreign trade was still very undeveloped; cattle served as a means of barter, money was only used in intercourse with the Romans.

There were as yet no separate trades, and the only social distinctions were between free men and slaves. The bondsmen were quite rare in those early times, this condition coming in under Roman rule and after the "Völkerwanderung." The owner of a little plot of land managed it with the help of his wife and children. Those somewhat wealthier hired a few servants of both sexes, but it was only on the estates of kings and nobles that a large retinue was maintained.3

Thus the organization of the labour of the Germans before the "Völkerwanderung" consisted of the three forms of the clan, the family, and foreign, i.e. external trade. Yet there was an evident trend towards a fourth form, to the authoritarian joint household. Therefore on their first appearance on the stage of history they had reached an economic stage, which shows a transition from our second, the higher clan phase, to our third, the early industrial.

It has been convenient to retain this name for the migration of the German tribes and the invasion of the barbarians (TRANS.).

2 Tacitus: Germania, c. I5.

3 F. Dahn: Deutsche Gesch. i. 209. 


\section{The Germans in the Early Middle Ages.}

\section{Manorial System.}

After the "Völkerwanderung" the clan system declined, and its place was taken by Authoritarian government. Society was differentiated into warrior and agricultural classes. The military, originally drawn from the bondsmen, rose in the course of time to nobility and freedom, while those originally free sank into bondage and hereditary dependence. This transition was passed through in the Frankish period. ${ }^{\mathrm{I}}$

This dependent condition of the bondsmen on their lords led to the Manorial system. ${ }^{2}$ The Manor (Fronhoffreehold, later villa) was a form of Authoritarian government where the dependents were not slaves, but serfs who were bound to the soil. Every secular and spiritual lord, even the monasteries, possessed one or more manors, that is estates which consisted of the house of the lord or master, the necessary buildings and the domain, often attaining to the size of a village, and all work was done by the serfs, who were differentiated into shepherds, swineherds, husbandmen, smiths, hunters, etc. The women also had their distinctive work; they made clothes, brewed beer and ground wheat. The serfs were bound to the performance of service, and were obliged to pay taxes in kind, such as bread, linen, beer, tubs, kettles, knives, shoes, and drinking horns. On the larger manors differentiation was carried further. In his directions about the management of his estates, Charlemagne wrote: "Under every steward there must be good workmen, as blacksmiths, gold and silver smiths, shoemakers, turners, carpenters, armourers, fishers, bird catchers, soap boilers, mead brewers, bakers and net makers." 3 In the large monasteries, too, which represented the whole State in miniature, differentiation among the bondsmen was very advanced: thus we find in the Abbey of Korvei as early as the beginning of the ninth century, bakers, brewers, shoemakers, leather workers, fullers, blacksmiths, armourers,

I Rachfahl: Jahrb. f. Nat. Ökon, iii., Folge xix., Bd. I96.

2 Maurer: Gesch. der Fronhöfe, 4 Bd.

3 Bücher, p. $187 \mathrm{ff}$. 


\section{THE HISTORY OF SOCIAL DEVELOPMENT}

parchment dressers, sword cutlers, carpenters, bricklayers, stonemasons, metal founders and doctors. The latter at that time were mostly Jews or slaves. ${ }^{\mathrm{I}}$

The first people to be differentiated were thus in the course of our economic evolution unfree men, or serfs, who were forced into division of labour under authority. There were, however, in Merovingian times, artisans and skilled workers who were not in dependence on a manor, but were perfectly free, ${ }^{2}$ and earned their living as gold, silver and weapon smiths, as architects and shield painters. But differentiated labour was found principally among the unfree. According to Maurer, the manors in Frankish times were so widely spread that villages-vicus, as distinguished from villa, manor-are comparatively rarely mentioned in early documents.

Thus labour organization in the early Middle Ages shows in its essential features the same economic types which we found among the semi-civilized people in Polynesia, and among the Greeks and Romans of the earliest times. It corresponds accordingly to our third or early industrial phase.

\section{Town Economy in the Middle Ages.}

\section{The Organization of Handicrafts.}

In the period just described, the transition of the Germanic peoples from barbarism to civilization was accomplished. The power of the clans declined, and was replaced by the state, and, as always, civilization and cities came hand in hand.

At first, as a result of the utter insecurity of the age, cities served primarily for martial purposes, as strongholds and fortresses, where the country folk could take refuge with their property in case of invasion. Yet in spite of their formidable walls and battlements, there was greater freedom in the mediaeval town from its beginning than in the cities of antiquity. The Roman Patricians dwelt in the towns,

- Maurer, i. 253.

2 Maurer, i. I8I. Henne am Rhyn : Deutsche Culturgesch., 1. I8. 
visiting their country seats in the hot season. The German aristocracy, on the contrary, had no taste for city life; they lived in their manors, in their castles and strongholds, out in the country. Through this absence of the highest classes a free Burgher class was able to spring up, and in course of time it acquired so much power that it threw off the rule of the nobles, and introduced a new era of liberty and peaceful labour in the place of the former crushing oppression; and the more the citizens were raised from a state of oppression, the more numerous grew the cities.

The eleventh, twelfth and thirteenth centuries, especially the twelfth, saw the foundation of many cities, and, with the higher civilization flourishing in them, the warlike aspect became less prominent, giving place to a safe home for trade and exchange within the walls, and the town became the centre of differentiated handicrafts.

The landless classes flocked into the new free towns to earn their living by the exercise of their craft, amongst them many artisans who till now had exercised their skill for their lords in a manor. "Town air gives freedom" was a proverb of the age. It was not long before the free artisans formed the most important part of the population of the towns. By the thirteenth century Guilds were being formed, at first for the protection of industrial interests, then later in their zenith, in the fourteenth and fifteenth centuries, they acquired political power and a share in the municipal government. During the whole of the middle and later periods of the Middle Ages, handicraft was the typical form of industry, to such an extent that the whole period has been called the era of handicrafts, in reference to its economic aspects.

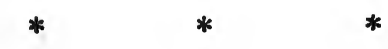

\section{Early Capitalistic Development.}

In addition to handicraft, another form of organization of labour was established in the towns. As in the cities of antiquity, this later growth developed from the other and older forms. It was 


\section{THE HISTORY OF SOCIAL DEVELOPMENT}

\section{Capitalistic Enterprise.}

Again, as in antiquity, it was international commerce and intercourse which, after the opening up of the East, first incited the spirit of enterprise to new achievements. In the Italian cities as far back as the fourteenth century, commerce assumed a strongly capitalistic character, and in the fifteenth century capitalistic trade on a large scale began to acquire a sure footing in the South German towns. ${ }^{\mathrm{x}}$

In the fifteenth and sixteenth centuries the new form of industry was no longer contented with commercial enterprise, but it encroached on the sphere of manufactures in the various countries of Europe. Then the capitalists stretched out their hand to mining, and acquired the control of brass foundries and iron and copper works. Soon wholesale industries in the form of manufactories and workshops were founded, ${ }^{2}$ then printing offices, paper mills, glass foundries, mirror factories and silk works. In I5I5 there was a large silk manufactory in Ulm, in 1676 a silk and woollen factory in Dresden, and in 1686 a cloth factory in Halle.

But factories and manufactures still remained unimportant for a long time, and the further development of capital entered upon a new course; it moved on to the so-called "Domestic" system, or home industry.3, In this form of industry a capitalist employs a number of workers in their own homes; the essence of the Domestic system consists, according to Von Pohle's definition, in the uniformly organized wholesale disposal of goods which have been produced by scattered home workers. By the sixteenth and seventeenth centuries, artisans associated themselves together in order to sell their goods on commission in distant markets. It was chiefly by this means that they preserved their independence, which they were destined to lose later. From the eighteenth century onwards home industry has assumed its present dreary form. 4

I Sombart: Der moderne Kapitalismus, 1. 398.

2 Conrado: Handwörterb. der Staatsw. Art. Fabrik.

3 Pohle: Die Entwickelung des Deutschen Wirtschaftslebens im $X I X$ Jahrhundert.

4 At the end of the nineteenth century there were still half a million home workers in Germany. 


\section{STRUCTURE OF ORGANIZATION OF LABOUR 183}

If we glance now over the interesting tract of development which we have just traversed, and which in two thousand years led the European races from primitive clans to nations on the threshold of capitalism, we find as result of the inquiry that the organization of labour developed out of the same elementary forms as those which we have already investigated. The new series gives an additional proof of the universality of the law already stated, which is:

I. Clan association.

2. The Family.

3. "Foreign " trade and barter.

4. Authoritarian joint households.

5. Free handicrafts.

6. Capitalistic enterprise.

(a) Wholesale business transactions.

(b) Wholesale industrial manufactures.

Similarly, in the succession of phases in the Middle Ages we find merely a repetition of the above arrangement. Whilst new forms were constantly evolved and each new form became absorbed in the earlier ones, the organization of labour became more unified, and new phases appeared. These phases among Germanic peoples may be divided into four:

I. Clan organization, which lasted from the earliest historic times to the Völkerwanderung; but even in Cæsar's time this showed evident tendencies towards transition into the following phase.

2. Early industrial organization, the manorial system, which included the first part of the Middle Ages, although it is not possible to assign exact dates, and led the European races out of Barbarism into Civilization.

3. Organization of handicrafts, due to the growth of towns, which occupied the middle and the latest Middle Ages, and

4. The early capitalistic phase, which, lasting from the beginning of modern times to the end of the eighteenth century, brings this recapitulation to a close.

The transition from the third to the fourth phase was 


\section{THE HISTORY OF SOCIAL DEVELOPMENT}

very gradual indeed, as the slow beginnings of early capitalism coincided with those of the town.

These four phases of labour organization correspond to the second, third, fourth and fifth phase of the former arrangement in all essential features. But however great the agreement, we must not omit to point out one distinguishing sign-the mediaeval development was more independent than that of antiquity. In the manors of the Middle Ages, instead of slaves, or in addition to slaves, serfs were enrolled who were not deprived of liberty and all rights, but were only bound to the soil and forced to give service and payments in kind. Secondly, for a reason cited earlier, in cities handicrafts could attain to a far higher degree of perfection than they could in antiquity. During the decline of the Roman Empire we find slaves emancipated in enormous numbers, and the granting of hereditary leases; the same conditions appeared in the later European developments which we are considering, and in all probability the classical instance served as a model for the mediaeval ones. In any case, earlier or later, the advantages of free labour over slavery must be realized.

\section{SIXTH OR MID CAPITALISTIC PHASE.}

\section{From the End of the Eighteenth Century in England and from the Middle of the Nineteenth Century in Germany.}

The beginning of capitalism was very slow; indeed, faint traces of it may be noticed in the time of the Crusades. At first it appeared as wholesale trade. But throughout the whole of the Middle Ages, this wholesale trade was quite an unimportant element, and even at the end of that period it was used only for the following items-I. roots and southern fruits; 2 . dried and salted fish, which were then the universal food of the people; 3. skins; 4. fine cloths; and 5. for the North German states, wine, and in various parts of Germany, salt, which was mostly bought by the State direct from the place of production. ${ }^{2}$ It is also characteristic of the weakness of early capitalistic commerce, that even in I825 the whole merchant fleet of Bremen did not number as many tons as an ordinary steamer of to-day.3 Then capitalistic enterprise

? For bibliography see Pohle, S. iv.

2 Bücher, p. I47. 3 Pohle, $p$ II 8. 
took possession of mining and set up factories and workshops, but even these remained rare up to the eighteenth or nineteenth centuries. After this came the Domestic system, which was the most important of the many forms of working for an entrepreneur, but even this was relatively small to the number of those who made everything for their own home consumption, and the small handicraftsman.

Capitalistic organization existed feebly for some fifteen hundred years, but had no particular energy until an epochmaking discovery excited it to fresh and strenuous life. This was the invention of the great labour-saving machines, and Steam strode in as a kingly giant to perform the work which had hitherto been done by the muscles of men and beasts, and to a small extent by the forces of wind and water. Then capitalistic enterprise advanced victoriously along the whole line, and there began the new economic era of High Capitalism.

The first great strides were made by those older trades which had previously developed as handicrafts, such as paper manufacture, soap refining, printing, tobacco, porcelain and chocolate manufacture, all of which underwent important expansions. Secondly came such newer ones as had grown up in the last century, as rubber goods, sugar industry, chemical works, and the older machine factories. But thirdly, this new power encroached on the sphere which for untold centuries had been managed by the labour of men's hands, and drove men from their heritage of work. This hand labour was especially spinning, weaving, tanning, milling, hat making, book binding, glove making, brick making, and pottery. The process of crowding out the workers unfortunately advanced very swiftly, often before labour conditions could be adjusted. It is not difficult to see the horrors that followed; a few steam machines threw thousands of spinners out of work, and men, women and children died in swarms from starvation. Now capitalistic enterprise became master of every situation where goods could be produced wholesale, as well as of trade and commercial exchange, navigation, railroads, postal system, mining for iron, coal, petroleum, etc. Capitalism concentrates the market for goods into large up-to-date depôts with dozens of branch establishments, and by this means brings numbers 


\section{THE HISTORY OF SOCIAL DEVELOPMENT}

of hitherto free workers under control ; it brings into existence huge co-operations with division of labour in which thousands of workers are associated in one enormous enterprise of superhuman power and capabilities; it leads to higher forms and mechanical power such as the world has never yet seen. And this mighty revolution was accomplished in the short space of a score or so of years. According to Pohle, the whole number of stationary steam-engines used for industry in Prussia in 1837 was about 7,000 horse power ; in I855 it was 62,000 ; and in 1875 two-thirds of a million. In Germany the mechanical power of engines in 1879 amounted to $4,5 \mathrm{I} 0,637$ horse power (one horse power is reckoned at the mechanical power of three horses or twenty men). ${ }^{x}$ According to Sombart's estimates, ${ }^{2}$ the productive power of society has been multiplied fivefold in the last hundred years. From I840 to I895, the productive power of the German nation has increased in the proportion of one to three.

Before the advent of the high capitalistic movement, we might compare the development of labour organization to the silent growth of a plant, which gradually puts forth sprout after sprout and rests quietly whilst its boughs grow green and blossom. Now all is changed. War to the knife breaks out between the old forms and the new-and the new always comes out as conqueror. To obtain a clear idea of the whole organization of labour we will look back on the fate of the older forms.

I. The clan associations died out and are forgotten. In their stead came feudalism, then absolute monarchy. Finally, with the appearance of the capitalistic phase, either constitutional monarchy or citizen republics. Yet even to the present day one important function of the clan is retained. Within certain limits, the inheritance and division of property is decided by relationship in our most recent law books.

2. The Family. - The Family remained through all the early phases of industry and civilization as the most important element of labour organization, producing through home work

$\checkmark$ Conrado: Handw. u Staatsw.

- Sombart: Sozialismus und Soziale Bewegung, Part 5, p. 8o. 
nearly everything needed. Later, as the work was differentiated, the Family was gradually deprived of many of its functions. Yet in mediaeval towns the artisans had a small piece of ground where they grew vegetables, kept pigs, and so on, without which by-products many of them could not have lived.

Capitalization gave the death-blow to the oikos-the self-sufficing household which is fast disappearing. Against great establishments with their organized labour, which undertake to do every necessary task by machinery, the oikon has no chance of competing. A new era of domestic economy is beginning: it opposes individual production, and preaches that the man who gives up his own goods to another is less a benefactor than the man who arranges for the most skilful division of labour, and so the household no longer plays the same part in the organization of labour that it played for so many centuries. Individual production is displaced all along the line by commercial production. One act of production after another, spinning and weaving, sewing and tailoring, baking and butchering, soap boiling and candle making, brewing and preserving, etc., is now detached from home economy and transferred to co-operative production.

Since most of the home activities were carried out by women, these latter were now deprived of a great part of their former occupations, and so the immense advance which co-operative labour has made through capitalistic organization was, as we shall see later on, one of the chief causes of the modern Feminist movement. For woman is now forced out of the home into business life, and takes her share in the ever-increasing work caused by differentiation.

3. The feudal or manorial forms of life passed away long ago, hastened to dissolution by the growth of many cities. ${ }^{\mathrm{I}}$ Dependents fled from stern lords and found freedom in the cities, and those lords soon learnt that if they would keep their serfs they must make their lot more comfortable. With the breaking up of serfdom-in I78I in Austria, under Joseph II ; in 1789 in France ; in $I 783$ in Baden ; in I807-II in Prussia 2-feudal conditions disappeared. The only remains of this condition now left are entailed estates and

Maurer, iv. $48 \mathrm{r}$.

a Stein. 
the right of primogeniture. These estates, however, do not attempt to provide food for their own upkeep only, but like the rest of the world for commercial purposes.

4. In the opinion of many economists, ${ }^{1}$ the free handicrafts have received a fatal blow from the rapid advance of capitalistic organization. The small industries without capital are compelled to give way before the gigantic accumulations of capitalism. Whilst the working shoemaker is busy with awl and hammer, a modern shoe factory is making use of no less than thirty-four different kinds of machines. Six hundred different kinds are used for the manufacture of guns, and sixteen for the production of lucifer matches. A single spinning machine increases the working power of the spinner a hundredfold. As a natural consequence, many trades are fast becoming extinct; for example, weaving and spinning have passed away, and tanning and furriery are near their end. In certain industries the artisan trader has become a dealer or a home worker, getting the most important parts of his goods from the wholesale manufactories, upon whom he is dependent. As examples of the latter are watchmakers, tinsmiths, locksmiths, shoemakers, etc. Some industries retired from the towns to the rural districts, where blacksmiths and cartwrights still prosper. Whilst formerly guild restrictions forbade any artisan from settling in rural districts; now there are in Germany 675,000 master workmen scattered over the country, 52 per cent. of whom are independent artisans. This shows clearly that although certain industries are disappearing since the beginning of the nineteenth century, the workmen have not decreased.

In the towns a few artisans have risen to be heads of retail businesses or masters of wholesale industries. Mary have become assistants in shops, but great numbers have fallen into proletarianism, keeping their heads above water with difficulty by turning their hand to odd jobs of their own trade, and any by-products they can manage.

And this process of transformation goes on incessantly as a result of new inventions, and the outlook into the future for the handicrafts that have taken the lead in the history

× More detailed information can be obtained from Sombart: Der moderne Kapitalismus, ii. 56ì. Der Verkrüppelungsprozess des Handwerks, Bücher, a.a. O. $215 \mathrm{ff}$. Der Niedergang des Handwerks, u.v.a. 
of labour for the last five hundred years grows darker and darker.

5. Every form of labour hitherto described has found a dangerous rival in capitalism, which has come forward by leaps and bounds, and has wrecked or retarded all their prosperity. The case of export and import trades and international labour organizations is just the reverse, as they have developed rapidly with the capitalistic system; and this must be noted as the greatest success of the capitalistic era.

A century ago exports and imports mostly represented luxuries, now, owing to the enormous spread of commerce and industry, these luxuries have become necessities to us. The population of the various countries are accustomed to have their coffee, tea, vegetables, cocoa, tobacco, cotton, wool, silk or petroleum imported and exported for them, and as a consequence of the enlarged differentiation of agrarian and industrial labour, the most highly civilized countries are dependent for food on other lands.

Thus the inhabitants of the whole earth are united by daily intercourse in one great organization of labour. The various nations produce and exchange such commodities as thrive best in their specific conditions, i.e. their geographical position, climate or civilization. In this way we are approaching nearer and nearer to the condition of worldwide economics, as foreign trade increases in power and unification.

\section{SEVENTH OR LATE CAPITALISTIC PHASE.}

\section{(1881 onward.)}

Kant's saying, "As progress becomes more rapid its phases are shorter," is confirmed by the history of labour. Clan association probably lasted for millenniums, civic organization rather more than five hundred years. The birth of the high capitalistic phase in Germany only dates from 1833, when the German " Zollverein " was founded; and yet another phase has been taking form year by year of late, that is the late capitalistic phase in which we now are.

Each new phase has been called into existence by the emergence of some new form of organization. The late capitalistic phase is perhaps destined to metamorphose the 
whole of the organization of labour, as it has transformed capitalistic enterprise, by means of

\section{Socialized Trade.}

This appears in two forms-State and Co-operative trading.

(a) State Trading. We enclose with this the County Council, Urban, District and Borough Councils. This has much in common with capitalistic enterprise, but is aistinguished from it in the first place by being for the welfare of society instead of the individual, and so may be called Socialized trade. The keen speculation of individual competition has no place here, and the dullness peculiar to bureaucracy takes its place. The second point of difference is the great advantage that the "Civil Servant" has in his work, and in the certainty of a pension, which is not ensured to the employees of capitalistic enterprise.

In Greece and Rome, even during their highest economic development, State trade scarcely existed. The profits of the royal prerogatives of salt works and of mining, in which State slaves worked, as well as the exaction of taxes and the levying of tolls, were simply entrusted to tenants, and as a rule all the works requisite for municipal affairs were more or less hired out by the authorities to middlemen. ${ }^{x}$ Antiquity knew nothing of State schools. The Roman state allowed soldiers to perform public works ; they were ordered, chiefly in the newly acquired countries, to build roads and bridges, entrenchments and fortifications, to burn bricks, break stones and bring waste land into cultivation, thus preventing the men from becoming idle or insubordinate. ${ }^{2}$ Again, in the Middle Ages, the State was not strong enough to cope with economic problems.

This condition only changed when civic life grew stronger and developed in power, order and extent. The modern State controls the coinage, tolls, taxes and forestry, and has introduced compulsory education among the children. It has organized insurance matters on a large scale-since 1883 Health Insurance; in I884 Accident Insurance; in I890

I Büchsenschütz: Besitz und Erwerb, p. 334 .

2 Honegger, II. 393. F. Dahn: Deutsche Gesch. I. I. 399 Anm. 3. 
Disablement and Old Age Insurance. Later, insurances assumed gigantic proportions at the close of the nineteenth century. Further, the State has founded Savings Banks, Fire Assurance, Orphan Asylums, and other philanthropic institutions; it protects women and children from being overworked and workpeople from accidents by the establishment of factory inspection; it builds streets, canals, bridges, lunatic asylums, children's homes, museums, public libraries and ships on its own wharves. It provides for the lighting and cleaning of the streets, for tramways, gas, water and waste pipes. In Germany and in many countries it has monopolized the manufacture of tobacco and the sale of alcohol, and it superintends the mining and salt works.

Above all, it has taken under its own management many of the most important works-the vast organization of transport and traffic affairs, the posts and railways, the telegraph and telephone. And all these activities it manages through a host of officials, whose number would astonish the Middle Ages, and which number is steadily increasing. From I882-I895, according to the statistics of the German Empire, 4, II 9 new professions arose, of which no fewer than 2,079 , i.e. over half, were Government positions. In I894 the personnel of the Post Office alone numbered I74,398 persons.

This enormous extension of the economic activity of the State is easily understood. In a development which tends from the lesser to the greater, the State is the most powerful of all human and material organizations, and, as the richest of all capitalists, must become more and more conscious of its power. The future will in all probability constantly bring new and greater problems which can only be solved by the giant State. Originally all the greater enterprises were due to the initiative of private capitalists. But the more these great enterprises increased in size and wealth, the more the desire of the employees tended towards service with the great public companies or co-operative unions in preference to the small private firms. Soon "State" undertakings, embracing County Councils, etc., appeared as rivals to capitalistic enterprise, and began to take its place in various directions in the same way as the latter had supplanted and partially destroyed the older forms of organ- 
ization. One example of this is the State absorption of railways.

Here, then, three phases are to be considered, viz. Private, Capitalistic and State enterprise.

As organizations increase in size, the tendency must always be towards amalgamation. Private interests unite into syndicates, trusts, rings, etc.; the necessity of this arises from our present means of production. At the same time we are threatened by the danger that private people may monopolize all branches of administration, so that the problem must come sooner or later to the State whether it is not bound to take these giant organizations under its control. The State will not always be content to stand by with folded arms during the disputes between the great coalitions of Capital and Labour, in which thousands, and even tens of thousands, of outside activities are involved; but here also it will have to interfere, at first by State control and regulation, but later by more active intervention. On every side the State is confronted with fresh problems. We are evidently entering on a new phase of development, and we can only conjecture the form it will take.

(b) Besides the State trading, the Co-operative Supply Associations belong to "Socialized Trade," for they, too, aim not at the private advantage of one single capitalistic entrepreneur but at the common benefit of all shareholders. But whilst the trades are organized so to speak from above downwards, the organization of associations stands on individual initiative from below upwards, through self-help. The first Co-operative Stores were founded in England. It denoted a land-mark in Social History ${ }^{\mathrm{I}}$ when in I844, in the town of Rochdale, the first small shop of a Company was opened which began with twenty-eight members, whose weekly turnover amounted to $£ 2$, and its united capital to $£ 28$, for this was the beginning of the Co-operative Stores movement, in which there are now about 2,000,000 shareholders and which administers a capital of $£ 25,000,000$ and has a turnover of $£ 50,000,000$. The English and Scotch Co-operative Stores alone have now a turnover of about $£ 25,000,000$, and the

× Sombart: Sozialismus und Sozials Bewegung, 5 Auf. S. II9. 


\section{STRUCTURE OF ORGANIZATION OF LABOUR 193}

English Co-operative Associations themselves possess factories which turn out for their own use annually goods to the value of $£$ Io,000,000. In Belgium and other countries the Cooperative principle has been carried further than in the land of its origin.

From what we have already seen of the whole course of development, it is evident that these beginnings will advance still further, and that, as with the introduction of Commerce and of Capitalistic enterprise, a new epoch of the organization of labour will be founded. In this sense, and also for reasons to be explained later, we may give the present or late capitalistic phase the alternative title of "Early Socialistic Phase," in analogy with the titles "Early Industrial" and "Early Capitalistic."

By this definition it is merely to be understood that in the coming phase socialized trade must be expected to assume special importance, and that this development will extend to yet higher forms of co-operation of labour, but of this at present we can form no accurate idea. 
CHAPTER II

\section{REFLECTIONS ON THE STRUCTURE OF ORGANIZATION OF LABOUR.}

Up to this point we have spoken of seven forms of Labour Organization. ${ }^{x}$ When chronologically arranged they are as follows :

I. The Clan, with communism of Labour, Food and Land.

2. The Family, with division of Labour only between the sexes.

3. Foreign Trade or external organization of Labour, combined with differentiation of production in adjacent localities.

4. Manorial System (Oikos, Fronhof, Villa), being an enlargement of the "Family" by the enrolment of slaves or serfs.

5. Free Handicrafts in the widest sense of the word, including all differentiated labour not coming under Capitalistic Organization, from simple home industries up to skilled artisans. ${ }^{2}$

6. Capitalistic Enterprise, in which the entrepreneur and a number of workers (slaves or free) are associated in a labour organization.

7. Socialized Industry, which resembles Capitalistic Enterprise as far as size and capital are concerned, but differs in that it is for the profit of the many instead of the Individual. Civic, Municipal and Co-operative Industries come under this head.

Compare the four forms of Industry of Schüz in Foundations of National Economy, 1843, and Sombart's "five Economic forms" in Braun's Archives, vol. 14, pp. 403-405.

2 See p. I9I. 
(Rise of the phases out of the elementary forms.) These were the elements out of which the organization of labour was composed at the separate economic stages, each new stage going gradually forward to higher activities through the improvement of old forms and amalgamating with new ones, and not as a rule through their destruction or violent transformation. Its growth may be compared to that of a palm tree which puts forth one shoot, and whilst that is increasing in size adds a second and a third. It is only when a number of the huge leaves have formed that the lower leaves wither and die away. The whole growth might be schematically represented :
I. Phase : $a$.
II. Phase : $a+b$.
III. Phase : $a+-b+c$.
IV. Phase : $a+b+c+d$, etc.

The same continuous development is shown throughout sociology. In the sphere of food production, for example, "hunting " and "wild fruit collecting" were not forgotten when fishing, cattle rearing and higher agriculture were known among men. In our own times people go into the woods to collect mushrooms and berries in their season. ${ }^{x}$ But in the process of linking old forms with new, if one has to be crowded out it is usually the old.

One must admit that the progression of the forms of the Organization of Labour was not quite so mathematically exact as the formula might suggest. New forms may influence the old ones favourably or unfavourably. Some have had a time of prosperity, and then become stunted or have even disappeared, and others through their whole development moved on from strength to strength.

The following table, if carefully studied, will explain the phases of development which each organization has passed through, rising and falling or merging into other forms whilst passing their functions on to their successors.

If this table is read in a perpendicular direction, from top to bottom, it gives information on the development

I Notably in certain towns in Switzerland municipal arrangements are made. 
TABLE OF THE STRUCTURE

\begin{tabular}{|c|c|c|c|}
\hline & Phases. & Peoples. & $\begin{array}{c}\text { Self-sufficing Clan. } \\
1 \\
\end{array}$ \\
\hline $\mathbf{I}$ & Early Clan Phase & $\begin{array}{l}\text { Only a few races remain- } \\
\text { ing. For example, in } \\
\text { Australia }\end{array}$ & Existent \\
\hline II & Later Clan Phase & $\begin{array}{l}\text { Hunters, Shepherds, } \\
\text { Indian Hunter-Agricul- } \\
\text { turists, etc. }\end{array}$ & $\begin{array}{l}\text { Zenith on the lowest } \\
\text { stage of Agriculture }\end{array}$ \\
\hline III & Early Industrial Phase & $\begin{array}{l}\text { Polynesians, Africans, } \\
\text { Germans in Early Middle } \\
\text { Ages }\end{array}$ & $\begin{array}{l}\text { Declining. In its } \\
\text { place village com- } \\
\text { munity and tribal } \\
\text { union }\end{array}$ \\
\hline IV & Later Industrial Phase & $\begin{array}{l}\text { Greeks and Romans of } \\
\text { Early Times. Germans } \\
\text { in High and Late Middle } \\
\text { Ages }\end{array}$ & $\begin{array}{l}\text { Disappeared. Rise of } \\
\text { the State and of } \\
\text { civilization }\end{array}$ \\
\hline $\mathbf{v}$ & Early Capitalistic Phase & $\begin{array}{l}\text { Greeks and Romans at } \\
\text { their highest stage of } \\
\text { development. European } \\
\text { peoples from sixteenth to } \\
\text { eighteenth centuries }\end{array}$ & - \\
\hline VI & Mid Capitalistic Phase & $\begin{array}{l}\text { European nations since } \\
\text { the end of the eighteenth } \\
\text { century }\end{array}$ & $\begin{array}{l}- \\
\cdots\end{array}$ \\
\hline VII & $\begin{array}{l}\text { Latest Capitalistic } \\
\text { Phase }\end{array}$ & $\begin{array}{l}\text { European nations since } \\
\text { the end of the nineteenth } \\
\text { century }\end{array}$ & - \\
\hline
\end{tabular}




\section{OF LABOUR ORGANIZATION}

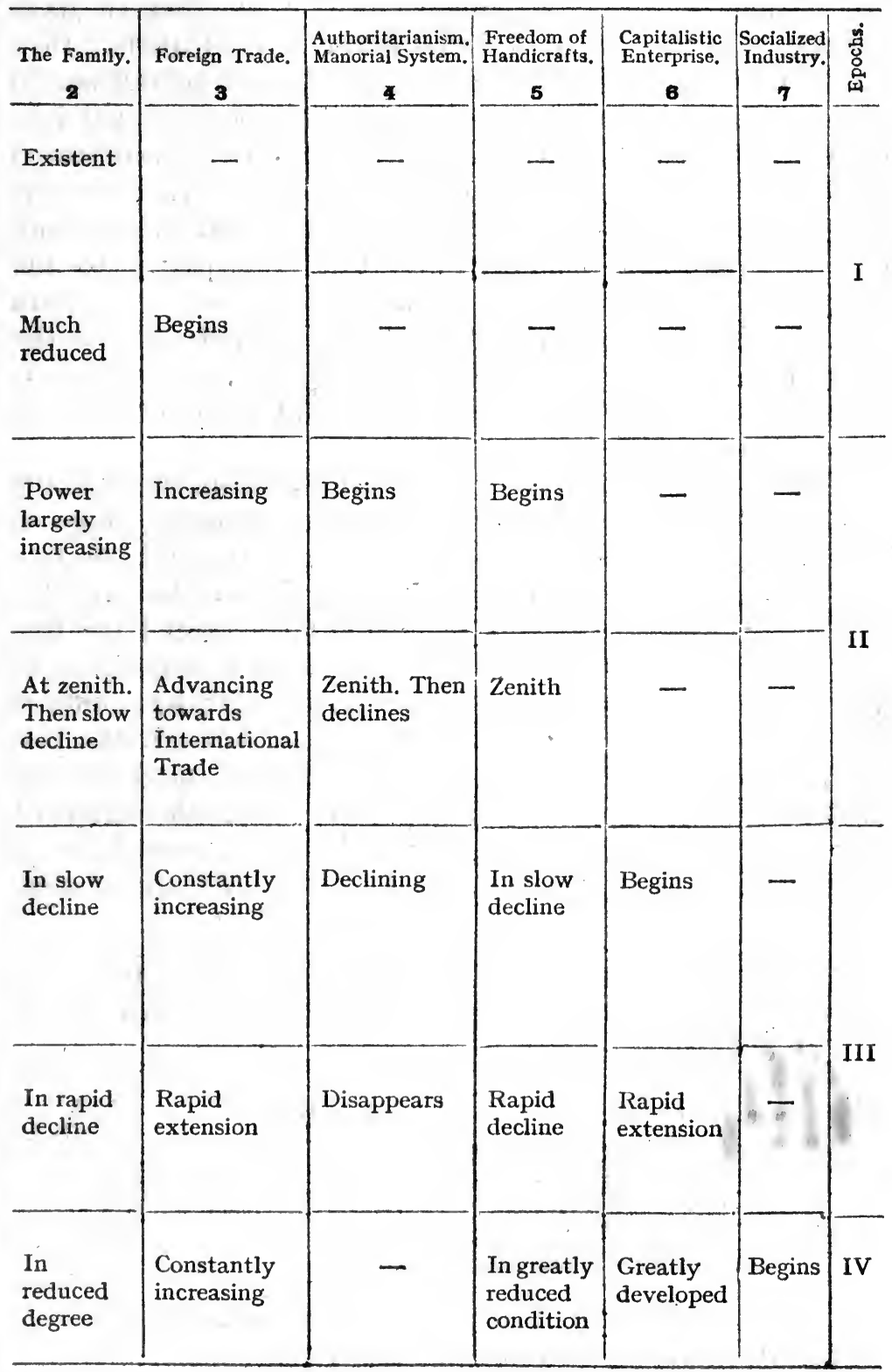




\section{THE HISTORY OF SOCIAL DEVELOPMENT}

which each separate organization has passed through in the various phases. We see, for example, in I, that clan association was already in existence in the lowest stage among hunters, shepherds and lower agriculturists; then on the lower stage of agriculture it attained its highest period of prosperity; and that then in the third phase it fell into decay among the higher agriculturists, and only disappeared in the early times of civilization-or, to put it more clearly, dissolves into village communities and tribal unions, and gave up its functions partly to these and partly to the Family. In II, the Family likewise endeavoured to attain a climax, which it reached after the decay of clan life in the IV phase on the lower grade of civilization, after which it sank down, at first slowly, then in the VI phase rapidly, to its present condition.

If the table is read in a horizontal direction, we perceive the composition of Labour Organization on every stage of its development. If we take as example the VII, or late capitalistic phase, the horizontal line shows that in this phase clan association and the manorial system have disappeared too, that the Family, which is now the oldest of all the elementary forms and free handicrafts, has suffered the loss of a great part of its functions through the rise of capitalism and is greatly reduced, that international trade and intercourse as throughout the whole development is constantly on the increase, and that as a new form of organization, socialized industry has made its appearance.

To summarize these details, the table shows that two successive phases are always united in each epoch, which can be defined as follows:

\section{Epoch : Clan Organization.}

(a) First or early clan phase

(Self-sufficing horde or clan organization).

(b) Second or later clan phase

(Extended clan organization).

II. EPoch : Industrial ORganization.

(a) Third or early industrial phase

(Manorial and village economies). 
(b) Fourth or later industrial phase

(Town economy).

III. Epoch : Capitalistic Organization.

(a) Fifth or early capitalistic phase

(Beginnings of national economy).

(b) Sixth or mid capitalistic phase

(National economy).

(c) Seventh or late capitalistic phase

(The beginnings of world economy). This may with reasonable probability be looked upon as the basis of a fourth epoch which is now dawning.

\section{THE ORGANOPLASTIC GROUPS.}

In the foregoing pages we have endeavoured from a purely morphological standpoint to obtain as clear a view as possible of the development of the organization of labour from the simplicity of clanship times to our own late capitalistic phase with all its complications. Before we proceed with the Phaseology of Labour, of which up to the present we have taken a one-sided view, we must widen our horizon by considering the human supporters of the movement, the men who have organized it and who are carrying it on.

We have already seen that all organized Labour is performed by simple co-operation, differentiation, or a combination of the two. We must now consider which groups or social units formed these organizations.

If we submit our material on this question to an investigation which will be much facilitated by the adjoined table, we come to the opinion that there were two different kinds of unions which have worked as organizing forces. Both these kinds we have already met on the lowest grade of culture known to us, in the social forms of the clan and family, and may be generally classified as:

r. The Social Union.

2. The Family Union.

We will consider first the Social union, which increases from stage to stage throughout all development. In primeval 
times there were separated bands scattered over wide districts, with no system of cohesion; then several of these hordes united into a tribe, then many tribes into a small state, and these uniting became nations.

In this long course from the horde to the nation, the following forms of the Organization of Labour were evolved :

I. In the first phase was clan association, with no social union outside the clan.

2. In the second phase, through the peaceful attitudes of neighbouring hordes, "Foreign" trading and labour organization evolved.

3. In the third or early industrial phase, the transition from the clan to authoritarian rule was accomplished, and in this transition the social union of some peoples became so strong that they were able to conquer neighbouring tribes and enslave the prisoners, whom they incorporated, as a lower class, into their own social union. Tribes amalgamated and villages appeared. In this phase, two new forms of Organization of Labour arise, the manorial system and the free handicrafts. The first form develops out of the growth of the "Family," and will be discussed later. The form of the Free Handicrafts owes its origin to "Social Union," and is an early expression of economic differentiation which became possible only when the social union was numerically large enough. In a community of twenty or thirty persons specialized industry could not thrive, for the butchers, bakers, etc., would not find in it a sufficiently large circle of customers. In the village community, on the contrary, the social union includes a sufficient number and renders early industrial differentiation possible, and so furnishes the ground in which free handicrafts can take root. The Family still holds an important place in this stage, for the handicrafts are often hereditary in it.

4. In the fourth phase, civic economy, a number of tribes are united into a larger political body, i.e. a nation. The state has arisen, first as a petty state which now includes a sufficient number of individuals to lead to fuller development the beginnings which industrial differentiation had made in the previous phases, and thus calls into existence 


\section{STRUCTURE OF ORGANIZATION OF LABOUR 201}

a new economic phase without requiring any new organizations.

5. The fifth, or early capitalistic phase, is a still larger solidarity which may be brought about either by conquest or economic connections; in both cases the conditions of existence of capitalistic enterprise are facilitated, and wholesale industries become practical and profitable in the larger markets afforded by the extended limits. Capitalistic enterprise, like handicraftship, is a result of social union. We must consider later to what extent the Family has contributed to the development of this phase.

6. We now come to the sixth or mid capitalistic phase, which dates from the time that capitalistic enterprise began to stand above every other form of organization. This went hand in hand with social union, which now in its continuous extension reached to all the nations of the world.

7. The latest capitalistic phase is that of socialized industries. Social union has grown to such power and extent in the modern state that it is capable of taking under its own control all those vast industries which are beyond the capacity of individual capitalists, and so it comes forward as a direct organizer. It is quite obvious that "Supply Associations" are also the offspring of social union.

There are thus five out of the seven forms of organization which are altogether or in great part due to "Social Union."

From kinship it produced the clan.

From the union of clans it was responsible for foreign or external organization of labour.

In the tribes and petty states it made free handicrafts possible.

In the union of states it brought forth Capitalistic Enterprise, and finally

In the modern great states "Socialized Industry."

In comparison to this imposing list of the productions of Social Union, the Family, which is only accountable for "the Family" and "Authoritarian" Government, seems to play quite a minor part. But until the introduction of 
the Higher Capitalistic Phase the "Family" union was of the greatest importance in the development of Labour Organization, and must be considered as its strongest element for a very long period. Before this phase, Individual labour predominated; the "Family" economy and Individual production coincide in the same way as do social union and production for an external demand.

As a result of this, Family solidarity and Social solidarity stand in opposition to each other-the more the one succeeds, the more is the other thrown out of gear, so that throughout the whole history of Labour there has been strife between these two organizing groups. This struggle is of great sociological interest, and its course is well understood by the foregoing table.

In the earliest phases it would be difficult to say which of the two groups was the more important, although among the pastoral people the balance inclines to the "Family."

But at the end of that early epoch, i.e. on the lower stage of agriculture, the clan makes an extraordinary forward movement, reaching there its high-water mark, and the result is that the Family transferred to the Clan most of its economic functions. Its members eat in common; they dig and cultivate the fields by combining forces, and share the harvest according to individual needs. In some cases, as among Indians and Malays, the weakening of the Family bond is so great that the husband and wife do not live together, each remaining with his or her clan, and in an economic sense the Family shrinks to nothingness. ${ }^{\text {I }}$

But after this triumph social union suffers a relapse which has long threatened it. In the third phase the clan begins to decline after ruling for many millenniums, and gives way to "Authoritarian" control. Social life next comes to a great transition period, while the clan is moribund and the state is still in its infancy. Social union is still very weak, and the "Family" system reaches its apogee. It takes over most of the functions of the clan, and widens itself by keeping its members together and through the enrolment of slaves (Famulus $=$ a servant, led to the Latin word Familia). This soon advanced to the Manorial System.

I A fuller treatment of this subject will be found in the second volume of the series. 


\section{STRUCTURE OF ORGANIZATION OF LABOUR 203}

This system held its own during the growth of cities and indeed until the mid capitalistic phase, yet with everdecreasing power, for its old adversary social union slowly took the foremost position. Now began a spell during which one home industry after another, baking, brewing, tailoring, etc., became specialized wholesale productions. Next came the first of the early capitalistic phases, which at first did not affect home industries to any great extent, but which, on looking back, one can easily see were the storm birds that announced the threatened extinction of private production.

In the mid capitalistic phase the struggle between the rival organizations reached a decisive point. With the invention of machines, an enormous expansion of capitalistic enterprise took place, and it was inevitable that in the struggle for supremacy that followed the small domestic industries went to the wall. Commercial production superseded Individual production, and the Association of Labour made more progress in the high capitalistic phase than it had ever done in any other phases.

Although the triumph of social union over its rival was decisive, yet it was by no means complete. Such economic functions as washing, cooking, etc., refuse stubbornly to be driven out of the Family life. Again, the money needed for the working of social union is in the hands of Families, and not as a rule in those of Individuals. It is an indispensable requisite for the continuance and prosperity of capitalistic enterprise that money can be transmitted by inheritance in families and the well-being of descendants guaranteed. But since in all probability the organization of Labour will continue on the same lines as it has formerly taken, we may expect that most of the economic achievements of the "Family" will be usurped by other organizations, and that the only differentiated function to be retained will be the most important of all, that of reproduction. ${ }^{X}$

$\checkmark$ Compare Schäffle's Structure and Existence of Social Bodies. 


\section{DEVELOPMENT OF DIVISION OF LABOUR (DIFFERENTIATION)}

\section{INTRODUCTION.}

WE have hinted before at Differentiation. Here we will study it from a new and higher standpoint.

Differentiation is indeed the universal fundamental law, according to which all development proceeds, not only in the intellectual world of human culture, but everywhere in animal nature. The more highly a plant or animal is developed, the more are its special organs fashioned for particular functions. On the lowest stage of the animal kingdom stands, or rather swims, a creature with only one organ, the amœba. This "creature" is microscopically small, and it appears to be homogeneous. Under a powerful microscope the reticulum and hyaloplasm are seen separately, but it appears homogeneous. It flows round any available food material, slowly digests it and expels refuse; it moves by the slow protrusion of ever-changing processes and reproduces by dividing into two daughter amœbæ, and this is apparently done with one organ and no division of labour.

The higher we rise in the scale of organisms the more complicated is the structure, and the further is the division of labour between the separate organs carried out. In a worm or a crustacean we find special organs for progress, consumption, propagation; further different organs of the senses and for seizing objects, for self-preservation, etc. ; but how low is a crab, which has to arrange for the seizing and chewing of food with its foot, and at the same time use this as an organ of progression, compared with a bird or a mammal! Even among the most highly developed animals 
this differentiation increases from grade to grade. Among apes all four limbs are employed in locomotion; among men a differentiation has taken place between the upper and lower extremities in the grasping and locomotive organs; and even both hands are differentiated, since the right is adapted to different special purposes from the left.

If we compare a primitive tribe of men with a modern city, we find the differentiation almost as distinct as between the doings of an amœba and a mammal. In the tribe is a small, almost homogeneous mass of individuals who are all engaged in nearly the same occupations, while in the city is a population, numbering millions, which is differentiated into many hundreds of the most varied callings. And as with animals and plants, so with human societies is Differentiation the most exact measurer of grades and a definite standard for the height of culture.

By applying this standard we divide the history of Labour into the following epochs:

I. The first epoch is "simply differentiation between the sexes, coinciding with the epoch of Clan organization.

II. In the second epoch the differentiation of man takes place, whilst women still remain undifferentiated. This epoch includes the "Industrial" and the beginning of "Capitalistic" organization.

III. The third epoch; in which women also are differentiated, corresponds with the mid capitalistic phase, and is only in its infancy now.

We will endeavour to classify these three epochs of differentiation according to the phaseological method.

\section{EPOCH. DIFFERENTIATION BETWEEN THE SEXES.}

(a) Among Hunter Folk.

On the lowest stage of culture known to us among the hunter folk, there is only one kind of division of labour, viz. that between the sexes. The man is a hunter and warrior, he procures all animal food, he prepares for himself 
the weapons and tools which he needs for that purpose, and trains his boys when they have reached a certain age. As a matter of course all other labours devolve on the woman, whose task is a much harder one. As a complement to the man, who procures the animal food, the woman is expected to gather vegetable food, berries, roots, bulbs, etc., from the forests, carry home water and wood, keep up the fire, erect and pull down the huts, prepare the skins and make the clothes. When travelling she is laden with all the goods as well as with the smaller children. In addition to this she naturally bears the children, who among nature folk are suckled for a very long time (on an average about three years).

Mrs. Eastman, speaking of the Dakota woman, says : "Her work is never done. She makes the summer and winter dwellings. For the former she peels the bark from the trees in the spring-time, and for the latter she sews the deerskins together. She tans the skins from which she has to make coats, shoes and gaiters for her family, and still other cares press upon her. If she bear a child she cannot rest and nurse herself. She has to row the boat for her husband. Pain and weakness must be forgotten." I From every sphere of action that is considered a man's part she is rigidly excluded, for custom and superstition enforce it. Among the now extinct Tasmanians, Bonwick says: "The men provided only the food taken in kangaroo hunting, but the women climbed trees to catch the pouched rat, they dug out roots with sticks, they gathered shellfish on the shore and dived into the sea for oysters and fish, in addition to their maternal duties." 2 Among the Eskimos "The man makes his weapons for hunting and also builds the boats, which the woman covers with leather. He hunts and fishes, but having made sure of his booty he troubles himself no more about it, and he would feel it a degradation even to draw a seal out of the water. The women kill the game, cook them, dress the skins, make clothes, shoes and boots from them. They also do duty as butchers, tanners, shoemakers and tailors ; unaided by the men they build and repair the houses and tents. They leave the procuring of the timber to the

I Waitz-Gerland, vol. iii. p. 100.

2 Daily Life of Tasmanians, p. 55. 
men, but not of the stones, which may be heavy enough to break their backs, still the men look on indifferently." x When marching, travelling or changing the place of their settlements, the women are laden like mules with all the household belongings. "The Abipones, having entrusted to the women all their luggage, i.e. bows and quivers, the whole of the household utensils, pots, calabashes, cans, weaving-loom, etc., they enter upon the journey bearing only a lance, so as to be fully prepared for fighting as well as for hunting." 2

On this culture stage the woman is generally considered as a specific burden bearer. Dobrizhoffer says that it is on the principle that the man must always have his hands free when on the march for hunting and fighting, but this argument is only partly correct. As we have already seen, the Eskimos never drag the shot seal out of the water. Of the Chippeways, Hearne says: 3 "When the men have killed a big beast, the women are sent out to bring it home." Even when travelling in quite peaceful times, with no opportunity of hunting, the women only are laden, whilst the men, as Forster has observed among the Tanna, "walk at their ease without any burden." 4 The chief reason of these actions must be the laziness of the men and the low position of the women.

Thus we see from these examples, which might be multiplied indefinitely, the differentiation between the labours of the sexes is sharply defined. This is rigidly fixed by custom and tradition, as well as by religious superstition. It is looked on as degrading to "do woman's work." Later on, in the same way, slave labour was despised by the free man. Because the woman is the weaker vessel she has, paradoxical as it sounds, to take upon herself all difficult, painful and thankless labours. She is looked upon as an enthralled, unhonoured beast of burden and work. From the economic standpoint this harsh relationship between man and woman, which has no parallel in the animal kingdom,

- David Cranz's History of Greenland, iii. p. I6.

2 Dobrizhoffer's History of the Abipones, ii. pp. 142-146.

3 Hearne's Journey to the Northern Ocean, p. 90.

4 Forster's A Voyage Round the World, B. iii. Io4. 


\section{THE HISTORY OF SOCIAL DEVELOPMENT}

is easily understood. Through differentiation of work man and woman supplement each other; they are economically dependent each on the other. The stronger creature profits by this dependence, and the woman, being the weaker, has to fall under the rule of the man, and this relationship of ruler finds its expression in primitive marriage and the family. Marriage is originally nothing else than the earliest form of slavery, the slavery of the woman, but this definition must of course not be taken in the wholly harsh sense of the later culture stages.

Differentiation between men on this stage is hardly existent. In rare instances a chief is chosen who takes the lead in times of war, but may be deposed at any moment, and holds very slight authority. There is, in addition, the " medicine-man," who claims direct intercourse with the spirits, and is the man especially consulted for internal diseases; but the veteran warrior is by far the most influential person in the whole tribe. Thus the later differentiated forms of king, priest and slave are already typified in a shadowy manner in the chief, the medicine-man and the wife.

(b) Pastoral People and Lower Agriculturists.

As we have already seen, the primitive sex division of labour among the hunter folk consisted in the fact that the man procured the animal food and the woman, beside many other labours, the vegetable. From hunting and the gathering of vegetables, the two natural sources of nourishment, there resulted two means of artificial food production, namely, cattle rearing and agriculture. When, then, a race rises from natural food production to cattle rearing, the man from a hunter becomes a herdsman, i.e. he becomes an artificial food producer, whilst the woman continues to contribute her share towards the maintenance of the family in the old primitive fashion by means of gathering vegetable food. But in the cases where the transition from savagery to barbarism goes on the lines of the artificial cultivation of vegetable food, then for a time the man still remains a 


\section{DEVELOPMENT OF DIVISION OF LABOUR 209}

hunter and fisher, whilst the woman rises to artificial food production. Cattle rearing has evolved itself out of hunting as agriculture out of plant gathering. Hence it has been said with reason: "Man discovered cattle rearing and woman agriculture."

Thus the division of labour between the sexes among pastoral people and lower agriculturists is now easily understood. The old primitive form of division of labour in which the man procures the animal and the woman the vegetable food is at first simply maintained. Among pastoral peoples cattle rearing is the business of the man exclusively; the flocks are the property of the man, and women are rigorously forbidden to have anything to do with the guarding, rearing or feeding of the flocks; hence all those labours devolve on the women, which we have already seen among the hunter folk-the procuring of vegetable food, the putting up and taking down of the tents, and all disagreeable and fatiguing occupations. Among the lower agriculturists husbandry is the exclusive affair of the women; the men among most of the Indians belonging to that stage ${ }^{\mathrm{r}}$ take no part in it, but unlike the pastoral peoples have remained on the lower stage of production as hunters and fishers. As will be perceived later on, we shall find the same principle of division of labour carried out in all its force among the same nature peoples who carry on cattle rearing and agriculture together ; here agriculture is all the more the exclusive business of the women, since all occupations relating to cattle rearing belong only to the men, and are strictly forbidden to women. The very important results of all this on the social position of women on these lower stages we must analyse more precisely elsewhere.

\section{EPOCH. DIFFERENTIATION AMONG MEN.}

Advancing from the Hunting, Pastoral and Agricultural Indians to the Oceanians and Africans, we find a higher form of differentiation of labour, as well as that of the sexes. This is differentiation among men and the specialization of Industries. Until now, economically speaking, man's work

I Waitz-Gerland, iii. 79. Lafitau: Meurs des Sauvages Americ. ii. 78 . 


\section{THE HISTORY OF SOCIAL DEVELOPMENT}

was homogeneous among each class, whether hunting or pastoral, war or the production of weapons and tools. ${ }^{x}$ This sociologically important process of differentiation was similar among the Polynesians, the African tribes, the Homeric Greeks and the early Romans under their kings, and among the races of Western Europe spoken of by Tacitus. The course of its development may be divided into three sub-stages:

(a) Earliest division of work among semi-civilized peoples.

(b) More developed industrial differentiation among civilized peoples.

(c) Differentiation among people having capitalistic organization.

The first of these sub-stages corresponds exactly with our early industrial phase; the second to the phase of cities, civic economy; the third to the early and mid capitalistic phase. As these are already known to us, our remarks need be few.

\section{The Continuous Growth of Differentiation.}

If we look at the development of differentiation as a whole, we are chiefly impressed by the fact that from stage to stage it grows continuously, fashions itself into ever more refined systems of ramifications, and becomes an increasingly important element in labour organization as a whole.

(a) At first Differentiation did not interfere seriously with individual production. Most of the differentiated workers were slaves in the large establishments which were almost self-sufficing, leaving very little work for the free independent artisan.

(b) On the lower stage of civilization, coinciding with the Metal Age, industrial differentiation reached a high level. The extraordinary progress which raised the technique of the Peruvians, Chinese, Japanese, Egyptians, Indians, Assyrio-Babylonians, etc., ${ }^{2}$ so high above that of all nature

I Waitz, iii. 99.

2 A bibliography on handicrafts in ancient states is given in Sombart, Dor mod. Kap. i. II5. 
folk, was directly due to the rise of the small workmen, the free as well as the unfree. And everywhere among these peoples the existence of numerous towns, those strongholds of differentiation which serve as a rallying point for all specialized forms of labour, from the small artisan to the sculptor, doctor, poet and philosopher, shows us that the organization of labour has entered upon a new phase. Numa Pompilius, the second king of Rome, has the credit of founding Guilds of flute players, goldsmiths, blacksmiths, fullers, dyers, potters, carpenters and shoemakers. These differentiated more and more, and in the early days of the Empire, when the commerce of Rome reached its high-water mark, the shoemaker's trade was specialized into sandal, boot and slipper making, as well as dainty shoes for women. The trade of the coppersmith was differentiated into that of the pottery moulder, makers of candelabra, lanterns, weights, helmets and shields. Of iron workers (ferrarii) there were four kinds: claustrarii (locksmiths), cultrarii (cutlers), falcarii (sickle makers), gladiarii (sword cutters). And in the municipal economy of the Middle Ages, the development of specialities was repeated in almost exactly the same order as in ancient Rome.

(c) But differentiation among men was at its highest point in capitalistic organization. Specialized production had struggled very unequally with the industrial organizations; the latter, however, had not always been successful. Now capitalization crowded out private enterprise, once for all removing every barrier which had prevented the union of the different forms of specialized labour, and Differentiation made a rapid bound upwards. Not only did it triumph in those vast labour co-operations in which thousands of operatives and powerful machinery unite in one complicated organization, which like some intelligent monster can accomplish gigantic labours, but it took possession of the life and habits of the private householders to the last man, and the ramifications are still continually spreading. ${ }^{x}$ In the sphere of electrotechnics alone, twenty-two new trade appellations had arisen, whilst in the manufacturing

I In 1882 the ind ustrial census notified no fewer than 6, I 79 different trades in the German Empire, and in 1895 this number had increased to 10,397 . 
industries they mounted from $2,66 \mathrm{I}$ to 5,506 , of which 2,079 were new occupations in the public service. ${ }^{x}$

\section{Economic and Social Differentiation.}

Whilst this long course of evolution was being traversed from the social unit, the tribe, up to the great civic organism, economic and social differentiation, or in other words trade organizations and class distinctions, were constantly amalgamating in a close and remarkable manner. Both phenomena stand in a reciprocal relationship, in which, however, it is not the trade organization as was formerly supposed, but the class distinction that must be looked upon as the originating force.

This fact is easily perceived in the origin of trade. If we except that early form of the industrial phase which we found in Africa, and which shows us that evolution might have taken quite a different course there, since the African type represents a departure from the main stream, we find that among all those peoples who have risen later on to Capitalism, trade organization was not the cause but the result of class distinction. At first, through the vicissitudes of war, there arose social differentiation between masters and servants, and among the latter the economic differentiation between various trades was then established; the first skilled workers were bondsmen who were forced to it by their masters, and even the first free craftsmen were the poor, the cripples and the aliens, who, yielding to the pressure of circumstances, consented to place their personal services at the disposal of some one who paid them. Thus at the very beginning class distinction was the primary and trade organization was the secondary motive.

In the developed industrial phase on the lower stage of civilization, the class system underwent a considerable expansion, and often became crystallized into a more or less rigid caste system: this is illustrated by the Egyptians, who, according to Herodotus, were divided into seven, and according to Diodorus Siculus, into five castes; by the Empire

× See Rauchberg: Gewerbezählung im d. R. 1895. Arch. f. söz. Gesetzgebung und Statistik, xiv. 270, 1899. 
of the Incas, whose abnormal development we might characterize as a huge " joint household" swollen into an empire; by the ancient Japanese and Chinese; and, as is well known, in its strictest sense by the Indians, who, under the influence of a ruling priestly caste, have built up the caste system into a monster of paltry complexity and foolish rigidity. The same principle as that by which the choice of profession is decided, not by individual talent or inclination, action or merit, but by birth, i.e. the class to which the individual belongs, is found in operation among the Greeks and Romans, then throughout the whole of the Middle Ages and up to the present day, although with gradually diminishing force. For even though in our modern society no limits are prescribed for the choice of a calling, yet this depends in so great a measure on the social and pecuniary position of the family that in most cases the choice of a calling is still determined by the class to which people belong, in spite of all legal freedom.

The widely spread idea that division into classes is a result of division of labour is thus an erroneous one. The history of labour from the very beginning makes it evident that the reverse is the case. If we consider the last century alone, we are forced to this conclusion, for in no period has economic differentiation made such gigantic progress, and at the same time never has there been such a levelling of classes.

This complicated relationship will be easily understood if we consider the intimate connection between class and profession. As we have already seen, all labour organization has been called into existence by two different kinds of organizing groups: by social union and family alliance. The latter by its own force has only produced the two organizations of the family and the manorial system, but was strongly reinforced by the rise and development of industrial and capitalistic organization, by means of hereditary trades and entailed property. Now there lies in the family alliance the cause of every class or caste system ; castes and classes are only possible because they transmit in certain families, from generation to generation, rights of some kind (either concerning rank or property) from which other families are excluded, for no castes or classes can be created by any 


\section{THE HISTORY OF SOCIAL DEVELOPMENT}

variety of personal effort. The special connection between calling and class and the principle, which at first sight might seem paradoxical, by which not individual endowment but the fact of belonging to a class decides the choice of a profession, explains the share taken by the family alliance in the organization of labour, and hence equally accounts for the other fact that in spite of increasing differentiation in the latest development, the severity and rigidity of the class system is disappearing; for in this development the family alliance, in its economic and social aspect, is weakening, and social union, which is hostile to all caste and class, is greatly strengthened and begins to overcome its rival.

\section{Differentiation among Men and Civilization.}

With differentiation among men there begins not only a new epoch in economic history, but also in the history of the whole process of culture; a new world comes into existence, the civilized world which at this point severs itself from that of nature folk. For it is only through the differentiation of labour that nobler cravings arise and have a chance of being satisfied. We can only enjoy civilized life when we have opportunity to do and give of the best that is in us, whether in the making of a tool or household implement, or in works of art or studies of Science and Philosophy.

After man had lived for countless millenniums in nature conditions, the artificial production of food brought in the first great change from nature to culture, and with the differentiation between men a second epoch-making change brought human society out of the condition of nature folk on to the stage of culture folk and up to civilization. As will be remembered, we endeavoured in a former chapter: to divide all the peoples of the earth into culture stages according to food production. And thus we arrived at the three stages of Savagery, Barbarism and Civilization. The first two were easily distinguished from each other: the artificial production of food by means of cattle rearing and agriculture furnished us with as clear and definite a character-

s. 84 . 
istic as we could wish for classification. But to the question as to the character of the III stage, the answer was still to seek. Now we can give that answer: from an economic standpoint, civilization is nothing else but the differentiation of men into callings. This statement we will now endeavour to prove.

If we compare civilized people with nature folk we shall find the following as the most characteristic signs of the existence of civilization:

I. All civilized peoples are agriculturists ; many combine cattle rearing with agriculture, but there are also civilizations in which cattle rearing is either altogether absent or plays a quite secondary part.

2. They are all sedentary.

3. They far surpass nature folk in the density and size of their population.

4. They are as a whole divided into classes.

5. Among all civilized peoples the division of labour goes beyond sex: the men are differentiated into labourers, artisans, merchants, soldiers, priests, rulers, etc.

6. There are everywhere towns as well as villages, and hence a contrast between town and country dwellers.

7. Goods are no longer exchanged directly, but by means of a universal standard : money.

8. A very distinguishing characteristic is writing, for all civilizations possess an alphabetical writing, while this, with the exception, of course, of recent instruction, is the case with no nature folks.

9. Whilst the nature folks live in groups, the civilized are organized into states. The state is a characteristic sign of civilization.

( $\mathrm{r}, 2$ and 3). Agriculture is the indispensable condition of civilization. In the first place, it makes people sedentary, and it is only by this means that the characteristic benefits of higher culture can be established; the roaming hunters and the pastoral nomads have to consider mobility and ease of transport above everything else. Secondly, only 


\section{THE HISTORY OF SOCIAL DEVELOPMENT}

through agriculture is the soil so thoroughly cultivated that the density of population, which for reasons to be explained later is so necessary to civilization, can be brought about.

(4). Although agriculture is the foundation and essential condition of all civilization, this has only recently been the case. We have studied a number of agricultural peoples, such as the maize-growing Indians, who have remained far beneath the stage of civilization. Another cause must therefore be added. Agriculture must be so effectually carried out that food is provided for the whole by the labours of a part of the population, so that certain forces may be freed for the intellectual life. But in order to extort this greater thoroughness of labour demanded by civilization from the innate laziness of men, pressure is necessary; and this pressure is exercised by compulsion, in particular by slavery, in general by the Class System.

(5). Through the collaboration of agriculture and slavery the economic differentiation of men is brought about, and hence we have now the turning point, the economic nerve, the key to the existence of civilization before us; for all the points under consideration until now were simply the external conditions, and all those still to be considered are nothing more than the results of this process of differentiation.

(6). Next, as far as the origin of the town is concerned, we have already seen in an earlier chapter that the town is and can be nothing else than the point of concentration of the different forces of labour, and in fact the whole course of development of civic affairs and of differentiation, especially in our time of great cities, proves in what intimate connection these two phenomena stand.

(7). As soon as differentiation has attained a certain grade of development, a universal standard, money, must be invented, for differentiated people can only exist if they are able to exchange their products, and money is originally only a medium for facilitating exchange. This facilitating of intercourse becomes an economic necessity when goods of such various kinds are produced that direct exchange becomes tedious and impossible.

(8). Similarly the function of writing must have originated after differentiation, for writing is communicating with another at a distance of space or time; a means of union 


\section{DEVELOPMENT OF DIVISION OF LABOUR 217}

quite unnecessary when every man lived for himself alone. For the differentiated need means of communication when apart, whilst among the non-differentiated this form of intercourse is either totally superfluous or can be managed in an amply sufficient way by means of simple signs, such as snapped twigs or pictures, etc.

For the same reason differentiation can only take root where the population is sufficiently dense; the great distances separating the hunting tribes and pastoral nomads living scattered in remote regions do not permit of intercourse between the differentiated workers, and so make a higher development of differentiation impossible. ${ }^{\mathrm{I}}$ This is the reason why towns are of such great importance for the expansion of this organization, for they represent the point of concentration of the population in which density and division of labour can proceed in a reciprocal relationship.

(9). Finally, the state from which Civilization takes its name ${ }^{2}$ arises originally from the fact that one tribe, or generally a group, subdues another and annexes the vanquished as slaves. If several such tribes unite on a warlike or peaceful footing, then a social body of considerable size comes into existence, which then stands under uniform leadership and produces a social division into two or more classes, into governing and governed, into those who profit and those who produce profit. The state is thus at first an organization which is composed of socially differentiated divisions, classes or castes, and this class-forming is, as we have already seen, an important factor in the differentiation of men. But while the separate classes undertake various economic and social functions, they form a complicated organism the separate parts of which, as Menenius Agrippa pointed out in his fable of "The Belly and its Members," stand in reciprocal relation to each other, are dependent on each other, yet are unconsciously inspired by directly opposed interests-class interests. In order to maintain this system erected on such an unsteady basis, some regulating power was needed-civic power. And " civic power" is originally simply the organization of the class which profits and which

I See Lubbock: Prehistoric Times, ii. 67.

2 Civilization $=$ relating to a community, with a radical meaning of work, and a resting-place.-(TRANS., see Skeat.) 
has a lively interest in the preservation of the state, and at the same time the power to maintain it in its hands. This it does through its organization, which the profit-producing class lacks. At the same time, the integrated sphere attains through the state the size which is necessary to raise the organization of differentiation into a system. The state is thus even in its very beginning an important preliminary to, and moreover the necessary result of, the differentiation of men. ${ }^{x}$

Summing up we may now say: The existence of Civilization depends on differentiation among men.

This conclusion is confirmed by History and Ethnology. The differentiation of men begins not suddenly but very gradually, and its beginnings extend over a long space of time. Equally gradually and everywhere there marches with it Civilization and the possession of writing; the peoples who stand in the beginnings of the differentiation of men, as for example the previously mentioned Oceanians, Africans and the Romano-Germanic peoples in the Middle Ages, are on that account generally and quite rightly called " semicivilized." As soon as Civilization has reached a certain high grade so that it is able to exercise its complete influence on the civic and intellectual life as among the historic nations of Antiquity and among the Christian peoples of the Middle Ages-then there comes unmistakably into evidence the clear figure of Civilization with all its characteristic features. And from that time differentiation and civilization proceed hand in hand in the closest connection and reciprocity. The differentiation of men and Civilization thus give evidence in History and Ethnology of a perfect parallelism in their course of development.

\section{EPOCH. THE DIFFERENTIATION AMONG WOMEN.}

The process of differentiation does not end with the second epoch, the organization of professions among men. There follows a third epoch, the differentiation of women, which began in the most recent times-the Woman's s See Part III. 


\section{DEVELOPMENT OF DIVISION OF LABOUR 219}

movement, which can only in the light of Phaseology be clearly understood in all its historical coherence and in its true significance.

The first epoch of division of labour, the so-called division between the sexes, consisted of the separation of male and female labour, whereby the activity of the men as well as of the women remained essentially homogeneous.

The second epoch, "the differentiation of men," which might be more accurately called the epoch of differentiated male labour and of homogeneous female labour, dates its earliest beginnings from the higher stage of Barbarism; with Civilization the movement sets in increasingly swiftly in the mid capitalistic phase, with rapid expansion taking possession of the sex. Even to the last man all abandon individual production and resort to co-operative labour.

Yet for long centuries this advance was limited to the men; until far on in the domain of civilization woman takes no share in it worth mentioning. The whole of female labour remains homogeneous, i.e. all women with diminishing exceptions still carry on undifferentiated activities which men designate "Domestic labour."

But the process does not come to a standstill with this second epoch. Differentiation does not stop with men, but with irresistible power extends beyond them and includes women. Therewith a new epoch of the division of labour dawns. If the process runs the same course among women as it did among men, a higher form of labour organization, a perfectly differentiated society must be the issue, and a third epoch in the history of labour, the epoch of differentiated men and differentiated women, ensue. We must admit we are still at an immense distance from this point, and as yet we know not towards what goal the development will progress. Still, statistics declare that already quite a third of all women over fourteen years old have been pressed into business life and pursue " callings," which in the second epoch was only the case with men. If only a fifth part is added, differentiated women will be in a majority. Thus the beginnings of a new epoch have made such headway that the phase theory cannot possibly pass over in silence this phenomenon with its extraordinary sociological importance. 


\section{Early History of the Differentiation of Women.}

The transition from the second to the third epoch was not accomplished quite so schematically as the above remarks might suggest, namely, in such a way that differentiation first included all men up to the very last one, and only then extended to the first woman; really the movement which we now call the "Emancipation of Women" has a much longer preliminary history. As far back as the Middle Ages there existed a "Woman's Question," although in a different sense from what it means in our day. For there were even then many women to whom marriage was denied, and who, therefore, were obliged to have recourse to other vocations. I In consequence of the vows of celibacy which forbade marriage to enormous numbers of priests and monks; of the ceaseless feuds and endless wars which decimated the men; and also of the decrees by which the guilds made marriage difficult for their members, even forbidding them to have a home of their own, the surplus of women in the Middle Ages was even greater than in our own time. Although we possess no exact statistics, various censuses make this quite evident; for instance, a census of the population of Frankfort in 1385 showed $I$, 000 males and I, I0o females, one at Nuremburg in I449 gave I,000 adult men and I,207 women, one at Basle in I454 gave I,000 men and I,246 women. ${ }^{2}$ Numbers of unmarried women found a refuge in the numerous convents and béguinages which sprang up everywhere in the thirteenth century, so that eventually there was a béguinage in every large town. The "béguines". were most helpful in the burghers' houses, where they did sewing, washing, spinning, weaving, etc. Many women were also employed in the manors. The spiritual and temporal lords possessed, as we know, in their strongholds and castles large workshops, in which often as many as three hundred bondwomen were engaged in sewing, embroidering, and weaving, and in making gala garments, of which a store was always kept. After the Crusades the position of young women was much improved. Maidens on horseback apparelled

× Bücher: Woman's Question in the Middle Ages, p. 4 et seq.

2 The following statements are mostly taken from Lili Braun's excellent book, The Woman's Question. 
in sumptuous clothes accompanied the spiritual and temporal lords to the imperial Diet and Councils, and went in galaxies into the hunting field, and in the towns they filled the sisterhoods. Women, too, forced themselves slowly into the trades. At first it was simply the wife and daughters who helped the artisan in his work ; then they came forward themselves as independent artisans, principally in wool and linen weaving, but also in furriery, baking, heraldic embroidery, gold spinning, etc. ; and now began the war between women and the guilds, with whom they competed by the undercutting of prices. At first the attempt was made to compel them to enter the guilds, and then diversely in the thirteenth century to drive them out again. The strife ended with the defeat of the women, and by the end of the seventeenth century they were everywhere excluded from the guilds.

\section{Modern Differentiation among Women.}

In the mid capitalistic phase, with the age of machinery the differentiation of women entered upon a new stage. The Middle Ages, while feigning compassion, had banished the women who were striving after a livelihood and independence into the melancholy retreats of the cloisters and the béguinages, and drove them decisively from handicraft; but now capitalistic organization, eager for profit, opened wide her markets to them. At first women only undertook home industries, which were the more popular as the workers need not leave their homes. Factory life now went one step further, and enticed large numbers of women out of the home circle; for the machine, which takes the place of muscular force, by steam power depreciated the physical superiority of men, and enabled women and even children, through underselling, to enter into successful competition with men. In 1788 there were in England and Scotland I 42 spinning factories, which employed 59,000 women and 48,000 children. Through the same two-edged means, that is by underselling, women were continually enabled to appropriate fresh vocations, especially in businesses as book-keepers, accountants, correspondents and as saleswomen, of whom there were very few even in the middle 


\section{THE HISTORY OF SOCIAL DEVELOPMENT}

of the nineteenth century, the rapid increase having occurred only in recent times. An equally rapid multiplication took place among barmaids. Other spheres of female activity were millinery, needlework, flower, feather and lace making; and frequently bookbinding, the making of cardboard, paper, gutta-percha and india-rubber, as well as the preparation of chemical, microscopic and surgical apparata, of perfumes, essences, photographs, etc. In a number of branches of industry the women outnumber the men, notably, as might be expected, in millinery, laundering and in the making of corsets, cravats, braces, artificial flowers, steel pens and gold and silver lace; in spinning, knitting, embroidery and glove making, and the sphere of labour is constantly extending and being recruited by ever-increasing numbers of " business women." In the postal and telegraph service, for example, in Great Britain alone, 25,928 women are employed; in 1864 there were 3,000 women teachers of music in Paris; in Prussia the number of schoolmistresses increased between 1825 and I86I from 705 to 7,306 . Finally, women acquire the so-called higher vocations for themselves and become nurses, apothecaries, journalists, painters, writers, doctors, etc. ; they are everywhere gaining ground, and in almost all countries the University course is open to them. In Australia, women enjoy nearly the same rights as men in regard to organization and pursuits; , they practise as doctors, teachers and lawyers without restriction, and are employed in the public service as factory and school inspectors and as ministerial officials. In Germany, development is very far from having reached this point. Even in 1898 the then Prussian minister of public instruction spoke of the projected "girls' public school" for Breslau as a "little flame" which he " must extinguish before it became a devastating fire."

But in spite of all natural and artificial hindrances, the course of the differentiation of women is progressing in the most varied spheres with the irresistible force of a natural law. Out of the female population of $26,36 \mathrm{I}, \mathrm{r} 23$, the trade census of June I4, I895, enumerated $6,578,356$, of whom I;313,957 were domestic servants who had some trade as chief occupation; taking out of account the children under fourteen years old, we find a percentage of 36.21 of women 
earning their own livelihood. If we include the women who engage in trade as a secondary occupation, more than another million must be added. We even find that the number of wage-earning women increases in swifter proportion than that of men. From I882 to I895 women's business activities increased to $1,005,290$, and men's to $2,133,517$; that is to say, women's increased one and a half times as rapidly as men's.

To sum up, there is no doubt that the modern woman's movement differs essentially from that of the Middle Ages; in the first place with regard to its extent, but above all with regard to the spheres accessible to female labour. On the whole, female labour in the Middle Ages was limited to the so-called specific womanly occupations, i.e. activities which are carried on within the home. Modern business, on the contrary, with the exception of domestic industry, withdraws women from the exclusive sphere of the home, and offers her new fields of labour which place her by the side of the business man.

\section{Causes of the Modern Differentiation among Women.}

But the causes, too, of the modern differentiation of women differ essentially from those of the Middle Ages. As a first cause of a general nature, one must consider the tendency inherent to higher culture of specializing labour more and more. The principle of the division of labour is so intensely efficacious that it could not possibly be confined to one half of humanity. When all men are differentiated, the women's turn must inevitably come. Differentiation is in fact, as we have already indicated, a universal law that governs not only the development of all human society, $i$ but all living organisms.

Secondly, through the growing differentiation of men, as we have already mentioned, more and more labours were abrogated from the mistress of the house, at first by handicrafts, then by capitalistically organized industries. In consequence of the cheapening of industrial produce, the domestic economy of the family becomes more and more limited; domestic labour undergoes an important reduction, 


\section{THE HISTORY OF SOCIAL DEVELOPMENT}

and women are more and more driven out of their former circle of activity. These activities of the house mistress were formerly of great value and wide extent, including the grinding of wheat, the preparation of flax, spinning, weaving, washing, bleaching, brewing, soap and candle making, the production of all kinds of preserved fruits and herb medicines for the sick, the storage of provisions, which were laid in in large quantities, further the making of clothes, baking of bread, the carrying of water, and for the most part the gardening and care of pigs and fowls. ${ }^{x}$ Women are now exempt from most of these toils through the growing co-operation of labour; what yet remains to the house mistress is substantially cooking, house cleaning and bringing up the children. And even in the remaining duties there is great amelioration through the introduction of water pipes into the houses, gas fires, electric and gas lighting, with central heating; and further, there are schools, kindergarten and training institutions. Again, in that most important sphere, the training of children, there have been radical reforms. The mediaeval women were overburdened with numerous children, among whom there was much more illness and mortality than in these times. Now, on the contrary, the over-population of the world has given rise to the adoption of the so-called "Two child system," which is spreading in ever widening social circles. Not only has the work of the mother become less in this way, but also the school has taken a great deal of the educational work out of her hands. The result is that the more highly gifted seek to escape from the circumscribed and petty sphere which furnishes no satisfactory life purpose, and specialize in their life work, and the less capable seek lucrative occupations and stream in large numbers into factories or business.

As a last reason we may mention the wide-spreading bachelorhood and late marriage among men, in consequence of which for women of the middle and higher classes the chances of good marriages are so unfavourable that the

I The preparation of food in the Middle Ages seems to have been very informal. In the burgher houses of the town the whole cooking for the week was done on Sunday, and the meals made hot if desired on the week days (Henne am Rhyn: History of the Habits of the German People, i. 346). 
fathers of daughters are compelled to let them learn a profession betimes unless they can provide them with an income.

Again, the increased expense of living in cities ${ }^{I}$ and the convenience of buying ready-made necessities has done much to contribute to the woman's movement. The garden, stable and kitchen no longer calling for woman's labour, and the house being small and compact, there is neither need nor space for the unmarried aunts and others who formerly lived and helped in the house; even domestic servants can be dispensed with, and must seek other work.

* $* *$ *

In consequence of these and other causes women are forced into outside work; the competition is so great that they take any wage, and offer themselves for very little money if they can only get work. For example, the Konfektionär, a newspaper of Posen, tells us that dressmakers earn nothing the first year, only six to ten marks a month in the second, and after two years never more than thirty marks a month. Plain needlework only brings in two marks for a dozen fine handkerchiefs, ladies' size, and three marks, gentleman's size, with extra fine workthe maximum rate of production being five handkerchiefs a day. For men's clothes the pay is from fifteen to twenty pfennigs (about $2 \mathrm{~d}$. to $2 \frac{1}{2} \mathrm{~d}$.) for making a pair of trousers.

* * *

\section{Concerning the Future of the Differentiation of Women.}

Against our division of the historic evolution of differentiation between the sexes among men and among women, the objection may be raised that it is quite uncertain whether the modern "woman's movement" actually represents the beginning of a new epoch, and that we have built up the third stage of our system in the future, and consequently on a completely hypothetical basis. Actually, the idea that differentiation in so far as it has included men will continue to advance until it includes all women, or the great majority of them, may at first sight seem Utopian. If one thinks of the outgrowths of the high capitalistic

I Sombart, ii. 493. 
phase, for example, the exploitation of children, ${ }^{\mathbf{r}}$ and pictures some of the results of a universal female differentiation, the assumption may well be that the present woman's movement is only one of those transitory errors which are unavoidable in such a universal revolution as that caused at the beginning of the Machine Age ; that it is not a question of a new epoch, but rather is it an unfortunate episode or a social disease which must be stamped out at all costs.

Whole libraries have been written on the question of the future of the differentiation of women. To summarize even briefly all that has been uttered at stormy meetings by its opponents (much fewer of late years) and by its partizans would exceed the limits of this work, and since only the future can give an answer, we might have passed it over lightly were it not a duty to phaseology to practise her own peculiar method of observation on a subject of such burning interest and of such extraordinary sociological importance.

If we consider the origin and development of all life on the earth-from the tiny amœba to the modern great statewe find that the ceaseless transformation of lower forms into higher is founded on a differentiation which is being improved from stage to stage.

This law leads the smallest simplest living organism through the whole organic kingdom up to man, and thence along the same lines it guides him without a break through the more highly organized kingdom of culture, from nomadic simple tribes up to the great states. If then differentiation is a universal law of evolution, an epoch of the differentiation of women will no longer seem so paradoxical as it formerly did; in fact, it will represent nothing more than a small extension of that interminable line exactly in the same direction as that in which development has moved for millions of years.

Descending to a somewhat lower point of view, we arrive at the same conclusion. The great law of all labour organization is co-operation. But there is no doubt whatever that an epoch in which not only men, but also women

I In the winter of 1895 it was stated that in the Dukedom of Meiningen there were 2,809 employed children as. compared with 2,037 unemployed adults (Stillech's The Toymaking Industries of the Meiningen Oberland, p. I9 et seq.). 


\section{DEVELOPMENT OF DIVISION OF LABOUR 227}

perform differentiated work, presents a higher stage of labour organization than another in which only the male half of the community is differentiated.

Yet if we leave these high watch towers which afford us such a comprehensive outlook but yet give no view of the land of the future, and look closely at the last tract which the process of differentiation has traversed, namely, the most modern epoch now dawning, the thought must arise whether a conclusion as to the coming epochs might not be drawn from the completed ones by a comparison between male and female differentiation. And in fact we find here remarkable analogies and parallels.

A first parallel is as follows. At the beginnings of differentiation man was torn away from his " natural callings" in order henceforth to perform work for others by skilled specialization, and no longer for himself alone. Only unwillingly did the man consent to this change ; necessity and strong compulsion, as we already know, had to conquer his resistance. And the same fate now threatens the women. Their ideal, their " natural calling" is that of mistress of a home, and only under the pressure of social conditions do most women specialize, and they look upon the calling they are obliged to follow as a disagreeable voyage on the high seas, and they leave it again as quickly as possible to take rest in the haven of marriage. But circumstances are stronger than men ; it is just in the great social movements that we are most clearly aware of the iron sway of inexorable sociological laws which, heedless of the wishes of individuals, govern development and continually transform society. And it is right that it should be so, for man is by nature a conservative " misoneist;" a hater of new things, he looks upon heredity and custom, especially when he is on a low stage of development, as a standard of conduct, so that no improvement could have taken place and no progress could have been possible from the beginning if the causes of development had been dependent on individual wishes. Therefore it is useless to discuss whether the differentiation of women is desirable or not.

* * *

In this first point there is agreement between male and 
female differentiation which we shall find wanting in a second aspect. As men specialized, the new) movement embodied itself in new forms of organization, in the manorial system, in the free handicrafts of the family, the tribe and the guild, and later into capitalistic forms of organization. The woman's movement, however, has originated no new organization up to the present; the differentiated women have simply become members of the old forms. And yet a complete development of female differentiation must be considered as an impossibility, unless it is based on a new form of organization and can take root in it.

The opponents of the woman's movement point out rightly that the most important calling of the woman, that of the mother, is not compatible with other callings, except that of mistress of the home. If the woman works in a factory or any other business the children must necessarily be neglected, and the nation, in which female differentiation spreads, will die out or fall into decay. The professional woman and marriage are antithetic and inimical; the differentiated woman cannot escape from the choice "business or marriage." Either business becomes to her a hateful chain which represses and stunts the strongest impulse of woman's nature, or it must be abandoned. On this very ground, say its-opponents, the differentiation of women must remain limited to a minority, whilst the majority, as it was in the beginning, is now and ever shall be, will see in the family and in the home their true sphere of action.

The partizans of the woman's movement cannot get away from the truth of this argument, but they bring forward the legitimate reply that the hindrance is not insuperable, but rather is based on the primitive form of our domestic organization with which naturally the differentiated woman is not in harmony. ${ }^{I} \mathrm{Up}$ to the present day, our housekeeping has tenaciously the characteristics of small concerns and detailed administration in the most extreme sense. In sixty households, sixty housekeepers are engaged in catering for sixty families, in kindling fires on sixty hearths and preparing food in several hundreds of pots and pans, and cleaning all these utensils by the drudgery of hand labour, since machines

I See Lili Braun's Franenarbeit und Hauswirtschaft, 1900. 
are not practicable in these Lilliputian industries. In an organized domestic association, on the contrary, a tenth part of the women would be able to accomplish all these labours in a better, cheaper and less arduous manner. If we united these sixty small industries into one organism, one great central kitchen, presided over by a qualified chef, we could offer a richer and more varied fare at much less cost. Each family might be connected with this centre by a lift, which would convey to it regularly the desired meats and drinks, like the little table in the fairy tales. Into this wholesale domestic administration would enter those labour saving machines, invented long but scarcely taken into use : a washing-up machine cleans in a few minutes hundreds of pots and pans, central heating saves the labour of carrying coals and ashes, a vacuum cleaner keeps the dwelling clean, boot-cleaning machines, gas fires, electric lighting, steam laundries, etc., would relieve the mistress of all those petty depressing occupations under which she now sighs. If we compare the two pictures, then the labour performed by the housewife in her dwarf industry, tedious and stupefying as it is, must from an economic point of view with regard to material and working power be looked upon as a waste of national resources, which must amount to millions daily. The upbringing of children also assumes another aspect in such an organization. Man is a social being, and his education must above all things be a social one. In the large families of former times the necessary conditions were present, but in the modern family the children are frequently brought up in isolation until their schooldays, and by this means is evolved the germ of that irritable and egotistical character which spoils so many lives.

In the new form of organized joint households the children would live together from their earliest days, at least during the hours while their mothers were occupied; they would early be accustomed to intercourse with their fellows under the supervision of women who are specially qualified for this position, and who are highly educated, as is not the case with many a house mother. By this means the really tragic compulsory choice which confronts the modern woman, "profession or marriage," would be eliminated-domestic organization makes "profession and marriage" perfectly 
compatible. For the woman can now devote to her children the whole of the time she does not give to her business, and allow the blessing of maternal influence to work upon them just as much as formerly, when the household made such demands on her time.

The future of female differentiation will thus in all probability depend on the development of a new form of organization, which would take its place as eighth after the seven already known to us, and which we might call the Co-operative joint household. But the rise of such an organization lies yet in the future. Assuredly there is among all differentiated women in towns an undeniable need for it. Therefore the immeasurable advantage of organization must certainly in time find expression, especially if we bear in mind the financial advantages. Moreover, the elements of the transformation of domestic dwarf industry into a co-operative wholesale industry exists certainly in the direction of the processes of labour co-operation and of our whole development. -Woman has relinquished brewing, baking, spinning and weaving already, and these labours will shortly be followed by cooking, cleaning, washing and dusting, to the proficiency of organized labour. No great alterations in building would be necessary. In cities there are already four-storied blocks of flats possessing all the disadvantages of living in communities without a single advantage that they would have if they were built for co-operative life. Yet it cannot be denied that tendencies towards such an organization are as yet only evident in germ, and are seen chiefly in co-operative industries and in those American hotels where well-to-do families, forced by the scarcity of domestic servants, take up their abode. Moreover, we must not refuse to admit that the development of domestic organization has to encounter enormous uneconomic obstacles, such as the mighty power of habit, of heredity, of custom, and the outspoken hostility of the non-differentiated woman, especially her anti-social outlook. As further factors there are our social sensitiveness, which has become self-conscious through our thousand divisions into classes and sub-classes, and the tendency towards exclusiveness inherent in every family union. Objections of such grave significance make it evident that the foundation of the first Co-operative joint household, 
which was certainly anticipated by the highly gifted Fourier, must be relegated to the dim future.

\section{Thus at the point at which we have arrived, mighty} obstacles stand in the way of the stream of development, and the new channel can only be hollowed out slowly. Yet from another point of view the slowness is not to be wondered at, for a fully developed female differentiation, as its opponents and partizans agree, is inconceivable without a thorough transformation of the whole of our culture. But great movements have, as we know, leaden feet, and this proposition brings us to a third point of comparison between male and female differentiation.

Even if we do not know how long the last prehistoric phase, which we called the early industrial one, lasted, yet it is evident from the history of technique ${ }^{\mathrm{I}}$ that this phase must have continued for countless centuries among all those peoples who first rose into civilization. Only a male differentiation slowly and gradually reached a certain height in which the discovery of metals may have played a similar part to the invention of machinery in our own dayonly then did it amount to a revolution in the whole structure of society, to the transition from barbarism to civilization, which last is essentially nothing else than the epoch of fully developed differentiation between men.

And as a new epoch dawned with the differentiation of men, so we venture to assert will the differentiation of women, if it should prevail, be accompanied by such tremendous effects and transformations, not only in the sphere of domestic economy, but over all spheres of culture, that we are justified in seeing in the still insignificant beginnings of the present woman's movement, the dawning of a new great epoch of the whole life of culture. For female differentiation denotes the economic independence and personal freedom of the woman, equal rights for both sexes, and the downfall of the sovereignty of man; the cleansing of marriage from venality in the portionless woman and dowry hunting in man, and the limitation of the family with regard to propagation and natural selection; and in consequence × P. 105 . 


\section{THE HISTORY OF SOCIAL DEVELOPMENT}

the breaking up of the class system and of capitalistic organization and equal social rights for all members of society. Moreover, it denotes an enormous increase in the power of production, or productivity, since now the whole of the second half of the human race is likewise differentiated or rather organized, and thereby performs work of the highest value, by which means the working time of men can be reduced to a reasonable standard. And finally, when labour association has forced the most reactionary element of society, that is woman, out from the darkness of the house and the vicious circle of petty and stupefying activities into the road of progress, the stream of the new development must gush forth fructifyingly over the most distant spheres of culture. The narrow theological religion, which is chiefly supported by women and is handed down from generation to generation, must give way to a nobler conception of the world of life. Morality, Justice, Art and the whole of life will blossom out under the strengthening force of womanly influence into lovelier and more human forms than was possible in the time of one-sided male rule. Briefly, as the differentiation of men led from Barbarism to Civilization, so will the differentiation of women lead out of the "Barbarism of Civilization" into a new epoch, and this transformation, proceeding on purely evolutionary lines, slowly and gradually gliding almost unnoticed over the generations, will only then be thoroughly perfected. On this account of all movements which at the present time are to be seen in the sociological planetary system, the process of female differentiation should be considered the most important and the most significant.

But we have lost ourselves in dreams of the future; if we turn our eyes again from these giddy heights to the deeps of the past out of which our culture has arisen, it will serve our purpose if we once again briefly recapitulate the most important changes in the history of woman's labour.

\section{Epoch : Differentiation between the Sexes.}

(a) Among Hunters. - The woman gathers food in woods and fields, and brings up the little children. In addition to 


\section{DEVELOPMENT OF DIVISION OF LABOUR 233}

this, all burdensome, difficult and disagreeable work devolves upon her, and she is looked upon as a specific beast of burden and general drudge. Since these peoples are nearest to nature one perceives what importance may be attached to the vague expression " natural callings of women."

(b) Among pastoral peoples the woman is responsible for the vegetable food and the man for the animal. Owning the flocks the man preserves his economic superiority, and the social position of the woman is very low. ${ }^{x}$

(c) Among the lower agriculturists, on the other hand, where the man continues to a great extent in the low productive methods of the hunter stage, while the woman cultivates the fields, she becomes economically the stronger, and attains the highest position in the whole culture development until then.

\section{Epoch : Differentiation among Men.}

The woman gives up the work in forest and field. Her sphere of activity is now transferred to the house, where the most manifold occupations, chiefly the preparation of raw materials, fall to her share. Her social position, especially on the lower stage of civilization, has again deteriorated.

\section{Epoch : Differentiation among Women.}

Capitalistic organization of men does away more and more with the need for woman's housework, and forces her now out of the house into differentiated occupations.

If we now review the whole course of the development of differentiation, we shall see its position more easily if we bring the seven phases of labour organization into the three epochs of differentiation, and characterize them as sub-stages by Arabic figures and italics, by which means the following combined summary will result :

I. Epoch: Differentiation between the Sexes.

(a) In the self-sufficing clan.

I. Primitive clan phase.

(b) In the extended clan.

2. High clan phase.

I See Sociologie der Fortpflanzung (Vol. II in this series). 


\section{THE HISTORY OF SOCIAL DEVELOPMENT}

II. Epoch : Differentiation among Men.

(a) Beginning of male differentiation.

3. Early industrial phase.

(b) Developed industrial differentiation among men.

4. High industrial phase.

(c) Capitalistic differentiation among men.

5 and 6. Early and high capitalistic phase.

In the latter begins the

III. Epoch : Differentiation among Women.

(a) Differentiation includes one-third of the adult women.

7. Later capitalistic phase. 


\section{PHASEOLOGY OF INTEGRATION}

IN the foregoing chapters we have twice traversed the vast sphere of the history of labour; the first time we considered exclusively the morphological structure of labour organization, and the second time the development of the division of labour or differentiation. But as a mountain must be looked at and climbed from all possible directions if we wish to know its configuration and peculiarities, so it is with the history of labour, which we may quite well compare with a mountain rich in ravines and ridges, summits and valleys. These first two ascents have not yet defined it exhaustively, and therefore we propose to attack the subject from yet another side, namely, from the standpoint of integration.

But what is integration?

As we have already said, differentiation is founded on the co-operation of labour. Every differentiated man is thrown upon the collaboration of others and dependent on them ; the tailor, the smith, the doctor, etc., can only exist if they can exchange their produce or services for others, and if they unite among themselves and with others-or, to speak scientifically, if they come into mutual integration. Integration in a sociological sense, as apart from the mathematical or biological, is nothing else but the sum total of all activities which unite differentiated elements, and in the shape of trade and commerce, of transport and mercantile association, arrange and effect the exchange of goods among differentiated persons. As in mathematics and biology, so also in sociology is integration the necessary antithesis to differentiation. The two ideas can be separated in theory but not in practice: the division of labour without exchange 


\section{THE .HISTORY OF SOCIAL DEVELOPMENT}

of goods is impossible, and equally an exchange of goods can only have any meaning when the division of labour makes it necessary. Both phenomena proceed consequently hand in hand; they stand in reciprocal relationship, in fact, they may be regarded as the two different sides of labour association, like the reverse and obverse of one and the same medal. We might interpret Integration as exchange of goods, in a sociological economic sense, if this idea were not too narrow, since this merely indicates the final aim of all the activities embraced by Integration. In a society constituted on the basis of ideal justice, one might be able quite rightly to say division of goods instead of " Integration," for if every one possessed only those goods which as a differentiated individual he had earned by his own labour, if every one consumed only in the proportion that he produced, then as a matter of fact the division of labour and of goods would be perfectly correlated ideas. Since, however, on account of family inheritance, we are as yet a long way from such a condition of the distribution of riches, ${ }^{\mathbf{I}}$ the expression Integration will commend itself as applicable to sociology, since it has already proved useful in other sciences as' an antithesis to differentiation.

If we now undertake to analyse the history of the development of Integration in its most important phases, it will not be a question here of sketching in a highly coloured picture of trade and commerce, but the problem upon which we must concentrate ourselves will consist first in finding a uniform principle of division, a standard with which we may gauge the height of Integration; and secondly, on the basis of this measurement in placing the whole course of development as clearly as possible into its natural sections.

For the phaseology of labour organization we employed as such a standard a number of forms of organization which, like the rings in a tree, gave the age and height of development; similarly for the phaseology of differentiation we made use of the proportion of the differentiated to the nondifferentiated members of the community. For the phaseology of Integration there is, as we shall see shortly, no more sharply defined principle of division and no more efficacious and natural standard than the way and manner in which - See Sociologie des Fortpflanzung. 
the exchange of goods is accomplished, that is, in other words, the height of development of the means of exchange - of money, in the broadest sense of the word.

As a consequence, we shall begin the brief sketch of the History of Integration which is everywhere connected with what we have already been considering with

\section{The Phaseology of the Medium of Exchange.}

I. Phase: Hordes without Barter.

On the lowest stage there is no exchange and no barter. The isolated hordes live apart, and the community may well be termed self-supporting. Since the only differentiation of labour is that between the man and woman, these only come into integral relationship, and the expression of this integration as we can now say is primitive marriage, which must be considered in the first place as an institution of a predominantly economic character.

\section{Phase: Intertribal Barter without Medium of EXCHANGE.}

The first exchange of goods originated in the fact that neighbouring tribes or hordes formed an alliance in order to exchange their local produce in intertribal markets in the form of guest gifts. ${ }^{x}$ On this stage there is external but no internal trade. Exchange among hunters, lower agriculturists, etc., is everywhere direct ; goods are bartered for goods, money does not exist.

\section{Indirect Exchange of Goods by Means of Natural Money.}

With the beginning of differentiation among men in the early industrial phase of labour organization, internal trade is now added to external or "Foreign" trade. At first, as for example among the Polynesians, this trade was carried on without means of exchange and without money, goods being exchanged for goods. But among the Melanesians, and still more among the Africans, the need of a medium of exchange appeared before this. That is to say, as long as

I See p. I6I. 


\section{THE HISTORY OF SOCIAL DEVELOPMENT}

only a few articles were exchanged, as for example in many Congo markets, where the shore dwellers exchanged their fish for the bananas of the inland tribes, the direct bargain, the exchange of one thing for another, sufficed, but as soon as trade spread to several kinds of goods, some medium had to be invented.

As a first medium, natural money sufficed, i.e. goods that were in such general demand that they would be received by every one in payment. Such goods are :

I. Food which will keep for a long time, such as dates, blocks of salt, Kola nuts, etc.

2. Clothing: woollen stuffs, skins, furs (fur money in North Europe), etc.

3. Ornaments, especially beads and shells.

4. Implements : hatchet blades, knives, swords, nails, etc.

Among many peoples these different kinds of natural money were arranged on a recognized system; thus among the Indians of the Missouri basin:

2 knives $=\mathrm{I}$ pair of stockings.

2 knives and I pair of stockings = I blanket.

The foregoing and $I$ blanket $=I$ gun.

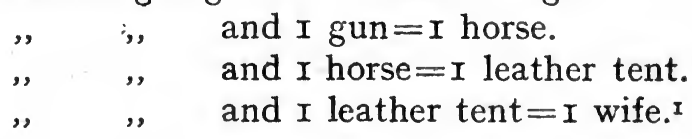

Among cattle rearing peoples the favourite kind of natural money is

5. Cattle money. Among pastoral communities cattle are the greatest treasure, towards the increase of which all their thoughts and energies are devoted. He who has cattle lives in abundance, and can buy wives with it who are obliged to work for him, and through sacrifices can procure the favour of the gods, can have his diseases cured by the witch doctors, and can have a ceremonial funeral. He who possesses no cattle is portionless, and has to hire himself out to others as a servant. Cattle money increases by itself, has the further advantage that like capital it yields interest, and

Is Schurtz: Entwicklungsgeschichte des Geldes, S. 157. 
even the clumsiness of this money is only illusory, since it can transport itself on its four legs. These advantages make cattle suitable for a general medium of exchange, and this cattle standard was especially widespread in ancient times among those peoples who rose later on into capitalism, particularly among the Indo-Germanic races. Thus in the poems of Homer, when real money was as yet entirely unknown, everything was measured by cattle, the value of all objects was so expressed. The brazen armour of Diomedes is worth nine head of cattle, that of Glaucus, which was of gold, was worth a hundred, a tripod costs twelve head of cattle, a skilful slave is reckoned at four, Eurykleia pays Laertes with twenty head of cattle. A girl is called "Alphesiboia" because she brings her father cattle at her marriage. Among the Celts "cumal" means at the same time a slave and the value of three cows. In old High German "fihu" (cattle) is the expression for money, whilst in older Russian kuna (money) means marten (fur money). The oldest Roman money was cattle. Pecunia, which is also money, comes, as is well known, from pecus $=$ cattle ; an ox was worth as much as ten sheep. ${ }^{\mathrm{I}}$

With the transition from barbarism to civilization and with the beginning of the Metal Age, there appeared a new medium of exchange, namely:

6. Metals. Among the Africans iron as well as cattle is already in use as natural money, and among the old American culture folks, in addition to cocoa beans, which were put in sacks containing. 24,000 each, and woollen stuffs, copper work in recognized forms, tin plates and gold dust in goose quills were current as a means of payment. In Oriental antiquity, among the Sumerians and the Hittites, the Assyrians and the Babylonians, in Egypt, Palestine and Phœnicia, metals were everywhere in use as a universal standard of value, although among the Greeks and Italians cattle still remained for a long time almost the only medium of exchange. ${ }^{2}$ In Greece and Rome it was copper that first came into favour as money; the Latin aestimare, to value, originally meant to value copper : aes timare. Metals were originally weighed in every single transaction, so that the

I Vgl. Schrader: Ling.-hist. Forschungen ubev Handelsgesch., i. I I 5

2 Schrader, i. I22. 
scales were the inseparable companions of every merchant. In the course of time metals were moulded for purposes of currency into certain forms, rings, discs and small pieces to put in the purse. Even in that condition the scales were still indispensable, so that metals had not yet cast off the character of customary or natural money; but the transition into money in the accepted sense of the word was not far distant.

IV. Phase: The Exchange of Goods by Means of a Minted Metal Currency.

This transition occurred through the invention of coinage. In order to avoid the clumsy proceeding of weighing the metal in every single transaction, the authorities and the body of the clergy furnished the wealthy sanctuaries with pieces of metal of fixed weight and bearing their stamp, which stated the value without weighing. Hence a new medium of exchange was created, which, irrespective of any other use, was exclusively intended to facilitate barter as its only function.

It was differentiation of all goods into the standard articles and means of exchange that was of such great importance not only to trade, but to the whole administration, that we may, with reason, call the introduction of coinage epoch making: with the transformation of natural money into coinage took place the transition of natural into money economy.

The invention is alleged to have originated with the Greeks of Asia Minor and quickly spread over the whole of the Old. World. In Athens, Solon changed the money fines of Draco, which were really cattle fines, into real money fines, whilst he fixed the price of a sheep at one drachma, and of an ox at five drachmas. In Rome, King Servius was the first to have coins made with the pictures of oxen, sheep and swine; coins which thus evidenced most clearly the transition from the cattle standard to the money standard.

V. Phase: Exchange by Toren Money.

Natural products of universal utility had sufficed for the exchange of goods in the early industrial phase-in the 
mid industrial phase it was necessary to replace the clumsy natural money then in use by coinage as a medium which should satisfy the increasing need of exchange. But metal money was too unwieldy for the great and rapid transposition to capitalistic organization, and now the last step was taken by which money was deprived of all material value, and, so to speak, of all weight; a sheet of paper with a few words written on it can, if supported by credit, represent any desired value, and renders far better service as a medium of exchange than big sums of ready money, of which the payment, despatch and transport would entail so many formalities that speedy transactions of considerable extent would be almost impossible, or in any case would be made enormously difficult.

Token money first came into use in the form of paper money issued by the State. Whereas previously the State had, in' times of distress, resorted to the depreciation of money, it now issued bank notes which had the advantage of not bearing interest. The first issue of state paper money $\mathbf{I}$ was at the end of the seventeenth century and at the beginning of the eighteenth : in I69o in Massachusetts, and in $I 720$ in France. The credit currency system, which depends on deposits and cheques, appeared everywhere with the beginning of the mid capitalistic phase, first in England and America, but in Germany only since the middle of the nineteenth century, and since then has so increased that in Germany now at least nine-tenths of all business transactions are effected by means of credit. Hence a new system of integration has been developed that stands in the same relation to capitalistic wholesale trade as metal money did to retail trade; in conjunction with the modern means of trade and transport this system lends wings to the unwieldy millions, and enables capital of any size to be concentrated without loss of time and without formalities wherever it can bring in interest and increase production to the greatest advantage.

If we pause for a backward glance, we see that there were

I Bills of exchange were issued as far back as the year 1200 (Blancard: Le commerce de Marseille au moyen age, p. 3). 


\section{THE HISTORY OF SOCIAL DEVELOPMENT}

five phases into which we could subdivide the history of the evolution of integration, namely:

I. Barterless horde economy.

II. Exchange of goods without a medium of exchange.

III. Exchange of goods by means of natural money.

IV. Exchange of goods by means of coinage.

V. Exchange of goods by means of token money.

If we connect the first three phases into one epoch, we arrive at a three-stage system, the one devised by Hildebrand $\mathrm{x}$ in his national economy, which is the universally accepted one, namely, the division into the three epochs of:

\section{Natural economy. \\ II. Money economy. \\ III. Credit economy.}

In the first of these epochs the exchange of goods is effected by natural exchange, in the second by means of money, and in the third chiefly on the basis of credit.

If to this classification we add the seven phases of labour organization (here given in italics and Arabic figures), the following conclusion is reached :

\section{Epoch : Natural Economy.}

(a) Barterless clan economy.

I. Early clan phase.

(b) Intertribal barter without medium of exchange.

2. Mid clan phase.

(c) Internal and foreign trade by means of natural money. 3. Early industrial phase.

\section{Epoch : Money Economy.}

(In Israel since the ninth and eighth centuries B.C., in Greece since the seventh and sixth, B.C., in Rome since the fifth and fourth, B.C., in Germany since the Crusades.)

4. Mid industrial phase, and

5. Early capitalistic phase.

× Jahrb. f. Nat. Ök. 1864 . 


\section{Epoch : Credit Economy.}

(In England since the end of the eighteenth century; in Germany since the middle of the nineteenth.)

6. Mid capitalistic phase.

7. Late capitalistic phase.

(A still more comprehensive summary will be found later on, pp. 252 and 324.)

\section{A WIDER SYSTEM OF INTEGRATION.}

The means of exchange is the most important standard of the development of integration, but not the only one: thus the means of transport and of communication, the distance between producer and consumer, the extent and number of intermediary changes, the size of the integrated unit, etc.-all these phenomena might be taken as standards of development. The phaseology of integration will assume a different aspect as classified by any one of these standards, but the graded system just drawn up will suffer no essential alteration through these new aspects, and it will scarcely be enriched by the use of them.

\section{A Phaseology of the Means of Transport}

would give us somewhat the following epochs :

I. Epoch: In antiquity the sole means of transport was man himself; all burdens had to be borne by human beings, a task which, as we have already seen, frequently fell to the women. As the earth's surface was for the most part covered with impenetrable forests, as there were no roads except those trodden out by the foot of man, and as impassable rivers, swamps and insurmountable mountain ranges impeded traffic on all sides, only light goods and those that took up little space could be exchanged, and the selfsufficing character of the tribe was a matter of necessity on account of the difficulty of transport.

In II. Epoch man invented artificial means of transport: he trained beasts of burden suitable for use on the steppes and the deserts, and he built means of conveyancethe ship and the cart. At that time the principal transport 


\section{THE HISTORY OF SOCIAL DEVELOPMENT}

was by water, which was used for trade and traffic during eht prevalent roadlessness. At first it was the rivers and streams which were navigated for purposes of trade on rafts and skiffs, on paunches and leather skins, which were sewn together and inflated, in dug-outs and in bark canoes, in fact, in vessels of all sorts; but when man had learnt how to make practicable boats the sea became the most important of all thoroughfares, the medium of integration par excellence. For whilst rivers often hinder a journey by their rapids, and also only lead in one direction, the sea on its broad shoulders bears the heaviest loads in all directions, and the wind drives them easily to their desired goal : hence in this and in all succeeding epochs the immeasurable importance of seaboard for the development of trade and traffic, as well as of culture as a whole.

III. Epoch : With the invention of the steam-engine, of the steamship and of railroads, the difficulties of land travel and the hindrances from wind and weather by sea are overcome. All countries of the earth are now united in a daily intercourse ; the epoch of world commerce begins.

\section{The Phaseology of the Means of Intercourse}

Is shown by a similar three-grade system :

I. Epoch: The only means of intercourse is speech. Later on comes communication by signals (nocturnal fire signals, the African drum language, etc.), and further the system of runners.

II. Epoch : Intercourse through writing.

III. Epoch : Intercourse through mechanical apparata, the press (newspapers), telegraph, telephone and postal system.

This grade system corresponds in all essentials with the division into natural, money and credit economy. Since therefore we arrive at no new divisions we will now bring the history of integration to a close, for this work has only attempted to sketch the outlines of phaseology, and not to fill in the enormous space with detail. 


\section{A FURTHER SYSTEM OF STAGES}

WE have now investigated the history of labour on three different sides, and have thus arrived at three different and mutually complementary systems of stages. But even then our subject is not exhaustively represented; there are yet other standpoints whence the history of labour may be treated phaseologically. From these further grade systems result, which can be added to the supplementary ones already discussed. A great number of such grade systems have been drawn up by ecomonic investigators, and have been subjected by Sombart $\mathrm{x}$ to a searching inspection and critical appreciation. However, we will give a brief account only of those economic systems which endow those already known to us with new aspects. In conclusion, all the sections will be collected into one great summary, which will enable us to review the whole phaseology of labour from all sides in one general picture.

\section{* * * *}

We met with one of the oldest of these economic grade systems in the last chapter (Development of Integration). This was the system of Hildebrand, who divided economic development into the three great epochs of natural, money and credit economy.

Engel's system follows this closely; his headings are :

I. Individual production for one's own needs.

II. Exchange economy, which may be subdivided differently according to the method of exchange :

I Die gewerbliche Arbeit und ihre Organization. Braun's Archiv. für soziale Gesetzgebung und Statistik, xiv. Bd. s. 368-405. 


\section{THE HISTORY OF SOCIAL DEVELOPMENT}

(a) An occasional phenomenon; exchange of superfluity.

(b) A regular phenomenon.

(c) An essential phenomenon.

III. Capitalistic economy, characterized by the production of goods according to the needs of supply and demand. This advance has been necessitated by the expansion of the economic sphere.

In this system the grade of labour association, or more strictly speaking the proportion of individual to co-operative production, is taken as the standard. The transition from the original individual economy into social economy here comes very clearly into evidence. If we compare this classification with Hildebrand's, "capitalistic economy" corresponds to " credit economy," the intermediate stage corresponds to " money economy," and the lowest grade to " natural economy." Both systems take integration as the standard.

Schmoller, ${ }^{\mathrm{I}}$ however, founds his system on quite another characteristic of development, namely, the size of the economic body, or of the circle of organization. His stages are :

I. Tribal, village or market economy.

II. Town economy.

III. Territorial economy.

IV. State or national economy.

The relationship of this division to our first (or form) system ${ }^{2}$ is easily perceived. In the first stage our first three phases are brought together rather too summarily for sociological methods; village economy answers to the earlier and civic economy to the developed "industrial organization" state, and national economy is our "capitalistic organization." The III stage is not equivalent to the others, but is a transition stage; hence from the sociological standpoint the classification would run better thus:

I. Clan economy.

Transition: Village economy.

ISchmoller: Jahrbuch, viii. 1884 , S. ${ }_{5} \mathrm{ff}$.

2 Refer to pp. 198 and 199. 


\section{Civic economy. \\ Transition : Territorial economy. \\ III. State or national economy.}

Closely connected with this is the widespread and much discussed system of Bücher, who takes "the distance which the goods must travel from producer to consumer" as the standard of development, and arrives at the following classification :

I. The stage of self-sufficing units (purely individual production, barterless economy) in which goods are consumed in the locality in which they are produced.

II. The civic stage (production to order or stage of direct barter), in which the goods pass directly from the producer to the consumer.

III. The national stage (production of wares for general sale, stage of circulation of products), in which goods have to pass regularly through the hands of a series of intermediaries before they come into use. ${ }^{\mathrm{x}}$

The three stages of the system correspond to the three stages of our first (or form) system in the following manner : The stage of self-sufficing units is clan organization, with which the phase of early industrial organization is to be included. The civic stage is developed industrial organization, and the national stage is capitalistic organization.

Bücher certainly puts his boundary line between the lowest stage and the two others quite differently to our own system. In his scheme the lowest stage includes not only the social economy of all nature folk, but also that of the whole of antiquity, including even the development of Athens and of the Roman Empire. The second stage only begins with the rise of the towns in the Middle Ages. This limit is drawn falsely, for it gives rise to the erroneous idea that the Middle Ages followed on antiquity as the next highest phase of development. But, as we have seen, social economy in antiquity advanced as far as the fifth, the early capitalistic phase; ${ }^{2}$ while the height of this development was only later attained by the Romano-Germanic peoples. 3 Accord-

× Bücher : Die Entstehung der Volkswirtschaft, 4 Aufl. 1904, S. 108.

See p. $173 \mathrm{ff}$.

3 See p. $177 \mathrm{ff}$. 
ing to Kulischer I it was at the close of the Middle Ages, but according to Ed. Meyer ${ }^{2}$ it was not until the seventeenth and eighteenth centuries.3 Secondly, with this arbitrary division which classes under one single head all the first five phases of development, amalgamating the social economy of the primitive tribes with that of the Roman Empire, the first important section of the history of labour and of social economy, namely, the rise of the differentiation of men, which divides nature folk from culture folk and calls civilization into being, is completely ignored and concealed by the very vague expression, " the stage of self-sufficing units," which would be better translated "predominant individual production," so that quite a false impression of development is the result. Thirdly, all historians and national economists agree that in antiquity, even in Greece from the seventh and sixth centuries B.C., and in Rome from the fifth and fourth centuries B.C., money economy has been prevalent. But self-sufficing units and money economy are wholly incompatible ideas. As long as the household is self-sufficing, as long as each family produces only for itself, the invention of money is as unnecessary as postage stamps would be in a country which possessed neither traffic nor a postal service.

But if we alter this boundary between the two first stages which does violence to facts as shown above, we make the civic stage begin with civilization, that is with the town, and we take the expression "the stage of self-sufficing units" in the literal sense; then the Bücher system, to which one might well add a fourth or future stage of world economy, gives a clear division of development. It is difficult for a summary to do justice to the theory, which should be read in the original, especially the brilliant exposition from page I65 onward.

The most thorough study of the national economic system has been made by Sombart, who, in his fine and oftquoted works, which contain a wealth of valuable thought and stimulating ideas for sociologists, arrives at the following classification :

- Jahrb. fur Nat. Ök. iii. Folge 18, Bd. S. 348.

2 Die wirtschaftliche Entwicklung des Altertums, ebenda 9, $\mathrm{Bd}$.

3 See also Beloch, ebenda I8, Bd. S. 626. Hartmann: Zeitschr. fur Sozial. und Wirtschaftsgesch., iv. Bd. I896, S. $153 \mathrm{ff}$. 
I. The stage of individual economy is that in which the whole demand of a unit is met by its own supply.

II. In the second or transitional stage, which might be described as a lower form of social economy, the demand of a unit is met by the supply from a number of co-operating units, but the individual unit still remains practically self-sufficing.

III. The stage of social economy is that in which the differentiation between producing units and their absorption into one indivisible whole is fully accomplished.

In this system, the extent of interdependence, as universally understood, is taken for the standard of development. The general conception suggests that the classification has become somewhat colourless, and that the dynamic force which flashes for example from Bücher's analysis has been lost. Besides, the expression "individual economy" is quite inaccurate, since man has always produced socially, and since, as Sombart himself says, "it is this very economic stage which exhibits communistic features." But this defect is merely a result of the abstract character of Sombart's own classification, which similarly represents the quintessence of all other systems of stages, classes them all together, and finds for the resulting mass the most comprehensive expression that can possibly be imagined.

Finally, I should like to mention yet another classification, that of Roscher, which indeed is not a system in the strictest sense of the word, but which strikingly characterizes the three much discussed epochs from a new standpoint.

All production of goods is, as we know, composed of three factors: I. Natural products ; 2. Labour; 3. Capital. Nature provides many things voluntarily, and these are essential for all production, since the raw material for all goods can be drawn from no other source. But most of the goods must be wrested from Nature by labour, i.e. by human agency, which alone can make the raw material available for use. Many labours can be performed simply by unaided physical means, and especially with the hands, but labour becomes much more effective through the employment of tools and other objects. Such things as are employed 
in the production of other things are, in the language of economists, called "capital."

Of these three sources of production, in the I Epoch of the course of development physical conditions predominated and the freely offered gifts of Nature were supreme; in the II Epoch it was Labour, consisting of all kinds of handicraft, which impressed her stamp on production; and in the III Epoch, Capital came to the fore, which, especially after the invention of machines, facilitated the production of goods to an unheard of degree. It is hardly necessary to add that these three epochs thus characterized correspond with the three epochs already brought forward in our first or form system, with "clan organization," with "industrial" (mechanical) and with "capitalistic organization."

There has been much discussion as to which of all these classifications deserves the first rank, or indeed which is the only right one. This discussion is unprofitable; not only are the various theories not at variance, but they mutually supplement each other in one great harmony. Since each system of stages presents its subject to us from a fixed and special point of view, no perfect view of the history of labour can be given in an exhaustive manner by any single one of these systems, but only through a uniform recapitulation. We indicate at the head of each column the peculiar feature that underlies each division; in the horizontal sections will be found a characterization of the separate phases of development, which is certainly more complete than if they were presented by any one single system.

If we glance through the table the next thing that will strike us is that the beginning and end of the different systems do not entirely coincide in the way which we might have expected. But this irregularity is only a superficial one, and easy to be explained. The epochs naturally do not pass over into one another with a sudden leap, but slowly and quite gradually. In every epoch we must distinguish a time of birth, of blossoming and of decay, thus causing three substages, which according to old custom we may call early, mid and late ; hence we notice that the "late" substage of one epoch always corresponds with the "early" 
substage of the succeeding one. Thus the first epoch is really divided into an early clan, a mid clan and a late clan, which last is identical with the early industrial ; and in the same way the late industrial is again identical with the early capitalistic, etc. Accordingly the "Form" division might be written out more in detail, and if the identical phases were each time joined in parentheses, it would run as follows :

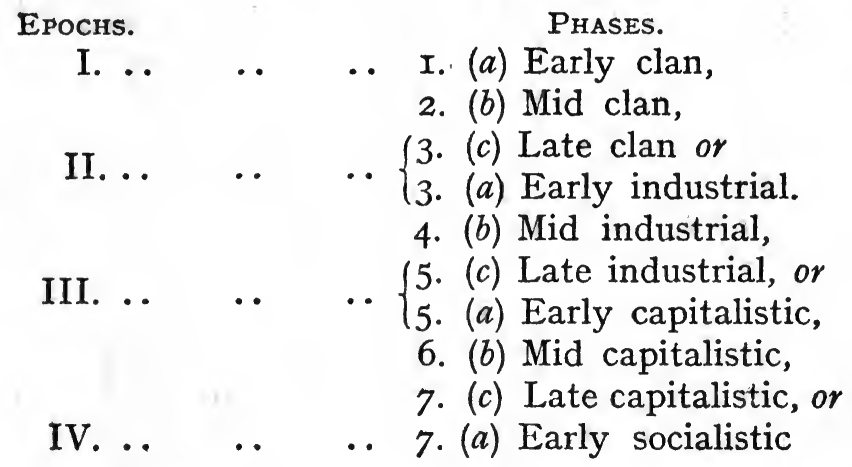

(which will probably lead to a mid socialistic phase, then a late socialistic one, which again may possibly be identical with an early anarchical one, and so on).

Such a recapitulation we will endeavour to give in the following final review.

The characteristics of each system thus prove in what manner the separate substages are united into epochs. In the Form system (columns I and 2, p. 252) the first appearance of a new organization is considered as "epoch making ;" in the other systems, on the contrary, only the full completion of a new social phenomenon is thus considered. Thus, for example, in Hildebrand's system the epoch of money economy does not begin with the appearance of money nor with the early industrial phase, but with the mid industrial ; the transition from natural to money economy - the phase of natural money, as it is significantly called-is reckoned in with the previous epoch ; and similarly the III Epoch does not start with the first beginnings, but only with the full development of credit economy, i.e. with the high capitalistic phase.

Thus with regard to the begining and ending of the 


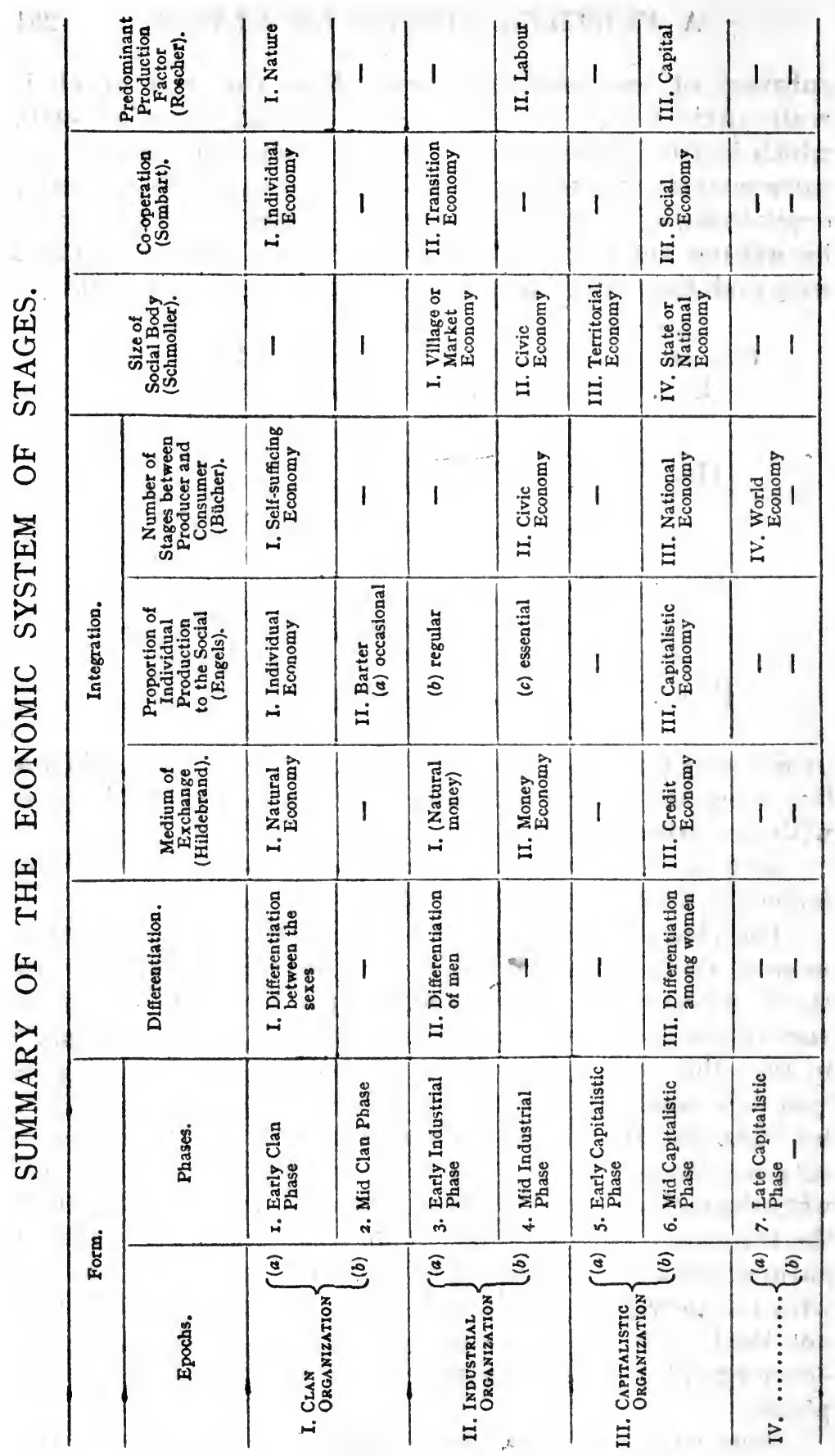


epochs the various theories are only in apparent or superficial contradiction. At the same time, we may perceive from this study - and this remark holds good for the whole of phaseology - that the division of development into phases gives us a much clearer and more accurate view of facts than the division into epochs, with which, for reasons of clarity. we cannot however dispense. 


\section{THE ECONOMIC LAWS OF DEVELOPMENT}

THE process of the development of culture constantly brings new forms to light ; phase follows after phase, everything moves onward, there is no stagnation. But the movement of culture has been slow to reach human consciousness ; and, since all new life is bound up with a destruction of old forms, man has attempted - and that not only in early times-to stem the process of culture, which made the course of evolution even more painful than it already is in itself. Truly the future stretches dark before us; what are the new forms, to which we shall have to accommodate ourselves and into which we shall irresistibly be amalgamated, and what are the worn-out ones which are to be cast aside?

It has been said that history teaches us nothing of these things. Since culture is constantly developing fresh phases, since nothing repeats itself-excepting for the case, which we need not here consider, of the progress of backward peoplesand since no link in the great chain of causality is like the previous one, except possibly in external appearance and that delusively, the inference of analogy fails; we cannot say that this condition of culture has already existed once, and that therefore we may expect the same results again. No, in the process of the development of culture circumstances are constantly changing; thus history teaches nothing.

But, as we have already explained, there is yet another method of inference. Culture is the constant development of new phases, not haphazard, but in a fixed direction. And if we can settle the direction of the movement we can conjecture coming events, i.e. the next phase of culture, but not the fate of this or that nation. For nations come and go, they have their struggle for existence and disappear, they 


\section{THE ECONOMIC LAWS OF DEVELOPMENT 255}

are, as it were, only the raw material of culture which glides over the countless races of short-lived nations like a highmasted frigate over the changeable waves. But our business here is not with the fate of nations, but with the course of culture phenomena.

What is then the direction in which the sociological function of political economy moves? I think the foregoing statements will have proved satisfactorily that, as a matter of fact, social development progresses in a definite and definable direction, and that it proceeds according to clearly recognized laws. Let us now try briefly to formulate these laws of the development of the organization of labour.

\section{The Law of Size.}

In every social body there exists the desire to extend.

In the same way as men tend to unite into groups, so these groups have the tendency to combine in increasingly greater social and economic forms. At first there were small independent hordes which roamed over wide regions, later the hordes united into tribes, then the tribes into nations, the nations into great states, and finally the great states into gigantic political systems. The goal of this movement is world empire, that shall weld together all the peoples of the earth into one great economic union. Examples of the temporary attainment of this ambition are the world empires of Persia, Rome, Great Britain and of modern commerce.

The law of agglomeration effects the increase of the economic body through the annexation of fresh groups either by force or by peaceful penetration due to trade, and through increase of the number of members by natural propagation. Further factors are natural selection and the struggle for existence, by which the stronger drives the weaker to the wall. Finally, in order to succeed, an organization must consist of individuals who are increasingly capable of co-operation.

\section{The Law of Form.}

The development of labour organization is caused by the continual entry of new elements, and with every new element 
there arises a new phase. But the new element does not so much supplant the older one as join on to it, so that the organization of labour is constantly adding fresh forms to those it already has, and only later on do the older elements wither away.

At every step the element that was just appearing in the last phase will become the main characteristic of the following one.

\section{The Law of Organoplastic Groups.}

There are two kinds of organoplastic groups : the social union and the family union. These have stood in a mutually antagonistic relation during the whole history of labour.

With the increasing activity of the social union the economic importance of the family union must decline.

\section{The Law of Coroperation.}

Simple co-operation such as that employed in building the Egyptian pyramids always merges into division of labour.

Since the beginning of the machine age a co-operation based on division of labour has arisen between mankind and machinery, by which purely mechanical labour which was formerly performed by man is increasingly devolved upon the machine.

\section{The Law of Differentiation.}

In every economic body there exists the tendency to differentiate more and more between the various forces contained in it.

As a rule, internal differentiation precedes external.

\section{The Law of Integration.}

Differentiation and integration stand in a reciprocal relationship. Every advance in the systematic division of occupations involves an advance in trade and intercourse; and vice versa.

Every economic body has the tendency to develop all the forces within it into a uniform system of integration, in which eventually every individual will come into more or less direct connection with all the others. 


\section{The Law of Centralization.}

Every economic body has a desire for centralization, i.e. uniformity of production. At first the separate industries produce only for themselves in an unconnected and haphazard way, and with mutual hostility. Later related industries in any given district amalgamate for labour saving purposes and form a trust or cartel. A number of such amalgamations may themselves amalgamate, and so on, until the whole of production is carried on in a uniformly organized and well ordered system. In the art of war this process of centralization has been developed much more quickly than in the domain of labour, because the struggle for existence makes much stronger measures necessary in the modern army than in industry, to prevent the dissipation of energy caused by friction in the huge machine.

\section{The Law of Concentration.}

Every, economic body makes an effort to concentrate its forces, and thus to save labour. At first, in a village of a hundred inhabitants every man makes his own footgear and fetches and carries his own letters; later on this work is condensed, and one shoemaker and one postman suffice. In the same way a train does the work of thousands of legs, a mincing-machine of thousands of jaws, and central heating reduces the work of all the inmates of the house.

\section{The Law of Association.}

We may summarize the above mentioned laws of development into one general formula as follows :

In every economic body there is an increasing tendency to associate in matters of labour. Step by step non-organized individual production is undermined by organized labour, which will eventually supplant it completely by higher and more perfect forms.

The economic phase in which we are at the moment is speeding swiftly away, and the coming phase must lie in the direction indicated by the law of evolution. 


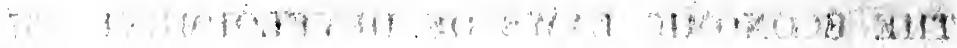

$$
\begin{aligned}
& \text { - Mat }
\end{aligned}
$$

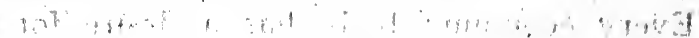


BOOK IV

THE CAUSES OF THE PROGRESS OF CULTURE 
1) $\mathrm{BHF}$ 


\title{
THE CAUSES OF THE PROGRESS OF CULTURE
}

\author{
... A Seeker after Truth, \\ Is like a cow on barren pasture. ...
}

In the "pre-scientific period," or rather in the theological and metaphysical stages of intellectual life, there was a method called hypothesis which consisted in endeavouring by strenuous reflection to evolve the truth out of one's inner consciousness, while at the same time contemptuously keeping aloof from the world of actuality. Great and noble thoughts were by this means brought to light; but most of them had one defect, that they did not agree with the despised reality, but were purely fancy pictures, though beautiful ones, and as such they remain. At that time sociology was not yet a science, but was still in its infancy under the name of " philosophy of history ' $X$; and philosophers, on the ground of the speculative method, had arrived at the conclusion that the history of mankind in general must be settled by "ideas," and that ideas, especially religious, legal, moral and philosophical ones, were the true bearers and fundamental causes of history and culture.

Then when the natural sciences entered upon their victorious career, the conviction grew that it is essential to make careful investigation before forming an opinion on any subject; in other words, that only scientific experience can lead up the steep road to truth. When this method was extended to intellectual science, quite different views obtained concerning the forces which govern history. In I859 a thinker; actuated by the new spirit, wrote the following startling sentence: "In the development of their social life men enter upon conditions which are fixed, necessary, and independent of their will, conditions of production which correspond to a certain stage in the evolution of their 


\section{THE HISTORY OF SOCIAL DEVELOPMENT}

material productive force. The sum of these conditions of production build up the economic structure of society, the real basis upon which a juristic superstructure is erected, and to which certain social forms of consciousness correspond. The manner of production of the material life in general qualifies the social, political and intellectual life process. It is not man's consciousness that determines his existence, but on the contrary, his social existence that determines his consciousness." I In other words, the course of history is determined not by conscious ideas, but by direct lineage through economic life. The changes in religious, moral, legal, aesthetic, philosophical and other ideas are not the causes, but the results of economic evolution. $X$

This theory, which is called historical materialism (in contradistinction to historic idealism) has certainly something very disenchanting about it. The forces which determine our lives are then no longer the noble thoughts of our religious schools and philosophers, but they lie in the lowly occupations of our everyday life. But surely it is typical of real science that it drags us down out of the clouds of selfcomplacent dreams and castles in the air, and plants us on the solid ground of truth, that it disturbs our illusions in order to hold our ideals before our eyes, not as an already acquired possession, but as a goal to be won.

Nevertheless, be this as it may, the materialistic theory of history contains a great truth. In the same way as the growth, nutrition and bloom of a plant depend on the manuring of the soil whence it springs, so is it clear that an extension of the sources of nature through agriculture, progress in the methods of production, as for example through the capitalistic system, technical inventions such as railroads, labour saving machines and similar advances exert an infinitely greater influence over the development of culture as a whole than moral exhortations, sermons, books, works of art, or philosophic systems. But we must not carry the theory too far, and represent the economic as the only propelling force of culture, for progress crawls on a thousand feet, and each new achievement on any of the domains of culture brings progress on other domains along with it, since all culture phenomena are materially interdependent, × K. Marx : Zur Kritik der politischen Ökonomie, Vorrede, S. xi. 


\section{CAUSES OF THE PROGRESS OF CULTURE 263}

and stand in an almost inextricable relationship one toward another. But surely among all sociological phenomena the economic influence is the most prominent one brought to bear upon the development of culture.

Taken in this sense, the materialistic theory of history is an acquisition which has influenced the science of culture in an extraordinarily fruitful way, and after bitter conflict is generally recognized and is constantly enlarging its sphere. In fact, several important works have recently appeared in which it has been shown that for example the structure of the family among the various nations is clearly traceable from their economic structure, $r$ and that an occurrence, which is apparently so purely spiritual as the Reformation, or even isolated dogmas, may have the simple explanation of the transition of the agricultural body politic into a commercial and industrial one. ${ }^{2}$

If then we see that the most important propelling force of the progress of culture is the development of economic life, what are the causes which impel social economy towards further development? We cannot possibly (although this has happened) fall into the old metaphysical error of prescientific times of looking upon social economy as an "entity," as a sort of independent personality which did little else than expand more and more through its own inward impulses and, as it were, drag the other culture phenomena after it in leading strings.

Upon this question of the deeper active causes lying behind economic development, the materialistic philosophy of history is silent. But it is precisely these deeper causes which are the forces that effect the progress of culture, and to the investigation of which this little treatise is devoted.

It is self-evident that the problem can only be solved by the inductive method. We must trace out the course of the phases of social economy closely, and ask ourselves at the introduction of each new phase through what causes the change came about.

As regards the course of the phases of social economy,

- Ernst Grosse: Die Former der Familie und die Former der Wirtschaft.

2 Brooks Adams: Das Grsetz der Zivibisation und des Verfalls. 


\section{THE HISTORY OF SOCIAL DEVELOPMENT}

we have elsewhere arrived at the following scheme, which we may here recapitulate with the utmost brevity:

In the earliest prehistoric phase, in all probability, association into hordes was the only medium (or form of organization) of economic activity.

In the succeeding early clan phase it develops into division of labour between man and woman; the woman is reduced to bondage by the man, and the family phase ensues, which now appears by the rise of horde or clan association as a second economic form of organization.

There follows upon this the transition from the early clan to the mid clan phase in which the first trade (" foreign trade ") comes about in the form of direct moneyless barter between neighbouring hordes.

These three phases form together the first economic epoch-that of clan organization or clan economy.

To this epoch there succeeds as second the epoch of industrial organization, which again is subdivided into two phases :

The early industrial phase is characterized by the rise of industries, the beginning of the differentiation of men in their professions. Barter is effected by natural money (Village economy).

In the mid industrial phase professional organization is built up into a system ; barter is facilitated by the invention of money (Civic economy).

The third epoch is capitalistic organization, which again is subdivided into three phases:

The early capitalistic phase is distinguished by the first introduction of capitalistic enterprise. Money is transformed into capital. (The beginning of national economy.)

The mid capitalistic phase begins with the invention of labour saving machines (towards the end of the eighteenth century). The whole of economic life undergoes transformation-individual production gives way to the production of wares for general sale. (The beginning of universal economy.)

With our present late capitalistic phase a new epoch dawns in which the whole of culture is slowly adapting itself to the changed economic conditions. 


\section{CAUSES OF THE PROGRESS OF CULTURE 265}

The course of economic phases can thus be summarized in the following grade system :

\section{Epoch of Clan Organization.}

(Prehistoric age, the representatives of which are extinct and unknown.)

r. Early clan phase (self-sufficing clan economy).

2. Mid clan phase (extended clan economy).

\section{Epoch of Industrial Organization.}

3. Early industrial phase (village economy).

4. Mid industrial phase (civic economy).

\section{Epoch of Capitalistic Organization.}

5. Early capitalistic phase (the beginning of national economy).

6. Mid-capitalistic phase (the beginning of universal economy).

7. Late capitalistic phase (universal economy).

We have devoted a detailed description to this grade system in the "History of the Development of Labour," but there intentionally (in order not to confuse the scheme) we have only considered the rise of the forms, and have completely ignored their causative forces. As we are now making an investigation of these causes, we shall add a necessary complement to this statement. For all formal statements can only be rigid, dead forms as long as we leave unfathomed the driving forces which have given rise to them and which lie concealed in them. However accurately we may dismember a corpse anatomically, however perfectly we may inspect the structure of a machine, they remain a riddle to us until we know the manner of their activity, when they possessed life and motion. And only thus shall we obtain a deeper understanding of social industry when we succeed in understanding the magic forces which govern human society, and which have carried on its development from the small prehistoric horde up to the modern great state in its perfection. But this theory of causation will not only explain culture to us as an occurrence, but 


\section{THE HISTORY OF SOCIAL DEVELOPMENT}

it will also give us a welcome opportunity of subjecting the results which we have as yet only superficially obtained to a fresh control and test.

The means that will lead to this end is here again the comparative method. If forms change, if phase passes over into phase, so may the causes which lie at the root of the movement suffer change. By comparing each phase with the succeeding one, we shall try to investigate step by step what causes have brought about the transition, and with it the new phase. In a second chapter we shall make the attempt to build up the facts which are thus recognized into a universal theory of progress. 


\section{THE CAUSES OF ECONOMIC DEVELOPMENT}

\section{THE ORIGIN OF THE SEPARATE FAMILY AND OF DIVISION OF LABOUR BETWEEN THE SEXES.}

ON the lowest culture stage known to us we found men united in small hordes within which two forms of organization were already established: clan association and the separate family. A still lower stage evidently preceded this one : the stage of nature conditions (antiquity or prehistoric stage of culture), as to which we have already (p. 38 et seq.) given our conjectures and in which in all probability there existed clan association, but as yet no separate families. For in nature conditions there is no work and consequently no division of labour.

Now in such a prehistoric horde how did the division of labour between the sexes, the enslaving of women and with it the separate family arise? Among all the hypotheses put forth the most probable one, and the one supported by sociologists of renown, is this: neighbouring tribes stand in hostile relationship towards one another, they fight, oppress, plunder one another. But there is very little to steal, the most valuable spoil is the woman. In fact, woman stealing, together with all kinds of acts of violence, is on this stage-and in isolated cases right up to the Trojan War and the Rape of the Sabines-a customary practice, and all the more popular as man has an instinctive desire for "foreign" women with whom he has not grown up and to whom he is not more or less related. (On this important psychologic feature, which in the prehistoric age of mankind was of pre-eminent importance, we shall speak more particularly in one of the later essays.) The stolen woman takes quite 


\section{THE HISTORY OF SOCIAL DEVELOPMENT}

a different position in the horde from the one who is a born member of the clan-she is the property, the chattel of the man who took her prisoner; she has to perform all toilsome labours for her master and be subject to him. The stolen woman is the first slave. For the hunter cannot hold men in bondage, they would soon disappear into the bush; the woman, on the contrary, becomes attached to her new husband, and her natural weakness, above all, the children which he begets by her, prevent her from running away and gaining her liberty. Thus arise in the horde the first separate families: But as soon as man has tasted the sweetness of power and-and this specially concerns his natural laziness-of being waited upon, these conditions extend slowly over the whole of the female members of the clan, the growth of separate families expands more and more, and eventually becomes a universal institution among primitive hordes. According to this view the family then arises from woman stealing (see Sociologie der Fortpflanzung) as a consequence of hostile tribes coming into collision; at the very first step in the theory of the causes of historical development we come across "the merging of groups," which, as we shall see later, is the mother of all progress.

\section{THE ORIGIN OF PRIMITIVE TRADE.}

The first and oldest form of the contact of groups is war, and the oldest form of the transference of property between hostile tribes is robbery. The stronger tribe deprives the weaker by violence of its land, its women, its weapons, etc., after the principle of the ancient Germans, who, as Tacitus says, " had no desire to acquire through the sweat of their brow what they could acquire through blood." And this principle still remains in force, even up to the present time. Not only by prehistoric hordes, by Caribbean Sea Islanders, by ancient Phœnicians, Etruscans, Greeks and Romans, but also by the Pisans, Venetians, Dutch, Spanish and English was it abundantly honoured. Even in the seventeenth and eighteenth centuries piracy was looked upon as a lawful calling, or, as was said, " as a profitable enterprise." 


\section{THE CAUSES OF ECONOMIC DEVELOPMENT 269}

But if the oldest form of group contact was a powerful one, so is the more modern and more peaceful kind; predatory warfare is succeeded by barter and trade. Yet at the beginning great obstacles opposed its start. The idea of balancing the scarcity of an article on one side from the overplus of the same on another by means of exchange is very familiar to us, but in a condition of lawlessness, when every stranger was looked upon as an enemy, it was not easy to realize. (In the ancient Aryan language the words for enemy and stranger, for example, "xenos," " hostis," were the same; whilst "sibja," "sippe," meant equally clan and peace.) The transition from robbery to barter has, as ethnology teaches, been brought about in several ways.

I. The way for a first peaceful approach between strange hordes was first paved by war. Through war and robbery the isolated hordes first became familiar with certain local products such as flint, beads, etc., which they could not produce themselves. As soon as tribes fairly equal in strength come in contact, plunder is not possible, and they are obliged to acquire the desired goods through exchange. When, for example, among the Polynesians, after hard fighting neither side gained the victory, or if before fighting both peoples acknowledged that neither was lord over the other, they entered into peaceful relationship, and the result was an alliance, and peace was sealed by exchange of presents. $x$ Or a man has robbed another tribe, fears their vengeance and therefore leaves presents behind to pacify them. For instance, the Akka in the fruit bearing season break into the fields of the negroes, steal bananas, bulbs and wheat, but leave an equivalent for them in meat. ${ }^{2}$ The Mountain Vedda, according to Sarasin, at night lay prey they have caught before the huts of Singalese smiths, but take a bloody revenge if after a few days they are not able to carry off as counter-gifts iron arrow heads. Such cases prove unmistakably the transition from robbery to socalled dumb barter.3

2. The same procedure that was employed in the exchange of other articles served for the most valuable possession of this culture stage-woman. Sanguinary vengeance

Sartorius, p. I. 2 Bücher, p. 85.

3 See Book III, p. I59. 
followed closely on the heels of every instance of woman stealing. In order to avoid this and yet satisfy the longing for "foreign" women they resort to exchange of women; thus exogamy comes into existence, which, as we shall see elsewhere, will become one of the most important means in the history of the world of the binding together of groups. Where exogamy takes root, the gates are opened wide to peaceful barter, for the exchanged women form a powerful bond between the formerly hostile groups.

3. Although it was war which first burst the narrow bounds and was the cause of peaceful trade, it is scarcely to be supposed that warlike contact was the only means of entrance into the first commercial relationship. The hostility between separate tribes is not always so absolute as it is usually represented. For instance, according to Lafitau, the American Indians when they have lost many men in battle adopt certain captive members of hostile tribes, receive them into the clan as brothers, and marry them to the widows of those that have fallen. The Eskimos often change from horde to horde. In Oceania, ships with their crews were often driven away by the wind to distant islands, and there the defenceless strangers were hospitably entertained in an early dawning of humanity. Such adopted persons then constitute a bond of union between strange tribes, by means of which commercial relationship can be established.

4. Further, through increase of population emigration becomes necessary, and neighbouring tribes spring up who fraternize and usually strengthen their friendly relationship by exogamy. It is among such tribes that barter by means of the so-called guest gifts I may have originated, whilst dumb barter may well be considered the oldest forerunner of commercial exchange.

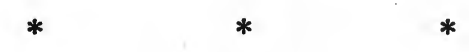

This, the oldest form of barter, arose in various ways, but in all cases external trade between foreign groups preceded the internal trade between the members of a group. This fact, which is important for the theory of progress, is easily explained. For the members of a group live in the I See Book III, p. 159. 


\section{THE CAUSES OF ECONOMIC DEVELOPMENT 271}

same nature conditions, consequently they produce similar articles and have no motive for exchange; on the other hand, different tribes have different specialities at their disposal, according to the quality of the soil. The first differentiation which followed on the one between the sexes was thus of necessity between foreign groups, and this later on (in the next or third phase) was succeeded by industrial specialization among men.

\section{THE ORIGIN OF SPECIALIZED INDUSTRIES.}

As we have already stated, the first condition and at the same time the first cause of specialized industries is agriculture. Only when the individual is in a position to produce more food than he consumes are the forces of labour free to devote themselves to such activities as extend beyond the mere provision of the means of existence. Such a pro. lific production of food can be attained by fishing, ${ }^{\mathrm{x}}$ but this is only in exceptional conditions, and in general it can only be won by agriculture.

Yet agriculture alone is not sufficient to cause trade to spring up: we have made acquaintance with many agricultural nations such as Indians, Malays, Papuans, etc., who have never known any industrial differentiation. A second essential condition is that the forces which had been freed through the artificial production of food should devote themselves effectively to new labour activities and should not fall victims to natural laziness and love of pleasure. From the standpoint of nature folk, the many hours of laborious work which the culture man has to perform is something unnatural and abominable. ${ }^{2}$ Their energy is employed in the excitements of the chase, of fishing, of war, in hut building, etc., and as soon as they have provided for their simple needs they give themselves to sweet idleness or fill up their leisure with joyful dances, gymnastic sports, revelry, solemn feasts and other diversions, or else they delight in endless gossip, the empty chatter of which fills the restless European with astonishment. This innate tendency of man towards pleas-

$\checkmark$ See p. 71 .

2 According to Grimm, even in German, labour (arbeit) originally meant oppression as well as toil. 
ure and laziness was first checked through an institution of extraordinary importance for economic development, that is slavery, which, like an iron rod wielded by avarice, forced on labour that intensity which was necessary in order to bring about differentiation and carry it up into continually higher forms.

In fact, the first beginnings of industrial division of labour followed closely on the heels of the establishment of authoritarian organization, i.e. differentiation between masters and servants, and characteristically simultaneously with the establishment of authority over unfree workers the first division of labour comes into existence.

Specialized industry has also a root in free labour. But the free artisans were recruited partly from freed men, i.e. from former slaves, partly from the indigent proletariat and foreigners, and even from the blind and cripples and weaklings, as, for instance, Homer and Hephaestus, who, not from free choice, but from need and the pressure of circumstances, took up specialized occupations.

The first industries were thus called into existence because agriculture created the soil for their formation; then followed want and oppression, which caused the bondmen and indigent to turn to new occupations to supply a limited and extraneous demand.

\section{THE ORIGIN OF DEVELOPED INDUSTRIAL ORGANIZATION.}

The labour organization of the fourth or mid industrial phase arose from the full evolution of the elements of organization which existed in the third or early industrial phase only in germ. ${ }^{I}$ The causes of this development are easily ascertained if we subject the nature folk belonging to the third phase (Oceanians, Africans, etc.) to a comparison with the civilized nations which had risen to the fourth phase (Peruvians, Mexicans, Chinese, Assyrians, Babylonians, Egyptians, Indians, etc.). We perceive then that the progress was effected through a change of environment by an emigration of culture into new regions, which offered far more 


\section{THE CAUSES OF ECONOMIC DEVELOPMENT 273}

favourable conditions for labour association than was the case either in Oceania or in Africa.

In Oceania the conditions for greater density of population do not exist, since the separate islands are too small and too far apart ; besides, the local products in the different parts of the archipelago are too similar to lead to trade and exchange to any considerable extent. The African continent is not divided up, it is poor in coastline and of clumsy formation, its climate is too hot and relaxing, and the fruitfulness of the soil is on both sides of the equator so luxuriant that the inhabitants can with difficulty be accustomed to strenuous and prolonged labour. (On the Cape Coast, for instance, a penny daily wage suffices to maintain life. ${ }^{x}$ )

Thus, unless culture is to remain stationary, it must seek out other more favourable regions; it must emigrate to countries which are neither too hot nor too fruitful, which make strenuous effort neither superfluous nor impossible, but rather offer incentive and stimulus to work, which at the same time provide a soil for the accumulation of dense masses of people and for the basis of far more uniformly regulated wealth, and which, by means of natural waterways and abundant coastlines, smooth the way for trade and traffic. And, in fact, if we picture to ourselves all the places of the earth's surface where formerly civilization flourished-the fruitful Chinese river basins of the Yangtze-kiang and the Hoang-ho, the Babylonian Mesopotamia, the Egyptian Nile region, Central America, rich in coasts and islands, the Highlands of Peru, the Ganges region of Eastern India, etc., there can be no doubt that the fourth phase arose out of the third through a geographical transplantation, and that the germs of organization. which had brought the most advanced nature folk to maturity ripened through these changes of soil to the development, which is characteristic of civilization. For the geographical and climatic conditions which we noted above as necessary to the wider development of labour organization are met in all countries of the oldest civilizations, perhaps not in every single country in their entirety, but yet on the whole in such a remarkable way that a glance at a map of the world makes further comparisons superfluous. Thus the progress out of

× Waitz-Gerland, ii. 79. 


\section{THE HISTORY OF SOCIAL DEVELOPMENT}

the third into the fourth phase is, in general, due to the migration of culture from the original dwelling place of men, from the tropical into the subtropical zone. The advantages which the temperate zone were later to bring to development were on this culture stage bound up with so many disadvantages that civilization in its early beginnings was unable to find a footing.

\section{THE ORIGIN OF CAPITALISM.}

The oldest civilization arose, as we have just said, in countries which, through position, configuration, fruitfulness and climate, were most suitable to bring the greatest number of tribes into association and to guarantee a livelihood to a numerous, dense and industrious population. But these first centres of civilization were isolated, they jutted out like separate scattered culture islands from the wide sea of barbarism ; separated from one another by geographical barriers, these different kingdoms could not get into touch with one another nor mutually affect, stimulate nor enrich one another. Hence, in ancient China, Japan, India, Egypt, etc., came the tendencies towards conservatism, towards rigidity in the old forms, which is such a distinguishing mark of the nations of the type of the oldest civilizations. From this condition of threatened stagnation development could only flow into fresh channels if the separating barriers fell away and if in some place in the world a number of civilized peoples were able to come into real contact and unite in a complicated economic body. This would make the co-operation of different nationalities possible, and thus lay the foundation of higher forms of the structure of labous association.

If we glance over the map of the world we shall find $\mathrm{nc}$ place which realizes the conditions for such an association in such a wonderful way as the three continents joinec together by the Mediterranean. The populations whicl inhabited the coasts, the Assyro-Babylonians of Asia Minor Persians, Phœnicians, Jews, Egyptians, Carthaginians Greeks, Italians, Celts, etc., belonged not only to three continents, but also to three different races-the Semitic Hamitic and Aryan. They stood moreover on unequal grades 


\section{THE CAUSES OF ECONOMIC DEVELOPMENT 275}

of development, and the products of their countries were so dissimilar and various that the exchange of them conduced in the highest degree to trade and traffic. And all these nations were united by one broad natural channel, the sea, which, in contrast to the immovable dry land, like a gigantic slave obediently carried the heaviest burdens with which its patient shoulders were loaded to the desired goal at any point of the compass.

It is now due to the many-sided international relations established by such circumstances (which later on found expression in the Roman Empire) that economic development took a forward step. The ever increasing trade led next to the invention of a universal standard of goods, money (see p. 240), natural economy merged into money economy, and out of the fourth phase, the mid industrial, arose the fifth or early capitalistic phase. For money became capital, and this change was effected in the following way:

At first all money was only a means of facilitating barter, a simple medium of exchange. But when this medium took the form of stamped metal money (coin), it soon became a force which embraced not only trade, but the whole of social economy, and moreover brought about as by magic a psychic change in men which remains without parallel in the history of human impulses.

Before the invention of money man secured the good services of his fellow man simply by violence. War was the most important occupation of men, and the purpose of endless wars was to plunder the vanquished or to reduce them to slavery, or at least to tributary provinces; in short, to govern them so as to plunder them. But the sovereignty of power has not by a long way the advantages of the sovereignty of money. The slave obeys against his will and has always to be kept in check; as soon as the whip is at rest his arm sinks. On the other hand, all willingly obey the rich man; they serve him with joy and zeal, his rule sways not only at home, but everywhere; wherever he appears with his magic wand all workers, from the artisan to the artist, crowd round him and deem themselves lucky to receive his orders. Then, too, coin can be heaped up illimitably, for it is not bulky in proportion to its value; it is portable, and it is not liable to change and decay like natural money. Whoever 


\section{THE HISTORY OF SOCIAL DEVELOPMENT}

succeeded in amassing a great quantity of this convenient wealth, this " coined freedom of will," as Dostojewskij says, had all the joys and pleasures of the world at his command-subservience and esteem of men, love of women, the opportunity of showing benevolence as well as luxury and sumptuousness, of developing his own personality to the highest point of attainable perfection, to live out his existence-scarcely any wish was denied him.

Such magic power must arouse the wildest emotion. The so-called pleonexy, i.e. that form of avarice which can never be satisfied and which is absolutely unknown to the nature man, awoke and filled with new riches the coffers and warehouses of fortune's favoured ones, the few but powerful who belonged to the ruling classes. But as long as the heaps of gold remained in the warehouses, they were only potential power, only dreamed of enjoyment; if one transformed them into actual enjoyment the painfully acquired treasure vanished perfidiously. Soon two different means of escape were found out of these lamentable alternatives.

First, the money was turned into durable goods, i.e things which last and yet afford continual enjoyment Lordly palaces were built, paintings and sculptures, golder armour, silver harness, jewels, costly household furniture and art work of all kinds were articles greatly in demand and in the early days of money economy, art, under the patronage of wealth, attained a golden age which it ha: never known since. For eagerness for interest on capita has a deadly influence on art.

A second way, far less ideal and more in accordance witl the spirit of capitalism, turning the money to good accoun without losing it, was the acquisition of ground and land, o landed property (Latifundia). The land owner who has hi land cultivated by others possesses property which at th same time yields a profit; he can enjoy his wealth withou diminishing it and without having to work himself. Henc in Greek and Roman times (and later) came the land hunge of the rich, through which free cultivators were driven is large numbers from house and home.

A third way out, which indeed led right into the domais of capitalism, was the investment of money in commercia enterprises. A capitalist would fit out a ship, buy th 


\section{THE CAUSES OF ECONOMIC DEVELOPMENT 277}

tecessary goods, and hire the crew, or advance the capital o an agent who undertook all this, as well as the sale of the oods. Hence out of insignificant retail trade arose capitalistic commerce. It is a fact important for the theory of drogress that the form in which capitalism first appeared vas above all that of foreign trade.

But if the profits from overseas trade were considerable, hey were uncertain owing to the dangers of the sea, and specially owing to piracy. It was soon perceived that the iseless accumulations of money would yield far greater profits on the land, and that this would involve much less isk than overseas trade. The possessor of capital builds vorkshops, buys a number of slaves, and sets over them all foreman or inspector, so that he has nothing more to do with the business than to pocket the surplus. ${ }^{x}$

Thus in various ways was solved the paradoxical problem of capitalism: the acquisition of wealth by means of wealth-the means of exchange had become the means of acquisition, or capital.

But yet another end had been attained; a new organization had arisen which, through the fructification of labour by means of capital, left the small industries and handicrafts far behind in respect of mechanical power, and even if in the early capitalistic phase of antiquity the new system could not arrive at completion, but rather sustained a great defeat in its beginnings, yet by its means a new epoch of social economy originated, and the association of labour took a decided step forward.

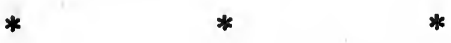

On looking back we find that the immediate cause of the rise of capitalism was the amassing of property in the form

I It is well shown by Schurtz, Entroicklungsgeschichte des Geldes, p. 24, how even on the lower stages the idea of capitalism is expressed from time to time. "A chief from Nyangwe on the Upper Congo expressed to Cameron in a naïve but convincing way his opinion that it would be more reasonable to invest his business profits in slaves than in ornaments. If he brought home a quantity of cowries, explained the cautious man, his wives would take them and adorn themselves with them, and he would have nothing. Slaves, on the other hand, could be employed at once, and did not lie useless, whilst the cowries yielded no profit until they were exchanged for slaves." 
of coined money; and the deeper cause lay in the increase of international relations, by means of which the peoples of the early capitalistic phase were united into a higher form of economic co-operation.

\section{THE ORIGIN OF MID CAPITALISTIC ORGANIZATION.}

After the decline of the ancient world, civilization turned towards the north and extended its kingdom slowly and gradually over the temperate zone. This change of environment was advantageous for the progress of labour organization. The northern climate makes much higher demands as regards food, clothing and dwelling than the sunny south The northerner has more needs than the southerner, and he is 2 accordingly forced to work more. But, moreover, he can work more strenuously, for the cooler climate is more favourable to effort, whether of the body or of the mind, than the relaxing heat of warmer countries. Besides, in the fine season of the year he has to consider how he is going to live during the long winter, when Nature is benumbed under snow and ice, when food is scarce and cold penetrates his dwelling. He must renounce the easy-going temperament of the Southerner, who lives for the moment and has nc cause for anxiety about the morrow, and must accustom himself to take the future into account. On the lowe stage certainly the North, with its swamps and impenetrable virgin forests, had been a hindrance to the progress of civil. ization; but as development rose higher and man learnec more and more to dominate Nature, these hindrances turnec into blessings for the progress of labour, because the over coming of difficulties called forth a greater resourcefulnes: than was the case in warmer countries. Moreover, the new arena to which culture now turned was in close connectior with the countries of the ancient world, and this circum. stance was conducive to wider development. For all the culture acquisitions which the highly advanced ancients had gained for themselves during a long course of time now flowed in a broad stream to the new peoples still in the barbarous stage. But even as a youthful scholar, althougt he enjoys the instruction of the best teacher, must first rise through a number of stages before he attains to the heighi 
f the master, and only then if he possess the talent may irpass him, so the Romano-Germanic peoples had first to ass through the phases which had been already travelled y their teachers. At the beginning of their history they 'ere in the phase of clan organization; they arrived through he phases of "manorial economy" and then of "civic conomy" at early capitalistic organization, and thereby, lthough only in its main outlines and with accelerated equence, repeated the career of development through which he peoples of antiquity had already passed. And as in ntiquity and in prehistoric times, the same causes lay at the oot of the origin of these phases - mutatis mutandis-as hose which we have already indicated.

The Romano-Germanic peoples, however, did not reain in the early capitalistic organization, but in the eightenth century they outstripped the ancients and soared ip into a stage of development unknown to the former, that I, into " mid capitalistic organization," and at this point ve must again gather up the threads of the doctrine of auses.

Although the mid capitalistic organization made its ppearance with unexampled weight and rapidity, yet the auses which led to its rise may be found in part in events which lie far back in history.

Here also international trade and intercourse lead the rocession of development. Primarily it was the opening ip of the East which gave the impulse towards the rise of apitalism. Even before the Crusades, Mohammedans und Christians, especially Italians (Amalfi, Venice) and seople in the South of France had commercial transactions vith each other, and as a result of the Crusades East and Nest were brought into closer contact in various ways. The rade with the East and between the nations of the West ed to wealth, to the amassing of vast sums of money by indiriduals-and hence to the transformation of money into apital, $\mathbf{I}$ and there arose the early capitalistic phase of the Middle Ages, which, like the same phase in antiquity, owed ts existence to international intercourse. 
In the following centuries international relations extended to new countries and whole continents of which the ancients had no idea. For the dazzling age of discovery followed. After the Polos had visited Mongolia, China, India and Sumatra in the thirteenth century, America was discovered in I492. In I498 Vasco de Gama sailed round Africa and found the sea route to India; in $\mathrm{I}_{5} \mathrm{I}_{3}$ Balbao discovered the Pacific Ocean after traversing the Isthmus of Panama; in 1522 Magelhaes was the first to sail round the world; in I6or the Portuguese Eredia landed on the coasts of Australia; and in 1768 Cook entered on his famous voyage to the Southern Seas. Whilst the ancient world consisted of a comparatively small circle of peoples, the central point of which were the countries bordering on the Mediterranean, the world of the Romano-Germanic peoples now embraced the whole surface of the earth. As now, inhabitants of all continents, men of all races and culture stages, came into contact, international trade entered on a new stage, it began from that time slowly and gradually to develop into international commerce, and by this means to drive the whole economic life of the European nations and to exert an ever increasing influence on it. ${ }^{x}$

But not only did trade and intercourse take an upward leap through the wholesale extension of the geographical horizon, but as a consequence the new international connections also made progress which extended to the whole sphere of culture and especially to the development of science. The opening up of the East had already kindled a new light in the western lands, which were sunk in superstitious ignorance; this light now shone in the laboratories of scholars, and called the study of the natural sciences into being. As soon as scientific progress had attained to a certain degree of completion, the giant that had grown in silence sprang out of the study of the investigator into practical life. Science entered into the domain of industry and heralded with it a new epoch in the history of labour. For the mighty event which, at the end of the eighteenth century, transformed the early capitalistic phase into the mid capitalistic by a

I After the discovery of America, for example, the influx of precious metals was so great that from $\mathrm{I}_{550}-165^{\circ}$ all goods were two and a half times as dear as they had formerly been. 


\section{THE CAUSES OF ECONOMIC DEVELOPMENT 281}

sudden revolution, was a fruit from the tree of the natural sciences-this was the invention of the great labour-saving machines. The enormous advances which were made in the domain of technical science through this invention helped capitalistic organization to gain a decisive victory. The older forms of production were now superseded by the greater mechanical power of huge machine industry; but for the establishment of a huge industry which works with numerous costly machines greater capital was needed, and hence, naturally, the new form of production fell into the hands of the capitalists.

Besides this, many forces which had hitherto been inseparably connected with handwork were now set free by machinery, and were able to turn to other departments of labour. In Adam Smith's time ten men by division of labour produced about 48,00o needles daily. According to Marx, I a machine produces 145,000 needles in eleven hours, and one single woman is enough to attend to four such machines, which amounts to a production of 600,000 needles daily. Thus this one woman deprives 130 men and their families of bread, but she also sets them free for other kinds of work. It was thus the machines themselves which, among other matters, saw to it that the head of the enterprise should have the necessary "hands" at his disposal.

A stage which had hitherto been unreached in the compulsion of unwilling workers to perform monotonous and prolonged labour was attained when bondage was abolished and the place of slaves was taken by hired labour.

In the history of compulsory labour, as will be here shown, four phases may be distinguished, each one of which gives evidence of an enhancement and accentuation of the previous condition.

I. In the first phase on the lowest culture stage, where the only division of labour known is that between the sexes, all arduous work is laid upon the oppressed wife; yet this compulsion is mitigated by the fact that the woman is in a relation of love and marriage towards her master as his wife, although as yet the relationship is a rough one.

2. In the second phase men are enslaved; but slavery

I Marx: Das Kapital, i. 425. 


\section{THE HISTORY OF SOCIAL DEVELOPMENT}

among nature folk is of a far freer and looser character than is generally supposed. ${ }^{1}$

The African master demands neither the punctuality, quickness nor thoroughness that the European master does. In Europe man is perplexed for want of time, in Africa he does not know what to do with it. When we see how easily here the lowest classes can support themselves, we are forced to remember with grief with what difficulty our own poor can sustain life, with what desperate eagerness occupation is sought-how hard the struggle for existence is. ${ }^{2}$ In a similar sense we may read the description of the patriarchal relations between masters and servants in the Oceanian Islands in Forster's Journey Round the World (i. 386 ), etc.

3. Civilization brings with it a definite accentuation of the condition of slavery. At first, as long as there was no money, as among the Homeric Greeks, slavery was as mild as among the nature folk-think of "the divine swineherd Eumaeus." But the invention of money awakened avarice, and from that time the oppression became more severe, as slaves were regarded by their masters as tools for the acquisition of riches. Nevertheless, the lot of the slave was comparatively an assured one; he was not greatly ill-treated, since injury to him meant the loss of his purchase money, and the master himself would suffer.

4. After the abolition of slavery this consideration for the health and life of the labourer was no longer necessary. Since the hired labourer was not bought, he could be dismissed at any moment by a simple wave of the hand, and find himself and his family exposed to hunger and misery. Hence much more thorough work was extorted from the free proletariat whose whole existence is at stake than from slaves who fear only the whip. The substitution of the proletariat for slaves was only practicable when the State was sufficiently strong and well organized to hold a tight rein over the whole of the indigent lower class; as long as that was not the case slaves must of necessity be possessed by individual masters.

I Schurtz: Afrikanisches Gewerbe., p. $9^{8}$.

2 Livingstone: New Missionary Journeys in South Africa, i. 293 (in Martin's translation to German). 
(5. We shall soon have to speak of a fifth phase in the history of compulsory labour, p. 297.)

The long peace after the Napoleonic wars led to an increase in the forces of labour available for industry, and with this came an enormous growth of population. In the countries having a capitalistic organization (Europe and the United States) the population in the nineteenth century rose from 153 millions in 1800 to 398 millions in I90o. This increase in prolification, which in former times had been retarded by wars, epidemics and famines, was chiefly due to the proletariat in the larger towns. But the long peace had also the result that the huge sums of money formerly. swallowed up by war were now at the disposal of industry and of capitalistic organization, and were utilized by them.

In the last few pages we have found that the chief causes which led to the fise of capitalistic organization were-the migration of culture to the temperate zone, the expansion of international intercourse, which after the age of discovery embraced nearly all the nations of the world, the dawn of natural sciences, the resultant invention of labour saving machines, which gave the direct and decisive impulse towards the development of mid capitalistic organization, and finally the increased thoroughness of work and the augmentations of the forces of labour, which were owing partly to the invention of machinery, and partly to the abolition of serfdom and to the long peace after the Napoleonic wars.

\section{THE ORIGIN OF THE LATE CAPITALISTIC PHASE.}

In the mid capitalistic phase mutual dependence made a great stride forward. The capitalistic system prevailed in every direction, so that the whole of social economy underwent a transformation. But the transition was accomplished so suddenly that the governments were shaken to their foundations. Since every progress in the economic sphere necessarily brings with it progress and change in all the other spheres of culture, the problem was suddenly placed before society to remodel the institutions handed 
down from antiquity in order to refashion them on the new economic basis. But such a transformation can only be the work of a prolonged process of adaptation, and consequently the first result of the sudden economic progress was extraordinary incongruity between the new economic system and the old customs, and disorder, perplexity and strife among individuals.

But if forces come into conflict they come gradually again into equilibrium; as Heraclitus says, "After strife comes harmony." If the mid capitalistic phase was marked by perplexity and disorder, now in the late capitalistic phase forces began to have sway which paved the way for a new order of things, and strove so to transform the social organism as slowly and gradually to restore the dynamic equilibrium.

The causes of the late capitalistic movement are also to be found in the sudden revolution produced by high capitalism. No influence from outside equals this event in importance; the ball had received such a mighty impetus that it now rolled on for a long time. If therefore we wish to understand the causes which have brought the late capitalistic period to the present condition of affairs, we must first turn our attention to that undesirable result of the capitalistic system which arose out of the incongruity between the new economic institutions and the former obsolete ones, which incongruity like an interminable and intolerable growth infected the social body and had to lead either to a severe malady or else to reform, and hence to healing or at least to improvement. This incongruity, which took place in the period of high capitalism, must now be described.

I. The chief economic event of the mid capitalistic phase was the transition, pregnant with results, of individual production into social production. The principle of labour association by which an object is manufactured, not by the one who needs it most, but by those who are the most qualified and most fitted for so doing, made such a decisive advance that individual production was driven back on all sides. In our wonderful world of labour no one works for himself, but each works for all, 


\section{THE CAUSES OF ECONOMIC DEVELOPMENT 285}

and in his turn has the productions of all others at his command. And this wholesale system of solidarity in which each for all and all for each are involved was not brought about by any extraordinary revolution of civilization, it was not the work of altruism, but of a refined egoism.

Whilst in the period of individual production every one laboriously made for himself what he needed, "The child of civilization," as Bastiat said, "would have had to work for centuries had he had to make for himself those objects which he enjoys in one single day." The enormous contrast between the two systems will become apparent to us if we transport ourselves for a moment to the stage of individual production, and consider the scenes which used to take place between European travellers and nature folk, scenes in which the representation of two contrasting worlds came into contact and could not sufficiently marvel at one another. Thus K. von den Steinen writes of his Bakaïri : "Whether I had made my shirt and stockings myself, was a vexing question which was constantly repeated, ' Had I made the hammocks and the mosquito curtains myself.' It surprised them greatly that there was nothing among the whole of my possessions that I could admit that I had made. I had given them a few knitting needles and shown them the only sewing needle I possessed; they brought me back a knitting needle asking me to make a hole in it such as the sewing needle had." s And as our system of production amazes nature folk, so are civilized travellers amazed at the way in which the nature man is able to help himself. "Throughout the whole course of my travels," writes Pickering, for example, "I have never met with a people more useful to strangers than the inhabitants of Tahiti ; for they seem to have at their command all the most essential commodities of life. Half an hour in the day sufficed them in which to build a hut out of the branches and leaves of the fehi-banana, and they kindled a fire by rubbing pieces of wood together. In one place flowing water was hidden deep under a rock; by use of banana leaves they brought it to the surface. The pursuit of eels, which in these moist well-water mountains are almost amphibious, gave another proof of their skill. With their teeth they tear apart the

I Zentral-Brasilien, p. 75. 
fibrous bark of the 'puran' (a kind of marshmallow), and in a few moments they catch little fishes in nets made from it. If any one were sent to fetch fruit, on the way he usually wove a basket from a cocoanut leaf. A mat was made almost as easily. Clothing was thus always at hand, and a banana leaf served as umbrella, whilst in the fine weather they wove garlands of flowers. Mugs and flasks were made out of bamboo canes, the long trunks of which furnished them with pails and casks; and even if we asked for an axe, a knife or spoon, a toothbrush or a washhand basin, our guides were never at a loss." (The Races of Men, p. 7I.)

The striking contrast between the two systems in these examples convince us clearly of the advantages and disadvantages of our co-operative production. On one side we owe to it a wealth and variety of material and intellectual possessions of which the nature man had not the slightest idea. But on the other hand our system, founded on the division of labour, has brought with it disadvantages which can scarcely be ignored. For whilst in the nature state man was able to live out his own life, employing himself in occupations which made use of all his energies equally, set his limbs in motion, excited his interest, called forth his sagacity, stimulated his energy, we, in consequence of division of labour, have all developed on one side only, and become one-sided stunted slaves of labour, some of whom, day in and day out for their whole lives, do nothing but dig; others bore or polish or write, or tend a machine. Which of the two kinds of occupation is the more attractive is evident from the fact that fishing and hunting, the daily occupation of the ordinary man in nature life, are now favourite amusements which only the well-to-do can enjoy. But not only is the labour of the culture man dull, it has an injurious, degenerating effect on the whole personality; for through the one-sided, uniform and prolonged occupation there arises in the artisan a deadening of the mental faculties, while among students a stunting of the organs of motion and of the upper part of the body leads to weakness and disease. It was therefore not entirely without reason that the ancients despised work, which, as they said, hindered the complete fullness of life and the harmonious beauty of the individual. "Handicrafts," says Xenophon, "destroy the body because they 


\section{THE CAUSES OF ECONOMIC DEVELOPMENT 287}

force it to sit still and live in the house." (Oek. 4, 2.) And according to Aristotle leisure is for the free man the highest end of life. (Pol. vii. r3.)

This disadvantage of our system is of such overwhelming significance that the division of labour would have to be considered rather as a curse than a blessing if the degeneracy of the individual and the joylessness of labour were so inseparably bound up with it as is mostly the case. But evidently it is not the division of labour in itself, but the excess of labour which entails such disastrous consequences. He who gives himself up for twelve or more hours daily to a one-sided and stupefying occupation " must," as Xenophon said, " become depraved," but he who only devotes a few hours of the day to such harmfulness and spends the rest of his time in different and compensating occupations, either useful or recreative, such as sport, reading, etc., need not fear baneful results, and can moreover enjoy all the advantages of the division of labour. Now national economists have reckoned that if all healthy adults took part in national production, if the organization of labour were thorough, if our mechanical forces were rationally distributed, if the population did not increase in an excessive and foolish way, and if the upper classes were prevented from abusing the forces of labour in a great degree for senseless display-that under those conditions only a few hours work per diem (according to Hertzka only three) would suffice to assure every one in our culture stage a sufficient livelihood. And since these suggested conditions would be in perfect harmony with a system of division of labour, we are forced to the conclusion that it is not the division of labour itself, but only the present form of it that can be looked upon as a curse for the individual, and that here a great wrong which calls loudly for reform oppresses the mass of the people.

2. Another result of the co-operation of labour consisted in the fact that while the nature man is independent (see p. 285) the culture man is absolutely dependent on association. For since the differentiated worker labours for others, for society at large, his well-being depends entirely on the remuneration allotted to him by society. And here we touch one of the greatest and hardest problems of the capitalistic age and an abnormal condition of things : the distribution of property at the present time. 
It strikes us at the first glance that our system of distribution is not a just one. Whilst a minority of wealthy persons, a great part of whom have never done any work at all, live in abundance and luxury, the masses undertake all the toil and labour, are contented with scanty pay, and lead an existence which would cause the nature man to shudder.

Whence comes this disproportion? The cause is easily recognized. Only production has become organized, not remuneration; the system of distribution of profits has remained the same as in the days of individual production, and prevails now as an absurdity. In the epoch of " selfsufficing units" each family worked for its own needs; the distribution of profits was simple, for it was self-evident that what it produced was its own property and was held in common, and it was equally self-evident that goods should be hereditary in the family. But through labour association inheritance within the family becomes more and more of a prerogative by means of which the individual, without himself having to work, is in the position of being able to appropriate to himself labour products made by others, and though idle, of living in wealth and abundance and as a mere parasite because he has inherited wealth. This prerogative must necessarily be regarded as an injustice in presence of organized production. For with the progress of labour association our ethical outlook has altered; family morality is more and more passing into social morality. Whilst in the time of "self-sufficing units" it was thought quite right that the sins of the fathers should be visited on the children up to the ninth generation, we now only recognize individual guilt, and consequently we can only recognize individual merit, and must think it unjust that an endless series of descendants should be rewarded for the merit of an ancestor, all the more because this reward is at the expense of the remaining associated workers ; for it is only on the face of it that the rich heir lives on the fortune of his ancestors-in reality it is on the labour products of his contemporaries, and he ought, therefore, like every one who consumes more than he produces, to be looked upon as prejudicial to society.

But, easy as it is to recognize the causes of our unjust system of distribution, it is difficult to remove them. For a society in which the property of the dead devolves on the 


\section{THE CAUSES OF ECONOMIC DEVELOPMENT 289}

community for the purpose of administration and distribution must be far more highly organized than our present one, and the process of disintegration through which the family is now passing must be immeasurably further advanced than is at present the case (see p. $202 \mathrm{ff}$.).

But even supposing the above mentioned causes of unjust distribution were removed, and the custom of family inheritance abolished, the problem of the distribution of goods in labour association still remains a very difficult one. For through co-operation there arises a community of ownership of an indivisible thing, and the share which falls to each of the co-workers in this labour product, whether a nail or a locomotive, can hardly be calculated by the qualitatively different services performed. Radical thinkers have found the way out by presenting universal community of goods as the rightful solution of the problem. If communism were simply the "spoiling of the strong by the weak" we might reconcile ourselves to it; for socialism has set before itself the noble duty of caring for the weak as well as the sickprovided they abstain from the propagation of their speciesand of not making their lot harder but sweeter. But if we reflect that in a community of goods the idle live at the expense of the industrious, that thus a premium would be placed on idleness, that self interest, the most powerful mainspring of culture and of happiness, would be ruled out, and finally that in the thus weakened social body all individual initiative and energy must be crippled, we can scarcely consider this solution of the problem a happy one, since it simply cuts the Gordian knot. We cannot call it a right principle to say: equal wages for unequal labours, but as the labour so the wage. The consumption and production of the individual must stand in proportion. Labours, which through duration, throroughness or quality take precedence of others, must therefore receive the compensation of proportionate reward. In a society in which all individuals had equal rights from birth and were only distinguished by personal merit this just principle would force its way by tself : for the most difficult and hardest labours would then find the fewest candidates, and the easiest and most pleasant the greatest number ; the more difficult and toilsome a labour, the more ought it to be recompensed, if the requisite number 
of workers are employed. The distribution of property would then be simply solved by the law of demand and supply as the price of goods is now.

Nevertheless, however a future society may solve the most difficult and important of all social questions, the beginning of the solution is accomplished. For even if association has deprived the individual of his independence, yet it has also made him absolutely independent of the caprices of nature ; henceforth man is no longer exposed to unreasoning and changeful forces, but to human reasoning ones, or rather to such as can slowly and gradually be made accessible to the influence of reason. In these circumstances we may feel sure that even the problem of the distribution of goods may one day find a reasonable solution. (This subject is discussed in more detail in Soziologie der Fortpflanzung.)

3. Inheritance and the transmission of property within the family-and certainly not the natural dissimilarity of individuals-are the causes of our class system. As long as some are born rich and others poor, the population is divided into two classes, the upper one of which has the monopoly of pleasant tasks and enjoyment, whilst the lower class, the majority, has to undertake the unpleasant tasks and is almost entirely excluded from all the higher pleasures provided by our culture.

In the mid capitalistic phase this plutocratic system reached a development and culmination that was accompanied by great severities. For capitalistic organization entailed the separation of the worker from the means of production. In the pre-capitalistic period every artisan possessed his own tools for himself. But when machine labour replaced hand labour, the capitalist class came into possession of the means of production, the cost of which made them unattainable by the ordinary man. Hence the worker fell defenceless into the hands of the capitalist, and the result was that compulsory labour attained its greatest height, ${ }^{\mathbf{x}}$ and the exploitation of the lower class was carried on with that terrible harshness which was characteristic of the mid capitalistic phase. For a wage which scarcely maintained existence, the many who owned nothing, not even the power of their own muscles, were I See p. 282 . 


\section{THE CAUSES OF ECONOMIC DEVELOPMENT 291}

forced to wear themselves out to stupefaction in fourteen or sixteen hours' work a day; and not the men only, but the women and children of the lower classes, who were now employed in multitudes in the factories, fall under the inhuman pleonexy of the entrepreneur. When all the strength had been drained from them, all that remained was the beggar's staff and the workhouse. Further, capitalistic organization, in consequence of its unexampled productiveness, made a prodigious number of things of which only the rich could make use. Since wealth was the most effective means of procuring more wealth, the disparity of fortune between the classes increased more and more; side by side with senseless luxury, pauperism and proletarianism increased in appalling proportions; exploitation and plutocracy reached a point which in the course of time became intolerable for the lower classes.

And yet the rise of the new class system must be looked upon as a progression, as a necessary stage on the road towards the overthrow of exploitation. For the new upper class drove out an older and stronger governing class, the aristocracy of birth, and hence opened up the road for a freer development, as will be shortly shown when we compare the two class systems of the mediaeval and the present times.

(a) In the older system the upper class, the nobility, had bound themselves together into a fixed, rigid caste, the privileges of which were guaranteed by law to the whole series of their descendants, and had kept themselves strictly apart from the lower classes by class endogamy and a taboo against intermarriage. On the contrary, the capitalistic class has not kept itself separate from the other classes by any such legal prohibitions, and every one, even from the lowest rung, may rise on the wings of talent and of good fortune to the highest. The principle of exploitation whereby not personal merit but birth decides the social position of an individual has thus been decidedly weakened in this new class system.

(b) Nobility of birth derives its strength from war, financial nobility from the results of peaceful labour. Thus a new spirit was infused into the new class system. War, which was formerly esteemed as the noblest occupation of man, will now be hated as the enemy of commerce and as a 
form of barbarity, while the formerly despised labour, raised to undreamed-of effectiveness through capitalistic organization, takes a front place in the general interest and becomes increasingly the most valuable and indeed the only occupation by which an individual can acquire merit.

(c) Nobility of birth was supported by landed property, plutocracy by capital, which is more mobile, and, as experience proves, rarely remains for many generations in the same family.

(d) The new class system replaced the bondsman, who was defenceless in his isolation, by the full proletariat (p. 282). The proletariat mass themselves together into whole armies in the great industrial centres, where, provoked by constant glimpses of the luxurious lives of the wealthy, the possibility is afforded them of banding themselves together. At the same time a highly developed journalism furnishes them with a readily available means of information as to how they stand, and of organizing themselves into an increasingly greater and uniformly directed union.

(e) Finally, the old aristocracy had a powerful means of dominion at its command in mediaeval religion. For that faith referred the oppressed to the world to come for their recompense, and the high places of the priesthood were for the most part filled by the nobility. The religion of the modern man, on the contrary, having by means of science been disencumbered of all theological conceits, has become the Gospel of humanity, and abandoning the service of the Divinity, devotes itself to the service of the oppressed.

Thus the old firmly established class system was replaced by a new one which, through its weakness and instability, and also through the extra oppression which it imposed on the masses, was destined to arouse the lower class out of its hereditary lethargy and incite it to rebellion.

4. In addition to social and political innovations, capitalism led to far-reaching psychological changes in man. Every article had become merchandise, so every one was a merchant. The commercial spirit began to permeate the whole of society and to fill it with unquenchable avarice, the so-called pleonexy. Of course, this new passion did not appear suddenly; it had its early history, which, as may be here briefly recapitulated can be divided into the following phases: 


\section{THE CAUSES OF ECONOMIC DEVELOPMENT - 293}

I. Phase: To the primitive man the demon spirit of pleonexy is utterly unknown; perhaps for the simple reason that on the lowest culture stage the commodities are too few to lure him out of his repose and plunge him into restless desire.

II. Phase: Pleonexy therefore first appears among the pastoral peoples, and, indeed, comes into really vigorous existence. For cattle, which increase of themselves, possess nearly all the attributes of capital and lead to unmistakable capitalistic tendencies in the herdsman. It is an interesting psychological fact that only such peoples as had previously passed through the stage of pastoral life have risen independently to capitalism.

III. Phase: With the invention of coinage the passion for acquisition entered on a new stage. Money, which satisfies all desires, and can be amassed to an unlimited extent, excites avarice to the highest degree, and since it is at the same time a universal standard of value for all things, it awakens that calculating spirit which is never satisfied in the struggle and the haggling over mine and thine, and thus robs man more and more of his natural nobility. Through Christianity-it sounds paradoxical-this commercial spirit was intensified. For each good action proceeding from natural benevolence must, according to the doctrine of future rewards, excite the hope that it would be some day rewarded, "turned to profit," and therefore the action degenerated into a selfish one.

IV. Phase: Pleonexy underwent further intensification through the rise of capitalism which added a new function to money, since it converted the simple medium of exchange into a means of acquisition without labour.

$V$. Phase: In the mid capitalistic phase this advance was carried to its furthermost limit. For capitalism now reached its era of greatest prosperity, and at the same time a number of other causes cropped up which contributed to strengthen avarice: in the precapitalistic age the individual had a strong claim on his family and on his clan, which were a support to him in need, sickness and old age. In the mid capitalistic phase the family and clan were so broken up and weakened that in most cases they were unable to offer any sure refuge. The old bonds were severed, and as yet the 


\section{THE HISTORY OF SOCIAL DEVELOPMENT}

newly formed State was not strong enough to offer a substitute. Hence, and in consequence of the general transformation and confusion in which things were, an uncertainty of existence hitherto unknown was felt; nearly every one had to face the possibility of some day being overtaken by misfortune and of sinking down as a pauper into the proletariat. At first there was only one means of providing against this uncertainty of the future : the amassing of as much wealth as possible. The uncertainty of existence was further increased by the enormous growth of the population, which was again caused by the long years of peace, improvements in hygienic conditions, and the outburst of industry, and this, like every excess of population, added terrible hardness and severity to the struggle for existence. Meanwhile the new system of production supplied the most attractive articles in lavish abundance without any trouble; the dazzling exhibitions in the shops in the towns and the sight of the lavish expenditure of the wealthy continually aroused new desires, and through the cheapening of many products, the needs even of the poorest became more varied and numerous.

Through such causes pleonexy was fanned to white heat. If formerly man earned to live, now he lived to earn. Whereas even in the Middle Ages the idea was entertained that labour should ensure to the worker an adequate return that should suffice for the support of himself and his family (ad sui et suae familiae sustentationem, as Thomas Aquinas says), usury was regarded as shameful and was forbidden by the Church as a deadly sin, now - a characteristic reaction-the position of the independent gentleman who, without working, lives on the interest of his capital was the ideal and the desired goal of all activities. But since, in order to amass capital, one must not only earn, but save, because the hen which lays the golden eggs must not be killed, avarice associated itself with greed, with the result that menkind starved mind and body beside their well-filled gold chests and lost the joy of life. That so-called Americanism, that view which looks upon industry as the aim of existence and on time as mere money, attacked great masses of the population like a contagious disease, so that they sacrificed their lives to the " dollar hunt" in order to die rich, whilst the lower classes, 


\section{THE CAUSES OF ECONOMIC DEVELOPMENT 295}

who were, of course, excluded from this prospect of wealth, are filled with envy and bitterness when they look on these fortunates.

Thus high capitalism created a hard and hateful world out of which pleonexy swept beauty and the joy of living. Discomfort and discontent drew ever wider circles. Among thinkers the majority gave themselves up to pessimism, that philosophy of the unsound social body, while others went in search of new ideals which might make life worth living once more.

5. Yet among the many bad results of pleonexy there were a few good ones, since it greatly contributed to raise production and to lead the organization of labour into higher forms. Money, that at first was spent on transient pleasures, was now mostly saved and amassed; and since every one wished to get interest for his capital, no matter how small, the savings, which were formerly kept hidden in boxes or in the stocking of the peasant, now flowed like a fructifying stream through the land of labour. This wealth now sought everywhere for the sphere in which it could yield the most interest. Equipped with such mighty powers, enterprise could venture even on the greatest expenditure; no coal, no metal lay too deep for it, no country was too remote, no industrial investment too great; where capital knocked, the door was opened to it. Hence the almost superhuman energy inherent in capitalism, which, however, it was only able to develop when the artificial barriers imposed by the Middle Ages on production were torn down. Thus, in place of the guilds came the system of free competition (industrial freedom), and the settled rates by means of which the upper classes tried to fix the price of goods for once and all were superseded by the free laissez-faire of the law of demand and supply.

But even these remarkable results of the capitalistic system had further consequences which wrought mischief. For while within each enterprise production was carried on in a systematic and uniform way, yet the various enterprises lacked cohesion and centralization, so that production as a whole was carried on in an unsystematic way, not unlike the life of an organism in which the separate parts were independent of each other and performed their functions 


\section{THE HISTORY OF SOCIAL DEVELOPMEN'T}

each for itself. Since the individual producer did not know how great a demand there was for the article he wished to place on the market, he tried blindly, as soon as he had announced the price, to produce and sell as much as possible. The consequence of this "anarchy of production" was over production; produce so accumulated that finally there were no more buyers, and there ensued commercial crises, or more accurately speaking periodical crises, those mighty recurring upheavals of commerce when production remains stagnant, those enterprises which were the least capable of resistance came to ruin, and great masses of artisans with their families went hungry and sank into poverty. Fundamentally it was not over production but under consumption which was to a great extent to blame for these disturbances. For whilst during these crises the warehouses were filled to overflowing with wheat, clothing, footgear, etc., at the same time millions had no good shirts to their backs, no good shoes on their feet, and had to satisfy their hunger with the poorest of food. The faulty system of distribution of which we have already spoken caused a lack of the necessary buying power among the lower classes for acquiring the surplus of goods produced, thus merchants were obliged to go to distant countries to find a market for wares which were badly needed at home. Thus, even in this sphere, the mid capitalistic phase bequeathed to its successor a difficult and pressing problem, the solution of which required nothing less than the centralization and organization of the whole of production in such a way as to bring it into equilibrium with consumption.

* * * *

Thus through the rapid rise of high capitalistic organization a disposition of affairs came about which must, in the long run, become insupportable for the indefatigable populations of a race of men as sound as the Romano-Germanic nations. And this disposition or rather indisposition of affairs became now the immediate cause of a whole series of economic movements which have given the late capitalistic phase its characteristic indications. Among these movements the most important are as follows : 


\section{(a) Associations of Workmen.}

Those who suffered the most from the change were first the lower classes, the "working classes," and these led by enterprising men originally of the upper class, began to defend themselves against the tyranny which confronted them, and, with a devoted courage worthy of the greatest admiration, to band together and organize themselves. Of their organizations we may chiefly call attention to

I. Political associations which endeavour to influence the legislature in favour of the lower classes;

2. Trade Unions whose chief object is the "collective labour contract " as well as the support of members in times of strike and illness; and

3. Co-operative societies or stores, those huge buying associations which have been already explained. ${ }^{\mathrm{I}}$

At first the political associations of workmen pursued essentially false tactics. In impotent animosity and from over-estimation of their own powers, they deluded themselves with the idea that within a fairly short time they would acquire political power and then suddenly present to the world a new culture epoch; and they therefore deemed it right until that great moment arrived to repulse haughtily any little advantage temporarily offered, so that on that longed-for day they might once and for ever take their place in the " State of the future." But this enthusiastic idea generally gives way to the better view that it is wiser and more practical to win the ground step by step by ceaseless reconnaissance, by persistent labour and uncompromising struggle to gain one advantage after another, and thus to press onward towards the goal of a slow but sure evolution, which cannot be accomplished suddenly and prematurely by revolution. Yet, in spite of these errors, or perhaps partly by means of it, the organizations soon acquired greater power in economic and national life. The "iron law of wages," that law of the maximum of labour and the minimum of subsistence, which has undeniably held sway long enough, fell before its gradual advance; executive power, which formerly favoured the upper classes almost exclusively, began, at first reluctantly, but 


\section{THE HISTORY OF SOCIAL DEVELOPMENT}

with a growing cordiality, to lend its ear to the resounding voice of the lower classes.

Hence, there now appears in the history of " compulsory labour" " a new (fifth) phase in which, side by side with compulsion, interest in the result of labour becomes a motive for work, and this development trends more and more towards the ideal according to which not only compulsion and necessity (the vis a tergo) but the remuneration for the work and what is equally important the pleasure in the work will furnish the motives for performing it. With the increasing organization of the lower class the history of exploitation reached a turning point and set off in a new direction, having as its final goal the abolition of all exploitation. This attempts to bring into the region of possibility the abolition of all artificial privileges of birth, whether as regards authority, office, title, honours or riches. For since the plutocratic class system means the exploitation of the majority by the minority it must be modified in some way, or brought to ruin as soon as the majority is sufficiently instructed and organized.

\section{(b) Associations of Entrepreneurs.}

But even the entrepreneur did not lie on a bed of roses under the prevailing " anarchy of production." Struggling against unlimited competition, at strife with the workers, whose claims were constantly increasing, and living under the Damoclean sword of sudden change of circumstances, many of them spent a precarious existence which might end at any moment with a plunge into the abyss of bankruptcy. With the energy characteristic of this profession, which is so well supplied with the talent of organization and men of genius, they sought for a remedy and themselves founded associations which had for their principal object the regulation of the price of goods, of the extent of production and of the sale of produce, and so by this means to bring stability and order into the process of production and to prevent the economic crises which were of such frequent occurrence.

These associations in general are called "cartels,' I P. 282. 


\section{THE CAUSES OF ECONOMIC DEVELOPMENT 299}

syndicates or conventions, and in particular trusts (in which almost all individual and similar industries are absorbed into one gigantic enterprise) and corners or rings, by which latter name are meant speculative associations for the purposes of making exorbitant profits.

Cartels, syndicates and trusts thus represent higher forms of labour association; in the same way that great industry unites a number of small industries under a uniform management, so a number of great industries unite into these cartels, etc., and create still higher forms of organization, the final goal of which is the universal sovereignty of production in the sense indicated by $\mathrm{K}$. Marx. This goal is not affected by the circumstance that the cartels through higher development contain in themselves the danger of being misused for despoiling the public by exorbitant prices through monopolizing whole departments of production. For, as soon as this point is reached, the authorities will find themselves forced to protect the interests of the community, and thus will bring us a step nearer to the socialization of production.

But at present the cartel movement is in its infancy, and opinions as to its future are divided. Most of the cartels, for example, are of recent establishment, and moreover, the small and medium industries still surpass the great industries in number and importance. Even the transference of industrial concerns out of the hands of individuals into those of joint stock companies is a movement which tends towards the goal of higher co-operation or socialization. For the means of production which were formerly the property of a single person thus become the property of many, and the function of the entrepreneur passes from the capitalist to a paid business manager.

\section{(c) Insurance.}

To the two great movements just described a third event must be added as being equally important, namely, the development of insurance. In order to counteract the uncertainty of existence ${ }^{I}$ and to remove anxiety for the future, the true solution was once more found in association. For 
an unlucky accident which may ruin one individual and expose his family to misery is no longer a fatal blow if its harmful results are spread among the greatest possible circle of individuals; just as a burden which drags a single person to the ground may be easily borne upon the shoulders of many. This idea came into prominence in the late capitalistic age. The modern man insures his person, his belongings, his property ; he insures against fire, theft, burglary, against accidents, illness, invalidity, old age (by the purchase of annuities) and death; he insures his family, and besides that even his daughters by endowment assurance and his sons in case of a year's military service. If he is a merchant he insures his ships (marine insurance), his goods and the transport of them; his glass windows; as an employee he insures himself in case of early superannuation; as a doctor, against infection and against indemnifications if malpractices are proved against him; as a farmer he insures his cattle against epidemics, his harvest against hail and so on.

But, in spite of the enormous development in insurance in the last ten years, the fundamental idea of reducing to a minimum the injury done by blind and threatening chance and of withdrawing the fate of the individual to a maximum extent from the casual control of nature and placing it under the protection of human reason by means of association, has only been realized as yet to a relatively small degree. For this idea can only be carried out by a general system of guarantees, the organization of which would be far beyond the powers of single joint stock companies, and could only be managed by the greatest form of power man has as yet created-the State. But our present national organization is not yet adequate to such a task; still some beginning has been made towards the State control of insurance, since the State has subjected all individuals to compulsory insurance, and has taken other matters such as old age and sickness insurance under its own control.

\section{(d) National Organization.}

We have already, in the description of the forms of organization (p. Igo), recognized the organizing power of the modern State as being specially characteristic of the 


\section{THE CAUSES OF ECONOMIC DEVELOPMENT 301}

late capitalistic phase, and the "law" according to which the organizing activity of the State has augmented itself has also occupied our attention several times. ${ }^{\text {I }}$

But the importance of the modern State lies, not only in the organizations which spring copiously from it, but also in the completely altered position it occupies with regard to the individual. The State, which originally was nothing but an institution for the exploitation of the oppressed, differing from a band of robbers only in size, stability and high organization (see Part III) will slowly, very slowly, be divested of its ethical character (see Part V), which changes it more and more into a huge benevolent institution, into a puissant servant of all, and into the highest good of man on the perfection of which all progress, all culture and all happiness depend. After the RomanoGermanic nations had spent their childhood under the protection of the ethical ideal on life's way (adorned with legends and fairy tales which were suited to their child-like powers of comprehension), she was now obliged in spite of all resistance to leave her children to the father State for further education. But when the State has completed its training, when too the epoch of socialism is surmounted, the independent associations will strive ceaselessly towards a far distant goal,

I Our bureaucratic apparatus, which, with its customs dating in part from mediaeval times, seems an anachronism in modern days, acts like a powerful drag on this development. Berolzheimer very rightly says (System der Rechts-und Wirtschafts philosophic, iii. 248) : " The marks of bureaucracy are formalism (superfluous clerical work and red tape), clumsiness of management, lack of initiative, horror rovi. Bureaucracy is lacking in creative power, and mostly puts form above facts. The conservative spirit in its degeneracy, this is bureaucracy. The preference for persevering mediocrity which is well affected to the government rather than self-willed talent which is prepared to take individual action is the means used to preserve bureaucratic management. ..." As the worst of these faults (for which, naturally, the system and not persons must be blamed), we must regard the formalistic spirit, which, so long as the form is correct, treats the sense and purpose of the matter as being secondary. This spirit also finds expression in the notorious "bureaucratic jargon" which, in order to produce a solemn effect, manages to make itself as incomprehensible as possible. But it would be unjust to ignore that bureaucracy is declining, and that even officialdom has striven in the last few years to adapt itself to the spirit of the new Age. 
when they, no longer needing a guardian, will maintain themselves in equipoise, and when they will understand the ideal of absolute masterlessness, i.e. that condition of perfect anarchy of which Schiller says:

"That law which rules the resistant with brass rods does not affect thee. What thou strivest for, that is law to thee."

For "the fellowship of willing men is the unconditional goal of social life" (Stammler).

\section{(e) The Modern Woman's Movement.}

High capitalism, which gave the death-blow to "selfsufficing units," helped to break up the family and drove many women out of the home into business, has created the modern woman's question, and the late capitalistic phase responded to this with the modern woman's move-

- ment. And of all late capitalistic movements, we consider the increasing differentiation of women the most important, because, in analogy with the differentiation of men, it must change society, silently but to its deepest depths, if it adheres to the direction already taken. The reasons for this opinion, which, however, is not shared by many sociologists, we have already stated in an earlier chapter (on the Development 1 of Differentiation). ${ }^{\mathrm{I}}$

Summarily, we have now submitted the rise of the late capitalistic phase to a more thorough investigation than that of the earlier phases, because the comprehension of the present time is one of the most important tasks of sociology, and also because an endeavour to do justice to this task would awaken a more general interest than work in the lumber rooms of archæology, without which, of course, such a comprehension cannot be acquired. If we now sum up the results we may say:

High capitalism has, with a decisive wrench, carried the social organism on to a new economic basis. Hence arose the enormous problem of re-establishing the whole of culture on this new foundation. Late capitalistic society has vigorously attacked the solution of this problem, but in its most important aspects-associations of workmen and of entre-

I Book III, chapter iii. 
oreneurs, insurance, national organization and differentiation of women-has only arrived at its first and very promisng beginning. These movements have for their goal the economic ideals of our age, which now enter into increasing conflict with the ideals of the past. These ideals can only be reached in a systematic advance after a long lapse of time, step by step, in steadily organized development, and with much labour and conflict. Thus we must look upon the late capitalistic phase not only as the final phase of a vanishing epoch, but at the same time as the initial phase of a newly dawning one. Whether this view is a right one future sociology will alone be able to decide. 


\section{THE GENERAL CAUSES OF PROGRESS (The Theory of Progress)}

WE have now endeavoured to ascertain in detail the causes which have brought about development in the economic sphere, from the social economy of the self-sufficing horde through the various industrial phases right up to the powerful capitalistic organizations of the present day. We have thus come upon a motley series of co-operating forces, and we now put the question whether within these we may not find one uniform law as the centre of gravity in the flight of these phenomena, or at least whether we cannot arrive at a connected and definite picture if, in close connection with our results, we examine what are the forces which, as general causes, lie at the root of the most wonderful of all the proceedings of nature known to us.

The universal and ultimate cause of progress and the driving force of culture as of all social happenings is evidently man himself, man with his social instincts which make him to join with his fellows in the highest and most complex organizations; with his articulate speech which enables him to inherit for all time and from race to race every advantage bestowed by chance or acquired by forethought and effort; with his intellect which, mounting up by means of speech, can raise him to boundless heights; with his exertions, which obviously exact labour from him and give him pleasure, make him eagerly receptive of progress, to imitate ${ }^{x}$ in a million ways and to retain tenaciously.

Progress is also favoured by the succession of generations which prevents customs from becoming rigid from long use and allows new generations to form new habits.

I See G. Tarde: Les Lois de l'Imitation. 
We have, moreover, seen in the history of labour how important necessity and compulsion are to progress. Compulsory labour, which is so necessary to the higher culture, is repulsive and unnatural to the nature man: he only overcomes his innate laziness and submits to continuous hard work under compulsion.

Leisure and plenty play the same important part in the history of invention as necessity and compulsion in the history of labour. The importance of this has been underestimated-for man has always a greater respect for his tormentor than for his benefactor-and according to a wellknown proverb invention has been ascribed to necessity. But necessity and compulsion do not contribute to discovery : the inventive genius of man, which is nothing else than the sporting instinct, ${ }^{\mathrm{x}}$ awakes only in leisure and plentyrows $\mathrm{It}$ was in a leisure moment that a hand first picked up a coloured stone, and, throwing it about, marked not only the rhythmic sound, but also its attractive force and impetus, which soon led to the first stone hammer; and later, in the casting it away the sporting instinct was excited probably by competitions as to who could throw the furthest. It was probably to delight his own eyes that the first man who had accidentally kindled sparks by boring wood coaxed the little flames into a fire and kept it going. The strange humming and resonance of a stretched cord probably led to the invention of the first primitive musical instrument, whence were derived both the bow and the drill. Speech, too, is due in great measure to the sporting instinct. The fondness for chattering and gossiping (which is also found among other gregarious animals, apes, parrots, etc.), the irresistible instinct towards communicativeness can alone explain the comparatively superabundant vocabulary which is used by the races even on the lowest culture stage, and which cannot possibly have sprung into being merely through necessity and strife. Pleasure in seeing the comical movements of captive animals, especially young ones, led to their taming, and gave rise to the first step towards the rearing of useful animals. Even as our children like to bring home squirrels, ring adders, hedgehogs, young foxes, birds, lizards and beetles out of the woods to bring them up and play with them, so

I This word is naturally here used in its psychological sense. 


\section{THE HISTORY OF SOCIAL DEVELOPMENT}

do many peoples who have not yet risen to cattle rearing (for example, Indians) tame not only dogs, but also for their own amusement apes, parrots, eagles, seagulls, magpies, cranes, ravens, deer, foxes, bears and wolves, ${ }^{x}$ so that their huts often seem like menageries.2 From this desultory intercourse with animals it is only a short step to cattle rearing. Then, too, for the revealing of the uses of agriculture we are indebted in far higher measure to plenty than to necessity. For among most of the useful plants there exists the crafty natural arrangement that it is just the palatable parts, fruits and roots, which serve at the same time for propagation. Poverty, which is driven by hunger to eat up every scrap, would not willingly spare any of the laboriously gathered plants, whilst abundance, heedlessly satisfied, could not fail to notice that leavings thrown on formerly barren places propagate themselves an hundredfold. In many cases superior intelligences may have grasped this fact. Thus, according to Sarasin, many Australians are in the habit of putting dug up yams in the ground again after cutting off the edible roots, so that they may strike out fresh roots and not die. In addition to this it was through articles of luxury (ornaments, foreign knick-knacks and toys) that primitive trade first came into existence. "It is" (as Schrader says) " one of the most remarkable facts brought out by the study of the origins of trade and commerce, that it was not so much the great questions of human existence, 'What shall we eat? What shall we drink? and Wherewithal shall we be clothed?' which more or less fixed the highways of commerce, but rather the aesthetic requirements and a higher degree of comfort in life which opened up distant countries and seas to the merchants of antiquity. The first trading expedition noted in history, undertaken by King Sankhkara in 2300 B.C., was to the land of myrrh.3 Gold, precious stones and fragrant sandalwood were taken by the ships of Solomon and Hiram out of the wonderland of Ophir. Amber necklaces, woollen stuffs, metal work of all kinds were traded by the Phœenicians in Homer's time on the shores of Greece." Finally, leisure and plenty were the good genie

×. Waitz, p. 87 .

- Peschel, p. 444.

3 The object of the expedition was to obtain a supply of myrrh. which was largely used for purposes of embalming. 
which have called into being all the arts and sciences. It was only when agriculture had relieved man from to-day's need, and from heavy anxiety for the morrow, and when trade and commerce had made him prosperous, that arts and sciences could arise. They then awoke and flourished in the same measure as riches increased, and furnished the material means which are a necessary condition for every higher activity of the mind. As soon then as science had taken firm root in the soil prepared by wealth, inventive activity, which had formerly been exposed to chance, entered on a new stage; with civilization began those times of invention and discovery which we investigated in an earlier treatise.

At whatever point we look, it is evident everywhere in the history of inventions that these are not due to necessity, but that they are rather the free daughters of leisure and. plenty. Necessity may indeed incite to labour and effort as a categoric imperative, but inventions cannot be made to order; they depend on the undisturbed play of thought and fancy which appears uncalled for in the mind which is free from all great cares. Necessity leads to industry, but leisure leads to invention. Leisure sets at liberty the sporting instinct, the inventor whom necessity wraps in chains. It is certainly no chance that the most inventive of all creatures should be also the most passionate of sportsmen; for among animals it is mostly only the young that play, whilst in the genus homo even adults participate in all possible games and sports, from the noblest to the most foolish, with real delight. Finally, it is easier to understand that some new thing should spring from abundance rather than from withered penury. For poverty stunts the intellectual life, and hence the minimum of inventive activity is found among primitive peoples who are certainly not lacking in necessity, whilst it celebrates its greatest triumphs among the richest nations.

If we now stop a moment to look back, it would seem that the above named causes are amply sufficient to explain the progress of culture, that as a matter of fact they must lead to such results. [And since these aforesaid causes lie partly in the peculiarities of human character and partly in circum- 


\section{THE HISTORY OF SOCIAL DEVELOPMENT}

stances such as necessity and-compulsion, leisure and plenty, which are found everywhere more or less, progress must be something inherent, immanent in man, or at least arising out of his own essence, and must needs appear where human society exists for any length of time.

But the facts do not always coincide with this conclusion. We know that nature folk may remain on one and the same stage for hundreds and thousands of years (as for example the hunters of the Stone Age) when they are left to themselves in unchanged conditions; we know that primitive peoples are incarnate "misoneists," who set their face against any new thing and mistrust all progress, that in their eyes traditional custom is the one and only wisdom which is to regulate everything, and that among them the formula " as our fathers did so do we" prevails as strongly and exercises as much influence over their minds as among our own peasant population not many decades ago.

These facts are so remarkable that even so great an authority on nature folk as Livingstone found himself forced to the same conclusion as other theologians, that man on the lower stage of culture is not capable of progress by himself, and that alone he could never create the culture process, and that therefore it must be admitted that progress has only become possible by means of a supernatural influence-the inspiration of God.

In harmony with this idea comes the thought that progress must not be looked upon as something immanent in man. What is immanent in man is rather a tremendous mental laziness which confronts all novelty with hostility. In order to conquer this inherent laziness something from without must enter into him which shall draw him forcibly out of his customary existence, and this something is nothing supernatural but quite palpable--it is nothing else but a forced or voluntary change of environment.

The weak are banished by the strong into other countries, or men are forced to emigrate by increase of numbers; and even if we did not possess ethnology, which contains records on all sides of migrations and changes of surroundings, we should already have concluded that changes of surroundings had in fact taken place at all periods, and that the human race had dispersed over the whole earth. 


\section{THE GENERAL CAUSES OF PROGRESS}

What are the results of such a change of environment ?

Already in a former treatise ${ }^{\mathrm{I}}$ we have sought to point out how the ancestors of man, by means of a tremendous change of surroundings no less than the descent from the tree to the ground, rose out of the animal into the human state. What happened in that special case we will now explain in general terms. If we put a cat into a strange room into which it has never been before, we shall notice that at first it shrinks back and then carefully reconnoitres its new territory from a safe corner. Then it advances and, with an explorer's thirst for knowledge, begins to subject the whole room to a close investigation. All the objects are examined with strained attention, sniffed at and touched with its paws. Then it wanders for a long time over chairs and tables until the examination is over, that is until pussy has made sure that there is nothing there to fear or to eat. Then she settles down quietly in a corner, and from that moment her interest is gone ; for the rest of her life she confronts with absolute apathy the objects she has once examined. In a similar way it must have happened with a horde of men newly arrived in a strange country. At first thousands of new objects, plants hitherto unseen, glittering stones and strange animals, will arouse curiosity and drag the men forcibly out of the dull routine of customary usage. For novelty awakens fear and hope, and constantly inspires the question in the stranger whether it conceals danger or whether it can be turned to a useful purpose. New interests awake, everything is carefully examined, new methods of hunting are devised and new tools manufactured; they embark upon a period of invention and progress which causes a mental excitement and brings the sporting instinct into play. But after a few generations, when the tribe becomes accustomed to its new surroundings and feels at home, all progressive life ceases, the man sinks back into his old apathy, tradition becomes all powerful and mental laziness absolute, and custom again becomes hostile to all improvement. With adaptation to the new environment the desire for advance dies, and the result is stagnation.

If, however, culture is to continue to develop, two ways lie open : 


\section{THE HISTORY OF SOCIAL DEVELOPMENT}

I. Change of Environment by Means of Continual Migration.-For this result each tribe must constantly enter upon fresh surroundings in order to rise to new stages by adding experience to experience. Quite apart from the consideration that by this proceeding gains due to the old surroundings would easily be lost, it is also unnecessarily laborious. Culture has taken a shorter and better road which can be described in the words

2. Change of Environment by Means of Amalgamation and Reciprocal Influence of Groups.-And this is the starting point of our theory of progress. Through amalgamation separate hordes became tribes, separate tribes nations, and separate nations the great states. In each amalgamation all the experiences which the separate groups had gathered together in the course of ages from different surroundings united into one whole and were raised to higher forms by mutual permeation and productiveness. But we must not only take into consideration the unions of the groups into higher political forms, which for the most part followed upon war, but also those equally important peaceful and purely intellectual unions, reciprocal actions and influences in which the groups were mutually brought together, especially by commerce and even by mere acquaintance.

In fact, experience teaches that on the one side " each social group remained.in a given condition until it was driven out of it by the influence of others," I and on the other side, that an acquaintance with hitherto unknown groups preceded every new epoch and that the most important progress was always made when a new amalgamation or reciprocal influence of groups had taken place, when strange peoples came into contact, whether this contact was of a warlike or a peaceful description. The deeper we go into the history of progress the more evident it becomes that this idea, which Sociology owes to L. Gumplowicz, is the real key to the understanding of the progress of culture. We can soon convince ourselves of this if we now again pass in brief review the apparently complicated history of social economy and turn our attention to the matters relating to groups through which one economic phase after another has been called into life.

x Gumplowicz: Grundriss der Soziologie, p. 73. 


\section{The Phaseology of Group Contact.}

The oldest, and in fact the only original form of group contact was war. The separate primeval hordes were hostile to each other, and the objects of their fighting, just as with animals, were the feeding grounds. The important result of these battles of antiquity was that the strong, that is the better organized, oppressed or destroyed the weak, and that in consequence the better organized tribes remained as victors.

When organization had attained to a certain height it came to a second kind of group contact, which we may call group amalgamation, namely, the rape of women (p. 267). The captive women formed, in fact, a kind of union between the previously hostile hordes, while they were able to impart to their new masters the accomplishments of their native horde. At the same time the rape of women led, as we have already seen, to primitive marriage, to the family and to division of labour between the sexes-and thus, through this form of group contact there arose out of the primeval conditions the first or clan phase of labour organization, self-sufficing hordes-economy with division of labour between the sexes.

In the succeeding phase for the first time appears a contact that has nothing to do with war-that is, the beginning of trade. In the place of robbery-of goods and womencame the more advantageous barter (p. 269), which now united several neighbouring tribes into one great alliance having division of labour, and out of this new union of groups arose our second or mid clan phase of labour organization : horde and clan organization with intertribal barter.

In the earlier phase the union of groups was held together by unstable contiguity, but after the discovery of agriculture it was effected by strong internal ties and formed a step towards further warlike oppression. For the neighbouring peoples being conquered are now enslaved, they become incorporated into the victorious race; and in the same way as the first differentiation, the one between the sexes, sprang out of the enslaving of woman, so now the second, the industrial, springs from the enslaving of man (p. 27I). Hence came the development into our third or " early industrial phase," and at the same time into the beginnings of civiliza- 


\section{THE HISTORY OF SOCIAL DEVELOPMENT}

tion, and even this great advance is thus directly attributable to a new form of group union. We must not forget that the discovery of agriculture furnished the possibility of the rise of differentiation of men, but the possibility only. For all agricultural people who, like the American Indians, did not enslave the conquered have also not risen into the early industrial stage, but merely possess division of labour between the sexes.

In the succeeding phase, the conflicts between neighbouring peoples (of which the early history of civilization is particularly full) led to the result that a still greater number of groups were united under a uniform leadership. Hence the "State" comes into being, and now appear all those reciprocal effects of the State and the differentiation between men which, as we have already explained (p. 215), led to the systematic establishment of organization in business and so to the stage of civilization. Thus the new group union, which welded together a greater number of tribes into a State, was the direct cause of the rise of the fourth or high industrial phase, the phase in which the industrial organization of labour was fully developed.

As long as the States, which were themselves large group unions, were isolated and dependent upon their own resources (like Egypt, India, Peru, Mexico, Japan in antiquity and China almost up to the present day), they showed an evident tendency towards stability, although this was naturally only relative; no matter how long their existence, they all remained steadily in the industrial stage and never rose to capitalistic organization. On the other hand, as soon as a number of states came into contact and thus formed a group union of a yet higher order (as did the nations on the shores of the Mediterranean in antiquity or the RomanoGermanic nations after the opening up of the East), there appeared at once a new phase of labour organization, namely, the "early capitalistic phase," which obviously owes its origin to international trade and commerce (p. $274 \mathrm{ff}$.).

Thus the sixth or mid capitalistic phase was preceded by a contact of groups of such wide universality as the world had never before seen. Then all the achievements of culture which the nations of antiquity, the Cimmerians, AssyroBabylonians, Persians, Indians, Egyptians, Phœnicians, 


\section{THE GENERAL CAUSES OF PROGRESS}

Celts, Greeks and Romans had amassed during centuries of prolonged labour fell into the lap of fortunate Europe like a gigantic legacy. It was not only the classic nations of antiquity who bequeathed an inheritance, but the Jews also gave a religion to aspiring Europe, and the Arabs, by the invention of the experimental method, pointed out the new roads of the natural sciences to the Westerns, whose minds even in the eleventh century were benumbed in orthodoxy. Natural sciences in their turn led to the epoch making invention of labour machines, which gave the decisive impetus to high capitalistic organization. Besides, ever since the Age of Discovery the geographical horizon had widened more and more, and finally had opened up the whole surface of the earth. The circle of group contacts became constantly more universal and more world embracing, and eventually placed nearly all the peoples of the earth in relationship with each other. All parts of the world now came into reciprocal action with each other, and culture, which now began to resemble a huge symphony in which everything in human shape took part, was raised to a height never before reached. But that the European nations did not raise themselves by their own strength (great though it was) to this high stage of culture, but by a number of group contacts and by a legacy of culture such as had never before universally existed, is amply proved if we only cast a glance at the whole of our culture treasure and its origin. For we owe the greater part of our wealth of culture, of our domestic animals, garden plants and implements, even our arts and sciences, either directly or indirectly to amalgamation and acquaintance with foreign peoples. Thus, to mention only a few of them, the vine comes from the Caucasus; the apricot from Armenia; the plane tree, peach and mulberry, and the rose and the lily from Persia ; melons, cucumbers, pumpkins from Turkestan; the date palm from Phœnicia and Arabia ; cypresses, tomatoes, caraway seeds, mustard from Asia Minor; cherries from Cerasus in Pontus; shalots from Askelon ; maize, potatoes, tobacco, chocolate from the New World; peas from Greece; lentils from the Romans; coffee from the Arabians; tea and silk from the Chinese; the domestic cat from Egypt ; the domestic fowl from India; the peacock from Ophir; the pheasant from Phasis. The 


\section{THE HISTORY OF SOCIAL DEVELOPMENT}

fatherland of the taming of domestic animals is to be found in Western Asia, in Mesopotamia, as Hahn's searching investigations have made probable. We obtained soap from the Celts through the Romans, glass making from the Egyptians, and the violin and guitar from the Arabs. For metals we are originally indebted to the East; for numbers, weights and measures to the Babylonians; for astronomy to the ancient Chaldeans; for writing to the Egyptians; for our system of numeration to the Indians ; for our modern natural sciences to the Arabs; for the science of history, art and philosophy to the Greeks; for our law to the Romans; for our religion to the Jews, etc. A complete enumeration of all our borrowings and accretions of culture would fill volumes, and Peschel could say with justice: "What we mean by civilization, culture and good breeding is nothing but a sum of brilliant ideas for the most part inherited by us and of Asiatic or Egyptian origin (Völkerkunde, 6 Aufl. p. 550).

Thus facts correspond absolutely with the theory, as this briefest of all surveys of the phaseology of group contacts must have shown. Each new economic phase was called forth by a new influence from without. The progress of culture is brought about by group contact, whether the reciprocal action between the groups consists in rape, oppression, slavery, incorporation or exploitation ; or, in peaceful contrast to these, in commercial treaty, or whether it is of a purely intellectual character and comes about simply through mere acquaintance with foreign nations, even with nations that are now extinct.

And hence we return to an idea we have already mentioned. Not in the strength and sovereignty of the individual man, as we said, lies the strength of the human race, but in the capacity for individuals to group themselves together into higher organizations. Similarly the cause of progress, and with it the cause of the whole of culture, is not to be found in the qualities of the individual man, but in the association of groups of men. Man was only qualified for greater life and power through union, and in the same way the creative power which is necessary to connect progress with progress can only be acquired by 
the union of separate groups of men into organizations of still higher kind.

Thus progress is brought about by the union of groups and the association of nations, and it is again extended by group contact, and by selection in the struggle for existence. For culture is power, and each new achievement of culture is a new accession of power. A progressive organization drives the backward ones out of the field, and either destroys them or incorporates them into its own social body. The same struggle by which culture peoples in the last two hundred years have driven back, annihilated or subdued nature peoples has everywhere and in all times raged among groups of men; the more advanced organizations always remained victorious, and thus progress became more and more universal.

Hence we might briefly formulate the following theory of progress: The root conditions of the progress of culture lie naturally in the physical and psychical qualities of man, in his social instincts, in his speech, his intellect, his sporting instinct, etc., but the driving force of progress is neither in the individual nor in the separate groups, but in group contact and group amalgamation. Thus selection by means of the struggle between groups provides that progress shall be diffused and become universal. 



\section{BOOK V}

SUMMARY OF THE CULTURE STAGES 



\section{CHAPTER I \\ THE STAGES OF CULTURE}

If Sociology aims at being more than a medley of other sciences, it must be confined, with certain exceptions, to the facts of historic ethnology in the same way that geometry is confined to the Science of Space.

Georg Simmel.

I. A MAN slowly approaching an ant-hill in a forest may be surprised that the appearance of such a gigantic creature as himself causes no excitement among the industrious little creatures, who calmly continue their occupations without noticing him.

In the same heedless fashion man goes on his way. The rapid journey of the earth round the sun would never have been discovered if men had lived as isolated units or small tribes, it is only when men assemble together and the " social intellect" grows and brightens by contact and conflict that the greatest truths are made known. The undeveloped unit can obtain no view of the Infinite, the two or three must first be gathered together and gradually increase in wisdom and numbers.

How many movements of the most extreme importance may not be going on around this earth of ours of which man has as little idea as the ants have of the life and designs of the man who is watching them ? The very devel'opment in which he is himself taking part is beyond his understanding, and is, as it were, a fourth dimension to him. Unnumbered millenniums elapsed before he perceived that a movement of culture was steadily directed towards a certain goal of perfection, and that this movement is a continuation of a still greater 
organic evolution which has brought life forward from the very simplest forms to its present condition. Even now most men are so engrossed in the labour necessary to earn the wherewithal to eat and drink, to marry and rear their families, that no thought can be given to the culture movement. Among the educated classes it is only the few who are realizing the importance of it.

Many argue from the history of the past, taking for examples Egypt, Assyria, Babylonia, Greece and Rome, that just as the individual goes through the stages of childhood, maturity and decline in a long or short life, so do the nations rise into long or short prosperity and then fall into decay, and in everlasting rotation return to the dust of nothingness from which they came. A certain progress, then relapse; a certain increase, then decrease; a certain growth, then decay.

This argument is founded on a confusion of ideas. The development of culture is a different question to the development of separate nations. Nations rise and fall, but culture moves on for ever. The dictum of Hippocrates: "Vita brevis, ars longa," applies to national as well as to individual life. In fact, if one studies with enlightened eyes, the death of nations has often been the means of advance of culture. If culture is to progress it must subjugate all nations that oppose it, advancing over their dead bodies. The civilization of the nations of antiquity which have passed away did not sink into nothingness; there is not a single instance of this. The people were either violently destroyed or absorbed by other nations more cultured or more capable of culture than those who had fallen victim to stagnation. There can be no standing still on the way. The victors were more capable than the vanquished of developing civilization, and were helped in their task by the culture of the conquered nation, for nothing is permanently lost.

The objection based on the decay of nations is and must remain invalid. The existence of a progressive improvement in human life by means of culture is a self-evident and now already an acknowledged truth whose discovery must be regarded as the first and most significant of the achievements of Sociology.

2. But although the continuously progressive develop- 
ment of culture is undoubted, it does not follow that we can accept any arbitrary system of the culture stages until we clear up the following questions.

Has the course of development throughout the whole world been so uniform that it can be brought into such a definite scheme? Have the separate peoples of the world now living under various nature conditions and belonging to various races gone through an identical course of development?

In answer, the facts are that each race possesses a history of development which does not exactly coincide with that of any other race. That the roads might run far apart was shown quite obviously in the stage of Barbarism, the worlds on both sides of the Atlantic choosing either Agriculture or Cattle Rearing, according to their environment (p. 88). The story of Cain and Abel told this in quite early times. Abel was a keeper of sheep, Cain was a tiller of the ground, and it is quite typical that the Shepherd and the Agriculturist each developed along his separate course. We have also noted other exceptions in the different manner of life among the fisher races of North-West America (p. 7I) ; the rise of free industries among the African races (p. I68); and the communistic establishments among the Incas (p. 2I3), etc. These examples may be multiplied to almost any extent, and show clearly that the development of culture should be compared not to the single upright trunk of the pine tree, but rather to those leafy shrubs which produce several stems more or less directly rising from the same root and which subdivide into branches and twigs.

But, in spite of differences, the progress of culture shows so many characteristics common to all nations that a universal system of stages may easily be arranged, if we ignore local peculiarities and consider the process in its essential features. It is true that nations live in the most manifold nature conditions, and that they belong to various races, yet environment exercises on the whole merely an accelerating or retarding power in the culture process; it influences the measure of the development more than the manner of it, giving only a local colouring. For example, the Germans, in consequence of their remote Northern habitat, reached development later than the Greeks and Romans, but, if 


\section{THE HISTORY OF SOCIAL DEVELOPMENT}

we ignore local peculiarities, the economic phases which they manifested were essentially the same as those through which the Greeks and Romans had passed. The heterogeneity of the races of men does not show such great diversities as the diversities of the culture stages. It should be noted that the culture of the hunter exhibits everywhere the same features, although the individual hunter-for instance, the Australian, the Eskimo, the Bushman and the men of the Ice Age-belong to the most diverse races. The culture of our day differs from that of the early Germans in far higher degree than the latter does from the culture of the Polynesians, and it has much more similarity with the culture of modern Japan than that of our forefathers. Moreover, although development springs up as it were into different branches and twigs, the whole sequence is still logical. The social economy of the Old World founded on cattle rearing was certainly very different from the agricultural economy of the New World, and yet we can put pastoral and agricultural peoples on the same culture stage, if we consider them as the first representatives of the stage of cultivation or artificial food production as opposed to the hunters, who had only the resources of uncultivated nature at their disposal.

If we strive to understand the mass of phenomena by abstraction, if we measure their development by the height at which the different branches bifurcate from the main trunk, and above all if we distinguish universal history from the merély local, we may beyond all question arrange the culture development of all nations in one simple stage system, just as we may, to revert to Schiller's simile, divide men into the stages of childhood, adolescence and maturity, in spite of all individual peculiarities. For everywhere over the earth's surface culture has advanced in general from small to great; from natural to artificial; from simple to complex; from homogeneous to heterogeneous; from concrete to abstract ; in short, from lower to higher forms.

A general system of culture stages is not only possible, but it is a scientific necessity. For as long as we cannot sketch the great lines through which development has passed, sociology stands perplexed before its material and cannot formulate a theory as biology has done, because instead of 
working with a well-ordered system of plants and animals it has to deal with an inextricable tangle of the most varied organisms. The first necessity is to define the universal features of the development of culture, and only then will the study of local differences, valuable as they are, become possible.

3. If development shows enough uniform features to be reduced to a system, the next question will be, "Wherewith shall it be measured?"

In a sense, every sociological faculty, every result of culture might be taken as a standard, either Art, Science, Custom, Social Economy, Government, the Freedom of the Individual, Philosophy, Women's Rights-even down to the use of soap. It would be immaterial what standard was chosen if, and here lies the difficulty, all culture phenomena had developed on parallel lines, in complete proportion with each other. But such is not the case. For instance, in Greek antiquity Art was in a higher state of perfection than it is now in our late capitalistic phase ; the women of that day held an inferior position to that occupied by the Huron Indian squaw; and morality in the Roman Empire was at a lower ebb than among most nature tribes. Fate and environment have urged the nations forward, one in one direction and the other in another, and often Progress in one sphere seems the cause of Retrogression and Contraction in another.

It is obvious that our standard must be very high, and especially characteristic of a nation. Before all else the following three considerations should be suitable : Social Economy, the System of Government, and the Intellectual Life as expressed in the Arts and Sciences and Customs of the people, and on these three we have built up the classification. ${ }^{x}$

None of these standards could be complete in itself, but of all sociological functions, Social Economy is the most necessary and fundamental. Progress moves slowly on its thousand feet, each new step leads to another, but yet

I Vierkant: Naturvölker und Kultuvvölkev, 1896; Die Kulturformen und ihre natürliche Verbreitung, 1897. Breysig: Dev Stufenbase und die Gesetze der Weltgeschichte, I905. These stage systems will be investigated more closely in Parts III and IV, " Phaseology of the Social Organizations" and "Phaseology of the Social Intellect." 


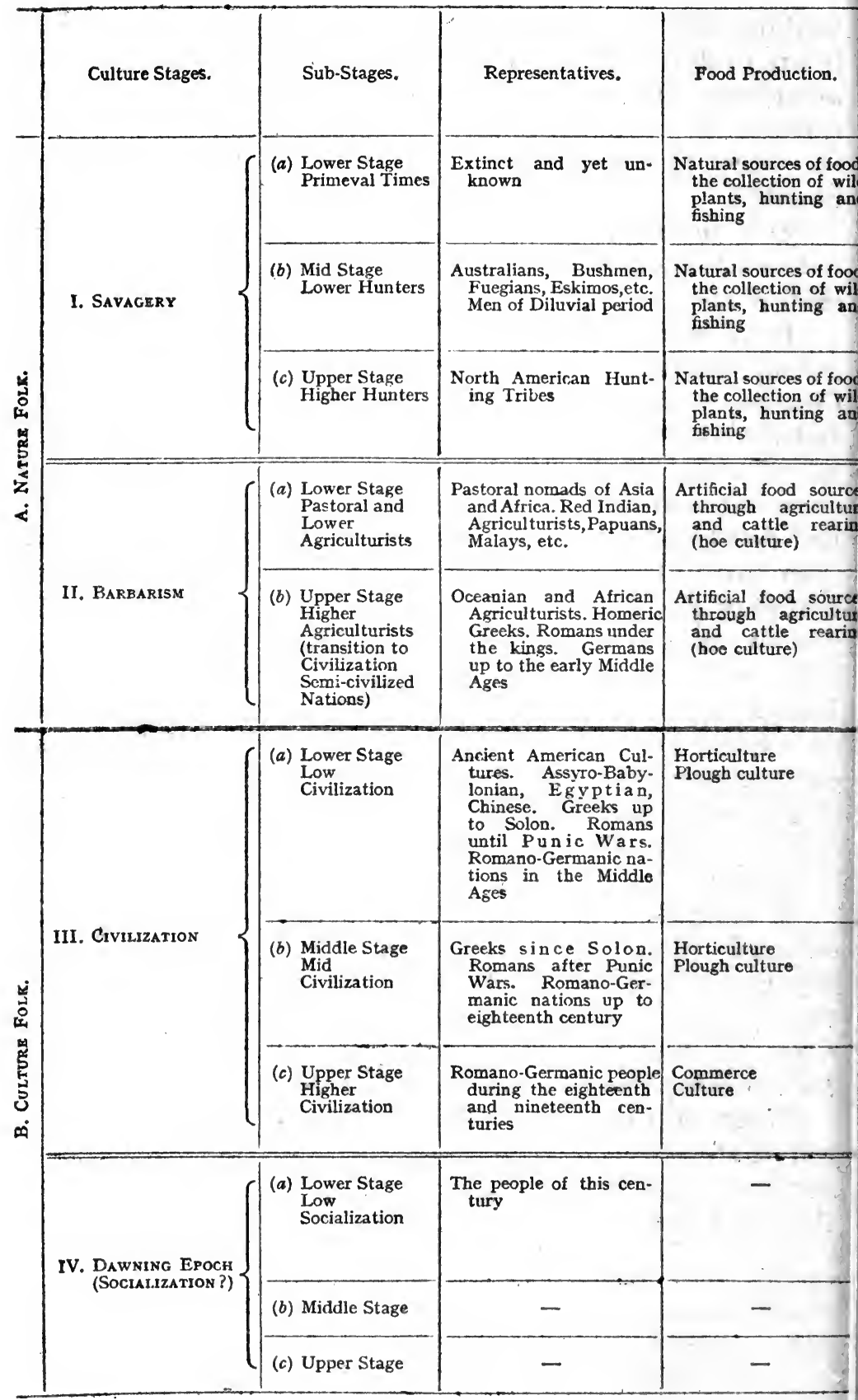




\begin{tabular}{|c|c|c|c|}
\hline & \multicolumn{3}{|c|}{ Organization of Labour. } \\
\hline tecungue. & $\begin{array}{c}\text { Form and Size of } \\
\text { Labour Organization. }\end{array}$ & Differentiation. & Integration. \\
\hline $\begin{array}{l}\text { Primitive wood and } \\
\text { s tone implements } \\
\text { until the discovery } \\
\text { of fire }\end{array}$ & $\begin{array}{l}\text { r. Early Clan Phase } \\
\text { Self-sufficing }\end{array}$ & Lacking & . - \\
\hline $\begin{array}{l}\text { Palæolithic } \\
\text { Older Stone Age }\end{array}$ & $\begin{array}{l}\text { 2. Later Clan Phase } \\
\text { Extended Clan } \\
\text { Economy }\end{array}$ & $\begin{array}{l}\text { Differentiation between } \\
\text { the sexes }\end{array}$ & Natural Economy \\
\hline $\begin{array}{l}\text { Palaolithic } \\
\text { Older Stone Age }\end{array}$ & $\begin{array}{l}\text { 2. Later Clan Phase } \\
\text { Extended Clan } \\
\text { Economy }\end{array}$ & $\begin{array}{l}\text { Differentiation between } \\
\text { the sexes }\end{array}$ & - \\
\hline $\begin{array}{l}\text { Neolithic or more re- } \\
\text { cent Stone (Pottery, } \\
\text { Weaving) }\end{array}$ & $\begin{array}{l}\text { 2. Later Clan Phase } \\
\text { Extended Clan } \\
\text { Economy }\end{array}$ & $\begin{array}{l}\text { Differentiation between } \\
\text { the sexes }\end{array}$ & - \\
\hline Transition to & $\begin{array}{l}\text { 3. Early Industrial } \\
\text { Phase } \\
\text { Manorial and } \\
\text { Village Economy }\end{array}$ & $\begin{array}{l}\text { Beginning of the Dif- } \\
\text { ferentiation of men }\end{array}$ & $\begin{array}{l}\text { Natural Money } \\
\text { Economy }\end{array}$ \\
\hline $\begin{array}{l}\text { Metal Age (Copper, } \\
\text { Bronze, Iron) }\end{array}$ & $\begin{array}{l}\text { 4. High Industrial } \\
\text { Phase } \\
\text { Town Economy }\end{array}$ & Differentiation of men & Money Economy \\
\hline $\begin{array}{l}\text { Metal Age (Copper, } \\
\text { Bronze, Iron) }\end{array}$ & $\begin{array}{l}\text { 5. Early Capitalistic } \\
\text { Phase } \\
\text { Beginning of } \\
\text { National Economy }\end{array}$ & Differentiation of men & - \\
\hline $\begin{array}{l}\text { Beginning of Machine } \\
\text { Age }\end{array}$ & $\begin{array}{l}\text { 6. Mid Capitalistic } \\
\text { Phase } \\
\text { National Economy }\end{array}$ & $\begin{array}{l}\text { Beginning of Differen- } \\
\text { tiation of women }\end{array}$ & Credit Economy \\
\hline- & $\begin{array}{l}\text { 7. Late Capitalistic } \\
\text { Phase } \\
\text { Beyinnings of } \\
\text { International } \\
\text { Economy }\end{array}$ & - & - \\
\hline 一 & 一 & 一 & - \\
\hline - & - & - & - \\
\hline
\end{tabular}




\section{THE HISTORY OF SOCIAL DEVELOPMENT}

the whole culture depends on the economic benefits which have been produced. A nation can only develop such Arts and Sciences, Refinement and Social Organization as its material prosperity will permit. Experience has shown how highly important social economy is to culture. Every great epoch was ushered in by the extension of natural resources, by technical inventions, or by new forms of labour organization.

The economic function as a standard of culture has another advantage ; it can everywhere be ascertained precisely and without any insurmountable difficulty, so that it is specially suitable for dividing and classifying nations into culture stages according to their purely external characteristics.

4. Long before Sociology, in the modern sense of the word, existed, culture science throughout the ages recognized the importance of social economy for purposes of classification. The ancient philosophers divided the peoples of the world into hunters, fishers, shepherds and agriculturists, thereby taking the production of food as a standard.

Archæologists based their classification on technique and the nature of tools and implements, and spoke of the Stone Age, the Bronze Age, and the Iron Age. Lastly followed the economists, who, considering the subject from a new point of view, made use of the "Organization of Labour" as a principle of division, and taught us to gauge the height of development by the grade of Labour association. Then we arrive at a

5th and final question.--Since the economic function is composed of different sub-functions, which of these subfunctions is to be taken as the standard of culture? This is best answered by putting the stages of development into a table showing the uniformity of growth of Food production, Technique and Labour Organization as well as the development of the most important phenomena of all economic life, to which we have given a very searching investigation in the foregoing treatises. (See Books II and III.)

It is evident from this table that the three functions show a remarkably parallel development, which makes it possible for us to characterize them in culture stages. On the lower ones, where life is principally spent in procuring 
the means of subsistence, Food Production plays the most important part ; whilst for the characterization of the stages above, where the higher advantages of culture are generated, the Organization of Labour must come to the front. This relationship we find similarly expressed in other culture systems, which we may cite here. In Schöneberg's Classification " the following stages are shown:

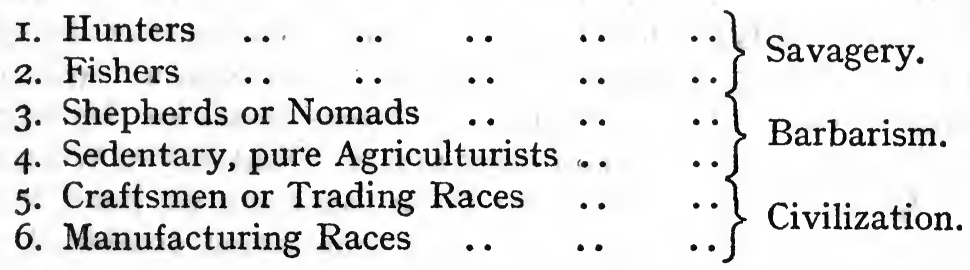

List places the five periods in almost identically the same way $:{ }^{2}$

I. Period of Hunters

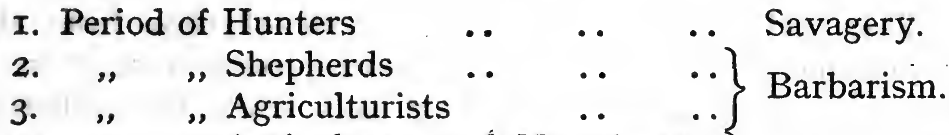

4. " "Agriculture and Manufacture 5. . " $\left.\quad \begin{array}{ccc}\text { Agriculture, Manufactures and } \\ \text { Trade }\end{array}\right\}$ Civilization.

Bos's system 3 is similar. He originated new specifications for the different economic activities which are very important in the separate culture stages:

I. The Industry of Collection (Savagery). The collection of plants, animals and minerals, hunting and fishing.

2. The Industry of Production (Barbarism) (agriculture and cattle rearing).

3. The Industry of Transformation (handicrafts, manufactures, etc.) $\quad$.. $\quad$.. $\quad$.. $\}$ Civilization.

4. The Industry of Locomotion (trade) ..

- Handb. d. polit. Okon. III. i. p. 29.

2 Das nationale System, Ges. Schr. Bd. iii. I4.

3 Bos. 
The designations in these systems are striking, but formal and clumsy, hence they have not been generally accepted. We prefer the older ones, firstly, because the majority of Sociologists accept and adopt them, and secondly, because their greater universality allows us to include in them many more functions. The element of contempt that lies in the words Savagery and Barbarism need not deter us. It is a part of the development of culture that the higher stage always regards the lower with a certain amount of contempt. In the coming centuries the word "Civilization" will be equally contemned, standing as it now does for Proletarianism, Pauperism, Exploitation and the Disability of Women.

If we therefore take the three functions of Food Production, Technique and Labour Organization combined as the standard of Culture, we can now characterize the Culture Stages as follows:

\section{Savagery.}

This includes the enormous periods of time from the beginning of Culture to the condition of Agriculture and Cattle Rearing. Man supported life on this stage by gathering wild plants, by hunting and fishing. The primitive tools and weapons were made from wood and stone or other materials taken directly from nature. The chief form of Labour Organization was the union of men into the tribal associations, and the only form of division of Labour was that between the sexes.

(a) The lowest stage of Savagery, the primeval age, is the childhood of the human race. It seems to have begun with the descent of the forerunners of man from the tree to the ground, when articulate speech arose and implements were contrived out of wood and stone. Neither labour nor the division of labour was known, but simply the necessity for keeping together in hordes. This stage ended with the discovery of the kindling of fire. This " Primeval Stage of Culture" in all probability exceeded all the others taken together in duration, and certainly did in importance and in results. For this reason, and also because its representatives are extinct and at present unknown, the primeval stage of mankind should not be confounded with the two higher stages of "Savagery," as is unfortunately often done. This 
period should rather be thought of as an ante-stage of all the later culture stages.

(b) The middle stage embraces the sociologically interesting group of the "Lower Hunters," Australians, Fuegians, Eskimos, Bushmen, etc., who, having been driven into the remotest corners of the habitable world and remaining on the lowest stage of culture known to us, are now fast dying out. These remnants of the Lower Hunters, roaming continually in small tribes, are omnivorous, i.e. they eat everything that can possibly be eaten in the animal and vegetable kingdoms; their tools and weapons correspond absolutely to those of Palæolithic men, and among all members of the group the only division of Labour is that between the sexes.

(c) The highest stage, that of the Higher Hunters, principally represented by the American Indian hunter folk, has no sharply dividing line between it and the middle stage. The culture of the Higher Hunters is only one grade above that of the Lower, and this superiority they owe to the more favourable habitat they occupy.x The invention of the bow and arrow has been taken as the distinguishing mark between the higher and lower stage. The bow was certainly invented later than the spear, but most of the Lower Hunters possess it, and this group shows so many features in common with the Higher that it seems wiser not to take this as a distinctive characteristic.

\section{Barbarism.}

This stage begins with the opening up of natural resources, with the discovery of Agriculture and Cattle Rearing. Technically, it corresponds to the Neolithic Age. Tools and weapons are now made with greater care-stone is polished and sometimes drilled-and Weaving and Pottery are invented.

With regard to the Organization of Labour, Barbarism may be divided into two sub-classes :

s An exceptional position falls to the lot of the Behring Straits fishers (see p. 7r). They form a group by themselves of local importance only. They must be clearly distinguished from the Higher Hunters, for they are a sedentary people and have many more features in common with Agriculturists than Hunters. 
(a) A lower stage, which includes shepherds and lower agriculturists, and on which, as in the previous epochs, the only division of Labour is that between the sexes; and

(b) An upper stage, in which the differentiation of men in the form of "village" and manorial economy makes its first weak beginnings, and thus prepares the way for the transition to civilization. These are the higher agriculturist and semi-civilized races. ${ }^{\mathrm{I}}$

\section{Civilization.}

This is, from an economic standpoint, essentially the differentiation of men. Industrial division of labour-for which agriculture is the preliminary stipulation-makes possible the production of the refinements of life, the possession of which characterizes "culture folk" as opposed to "nature folk." Following closely upon the differentiation of work among men, we find the rise of the state; the town, the invention of writing, and the amplification of Science and of Art. Technically speaking, Civilization corresponds to the Metal Age. Naturally, there have been many races still on the Upper Stage of Barbarism who knew the use of metals; but this knowledge had been handed to them by others on the Stage of Civilization, and the cognizance thus gained did not raise their culture to the stage of the "Metal Age." There have been no epoch making discoveries with regard to Food made in this civilized age, but old methods of Horticulture and Husbandry have improved into higher forms. Civilized nations may be divided into the following sub-classes according to their grade of Labour association:

(a) Lower civilized, who, like many of the Chinese of

- Certain sociologists comprehend all agricultural nature folk as Lower Agriculturists, and civilized people as Higher Agriculturists. By this classification either all agricultural nature folk, whatever their stage of development, are thrown together, and similarly with civilized people; or else the agricultural peoples of the earth must be divided into Lower Lower, Higher Lower, Lower Higher, Middle Higher, etc. It is therefore expedient to divide the agricultural nature folk into the Lower (without differentiation) and the Higher (with differentiation), and to call the civilized agriculturalists not the Higher, but simply Civilized, in the usual sense of the term. 
to-day, have not yet emerged from the merely industrial organization;

(b) Mid civilized, who have risen to the beginning of capitalistic organization; and

(c) Higher civilized, who possess a developed capitalistic organization. On the upper stage of Civilization there appear the Machine Age and the Differentiation of Women's Work.

\section{The Dawning Epoch. Socialization (?).}

A popular but unscientific delusion would like to teach us that Civilization is the goal of the Culture process : this could only end in stagnation or retrogression, whereas the pace of development, in fact, is continually accelerating. Since the Late Capitalistic phase is only now dawning, we cannot clearly explain it. The new stage can only show its true constitution when the position of women is rightly established, just as the stage now passing away only showed its most important characteristic after the differentiation of men's work had made considerable progress. But it is certain that Co-operation or Socialization of Labour will rise to far higher forms, of the shapings of which we can conceive no more idea, perhaps, than man on the stage of Barbarism could have conceived of the results of Civilization.

If we would condense the four Culture Stages still more, we might use the following formula :

I. Savagery: Natural Sources of Food.

II. Barbarism: Artificial Sources of Food.

III. Civilization: Differentiation of Men's Work.

IV. Socialization : Differentiation of Women's Work (?). 


\section{ON THE DURATION OF THE CULTURE PERIODS}

THE less the human intellect is cultivated the lower the stage of development on which it stands, and the narrower are the ideas about the size of the "World," about the space man occupies and about the duration of his existence. Not long ago, only a few centuries, men thought that the earth was the centre of the Universe, around which the crystal vault of Heaven, with the glittering stars, in fact, the whole universe, revolved; and nature folk on a very low culture stage still believe that the stars are not poised at all in immeasurable distance, but that they can be easily reached by men under certain conditions. For instance, the Tahitians, when they began to realize the length of the ocean journeys of Europeans, once asked the Englishman Bligh, quite seriously, whether he had not visited the Sun and Moon on his journey; and we shall come across many similar ideas of primitive intelligence. (See The History of Human Intelligence.)

Further study has taught us that even the fraction of the universe visible to us is of enormous extent, surpassing all our powers of imagination. Light, which travels 48,000 miles a second, needs 6,000 years to reach us from the Milky Way, so that even if this were to be suddenly destroyed, mankind would still see its light shining in the sky for the next 6,000 years. With these thoughts of space in our minds, the earth appears to us as only an atom. And even this vast space which science has thrown open to us, furnished with its myriads of stars, with waxing and waning solar systems, is as it were a microscopic spot, a nothing, in comparison with the illimitable size of the universe. 


\section{ON DURATION OF THE CULTURE PERIODS 333}

\section{The Age of the Earth.}

To these illimitable spaces correspond illimitable periods of time.

But whilst more correct ideas on the size of the Universe are now widely spread, we have still remained slaves to the obsolete opinions regarding conditions of Time; especially as regards the questions-How old is the Earth? How old is the Human Race and its Culture ? The causes of this want of proportion are easily understood. For imperishable Space is more easily subjected to mathematical calculations than fleeting Time, which we can only approximately estimate by complicated methods of inference and indirect premises.

Hence even among scientists, opinion as to the age of the earth differ very widely. Astronomers, physicists and geologists are only agreed in this, that the age of the earth is not to be reckoned as formerly believed by thousands of years I but by millions. Thus the physicist Thomson estimates the age of the earth at 100,000,000 years; the astronomer Hermann Klein reckons that since the hardening of the surface of the earth from two to four thousand million years have elapsed; Blandet and Vinot give six thousand million, and so on.

Everywhere, if the crust of the earth is considered from a geological standpoint, we come, even in the separate strata, upon figures not easy to realize. The layers of guano which are found thirty metres thick were computed by Alexander Humboldt to have taken nine hundred thousand years to form. The formation of many a coal stratum must have taken from ten to twenty million years, if we admit with Liebig that a square decimetre of forest land would yield

I Different writers who endeavour to judge the date of the creation of the world by the inspired Hebrew writings have different ideas. The period between the creation of Adam and the birth of Christ amounted-

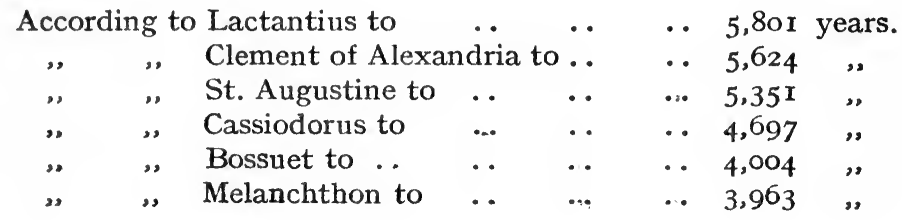




\section{THE HISTORY OF SOCIAL DEVELOPMENT}

yearly about one-fortieth of a pound of coal. I Many geologists estimate the duration of the different epochs in the following way :

\section{The Primordial, 52,000,000 years. \\ ", Primary or Palæozoic, 34,000,000 years. \\ "Secondary or Mesozoic, II,000,000 years. \\ "Tertiary or Cainozoic, 3,000,000 years. \\ ", Quaternary, 100,000 years.}

\section{Age of the Human Race and Culture.}

Naturally, such estimates can make no claim to accuracy. However, this is certain, that the existence of the earth extends over such a vast period of time that the mind of man finds it impossible to conceive its length if he thinks to measure it by his own ephemeral life.

How old then is culture? Or, what is equally important, how long has man been on the earth?

We know for a certainty that man already existed in the Ice Age, in the Diluvial period. Lyell considers that the stone weapons and implements found in the valley of the Somme are-at a moderate estimate-a hundred thousand years old. Lubbock claims for the oldest Palæolithic implements an age of from one hundred thousand to two hundred and forty thousand years; G. de Mortillet putting it at two hundred and fifty thousand years. According to Crole, the Ice Age began about two hundred thousand years ago, and lasted about a hundred and sixty thousand years. According to Prestwich the duration of the Ice Age was only twentyfive to thirty-five thousand years, and according to Warren Upham from twenty to thirty thousand years; whilst George Taylor gives it a hundred and fifty to three hundred thousand years, and Penck, who is now considered the greatest authority on the subject, gives five hundred thousand years.

I “. . wenn man mit Liebig annimmt, dass I $\square$ ' Waldboden jährlich ca. I/40 Pfund Kohle erzeugt." We have been unable to trace either the exact meaning of the measurement sign or the quoted reference to Liebig in the Geological Museum in Jermyn Street or the South Kensington Natural History Museum, but we were assured in the latter place that the translation as given is substantially correct. -(TRANS.) 


\section{ON DURATION OF THE CULTURE PERIODS 335}

Yet these figures are not so contradictory as they appear at first sight. For it is not one Ice Age only that we have had, but several, and we can easily admit with Penck that, in all probability, from the beginning of the first Ice Age perhaps half a million years may have elapsed, and that the last short Glacial period may date only from ten to twenty thousand years ago.

But man is much older than the Ice Age, for Diluvial man possessed a comparatively advanced culture, and had, as Archæology shows, planted his foot firmly in various parts of the earth, carrying with him the weapons he had made, a knowledge of the kindling of fire and other acquisitions.

Thus the Primeval stage of culture must be placed much further back than this, and although vestiges of Tertiary man have not yet been indicated with certainty, ${ }^{\mathrm{I}}$ yet we are bound to conclude that the long and slow process of development which we designate "Primeval " must certainly have occurred in the Tertiary Period. In any case, the age of the human race is not to be reckoned by thousands, but by hundreds of thousands of years.

\section{The Age of the Neolithic Period.}

In Scandinavia and Denmark no traces of Diluvial man have been found ; the oldest vestiges of human culture there, dating from Neolithic times, are contained in the kitchenmiddens and peat-bogs. These peat-bogs are important, as they furnish us with a kind of prehistoric calendar. The four strata may be described as follows:

The lowest stratum is composed of the débris of great pine woods, a mass of pine needles, pine cones and well preserved trunks, many of which must have reached an age of three or four hundred years. These pine forests once covered the whole of Denmark. Then the pine was supplanted by the alder, the remains of which compose the second stratum. The oak followed, as the third stratum showed, and finally the beech, whose glorious woods now cover Denmark, the pine being extinct in the country.

- Translator's note.-This book was written in 1908, before the discovery of the Piltdown Skull. 


\section{THE HISTORY OF SOCIAL DEVELOPMENT}

Each layer is from five to seven metres thick. Steenstrup considers that the formation of the whole may have taken ten to twelve thousand years, the pine trees holding their pre-eminence for the greater part of that period.

The date of the pine woods, as Archæological discoveries prove, was that of the Neolithic period; it is believed that it lasted till about B.C. I500.

At this time the oak began to supersede the pine, and it was approximately then that the Bronze Age began.

About the beginning of our chronology, the oak in its turn was superseded by the beech simultaneously with the beginning of the Iron Age. The beech has held the chief place now for nineteen hundred years.

All the other parts of Europe were covered with the primeval forests in Neolithic times, and this no doubt induced men to make their homes in the pile dwellings on the lakes. To these lake dwellings an age of about five thousand years is ascribed. They had disappeared before history begins; no ancient writer mentions these people of the Neolithic Age, who had obviously practised Agriculture and Cattle Rearing. The fact that the original kinds of wild growing wheat, rye and maize are everywhere extinct bears witness to the great antiquity of Agriculture.

\section{The Comparative Duration of the Separate Culture Epochs.}

As regards the comparative duration of the separate culture epochs, we can only form an approximate idea.

A general opinion as brought forward by Kant teaches that the culture epochs become increasingly shorter, or that the periods in which equal progress has been made follow each other with increasing rapidity. Whilst progress leads to more progress, the acquisitions of culture do not all accumulate proportionately in the same time ; yet the rate of accumulation increases continually in rapidity. This proposition, plausible in itself, is confirmed by history. The progress of the last thirty years was greater than that of the previous hundred years; and this again was greater than that of the previous five hundred years. Historians support the truth of this statement in a remarkable manner by the classification they made of the epochs of Universal History. The following is what they taught: 


\section{ON DURATION OF THE CULTURE PERIODS 337}

1. Duration of Antiquity about five thousand years.

2. " " the Middle Ages something over a thousand years.

3. " " the New Age three and a half centuries.

4. " " the Present Age only a dozen decades.

Thus it is clear that the further back the culture stages lie, the longer they lasted.

Those primeval ages, in which man evolved primitive culture out of his purely animal existence, must have resembled at first to a large extent the unprogressive life of the animal, and the duration of this period must have been enormous ; firstly, because the progress made in it was enormous, and secondly, because of the obstinate conservatism of primitive man, which passes for supreme law with his posterity. All beginnings are difficult, and we must admit that those primeval times which gave man his characteristic qualities, even now innate in him, extended over many hundreds of thousands of years, and had a much longer duration than all the other culture epochs put together. Every succeeding epoch in turn became shorter, and the few thousand years of civilization which were considered "Universal History " can, as far as time goes, be considered as only a small fraction in the course of evolution. What the early historians counted as "Antiquity," the epoch primeval, the beginning of all human activities, we see by the aid of Sociology to be comparatively recent times, the latest and shortest phase in the evolution of culture.

Whereby we come to this result :

I. The age of the human race and of culture is not to be reckoned merely by thousands, but by hundreds of thousands of years.

2. The primeval had the longest duration of all the culture stages, and probably it was much longer than all the other epochs added together.

3. Each succeeding culture epoch was of shorter duration than the preceding one.

4. The few thousand years of Civilization which we call "Universal History" represent, in respect of time, a small fraction of the whole course of culture. 


\section{GENERAL SUMMARY.}

Reviewing the history of the Earth and the history of mankind, which has been played in it like a single scene in a great drama, we may distinguish the following phases:

\section{Astronomical Phases.}

I. The Earth is a gaseous body, with only one aggregate condition prevailing, the gaseous.

2. Through changes of temperature fluids are precipitated; thus two aggregate conditions exist, gases and fluids.

3. The surface hardens, there exist now solid bodies; thus three aggregate conditions exist at the same time.

Thereupon begin

\section{The Geological Phases.}

I. The first of which is called Azoic, because as yet no signs of Organic Life have been discovered.

2. The second, the Organic, with remains of plants and animals.

3. The Higher Organic, in which man appears and with him Culture. This section is again sub-divided into:

(a) Prehistoric Phases.

I. The Primeval Age,

2. Savagery,

3. Barbarism, and

(b) Historic Phases.

Civilization.

So in the endless vicissitudes other Phases are coming. The cooling process of the Earth continues; the gaseous bodies disappear or change into fluid, and the fluid into solid. The Sun, the Lifegiver-for all life on earth is transformed sunshine-is growing cooler and cooler. The silver cord will be loosed and the benumbed earth for long ages will revolve round the sun, as the moon now revolves round the earth. Life is only a short episode in the Earth-history ; like a passing blush, it colours the cheeks of the still youthful Mother-Earth, where stony calm and chill immobility wiil 


\section{ON DURATION OF THE CULTURE PERIODS 339}

follow unless some astronomical collision brings about the end. This is the icy waste on which the eye of the imagination may rest from the astronomical standpoint.r But if we descend into the smiling valley that the Sociological standpoint shows us, the future assumes a pleasanter aspect, and the period of life upon earth seems almost endless. For on the mighty World-clock the hand moves forward so slowly that the movement is unperceived, and the pendulum takes an eternity to accomplish a single swing. According to a calculation by Helmholz, for instance, only after twenty million years will the heat of the sun be diminished by a single degree (Celsius), and everywhere we speak of numbers i so great as not to be easily realized with regard to the changes which, it is foretold, will usher in the destruction of this world. In all probability Homer's sun will still shine upon mankind for millions of years, and the mighty progress we have already made is probably only a prelude, just a beginning of a longer period of a more perfect culture.

What has been already achieved justifies humanity in these aspirations.

I Wilhelm Meyer : Weltuntergang. 
$x-41301$ 


\section{BOOK VI}

\section{CULTURE AND HAPPINESS}





\section{ON THE MEANING OF CULTURE AND ON THE IMPORTANCE OF THE IDEA OF PROGRESS}

(Culture and Happiness)

Ir is customary to define culture as an aggregate means of achievement and of progress, ${ }^{x}$ from which the conclusion is to be drawn that human life, through the culture process, is undergoing an ever increasing improvement and completion. But experience does not seem to coincide with this inference; certainly culture has endowed human society with power and wealth, but at the same time it has burdened the individual with such an oppressive load of duties and restraints that the care-free life of the nature man may well seem one to be desired. Obviously retrogression and loss in one direction go hand in hand with progress in another.

Even if we are to look upon culture as undoubtedly " a progressive movement," the question still remains, to what extent has real "progress" been made? What has been specially achieved by culture? What has been lost by it?

Since the goal of all human endeavour is happiness, we should imagine that the word culture progress, if a reasonable meaning is to be found in it, can have no other signification than that man may become happier through such culture.

The question as to whether this happens can naturally only be answered if we succeed in defining clearly the indefinite idea "happiness"; for we know that opinions differ widely as to what happiness is. The most superficial, but a very prevalent idea, understands by happiness a sort

\footnotetext{
× See "Introduction to Sociology," p. 29. 


\section{THE HISTORY OF SOCIAL DEVELOPMENT}

of lazy, purposeless life, where the streams flow with milk and honey, where roast pigeons fly into the mouth; in short, where every wish is fulfilled without costing the slightest effort. The origin of this paradisaic dream is psychologically easy enough to explain, for the goal hovering before all men is to procure the greatest possible amount of good things with the least possible amount of work. Yet the fulfilment of this Midas wish would be no blessing to man, but rather a curse. For such a paradise would deprive man of all his aspirations and wishes, all his occupations and voluntary activities. It would make his life a torment and a misery, and the world into a desert in which, wrapped in unbearable ennui, he would be unhappy, and out of which he would long with his whole heart to escape, as did the knight Tannhäuser from the Hörselberg. For the sensation of happiness lies not in slothful calm, not in inactive satiety, but in successful activity - not in the goal, as a lifelong illusion has deceived us into believing, but in the attainment of the goal; not in possession, but in the winning and striving for it. It is a fundamental mistake to think that happiness can be a condition which once reached will be always maintained; practically the feeling of happiness is, on the whole, like life, a process, which can only be maintained on condition of continual renewal and expansion. The road is everything, the goal is nothing. On that account happiness ought not to be confused, as it often is, with that condition of apathetic animal enjoyment which the creature of habit feels when he allows nothing to disturb him in the unchanging monotony of his life. Far happier is the man who, bringing into play all the expanding forces slumbering and germinating within him, can satisfy new desires and new needs by new efforts, and, overcoming obstacles, can proceed from one result to another, and so succeed in bringing all his powers, capabilities and talents (which naturally are individually very varied) into one great and harmonious development, and his own personality into a higher state of perfection. Happiness may thus be sought, as a well known and true proverb says, in the full and harmonious expression of individuality, in the free development and continuous completion of personality. Experience confirms 
the truth of the saying, for in general those men feel the happiest who live their life in the environment most favourable to their inherent individuality, and who can freely and fully develop their talents.

If we again take up our question we notice next that the opinions of experts as to whether men have become happier by means of culture are widely at variance. Only a few answer the question in the affirmative, among them so great a scientist as Sir John Lubbock, one of the founders of sociology. Of the great number of sociologists some evade the question, some declare it unanswerable, and some assert that culture has no appreciable influence on human happiness ; not a few have tried to prove that man has not improved his lot by culture, but has made it worsethus while some look on culture as a blessing others regard it almost as a curse. It must be obvious from the contrariety of these views that culture cannot essentially or immediately improve the lot of the individual. The variety of views is probably due to the fact that the separate investigators have compared different classes of civilized nations with nature folk. It is true that certain classes of the population have been raised by means of culture to a higher scale of existence than nature folk could ever have attained. But if we consider-and this is the point-the life-conditions of the vast masses on the higher culture stage, I think we are bound to admit that culture has, in general, made the lot of the individuals worse rather than better. Man in his primitive natural condition can obviously employ his ability to the height of his own power and in harmony with his own tastes. $\mathrm{He}$ is free from anxiety for the future, and contented with his lot; whilst the great mass of people on the stage of civilization, crowded on to a never-ceasing treadmill of specialized labour, cramped in a complicated system of duties and restrictions on all sides, tormented by care or by pleonexy, assailed by endless insatiable yearnings, have to lead a stunted and troubled existence which the nature man views with unconquerable horror. 


\section{THE HISTORY OF SOCIAL DEVELOPMENT}

This result of our reflections can naturally only be set forth in detail in the concluding volume of this work, ${ }^{\mathbf{}}$ and must at first sight seem astonishing-almost incredible. Through countless thousands of years has man added achievement to achievement, piled up invention on invention, ranked progress with progress ; through mighty efforts, through the remarkable labours of his most ingenious leaders, he has attained the sovereign power which has raised him far above all his fellow creatures, and has given him dominion over all the earth-and with all these splendid things shall he have attained nothing, indeed less than nothing? By means of higher civilization has he merely forged for himself chains which drag him down to be the slave of his own work? Yet the riddle should not be hard to read.

As we have already seen, in the struggle for existence man fights rot individually but socially, not as individual against individual but as community against community. The strongest weapon of a community in the struggle for existence is organization. Now since the community with the higher and more rigid organization drives every other one from the field, so increasingly rigid and more highly organized communities must survive as the dominant force, and in the struggle for existence social organization fiust by means of selection be continually forced upwards to a higher plane. What becomes of the separate individual in this organization is quite immaterial to the advance of this process. Let us explain this important proceeding by a few examples: A tribe which subjugates another and makes the members of it work for it as a slave class, while the victorious class devote themselves exclusively to the art of war, is better organized and more powerful than another that has not slaves at its disposal; and thus at a certain stage of culture the establishment of slavery became dominant and generally prevalent, although by means of it the happiness of a majority of individuals obviously suffered an essential loss. A community which forces a majority of its members into the most unnatural and severest division of labour is more powerful than another

I The History of Social Development is one of a series of volumes by the author.-(Trans.) 
without division of labour, and thus those communities with a division of labour must subdue those other communities which did not possess this arrangement, although by means of it the happiness of the majority was not augmented, but rather diminished. A society which does not make use of the acquisitions of culture for the qualitative amelioration of the lot of the individual, but merely or chiefly for the increase and solidification of the masses, and these only for the quantitative uplift of life, is stronger than another community that uses it in the reverse way, and on that account is suitable for and capable of crowding out, destroying and subduing the other society, although this stands higher on the scale of humanity. In this fashion in the struggle for existence selection must always yield more perfect organization, and greater, stronger, more differentiated and more rigidly disciplined social corporations. The comfort of the individual in this compulsory system was of comparatively subordinate importance in the process of selection.

This consideration makes it quite clear why the happiness of the individual was not increased by culture in spite of all its achievements and progress. We can, however, draw from it not only a negative but a positive result. We recognize now clearly in what the sense and importance of culture has hitherto consisted; progress was chiefly concerned, not with the well-being of the individual, but only and solely with the perfecting of the community, even if it were at the expense of the individual. The more perfect the society the more must the individual allow himself to become merely a part of the machinery of life and adapt himself to it, whether it be for his own good or his own ill. That was all about which natural selection cared in the struggle for existence. The victors were simply the better organized, the better disciplined and the better governed servants of society. The acquisitions of culture came as no boon to the individual, because they were employed for the power and greatness of the organization, for the perfecting of the social body. The truth of this assertion is perceived at a glance if we compare the beginning and end of the culture processes that have elapsed up to the present. A modern great country of to-day is sublime and perfect 


\section{THE HISTORY OF SOCIAL DEVELOPMENT}

when compared with a horde of savages, but by the side of this perfecting process the result for the individual with his aspirations and desires has been disappointing.

Thus we now realize that the meaning and importance of culture up to now was not the raising of individual happiness but the perfecting of social organization, even at the expense of the individual.

But, since we cannot admit from our human standpoint that the state is the goal of the individual, $\mathbf{r}$ but must rather regard the state as a means to lead the individual towards his destiny, we arrive at the further conclusion that up to the present the total process was nothing but a perfectly meaningless, planless and purposeless proceeding, that like every other process of nature (as far as human comprehension can read), it was the cold, callous play of blindly working forces, and not of the purposeful will.

How could it be otherwise? Man has stood until now so low on the intellectual stage of development that he was hardly conscious of the culture process! How could he set to work with a purpose in this process? The individual man acts designedly, conscious of a goal, but human society, which consists of a mass of intersecting separate wills, grows and develops like a plant or an animal with no goal hovering before it, without knowing the way it is to take, and obedient to laws quite unknown to it. Hence it happens that, since the upper stage of barbarism, society has been divided into classes with a ruling minority and a ruled majority. Now it cannot be denied that in many respects the interests of both coincide, but in many more, and in the most important things, the contrary is the case. The interests of the exploiter are opposed to the interests of the exploited, and since all power is in the hands of the minority, through this system the masses must be crushed down in an increasingly unfavourable position.

It was thus by the co-operation of blind and crude forces that the wonderful structure of culture was raised. Therefore it is not astonishing that the progressive movement which was guided on its way by these forces, cannot be dis-

I This view, which might also be called Social Masochism, has been brilliantly refuted by Schiller in various of his prose writings, as, for example, Die Gesetzgebung des Lykurgus und Solon. 
inguished in its essential characteristics from the processes which are going on in the world outside humanity according to the fixed law of infinitely sublime and mysterious nature. It is quite apparent that the essential characteristics of the process of culture are the same as those of organic development, of which it is in fact a continuation. Hence we have now reached the point where it is at last possible to say what the word "culture progress" really signifies. Just as in organic nature a progressive movement exists from the monad to the mammal, so is it in culture. And in both developments the movement goes from small to great, from simple to complex, from homogeneous to heterogeneous, and in these processes of increase, combination and differentiation (along with integration) lies progress-and it lies in nothing else. That is the objective formula of the idea of culture progress. The happiness of the individual has no place therein, For nature offers up the individual everywhere with cruel indifference on the altar of-the Type.

These are bitter truths, which at first sight must have a crushing effect on the lover of culture. If human happiness is not itself increased by the culture process, it would be capricious to be filled any longer with enthusiasm for the culture process. If culture proves itself to be a force which works inimically against the destiny of man it must be regarded as a reprehensible folly, which we ought to oppose with all our might. The longing of all would then have to be, "Away with culture, back to the nature conditions." As a matter of fact this conclusion has been reached by Rousseau, who ascribed all human misery to culture, and looked upon the culture man as a degenerate animal.

But this deduction of the brilliant writer is, as we now admit, quite incorrect. Although hitherto the individual has been sacrificed to culture, the pessimistic inference is by no means a matter of course that it must always be so ; "there is nothing new under the sun " are only the words

I Vischer, in one of the deepest and most intellectual books of our literature, has called the Infinite, which to our comprehension is meaningless, Selinur, in contradistinction to the Taliesin, the radiant, practical human spirit. 
of effete wisdom. The logic of facts leads us to expect just the reverse : a second development must follow on the development already gained, in which man by means of the progress of culture has arrived at undreamed-of power, and this power will be made conducive to the welfare of the individual. Indeed, the hitherto existing epoch, "the perfecting of society," is only to be regarded as a prelude to a second epoch, "the perfecting of the individual." Actually, this wonderful revolution is already taking place before our eyes in our late capitalistic phase ; it is no optimistic dream, but to the sociologically sharpened eye it is a truth, which, as the following remarks will show, is made evident by the facts of the whole and especially of the latest development.

Firstly, it must not be thought that culture from the height of its development will fall back again to its starting point. The culture man can as little return to the state of nature as a man can transform himself back into a child. Since, therefore, the possibility is excluded of development remaining in its present phase, or of suddenly coming to a standstill, the only alternative is movement in a forward direction. It is, too, quite improbable that this movement will for all future time maintain its present character, that the perfecting of the community at the cost of the individual is to be the last word of culture. It is a fact that in animal communities nature has carried out this principle with gruesome consequences, as for example in the case of ants, termites and bees, these most developed of all insects. Here the process is so far advanced that there are males and females which are nothing more than independent sexual organs, while other individuals are deprived of the organs of reproduction so that they may serve exclusively as workers or soldiers of the community. Moreover, there are slaveowners whose organs for self-nourishment are so stunted that they starve if they are not fed by their slaves. In fact, among the ants, individuals are filled with sweet sap and suspended in the cells so that they may sacrifice their existence to the community as flasks or as living honey jars. We see by this where the road leads : to the stunting and deterioration of the individual. Nor are there wanting the beginnings of such deterioration in human communities, but it has in nowise come as yet to anatomical changes which are here- 
ditary, and it never will. Man would sink down to the stage of insects if he allowed himself to be abandoned to the nature process. He has risen too high for that ; in every individual there is an innate trend towards perfect manhood, and everywhere and always human sentiment resents with all its strength the idea that the good of society should be bought by the degeneration and degradation of the individual.

As culture grows it becomes more intense and more vehement, for through culture man becomes more capable of enjoyment, but also more sensitive to pain. In favourable conditions the culture man will be happier than the animal or natural man, but in unfavourable surroundings he will necessarily feel more unhappy. So with increasing culture the thought "what life might be" and "what it is" must strike him ever more forcibly, and the desire for another world in which he may fully and freely develop the longing for happiness must become more ardent and irrepressible. We cannot conceive that man, after he has acquired power through culture to procure joy and ward off pain, should consent to remain for ever the victim of the community; the "cannon fodder" of culture. Truly our own time, in which the lower classes, who are the most exposed to deterioration, are raising their voice, and woman, the oldest slave of humanity, wishes to become independent, proves the justice of this view. Both these great words, "individualism" and "socialism," with which our century is ringing, prove nothing else than the uprising of this longing for happiness.

For these two watchwords are not opposed to each other as is usually thought, they are only different expressions of one and the same effort. Truly, if by individualism we take that distorted view in which every man is the born enemy of the other, and as far as possible is a lonely sail, and if by socialism we can imagine nothing but a mighty equality which would condemn all the world to dreary barracks life, then these two principles would be absolute antitheses. But if we leave such repugnant caricatures alone and acknowledge that "individualism" can mean nothing else than the organization of freedom, and "socialism" nothing else than the organization of labour-or, to express it more accurately, rational co-operation (socialization of production) and equitable, i.e. proportionate distribution of the results of labour- 


\section{THE HISTORY OF SOCIAL DEVELOPMENT}

then socialism understood in this sense is the indispensable condition of individualism, for it is, at least in our phase of development, not only the best but the sole form which provides the individual with that sphere of power and freedom in which he can fully develop his life. For as a social being, man can only fulfil his destiny in a social way. That the richer classes lay more stress on individualism, and the poorer masses on socialism, is quite easy to understand; but from the sociological standpoint it is one-sided and false. The just expression for the striving after the happiness of humanity, if we want a word for it, must be "social individualism."

Until now man has for the most part made this longing for happiness unfruitful, because he has relegated it to another world. This belief was a boon to the suffering individual of the first epoch, but to the active individual of the second epoch, who has to devote all his energies to the present world, it acts as a brake. Now the more this idea dwindles, the more in place of it the opinion gains ground that almost every individual evil which confronts the defenceless unit is the outcome of social disarrangement, and can only be averted by social re-arrangement-the more will he feel every misfortune that overtakes him to be a fresh stimulus to social endeavour. Whilst the old religion was only able to console and calm, this new religion will stimulate to transmute pain not into empty hopes, but into deeds which are destined to call true progress into life.

Again, in our day we see a whole series of other obstacles which have impeded the striving after happiness tottering to their fall owing to assaults to which they are bound eventually to succumb. As we mentioned above, one of the principal reasons why culture could do so little to further the happiness of the individual was that the great masses of the nation were kept down and despoiled by small ruling minorities. It is one of the most important events of our time that these masses are awakened out of their apathetic slumber and are beginning to organize, and hence gradually to attain to the power which is requisite to lend weight to their claims.

With just instinct the oppressed feel that this oppression can only come to an end when the struggle for existence between the "groups" is humanized, and that such result 
can only be accomplished by international arrangements. In this opposition to the brutality of the struggle for existence, the deeply rooted form of which is war, the lower classes come to the help of the situation, because meanwhile the war community is transformed into the labour community. (See Part III.) In the place of warlike collisions, commercial relations come increasingly into force which unite all nations of the world into one great community of labour. In the labour community the interests of the individual need no longer be sacrificed wholly to society as in the war community, but the state becomes more and more the medium for the welfare of the individual.

While peaceful labour organization increases, and should shortly include all the nations on earth, there comes in, according to the theory of progress stated elsewhere, a new turning-point of even greater importance to the raising of individual happiness by means of culture. As we pointed out in "The Causes of the Progress of Culture" (p. 3II et seq.), the most important cause of "the progress of culture " is to be found in the "reciprocal influence" of groups. Progress receives its strongest impulse as soon as nations formerly hostile come into reciprocal relationship. The rapid progress of the last centuries can be explained by the fact that the most advanced nations came rapidly one after another into contact with new peoples until the whole surface of the earth was opened up to them. As long as culture advances headlong and by fits and starts, no true adaptation can take place in any one of the swiftly changing conditions. As long as no adaptation and no system ensues, individuals are thrown together pell-mell ; they can get no sure footing, and on that account sudden transition periods are very unfavourable to individual happiness, which can only develop undisturbed during slow, social adaptation. Now if our theory of progress be correct the era of rapid and haphazard advance must be nearing its end, for there are no more new nations in the world who can impart new and sudden shocks to development. A long time must elapse before impulses, already received in this manner, are equalized. But then progress will probably travel along smoother paths, a condition of relative stability will come about as J. S. Mill prophesied, i.e. a time of regulated progress, but it will no 
longer exclude social adaptation, and will be far more serviceable to individual welfare than has hitherto been the case.

We must not fail to mention that in the opinion of expert sociologists since the time of Malthus, the greater part of the suffering amongst civilized nations is caused by excessive increase of population. It is evident that the achievements of culture contribute in less measure to the raising of individual life the more their use is employed in a one-sided fashion for the increase of the population; that such a senseless increase as has taken place in the nineteenth century in Europe and the United States, from ${ }_{53}$ to 398 millions, must necessarily result in misery and suffering of every description; in disease, crime and lamentable increase of difficulty in the struggle for existence, and that the increase of the population in any case cannot continue in these proportions. Now, in the most highly advanced culture lands the conviction is spreading more and more that parents who bring forth large numbers of children to whom they can neither give a desirable education nor guarantee a decent livelihood act immorally, and injure themselves even more than others. And this view has led, in those countries, to a perceptible diminution of the birthrate as a result. This is a momentous event in the relation between culture and happiness, for what we see arise here is no other than the first beginning of a humanizing of propagation by means of which an undreamed of amount of suffering will be avoided. ${ }^{\mathrm{x}}$

Thus we see forces everywhere at work which prepare the way for individual happiness, and engage the opposing hindrances in victorious conflict.

At the same time in the scientific sphere an event of great importance has taken place-the discovery of the culture movement. As everywhere in nature unconsciousness precedes consciousness (for example in organic development, and the development of the individual man), the culture movement up to now was unconscious, and hence as it were involuntary. But while development advances, sooner or later a point must be reached when mankind will become conscious of its existence. With the rise of sociology this event took place, and now a new hour has struck on the

I This is given in greater detail in Sociologie der Fortpflanzung. 
great clock of the world. It announces the emergence of man out of the twilight of instinctive life into the clear daylight of consciousness, the awakening of the slumbering giant now conscious of his aim, to the purposeful struggle to labour. Humanity, which hitherto has worked as a blind nature force, can now see. Dark shadows still lie in the valleys, but the mountain tops are beginning to grow rosy with the dawn : the social intellect has entered the zone of selfconsciousness. Hence the character of the culture movement must necessarily change. As long as man had no idea of the existence and reality of this development, it followed as a matter of course that he must bear everything patiently as his destiny. Now science will furnish him with a means of adapting this movement more and more to his own advantage. As humanity by means of natural science has been able to have dominion over nature, so will it learn by means of the science of culture to control the strange creation of culture which it has blindly brought into being, and become lord over it for its own purpose. "The science of social forces will itself become a social force," and put man in the position of being able to climb the ladder of his fate, no longer driven by blind forces, but now in full consciousness of his goal.

To sum up all these considerations : humanity has hitherto assumed successively higher forms of organization by long circumlocutions and endless struggles, without knowledge and without volition. In this epoch, which extended over hundreds of thousands of years, society underwent a process of completion the cost of which was the happiness of the individual. In consequence of this process, organized associations of men have risen to high understanding and great power, and thus a point was reached when humanity awoke to a consciousness of its life. And now begins, as we perceive from all the indications, a second epoch, a new era in which the culture achievements which have been so laboriously acquired by the human spirit striving purposefully towards the only reasonable goal there is, or can be, are brought into service for the improvement of the welfare of the individual, when man, till now the slave of culture, the fool 
of his own creation, begins to raise himself as its lord and master.

Astronomical and geological reasons guarantee that this second epoch, through the beginnings of which we are now passing, will last for hundreds of thousands, perhaps even millions of years (see p. 339). After the enormous progress of the last two thousand years, we are justified in supposing that this future development will rise to undreamed of heights, and will lead on to an era of perfect culture, in the light of which all the phases of our present half culture put together will seem like a kind of childhood of the human race. Only in this coming age, when culture has fully blossomed out, will man be able to appreciate justly its value.

If we consider the development of culture in the light of sociology, it would follow that an impartial and calm review of culture would in no wise lead to a pessimistic conclusion. On the contrary, we almost receive the impression that throughout the course of the tremendous drama of humanity there has been glimmering a secret plan of salvation and blessing, and that this development would not have shaped itself very differently if it had been guided by a purposeful power. For the medium, the instrument, must first be created before it can fulfil its purpose. "If I make an axe for myself, while I am making it I am only the means to an end, and only when I have made it, when I swing it freely in my hand, am I its master. We might well invert Goethe and say: "At first we were servants, and only later were we free."

Thus our misfortune is not that we have already had too much culture, but rather that we have had too little. Not " back to nature conditions," but " on towards complete culture " should be our cry. It would be a foolish proceeding if man gave up the enormous power he had procured for himself by culture, instead of turning it to good account and utilizing it for himself. He would resemble a fool who has devoted half his life to the amassing of wealth, and then, from annoyance that this treasure has cost him so much trouble and anxiety, throws the valuable possession away instead of enjoying it. 
Man can only attain to his ideal by means of culture, and all our energies ought to be concentrated towards this end. Even he who does not share these hopes will find the highest satisfaction that human life can afford in the work of culture. For as we have already said, Not at the goal, but on the road towards it, not in the final condition, but in the process leading to it, not in peaceful possession, but in steady advance, in endeavour and in the struggle towards better things, can true happiness be found. 



\section{LIST OF REFERENCES QUOTED IN TEXT}

(See also acknowledgements on pp. 14-15)

Adams, Brooks. Das Gesetz der Zivilisation und des Verfalls . . $\quad 263$

Arch. f. soz. Gesetzgebung und Statistik, 1899 . . . . . . 212

ARIstotle. Politics . $\quad \cdot \quad \cdot \quad \cdot \quad \cdot \quad \cdot \quad \cdot \quad \cdot \quad$ III, 287

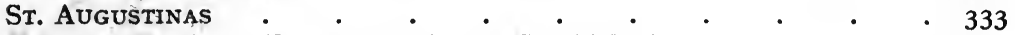

Bastiat (Bastian. Der Mensch in der Geschichte) . . . . 285

Bezосн. Jahrb. f. Nat. Ökon. . . . . . . 176, 248

BERolzheimer. System der Rechts-und Wirtschafts philosophie. . $3 \mathbf{I}$

Blancard. Le commerce de Marseille au moyen âge . . . . . 241

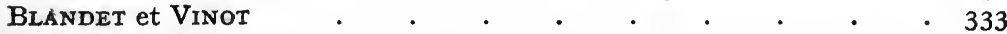

BLÜMNER. Die gewerbliche Tätigkeit der Völker des klassichen Alter-

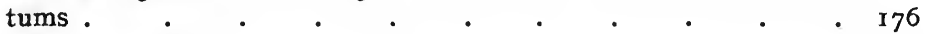

Bock. Unter den Kanibalen auf Borneo . $\quad . \quad$. $\quad . \quad$. $\quad$ I59

Bölsche. Die Abstammung des Menschen . . . . • . 45

Bonwick. Daily life, etc., of Tasmanians . . . . $\quad$. 206

Bos. Jagd. Viehzucht und Ackerbau als Kulturstufen . $\quad$ - 84,327

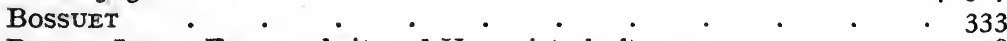

Braun, LILI. Frauenarbeit und Hauswirtschaft, 1900 . . . 228

Die Frauenfrage . . . . . . . . 220

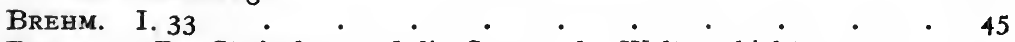

BReysig. Der Stufenbau und die Gesetze der Weltgeschichte, 1905 • 323

BRocA. (Instructions Craniologiques ?) . . . . . . Ir5

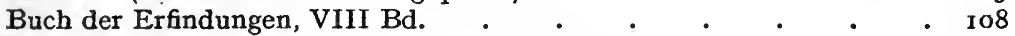

Bücher. Die Entstehung der Volkswirtschaft

Die Frauenfrage im Mittelalter . . . . . . . 220

$157,167,175,176,179,184,188,247,269$

Büchsenschürz. Erwerb und Besitz im griechischen Altertum Besitz

und Erwerb. $\quad . \quad . \quad . \quad . \quad . \quad . \quad 165,175,176,190$

Die Hauptstätten des Gewerbefleisses im griechischen Altertum

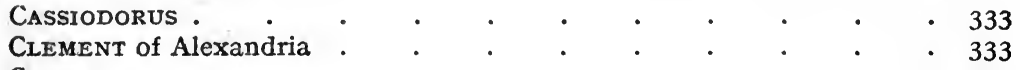

$75,172,175,176$

Clion .

CLEOPHON

Conrado. Handwörterb. d. Staatsw. Art. Fabrik.

Cook's Voyages

CRANZ, David. Historie von Grönland

Croll

DaHn, F. Deutsche Geschichte

DAMPIER. Voyage round the World (1697)

DARwin, C. R. Natural Selection, $185^{8}$

The Descent of Man, I 871

The Origin of Species, I 859

Zoology of the Voyage of the Beagle

Demosthenes. Aphobus

DOBRIZHOFFER. Geschichte der Abiponer

DUPONT

Eastmann, Mrs. (Of Dakota Women)

. 175

182,186

- 159

- 207

- 334

178,180

- 159

- 45

45,47

- 45

I 56

I 75

207

49
206 


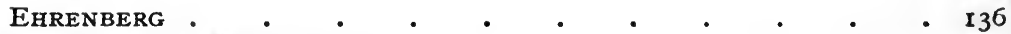

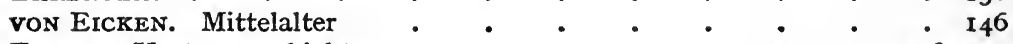
FALKe. Kostümgeschichte . . . . . . . 138, 139

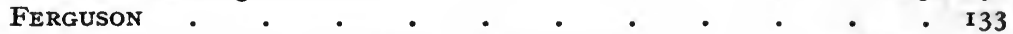
Forster, J. G. A. A Voyage round the World (1777) 75, 156, 207, 282 FRIEDLÄNDER. Sittengeschichte Roms . . . 173, 174, 175, 176 Fritsch, Gust. (Bekleidung und Sittlichkeit (in Pol-anthropol, Revue I, 876$, I 903$)$

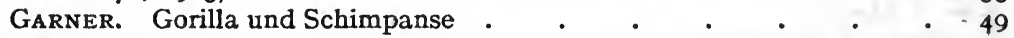

GeIger, LAZarus. Ursprung und Entwicklung der menschlichen Sprache und Vernunft, 1868

Gerland. Anthropolog. Beiträge, i. 1875

GOETHE $50,52,54,57,87$

GRIMM

57. 356

Groos. Die Spiele der Tiere, 1898 . $\quad . \quad . \quad . \quad . \quad . \quad . \quad . \quad 86$

Grosse, ERnst. Die Former der Familie und die Former der Wirtschaft .

Gumplowicz. Grundriss der Soziologie

HĀCKEL. Anthropogenie.

Нанм. Die Haustiere und ihre Beziehungen zur Wirtschaft des Menschen

72,84

Hahn, EdUARd. (Chinese horticulture) - • • . 81, 89, 90, 92

Hartmant, L. M. Zietschr. f. Sozial-und Wirtschaftsgeschichte. I76, 248

Hearne. Journey to the Northern Ocean . . . . . 207

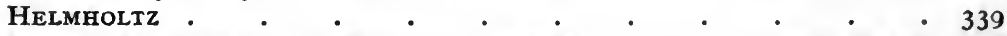

Henne am Rhys. Deutsche Kulturgeschichte des deutschen Volkes

Hermans. Privat altertümer

I 46, I 80, 224

HERODOTUS

HERTZKA

HildeBRAND. Jahrbuch für National-Ökonomie, 1864

160.174

Hippocrates .

HOMER. Iliad

Odyssey, XXI .

HoNEgGer. Kulturgeschichte .

Hörnes. Die Urgeschichte der Menschheit Wien, is92 (with bibliography)

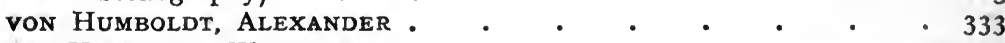

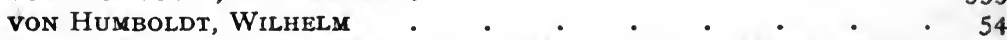

HuXley, T. H. Zoological Evidence of Man's Place in Nature, 1863 • 45

HYPERBolos . . . . . . . . . • . I75

Internat. Archiv. f. Ethnographie, x. $187 . \quad$. $\quad . \quad$. $\quad . \quad$. 84

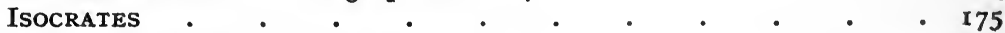

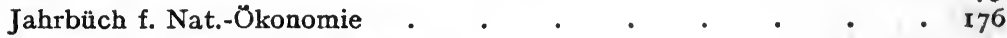

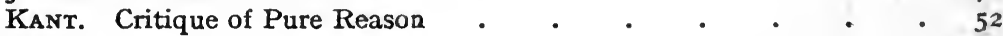

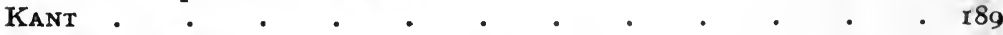

Klein, Hermann

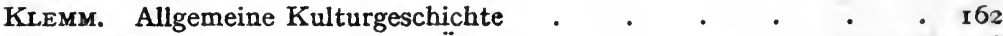

Kulrscher. Jahrbuch. fut Nat.-Ök. ․ . . . $\quad$ r $60,176,248$

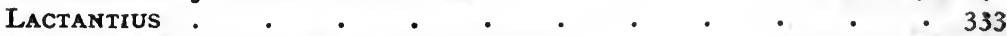

Lafrtau. Moeurs des Sauvages Américains . . . . 75, 209

Landwirtschaftl. Jahrbuch ix. 853 . . . . . . . . 84

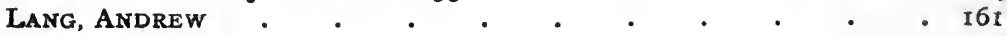


LIEBIG

L • • • • • • • • • 333

LIPPERT. Kulturgeschichte (bb. I. 66) • . . . . . $\quad$ 132

Lrst. Das nationale System . $\quad$. $\quad . \quad$. $\quad . \quad$. 327

Livingstone. Missionary Travels in South Africa . . 1 57, 282, 308

Loskiel. Mission der evangelischen Brüden . . . . • • 157

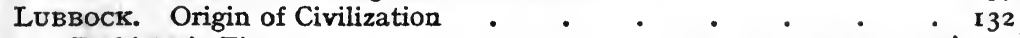

Prehistoric Times . . . . . 70, 99, 133, 217, 334, 345

LUCRetrus. De natura rerum . . . . . . . . 124

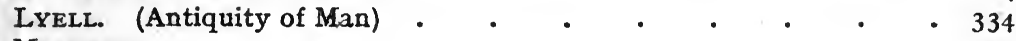

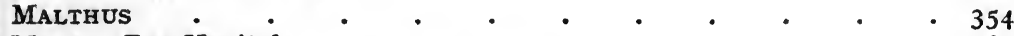

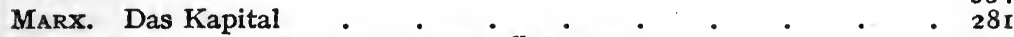

MARX, K. Zur Kritik der politischen Ökonomie $\quad$ - . . . . 262

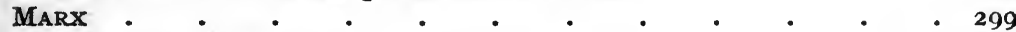

von MAURER. Gesch. der Fronhöfe . • . . . 179, 180, 187

Mertzen. Siedelung . . . . . . . . . . . .

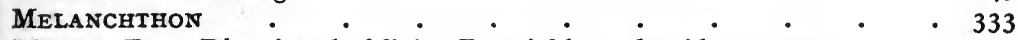

MEyer, ED. Die wirtschaftliche Entwicklung des Altertums

MEYER, J. B. Globus, $1874 \quad 172,175,176,248$

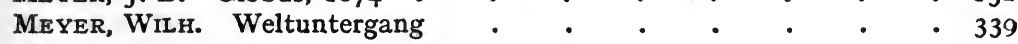

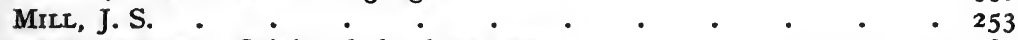

DE Mortillet. Origine de la chasse, etc. $\quad$. $\quad . \quad$. . . . 84

de Mortiller, G. Le Préhistorique ․ . . 46, $113,115,334$

NoIrÉ. Das Werkzeug • • • . • • • . 52, 55, 75

NowACKI. Über die Entwicklung der Landwirtschaft in der Urzeit . 84

Penck • . . . . . . . . . . . . . . II4, 334

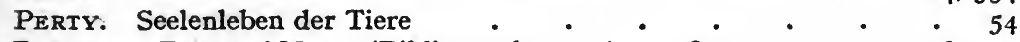

Peschel. Races of Man. (Bibliography, 174) • 58, 105, 117, 132, 306, 314

Philipp. (Natives of Botany Bay) • . . . . . . 135

Pickering. The Races of Men . . . . . . . $\quad$. 286

Pонце. Die Entwicklung des Deutschen Wirtschaftslebens im XIX

Jahrhundert. BB. part iv . . . . . . 182, 184

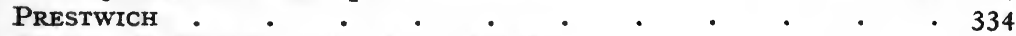

PRUTz. Kulturgeschichte der Kreuzzŭge . • . . . . . 108

RachFahl. Jahrbuch für Nat.-Okon. . . . . . . . . $\quad$. 179

Ranke. Der Mensch. • . . . . . . . . $\quad$ II3

RAUChBERG. Gewerbezählung im d. R. r895 . . . . . 212

REUleaUX .

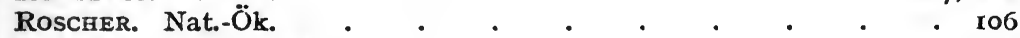

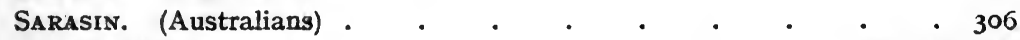

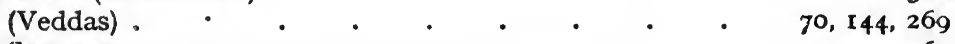

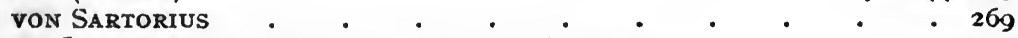

SCHÄFfle. Bau und Leben des sozialen Körpers . . . . $\quad 203$

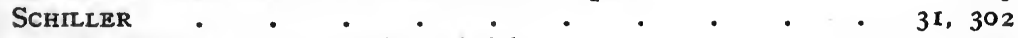

Einführung in die Gesellschaftslehre . . . . $\quad$ r22

Die Gesetzgebung des Lykurgus und Solon . • . . . $\quad 348$

SCHMOLLER. Jahrbuch. VIII. I884 • • . • . • . 246

Schöneberg. Handb. d. polit. Ökon. . . . . . . $\quad 327$

SCHRADER. Linguist.-histor. Forschungen über Handelsgeschichte

Sprachvergleichung und Urgeschichte

ScruRTz. Das afrikanisches Gewerbe . . . $\quad$ r60, r67, r68, 282

Grundritz einer Entwicklungs geschichte des Geldes 157, 238, 277 
SEECK. Gesch. d. Untergangs d. antiken Welt .

Simon, G. E. La cité chinoise . . . . . . $78,80,8 \mathrm{r}$

SMITH, ADAM . . . . . . . . . . . 28I

Sombart, W. Die gewerbliche Arbeit und ihre Organization. Braun's

Archiv. für soziale Gesetzgebung und Statistik

$97,194,245$

Der moderne Kapitalismus

$182,188,210$

STAMMLER

Sozialismus und soziale Bewegung . . . . $\quad$ 186, 192, 194, 225

STEIN TAMER •

K. VON DEN STEINEN, Unter den Naturvölkern Zentral-Brasiliens 00187

Srillich. Die Spielwaren-Industrie des Meininger Oberlandes . 226

TACitus. Germania $. \quad . \quad . \quad . \quad . \quad . \quad . \quad$ I 78,268

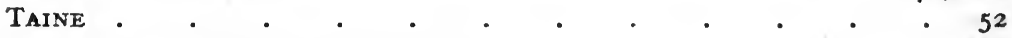

TARDE, G. Les Lois de l'Imitation . . . . . . . . 304

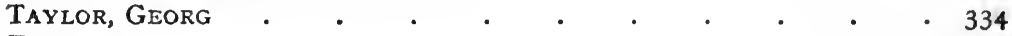

Thales . . . . . . . . . . . .

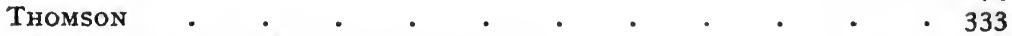

IM THURN. Among the Indians of Guiana . . . . . $\quad$ I60

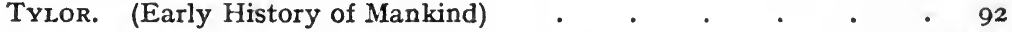

UPHAM, WARREN

VIERKANT. Naturbölker und Kulturvölker, I896 • • • • • 323

Die Kultur formen und ihre natürliche Verbreitung, 1897 • . 323

VINOT • • • • • • • • • • • • • • • 333

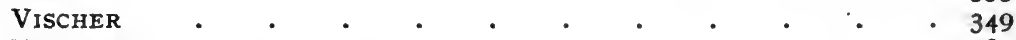

VOLTAIRE . . . . . . . . 80

Waitz-Gerland. Anthropologie der Naturvölker, bb. I. 357

IOI, 104, II 7, 132, I 57, 206, 209, 273, 306

WAITZ. I. 358 . $\quad . \quad$. $\quad . \quad . \quad . \quad . \quad . \quad$. 133

Wallace. Malay Archipelago . . . . . . . $\quad$. 54

von Waltershausen, Sartorius. Ztschr. f. Sozial-und Wirtschafts-

gesch, $1896 \quad$. $\quad . \quad$. . . . . . . . 164

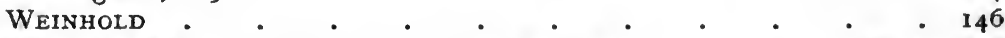

Westermarck, E. History of Human Marriage $\quad . \quad$. $\quad 46,48,132$

Wibel. Kultur der Bronze zeit . . . . . . . 120

Wiedersham. Der Bau des menschlichen Körpers als Zeuge seiner

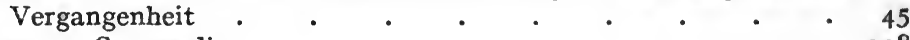

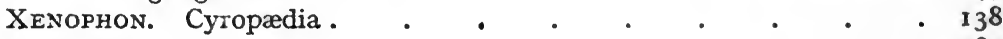

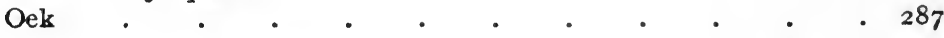

"Der dritte Stand" (Friedlander ?) . . . . . . . . . I76

Der Handelsverkehr. (Friedlander ?) . . . . . . . . 176

“Der Niedergang des Handwerks" (possibly Bücher, 215 ff.) • I88

"Der Verkrüppelungsprozess des Handwerks" (possibly Sombart, Der Moderne Kap. ii, 56r) . . . . . . . 188 



14 DAY USE BORROWED RETURN TO DESK FROM DEPT. This book is due on the last date stamped below, of This book is due on the last date to which renewed.
on the date rall.
Renewed books are subject to immediate recall

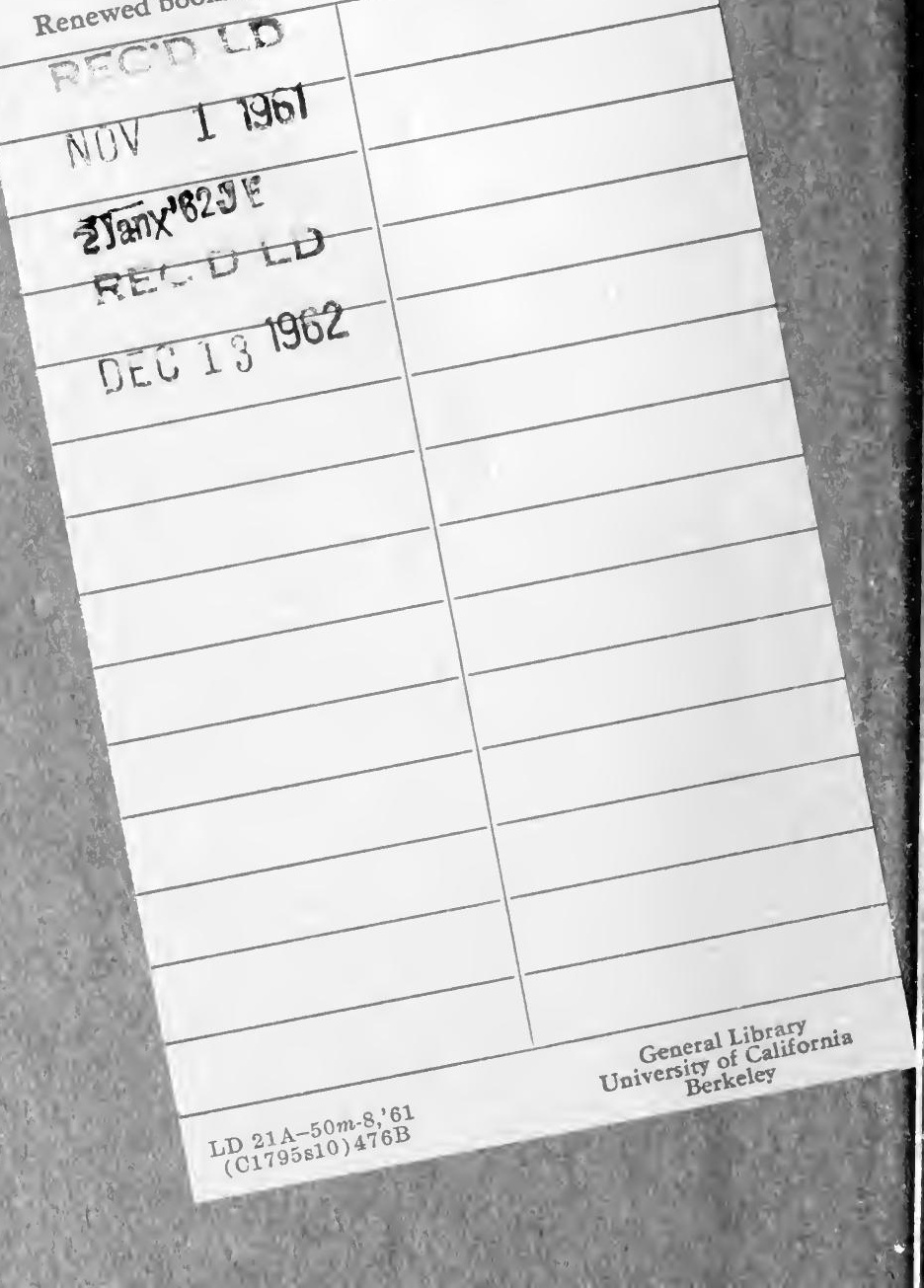




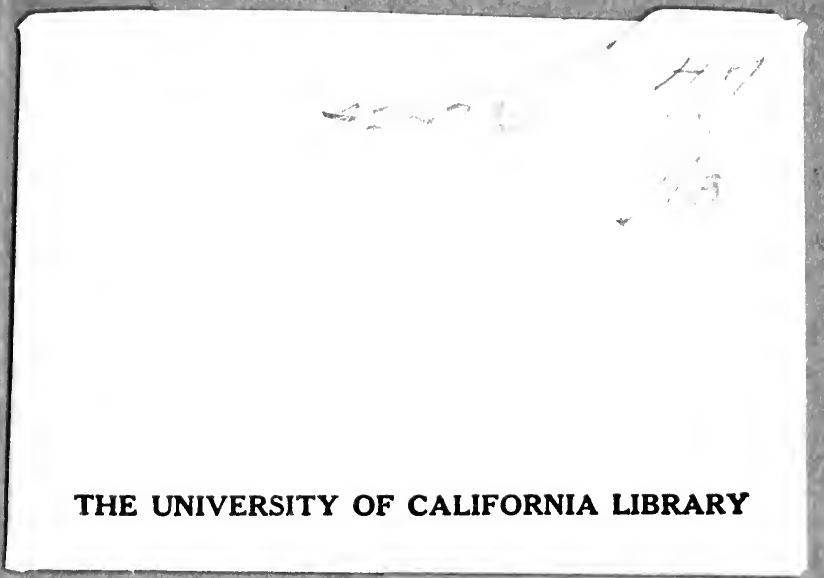


